UNIVERSIDADE DE SÃO PAULO

MUSEU DE ARQUEOLOGIA E ETNOLOGIA

PROGRAMA DE PÓS-GRADUAÇÃO EM ARQUEOLOGIA

EDUARDO KAZUO TAMANAHA

\title{
Um panorama comparativo da Amazônia no ano 1.000
}

VOLUME I

SÃO PAULO

2018 


\section{Um panorama comparativo da Amazônia no ano 1.000}

Tese apresentada ao Programa de PósGraduação em Arqueologia do Museu de Arqueologia e Etnologia da Universidade de São Paulo para obtenção do título de Doutor em Arqueologia

Área de Concentração: Arqueologia

Orientador: Prof. Dr. Eduardo Góes Neves

Linha de Pesquisa: Arqueologia e Identidade

Durante o desenvolvimento deste trabalho o autor recebeu auxílio financeiro da CAPES.

\section{VOLUME I}

São Paulo 2018 


\title{
RESUMO
}

Nesta tese buscou-se esboçar um cenário das ocupações ceramistas pré-coloniais, entre 600 e 1.400 DC, na região da Amazônia brasileira. Através do banco de dados georreferenciado foram realizadas análises correlacionando diferentes aspectos que compõem o sítio arqueológico, possibilitando a identificação de mudanças ou continuidades de determinadas sociedades em escala regional. Ao final percebeu-se que algumas áreas possuíam maior trânsito de pessoas e ideias do que outras regiões, refletindo em diferentes níveis de variabilidade observadas no contexto arqueológico.

Palavras-Chaves: Arqueologia Amazônica, Banco de Dados Georreferenciado, Análise Espacial, Cronologia das Ocupações, Tradições Cerâmicas

\begin{abstract}
This thesis sought to outline a scenario of precolonial ceramic occupations, between 600 and $1400 \mathrm{AD}$ in the Brazilian Amazon region. Through the georeferenced database, analyzes were carried out correlating different aspects that make up the archaeological site, allowing the identification of changes or continuities of certain societies on a regional scale. At the end it was realized that some areas had greater movement of people and ideas than other regions, reflecting different levels of variability observed in the archaeological context.
\end{abstract}

Key words: Amazonian Archeology, Georeferenced Database, Spatial Analysis, Chronology of Occupations, Ceramic Traditions 


\section{AGRADECIMENTOS}

Pode parecer bem clichê, mas é sempre bom lembrar que o resultado de qualquer pesquisa arqueológica só é possível graças as inúmeras contribuições de amigos e colegas que compartilham da mesma paixão que você. Essa tese não seguiu um caminho diferente e representa os meus 16 anos de trajetória na arqueologia amazônica.

Existem dezenas de pessoas que preciso agradecer, pois sem elas esse trabalho não seria possível. Pode ser que eu esqueça de colocar alguns nomes e já peço desculpas por isso, mas sintam-se todxs agradecidxs!!!

Primeiramente, agradeço ao meu orientador e amigo Eduardo Neves, que permitiu que eu ingressasse nesse maravilhoso mundo da arqueologia amazônica e nunca deixou de me apoiar, mesmo que eu tenha vacilado inúmeras vezes. Obrigado por acreditar em mim! Que a nossa parceria e amizade continue por muito anos!!!

Outra pessoa que merece um agradecimento especial é o Fernando Almeida (Fernandão). Além de ter participado da minha banca de qualificação, ele me aturou por meses via Skype com conversas, reflexões, dúvidas, leituras e besteiras em geral, sempre falando sobre arqueologia, tese, trabalho, etc. Seu alto astral, mesmo nos momentos mais difíceis (para ambos), sempre foi um grande motivador para seguir adiante! Obrigado por tudo!!

Um agradecimento especial aos amigos que conheci no MAE-USP: Helena Lima, Juliana Machado, Fabi Belém, Patrícia Fischer, Vinicius Melquíades, Bruno Sanchez, Viviana Monaco, Patrícia Marinho, Thiago Trindade, Claide Moraes, Anne Rapp PyDaniel, Carla Gibertoni, Silvia Cunha Lima, Raoní Valle, Guilherme Mongeló, Filippo Stampanoni, Marta Cavallini, Camila Jácome, Leandro Cascon, Carol Caromano, Jaque Belletti, Bruna Rocha, Vinicius Honorato, Jaque Gomes, Maurício Silva, Erêndira Oliveira, Débora Soares, Dani Amaral, Lorena Garcia, Myrtle Shock, Gabriela Carneiro, Márcio Figueiredo, Tiago Atorre, Fábio Guaraldo, Rodrigo Suñer, Márcia Arcuri, Eduardo Bespalez, Laura Furquim, Rafael Lopes, Thiago Kater, João Saldanha, Arkley Bandeira, Emerson Nobre, Francisco Pugliese, Carlos Augusto Zimpel, Ximena Suarez, Jennifer Watling e muitas outras pessoas que, por não estarem citadas, não são menos importantes! Ainda no ambiente MAE-USP, agradeço a todos os (ex) servidores que auxiliaram e apoiaram nessa longa trajetória, cada qual a sua maneira: professores, técnicos, seção acadêmica, biblioteca, xerox, educativo, etc. Obrigado!! 
Agradeço aos vários parceiros que conheci em Manaus: Felipe Rossoni, Boris, Marina Vieira (IPI), Charles Clemment, Carol Levis, André Junqueira, Juliana Lins (INPA), Fabiano, Satya (FVA), Iberê, Luiza, Viviane, Valério, Catarina, Raul, Tijolo (UEA/UFAM). Que possamos nos encontrar muitas vezes nessa "pequena” Amazônia!

Em Tefé um novo ciclo se iniciou e novas amizades se formaram. Agradeço imensamente a Verônica Lima, que me ajudou tanto nessa chegada em Tefé e até hoje segue firme e forte na arqueologia. Ao Márcio Amaral pelo companheirismo diário, seja no trabalho ou fora dele, e sua perspicácia em enxergar soluções para todos os problemas. Kelly Brandão pelo seu alto astral e sorriso contagiante frente a todas adversidades que passamos em 2015! Mariana Cassino pelos ensinamentos botânicos, companherismo e a paciência zen! Agradeço a todos membros e ex-membros do GP Org. Social pela acolhida: Nelissa, Marília, Viviane, Ronisson, Eliomara, Hilkiene, Juliana, Laísse, Alex, Zé Candido e Rafael Barbi. E também aos vários pesquisadores, bolsistas, técnicos do Instituto Mamirauá: João Valsecchi, Helder, Ângela, Iury, Vanessa, Jéssica Jaine, Amanda Lelis, JP, Cissa, Jefferson, Maria Isabel, Luis, Lisley, Caetano, João Cunha, Patrícia, Cláudio, entre tantos outros!! Muito obrigado a todos vocês!!

Ao núcleo de pesquisa CaSES da Universitat Pompeu-Fabra, em Barcelona, e sua equipe ítalo-hispânica: Marco Madella, Umberto Lombardo, Javier Ruiz, Carla Lancelloti, Stefano Biagetti e Marta Perelló. Grazie mille per tutto! - Moltes gràcies per tot.

Agradeço à Fundação Coordenação de Aperfeiçoamento de Pessoal de Nível Superior (Capes) pela bolsa de pesquisa concedida no início do doutoramento.

Agradeço ao Instituto Mamirauá que viabilizou as primeiras etapas de campo do meu primeiro projeto de doutorado e que, atualmente, permite que eu desenvolva tantos outros projetos.

Aos membros da banca de qualificação Sanna Saunaluoma e Fernando Almeida (de novo!), muito obrigado pela valiosas considerações, norteamentos e sugestões para o doutorado!!

Agradeço ao meu núcleo familiar Tamanaha-Tsuhako/Nascimento Lima pelo constante suporte e animação nessa empreitada acadêmica e amazônica. À minha mãe por atravessar o país para estar com o filho, nora e neto. 
Não há palavras para exprimir os meus agradecimentos à Márjorie, que esteve presente em todos os momentos, vivenciando todas as emoções dessa trajetória antes e durante a tese, além de ter sido uma companheira de muitas jornadas. Não teria conseguido sem você!

Por fim, agradeço ao meu filho Vinícius. Não teria conseguido sem o seu sorriso, alto astral e compreensão, principalmente nos belos dias de sol em que me ausentei para trabalhar na tese.

Aquí no se perdona al tonto majadero Aquí de nada vale tu apellido, tu dinero Se respeta el carácter de la gente con que andamos Nacimos de muchas madres pero aquí sólo hay Hermanos 


\section{Lista de Gráficos}

Gráfico 1.3-1: Cronologia das Tradições cerâmicas utilizadas

nesse trabalho.

Gráfico 2.1-1: Diferentes fontes consultadas para o banco de dados.

Gráfico 2.1-2: Quantidade de sítios obtidos por fonte consultada 45

Gráfico 3.1-1: Quantidade total de sítios arqueológicos por país. 50

Gráfico 3.1-2: Quantidade total de sítios arqueológicos por estado.

Gráfico 3.1-3: Relação do total de sítios arqueológicos encontrados nos municípios.

Gráfico 3.1-4: Quantidade de sítios arqueológicos por sub-bacia hidrográfica.

Gráfico 3.3.2-1: Sítios arqueológicos com TPI, sem TPI e os sem informações.

Gráfico 3.3.3-1: Quantidade de sítios arqueológicos unicomponenciais, multicomponenciais e sem informação.

Gráfico 3.5.1-1: Quantidade de sítios arqueológicos e datações divididos por intervalos de mil anos.

Gráfico 3.5.1-2: Quantidade de sítios e datações do primeiro e segundo milênio DC, divididos em intervalos de 200 anos. Destaque para o período entre 600 e 1.400 DC.

Gráfico 3.5.2: Quantidade de sítios arqueológicos com suas respectivas Tradições associadas entre 600 e 1.400 DC. 


\section{Lista de Tabelas}

Tabela 3.1-1: Os 10 municípios com maior quantidade de sítios arqueológicos

Tabela 3.1-2: Quantidade de sítios por cada sub-bacia.

Tabela 3.2-1: Quantidade de sítios arqueológicos por área de concentração.

Tabela 3.3.1-1: Quantidade de sítios arqueológicos maiores e menores que 10 hectares de área.

Tabela 3.3.1-2: Relação entre os sítios maiores e menores que

10 hectares conforme as áreas com maior concentração.

Tabela 3.3.1-2: Outras áreas amostradas na relação de sítios maiores ou menores que 10 hectares.

Tabela 3.3.4-1: Quantidade de sítios arqueológicos por características analisadas.

Tabela 3.3.4-2: Quantidade de sítios arqueológicos para cada tipo de correlação.

Tabela 3.3.4-3: Quantidade de sítios arqueológicos com maior variabilidade na correlação de componentes com dimensão.

Tabela 3.3.4-4: Quantidade de sítios arqueológicos com menor variabilidade na correlação de componentes com dimensão (unicomponenciais maiores e menores que 10 hectares).

Tabela 3.3.4-5: Quantidade de sítios arqueológicos com menor variabilidade na correlação de componentes com dimensão (uni e multicomponenciais menores que 10 hectares).

Tabela 3.3.4-6: Quantidade de sítios arqueológicos com maior variabilidade na correlação da dimensão com o tipo de solo.

Tabela 3.3.4-7: Quantidade de sítios arqueológicos com menor variabilidade na correlação da dimensão com o tipo de solo (com TPI maiores ou menores que 10 hectares).

Tabela 3.3.4-8: Quantidade de sítios arqueológicos com menor variabilidade na correlação da dimensão com o tipo de solo (sem TPI maiores ou menores que 10 hectares)

Tabela 3.3.4-9: Quantidade de sítios arqueológicos com menor variabilidade na correlação da dimensão com o tipo de solo (menores que 10 hectares com e sem TPI).

Tabela 3.3.4-10: Quantidade de sítios arqueológicos na correlação da dimensão com o tipo de solo (menores que 10 hectares sem TPI). 
Tabela 3.3.4-11: Quantidade de sítios arqueológicos na correlação da dimensão com o tipo de solo (menores que 10 hectares com TPI).

Tabela 3.3.4-12: Quantidade de sítios arqueológicos com maior variabilidade na correlação dos componentes com o tipo de solo.

Tabela 3.3.4-13: Quantidade de sítios arqueológicos com menor variabilidade na correlação dos componentes com o tipo de solo.

Tabela 3.3.4-14: Quantidade de sítios arqueológicos na correlação dos componentes com o tipo de solo (unicomponenciais com TPI).

Tabela 3.3.4-15: Quantidade de sítios arqueológicos na correlação dos componentes com o tipo de solo (unicomponenciais sem TPI).

Tabela 3.3.4-16: Quantidade de sítios arqueológicos na correlação do tipo de solo, componentes e dimensão.

Tabela 3.3.4-17: Quantidade de sítios arqueológicos com maior variabilidade na correlação do tipo de solo, componentes e dimensão.

Tabela 3.3.4-18: Quantidade de sítios arqueológicos com menor variabilidade na correlação do tipo de solo, componentes e dimensão (unicomponenciais, com TPI, maiores ou menores que 10 hectares).

Tabela 3.3.4-19: Quantidade de sítios arqueológicos com menor variabilidade na correlação do tipo de solo, componentes e dimensão (unicomponenciais, menores que 10 hectares, com ou sem TPI).

Tabela 3.3.4-20: Quantidade de sítios arqueológicos na correlação do tipo de solo, componentes e dimensão (unicomponenciais, menores que 10 hectares e sem TPI).

Tabela 3.3.5-1: Regiões com maior e menor variabilidade ou uniformidade, separado de acordo com o tipo de correlação utilizado.

Tabela 3.4.1-1: Quantidade de sítios arqueológicos, separados por Tradições, utilizados nas análises.

Tabela 3.4.1-2: Quantidade de sítios arqueológicos associados à TPA de acordo com as correlações dimensão, tipo de solo e componentes.

Tabela 3.4.1-3: Quantidade de sítios arqueológicos associados à TPA de acordo com as correlações dimensão, tipo de solo e componentes, divididos entre oriental e ocidental.

Tabela 3.4.1-4: Quantidade de sítios arqueológicos associados à TIP de acordo com as correlações dimensão, tipo de solo e componentes. 
Tabela 3.4.1-5: Quantidade de sítios arqueológicos associados à TBI de acordo com as correlações dimensão, tipo de solo e componentes.

Tabela 3.4.1-6: Quantidade de sítios arqueológicos associados à STA de acordo com as correlações dimensão, tipo de solo e componentes.

Tabela 3.4.1-7: Quantidade de sítios arqueológicos associados à TM de acordo com as correlações dimensão, tipo de solo e componentes.

Tabela 3.4.1-8: Quantidade de sítios arqueológicos associados à TRS de acordo com as correlações dimensão, tipo de solo e componentes.

Tabela 3.4.1-9: Quantidade de sítios arqueológicos associados à TP-A de acordo com as correlações dimensão, tipo de solo e componentes.

Tabela 3.4.2-1: Quantidade de sítios arqueológicos conforme a Tradição e quantidade componentes na área de confluência dos rios Solimões-Negro-Madeira-Amazonas.

Tabela 3.4.2-2: Combinações de Tradições para os sítios multicomponencias da área de confluência dos rios SolimõesNegro-Madeira-Amazonas.

Tabela 3.5.1-1: Quantidade de sítios e datações divididos por intervalos de 1000 anos. 100

Tabela 3.5.1-2: Quantidade de sítios e datações divididos nas áreas de maior e menor concentração.

Tabela 3.5.1-3: Quantidade de sítios e datações do primeiro e segundo milênio DC, divididos em intervalos de 200 anos.

Tabela 3.5.2-1: Quantidade de sítios e datações entre 600 e 1.400 DC, divididos em intervalos de 200 anos. 


\section{Lista de Figuras}

Figura 1.3.6-1: Diagrama representando a hipótese de fronteira cultural no rio Urubu. Extraído de Bassi, 2015

Figura 2-1: Tipos de informações utilizadas no banco de dados georreferenciado.

Figura 3.1-4: As quatro grandes bacias hidrográficas e suas respectivas sub-bacias. 


\section{Sumário}

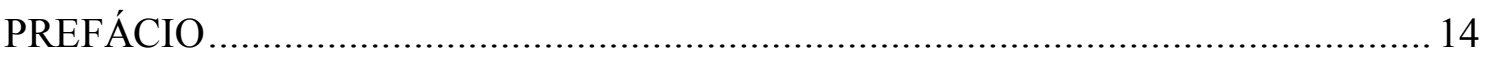

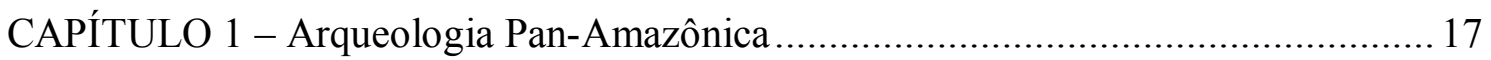

1.1 Amazônia Legal Brasileira e o bioma Amazônico .................................................... 19

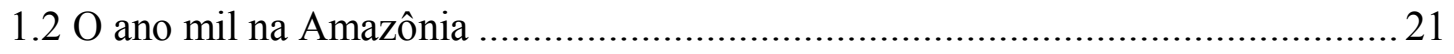

1.3 As Tradições Cerâmicas e seus contextos …………………………………....24

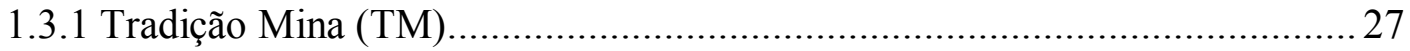

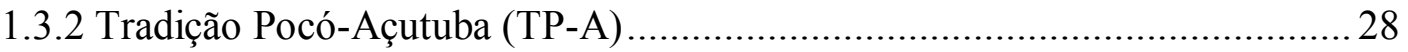

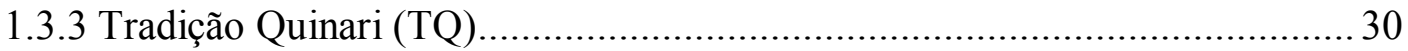

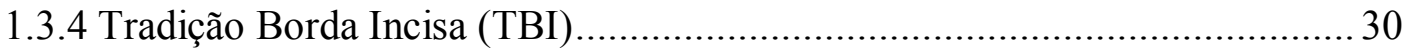

1.3.5 Subtradição Tupinambá da Amazônia (STA) ................................................. 32

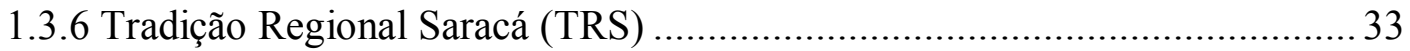

1.3.7 Tradição Polícroma da Amazônia (TPA) ………………………………........ 35

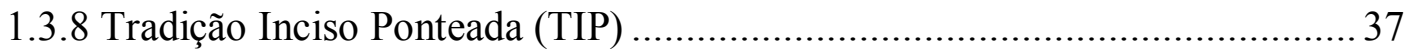

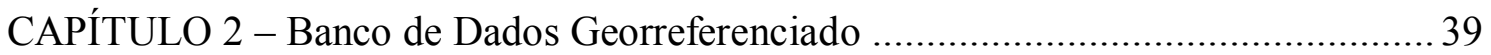

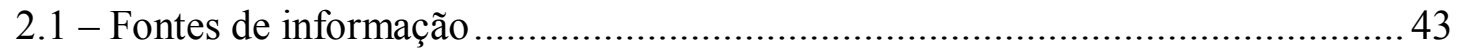

2.2 - Dificuldades na obtenção de dados e suas limitações ........................................ 45

CAPÍTULO 3 - Os sítios arqueológicos e seus contextos ............................................. 48

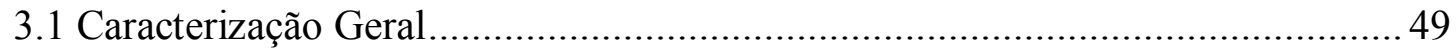

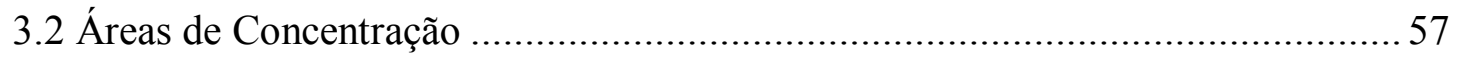

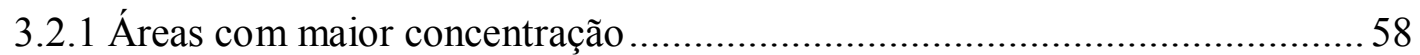

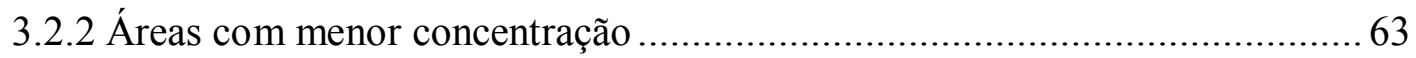

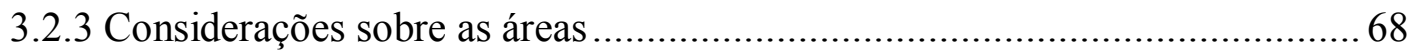

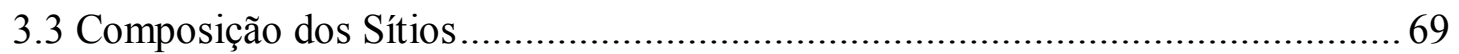

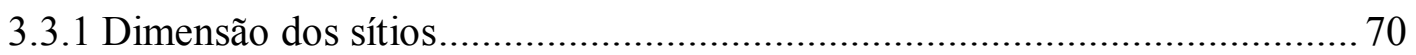

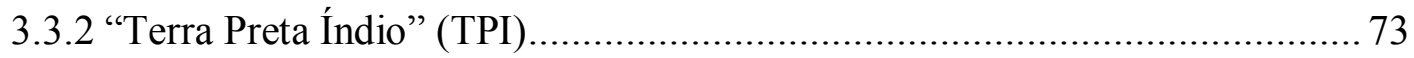

3.3.3 Unicomponencial e Multicomponencial ..................................................... 75

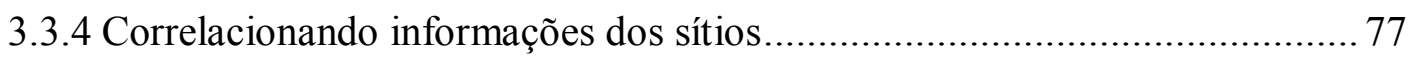

3.3.5 Considerações sobre a composição dos sítios ............................................. 87

3.4 As Tradições Cerâmicas na Amazônia ............................................................. 90

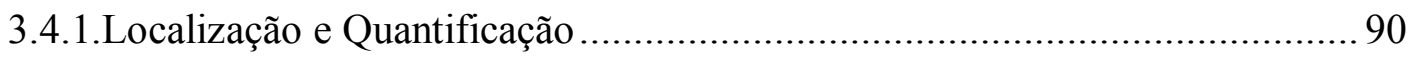

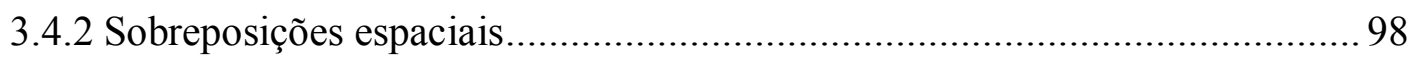

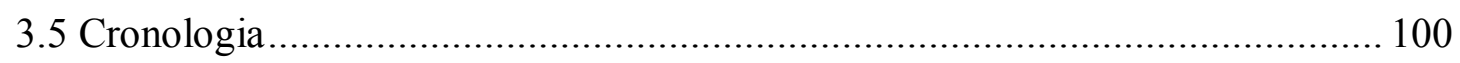

3.5.1 Caracterização geral .............................................................................. 100 
3.5.2 Tradições e cronologia ....................................................................... 104

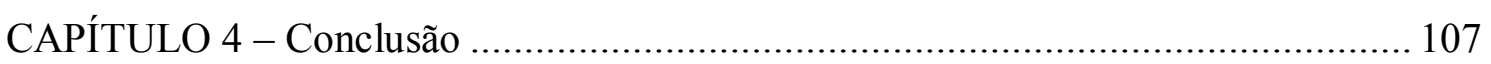

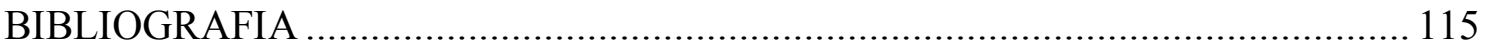




\section{PREFÁCIO}

Falar de mudanças, transformações, rupturas e continuidades é algo muito bem explorado em pesquisas socioculturais, pois entender como as coisas alteraram ao longo do tempo, quais foram os agentes e de que maneira isso ocorreu é algo que atiça qualquer pesquisador que trabalhe com investigações históricas ou arqueológicas. É um grande esforço identificar os diferentes fatores que atuaram nessas trajetórias, independente da escala espaço-temporal, e se aprofundar nesse tema utilizando toda a bibliografia possível, bem como fontes primárias.

O objetivo dessa tese é ambicioso e busca propor um panorama sociocultural geral de sociedades pretéritas, apesar de todas as dificuldades encontradas. Tento esboçar esse quadro da Amazônia pré-colonial no entorno do ano mil DC, utilizando uma grande diversidade de dados, como as datações disponíveis, as classificações cerâmicas préestabelecidas na literatura arqueológica e as características físicas dos sítios arqueológicos. Há, porém, uma trajetória marcada por esse percurso e não me refiro aos resultados da tese, mas sim aos quatro anos de doutoramento. Farei, portanto, um rápido histórico da trajetória dessa tese.

Inicialmente, o projeto proposto para tese era uma continuidade do meu mestrado (TAMANAHA, 2012) e a oportunidade de dialogar com muitos outros colegas que estavam trabalhando com a Tradição Polícroma da Amazônia (ALMEIDA, 2013; MORAES, 2013; BELLETTI, 2015; OLIVEIRA, 2016). É bem verdade que o projeto possuía um título horrível ${ }^{1}$ e meu orientador sempre me lembrou disso, mas a hipótese era que houve uma "buffer zone" anterior ao ano mil e que, posteriormente, seria ocupada por diferentes grupos da Tradição Polícroma da Amazônia, formando uma fronteira cultural entre o baixo e médio curso do rio Solimões, pouco antes do início do período colonial, visível através das análises estilísticas da cerâmica. Essa proposta permitia que fossemos a campo testar essas hipóteses e, apesar de ser uma ideia megalomaníaca (prérequisito para se trabalhar no Arqueotrop), existia uma verba anual cedida pelo antigo Ministério da Ciência, Tecnologia e Informação (MCTI), através do Instituto de Desenvolvimento Sustentável Mamirauá (IDSM), que possibilitava acessarmos áreas

\footnotetext{
1 "Zona Tampão e a Tradição Polícroma da Amazônia no Baixo/Médio Solimões" - projeto submetido ao Programa de Pós-Graduação em Arqueologia do Museu de Arqueologia e Etnologia da Universidade de São Paulo (MAE/USP) no ano de 2013.
} 
mais distantes e escavarmos os sítios com uma grande equipe. Naquele momento, o IDSM estava interessado em ampliar suas pesquisas no médio Solimões e nós, da arqueologia, tínhamos muitas propostas para colaborarmos. Eu e Márjorie Lima (companheira e arqueóloga) iríamos morar em Tefé, onde está a sede do IDSM, para executarmos nossos projetos de pesquisas, com (quase) tudo pago.

Cancelada a vida em Tefé por conta de uma gestação inesperada (e muito bemvinda), ao longo de 2014 foram realizadas duas etapas de campo na área de pesquisa: uma nos lagos Caiambé e Jutica (TAMANAHA et al., 2015), no município de Tefé, e outra em parceria com o Instituto Piagaçu-Purus na Reserva de Desenvolvimento Sustentável (RDS) Piagaçu-Purus, no baixo curso do rio Purus. Foram realizados os primeiros contatos com os moradores dessas duas áreas e com a promessa que voltaríamos para escavar algum dos sítios identificados.

No fim de 2014 o IDSM abriu a contratação para um arqueólogo, a qual eu fui o felizardo em passar no processo seletivo. Com isso, no início de 2015, nos mudamos para Tefé para desenvolver nossos projetos de pesquisas, bem como consolidar institucionalmente a área de arqueologia no IDSM. No entanto, ao longo de 2015 a situação política no país se agravou, o que implicou diretamente na gestão do MCTI e nos seus repasses de verbas, ou seja, muitos projetos no IDSM ficaram suspensos e sem prazo para voltarem a ativa (incluindo meu projeto de doutorado).

Faltando dois anos para encerrar o doutorado, sem a possibilidade de continuar com o projeto e com o prazo de qualificação muito próximo, eu e meu orientador encontramos uma solução: mudar todo o projeto para o sudoeste amazônico (TAMANAHA, 2015). A ideia era trabalhar com as cerâmicas do recém escavado sítio Sol de Campinas do Acre, no município de Senador Guiomard, bacia do alto rio Purus, estado do Acre. Trata-se de um sítio do segundo milênio DC (contemporâneo à Tradição Polícroma da Amazônia), formado por 15 montículos artificiais dispostos em formato de uma elipse ( 120m de diâmetro) e com uma cerâmica (Tradição Quinari) diferente de regiões adjacentes, como o alto rio Madeira (ALMEIDA, 2013; ZUSE, 2014).

No processo de qualificação do doutorado a banca formada pela Dra. Sanna Saunaluoma e Dr. Fernando Almeida foi pontual com sugestões que clarearam minhas ideias. Resumidamente, eles perceberam que a ideia era ótima, mas com um curto prazo de execução. A situação acordada naquele momento era não abandonar o rio Solimões e nem o sudoeste Amazônico, mas tentar olhar para a Amazônia pré-colombiana em torno 
do ano mil - contexto cronológico de ambos os projetos - através das classificações cerâmicas existentes até o presente momento. Essa ideia só era viável por conta do banco de dados que eu e outros colegas estávamos organizando e expandindo naquele momento. Eu fiquei feliz, o orientador ficou feliz, a banca ficou feliz e assim chegamos ao formato dessa tese.

Tendo contextualizado toda a trajetória de mudanças, partimos para a estruturação da tese. O capítulo 1 apresenta os 3 eixos que nortearam esse trabalho: recorte espacial, cronológico e as Tradições cerâmicas que serão incorporadas no estudo. O capítulo 2 trata do banco de dados de sítios georreferenciados utilizado na pesquisa, relatando o seu histórico de criação, a definição das categorias que caracterizariam os sítios e os limites e problemas encontrados nas diferentes fontes de informação. No capítulo $\mathbf{3}$ partimos para as diferentes análises quantitativas, cruzando diferentes níveis de informação em uma escala espacial e cronológica, tanto pelo contexto arqueológico quanto pelo contexto das pesquisas na Amazônia. No capítulo 4 faço uma interpretação desses dados a partir de diferentes teorias vigentes sobre as ocupações dos grupos ceramistas, sob diferentes perspectivas, propondo um possível cenário cultural da Amazônia na transição do primeiro para o segundo milênio DC. Todos os mapas utilizados nesta tese encontram-se no Volume II. 


\section{CAPÍTULO 1 - Arqueologia Pan-Amazônica}

Nas últimas décadas, uma série de pesquisas arqueológicas na Amazônia vem buscando compreender os significados dos diferentes contextos evidenciados nas prospecções e escavações. São centenas de trabalhos, em escala local ou regional, que reconstroem um pequeno pedaço da história indígena pré-colonial sob diferentes perspectivas. Eventualmente, alguns arqueólogos, tendem a fazer grandes revisões ou compilações dos resultados de pesquisas que vem sendo produzido para toda Amazônia (e.g.: HECKENBERGER \& NEVES, 2009). Enquanto outros buscam sistematizar todas essas informações em banco de dados, para depois analisar e correlacionar em diferentes níveis, permitindo a criação de modelos preditivos, hipóteses ou dando um sentido para aqueles milhares de informações que são convertidos em números. Essa tese se encaixaria nessa última opção.

O banco de dados utilizado nesse trabalho não foi planejado para se tornar a base desta (ou de outras) pesquisas. Ele surgiu no ano de 2007 pela necessidade de sistematizarmos os sítios arqueológicos que estavam sendo levantados pela equipe do PAC (Projeto Amazônia Central), coordenado por Eduardo Neves. Nesse mesmo período havia sido lançado a primeira versão gratuita do programa Google Earth e, somado a uma planilha de Excel, os sítios começaram a ser plotados e a visualização espacial dinâmica que o programa permite auxiliava a identificar lacunas para identificação de sítios ou realizar planejamentos futuros. Desde então, essa base é continuamente revisada e ampliada através de levantamentos bibliográficos e pesquisas de campo. Sua primeira utilização, para além da produção de mapas, foi no estudo publicado por McMichael et al. (2014), onde os autores (incluso eu) juntaram essa base de dados arqueológica com outras existentes, objetivando criar um modelo preditivo para a ocorrência de solos antrópicos ("Terra Preta de Índio" - TPI). Nos últimos anos, o banco de dados ganhou um fôlego maior com a participação ativa de outros pesquisadores, que focados em suas respectivas áreas de pesquisas foram adicionando novos dados à base, criando uma rede de pesquisadores chamada AmazonArch (Amazonian Archaeological Sites Network).

E é nesse contexto de criação do banco de dados que ele acabou sendo incorporado nessa tese, como descrevi no Prefácio. Nesse sentido, o objetivo desse estudo é esboçar um quadro cultural da Amazônia pré-colonial em torno de 600 a 1400 DC. No entanto, também será apresentado e contextualizado o "estado da arte" do banco de dados e sua 
correlação com o contexto de pesquisas arqueológicas na Amazônia, utilizando limites políticos, bacias hidrográficas e de concentração (capítulo 3). Mas, primeiramente, irei contextualizar os três aspectos fundamentais que nortearam o estudo: o objeto de estudo em si, a espacialidade e cronologia.

Sobre o objeto de estudo, se por um lado existem diversas pesquisas arqueológicas na Amazônia focados na variabilidade artefatual (e.g. cerâmicas ou líticos), em microrregiões específicas e ao longo do tempo, a minha proposta é apresentar uma perspectiva macroespacial a partir dos sítios arqueológicos em si. Os contextos arqueológicos dos fragmentos cerâmicos serão um dos norteadores da pesquisa, mas não estou propondo revisar as classificações dos vestígios encontrados nesses sítios, nem mesmo redefini-los dentro de suas categorias estilísticas, pois muitas pessoas já o fizeram para diferentes regiões (inclusive eu mesmo em meu mestrado). Portanto, a ideia é utilizar os diferentes atributos que caracterizam o sítio arqueológico, como a sua localização (coordenada geográfica), seu tamanho (área), presença/ausência de solos antrópicos, quantidade de camadas culturais e cronologia. Como será explicado no capítulo 2, o banco de dados compila informações geradas em diferentes estudos nos últimos 50 anos, mas sempre ciente de que podem haver problemas nas análises contextuais, principalmente na interpretação estratigráfica ou na cronologia.

De toda forma, se estou me propondo utilizar os sítios arqueológicos como unidade analítica e comparativa entre diferentes regiões, é imprescindível que utilize uma macrorregião como recorte espacial. Trabalhos como de Eriksen (2011) e Correa (2014), e em outra escala os de Trindade (2015) e Saldanha (2017), utilizaram macrorregiões para entender a espacialidade de determinados traços estilísticos, de estruturas de terra artificiais ou da ocupação de uma região. Na espacialidade, o meu caso é mais parecido com o estudo de Eriksen que utilizou todo o bioma amazônico para correlacionar dados arqueológicos, linguísticos, geográficos e etnohistóricos. No entanto, como será explicado no capítulo 2, a maior parte das informações obtidas são em território brasileiro e por conta disso me limitei ao polígono da Amazônia Legal Brasileira.

Se o espaço é extenso, o período cronológico escolhido na pesquisa é relativamente menor. $\mathrm{O}$ foco da tese é em torno do ano mil DC e com uma variação de \pm 400 anos. Pela mesma razão do recorte espacial, esse é o intervalo temporal que possuímos a maior quantidade de informações arqueológicas e não acredito que seja uma questão amostral ou simplesmente tafonômica. As pesquisas até o momento têm mostrado 
que o ano mil é o momento de adensamento demográfico, com uma organização social pautada em chefias regionais e mudanças culturais significativas, tornando esse período de maior visibilidade no registro arqueológico (NEVES, 2012; MORAES \& NEVES, 2012; HECKENBERGER \& NEVES, 2009).

Como estamos trabalhando com macro escala, informações de milhares de sítios e um período de grandes mudanças culturais, me pareceu sensato utilizar as macro informações arqueológicas de cada sítio, entre elas as Tradições cerâmicas, seus contextos associados e as datações. Ao contrário da utilização inicial feita pelo PRONAPA (MEGGERS \& EVANS, 1970), entendo a ideia de Tradição como um conjunto de atributos estilísticos e tecnológicos expressos na cerâmica e que estão sendo compartilhados por um grupo de pessoas, tanto em uma escala temporal quanto espacial. Contudo, a Tradição não é caracterizada apenas pela cerâmica, mas também pela ocorrência de outros elementos no contexto arqueológico (e.g. Terra Preta de Índio, estruturas artificiais, tamanho e forma dos assentamentos, etc.). Essa definição já vem sendo utilizada e repensada por vários arqueólogos na Amazônia, em diferentes contextos, onde a Tradição é definida por uma complexa combinação de elementos (incluindo solos antrópicos, por exemplo) sendo que nenhum deles isoladamente é definidor de um período ou outro (HECKENBERGER, 2001; LIMA, 2008; NEVES, 2010; MORAES, 2013; ALMEIDA, 2013; LIMA, 2014). Isto é, as novas abordagens têm fugido da visão essencialista das culturas que havia sido utilizada em pesquisas anteriores.

A seguir descreverei de forma mais detalhada os três aspectos utilizados na tese: Amazônia Legal Brasileira, o ano 1.000 DC e as Tradições Cerâmicas presente nos sítios arqueológicos.

\subsection{Amazônia Legal Brasileira e o bioma Amazônico}

A Amazônia Legal Brasileira possui mais de 5.217.423 de km², correspondendo a $61 \%$ do território nacional e abrange, na totalidade, os estados do Acre, Amazonas, Amapá, Pará, Mato Grosso, Rondônia, Roraima e Tocantins, além de municípios do Maranhão localizados a oeste do meridiano $44^{\circ} \mathrm{O}$, totalizando 772 municípios. Além de abrigar todo o bioma amazônico brasileiro, ainda possui 20\% do bioma Cerrado e parte do Pantanal Mato-grossense. A definição desse limite territorial tem um viés sociopolítico e não geográfico, ou seja, ele não foi estabelecido em função do bioma Amazônico e sim pelas necessidades de desenvolvimento social e econômico da região (IBGE, 2017). 
O intuito de utilizar esse polígono como recorte geográfico nessa pesquisa tem relação com a quantidade de informações arqueológicas presentes nessa área e, também, por abarcar parte dos biomas circundantes. Isso nos permite dialogar e extrapolar de forma mais abrangente, pensando na circulação de ideias e pessoas entre áreas com características distintas. No entanto, vale ressaltar, que a maior parte das informações arqueológicas compiladas para essa pesquisa se encontram exclusivamente no bioma Amazônico. Para facilitar a compreensão espacial, principalmente hidrográfica, dessa região podem-se consultar os mapas 1.1-1 e 1.1-2.

Ao confrontar as informações arqueológicas inseridas no bioma amazônico, considero importante apresentar as diferentes maneiras que a ciência discute a relação entre as populações do passado pré-colonial e o bioma amazônico. Esse tema vem sendo discutido há décadas na arqueologia, incorporando diversas disciplinas, como a geografia, ecologia, botânica e pedologia (BARLOW et al., 2012; CLEMENT \& JUNQUEIRA, 2010; DENEVAN, 1992; HECKENBERGER et al., 2003; NEVES, 2012). As hipóteses geradas pelos pesquisadores sobre a relação dessas populações com o bioma amazônico, a grosso modo, se dividiram em dois blocos: proposta de pequenos grupos com alto grau de mobilidade e baixo impacto ao meio ambiente (MEGGERS 1954, 1976; MCMICHAEL et al., 2012) e grupos maiores com ocupações de longa duração em uma mesma área e que cujas as atividades provocaram modificações de grande escala, tanto na fertilidade dos solos quanto na biodiversidade da floresta (HECKENBERGER et al., 2008; ROOSEVELT, 2014; NEVES, 2012; CLEMENT et. al., 2015; LEVIS et al. 2017).

Segundo o modelo de Meggers (1976), influenciada pelos conceitos da Cultura de Floresta Tropical de Steward (1948) e Lowie (1948), o bioma amazônico não poderia sustentar sociedades hierarquizadas e sedentárias devido aos recursos esparsos e de difícil obtenção. Em contrapartida, outros arqueólogos (LATHRAP, 1970; BROCHADO, 1989; DENEVAN, 1996; OLIVER, 2008) propuseram que a agricultura de várzea e o acesso à proteína aquática permitiriam um grande adensamento demográfico, sustentando sociedades com alto desenvolvimento cultural.

Posteriormente, com os avanços das pesquisas, reconheceu-se que tecnologias de manejo ambiental eram utilizadas pelas populações pretéritas levando a formação do que se conhece por Terra Preta Antropogênica ou "Terra Preta de Índio" (TPI). Ainda não está claro o quanto de sua produção foi intencional ou não, mas esse fenômeno é interpretado como marcador cronológico, cultural e social, indicando aumento da 
densidade demográfica e do estabelecimento de assentamentos sedentários na Amazônia (PETERSEN, NEVES \& HECKENBERGER, 2001; ARROYO-KALIN, 2010). Tais solos apresentam coloração escura, considerável índice de matéria orgânica, pH elevado, teores elevados de cálcio, magnésio e fósforo (LEHMANN et al., 2003; FALCÃO et al., 2008), sendo normalmente mais férteis e com uma grande biodiversidade florística (FRASER, JUNQUEIRA \& CLEMENT, 2011; LINS et al., 2015).

Mais recentemente, algumas pesquisas têm focado nos níveis de impactos humano causados ao longo da história sobre a paisagem amazônica. Os dados indicam a existência de florestas antropogênicas contendo alta densidade de plantas úteis introduzidas pelas práticas agroflorestais (LEVIS et al., 2017; TER STEEGE et al., 2013; SHEPARD \& RAMIREZ, 2011; BALÉE, 2010; JUNQUEIRA et al., 2010; POLITIS, 1996). Essas pesquisas, baseadas principalmente na ecologia e botânica, propuseram a ocorrência de grandes populações sedentárias que manipulavam o meio ambiente para sua subsistência e deixavam uma assinatura nas plantas e nos solos que se encontram na Amazônia até hoje. No entanto, ainda não está claro em que período histórico essas modificações florísticas ocorreram (e.g. Período da Borracha ou Período Pré-Colonial), qual sua relação com os sítios arqueológicos (PIPERNO, MCMICHAEL \& BUSH, 2015) e o grau e área de abrangência dessa atividade humana (CARSON et al., 2014; MCMICHAEL et al., 2012; LEVIS et al., 2012).

A escala de impacto humano no ambiente amazônico e os modos de subsistência das populações indígenas ainda apresentam muitas questões a serem esclarecidas (e.g.: solos e florestas antrópicas) e permanecem assuntos essenciais para se compreender a Amazônia no passado e no presente. Estamos diante de um bioma com alta diversidade biológica (AB'SABER, 2003), onde diferentes estratégias de ocupação e manejo ambiental podem ter sido utilizadas conforme o período e a região. Para além do conhecimento histórico ecológico de uma região, os dados arqueológicos podem subsidiar políticas públicas de conservação e o uso sustentável dos recursos naturais (ROBERTS et al., 2017).

\section{$\underline{1.2}$ O ano mil na Amazônia}

O recorte temporal utilizado para essa tese remete ao ano 1.000 d.C., com uma variação de 400 anos para mais e para menos (600 - 1.400 d.C.). Esse período nos pareceu interessante como recorte de análise porque é nele que foram identificadas diversas 
mudanças culturais nas ocupações dos sítios arqueológicos amazônicos. Diferentes de outros períodos de mudanças, nessa faixa temporal elas ocorrem frequentemente, em várias regiões, e estimamos que esses fenômenos não estejam isolados. Nesse intervalo de tempo é observado, por exemplo, através dos vestígios cerâmicos e das construções de estruturas de terra, a expansão de um determinado grupo ocupando novas áreas ou a transição entre dois grupos distintos culturalmente, podendo ter ocorrido de forma abrupta ou gradual (MORAES \& NEVES, 2012; TAMANAHA, 2012; ROSTAIN \& DE SAULIEU, 2013; NEVES, 2012; BELLETTI, 2015).

Existe uma série de sítios arqueológicos na Amazônia com evidências de mudanças culturais, em diferentes regiões, em torno do ano $1.000 \pm 400 \mathrm{DC}$, como:

- Declínio das ocupações das fases Paredão e Axinim, da Tradição Borda Incisa, na área de confluência entre os rios Solimões, Negro e Madeira. Foram encontradas evidências de guerra (valas e paliçadas) no momento em que grupos exógenos, associados à Tradição Policroma da Amazônia, chegavam à região (MORAES \& NEVES, 2012);

- No médio rio Solimões é observado uma mudança gradual no estilo cerâmico, especificamente da fase Caiambé (Tradição Borda Incisa) para a fase Tefé (Tradição Policroma da Amazônia) (BELLETTI, 2015);

- Formação de uma fronteira cultural entre a Tradição Policroma da Amazônia (oeste) e a Tradição Inciso Ponteada (leste), na margem norte do rio Amazonas, próximo a confluência dos rios Solimões, Negro, Madeira, representada pela cerâmica da Tradição Saracá (LIMA, 2013; BASSI, 2015);

- Aparecimento de sítios com conjuntos de estruturas montículares, de formato elipsoidal, no sudoeste amazônico (estado do Acre). Ao que tudo indica, esses assentamentos seriam posteriores aos sítios com valas (geoglifos), construídos no início do primeiro milênio DC (SAUNALUOMA et al., 2018);

- Expansão da Tradição Uru, que pode ter uma origem amazônica (alto rio Guaporé), em direção a leste. Suas evidências são encontradas em áreas de Cerrado, na região do médio e alto rio Tocantins e Araguaia (ROBRAHNGONZALEZ, 1996)

- Construção de estruturas megalíticas, associadas às cerâmicas Aristé, no norte do estado do Amapá e a expansão da cerâmica Koriabo em várias regiões das Guianas (SALDANHA, 2016; CABRAL, 2011; CABRAL e SALDANHA, 2008); 
- Apogeu e declínio da fase Marajoara (Tradição Policroma da Amazônia) e a construção dos tesos, na foz do Amazonas, em concomitância com outras cerâmicas, como a Aristé (SCHAAN, 2008);

- Expansão territorial e aumento de sítios arqueológicos relacionados à fase Santarém, na foz do Tapajós, e a fase Konduri na região do Nhamundá-Trombetas, ambos da Tradição Inciso Ponteada (QUINN, 2004; JÁCOME, 2017);

- Chegada dos antepassados dos atuais povos Arawak, na região do alto rio Xingu, representado na cerâmica da fase Ipavu (Tradição Inciso Ponteada) (HECKENBERGER, 2005; TONEY, 2016);

- Surgimento da cerâmica Huapula, provável correlato dos atuais grupos Jívaros/Achuar, na região da Alta Amazônia, no Equador (ROSTAIN, 2006);

- Ascensão da cultura Chachapoya no interflúvio Marañon-Huallaga, no Peru (CHURCH \& VON HAGEN, 2008).

Esses são alguns exemplos de mudanças ocorridas em no período compreendido entre 600 e 1.400 DC e, não necessariamente, estão todas interligadas. No capítulo 3, onde os dados da tese serão analisados, veremos que esses contextos se corroboram e de que maneira as mudanças podem ter afetado uma região.

Ainda não está claro quais foram os fatores que influenciaram essas mudanças, sendo necessário analisar cada caso de forma contextual e levando em consideração diferentes influências de ordem social, política, religiosa, ecológica, etc. Por exemplo, no caso da área de confluência dos rios Solimões, Negro e Madeira sabemos que o conflito bélico entre os grupos associados à Tradição Policroma da Amazônia e a Tradição Borda Incisa, levou ao declínio desses últimos (MORAES \& NEVES, 2012). Porém, ainda não se sabe o que motivou a expansão da Tradição Policroma e se o conflito marcado entre eles era algo restrito a essa região.

Na Alta Amazônia (Equador) há evidências de atividades vulcânicas, em torno de 600 DC, que levaram ao desaparecimento da cultura Upano, no vale do rio Upano, após 1.300 anos de ocupação contínua. O local seria reocupado, após 200 anos de abandono, pelos antepassados dos grupos Jívaros/Achuar (ROSTAIN, 2006). Na bacia do rio Ucayali, no Peru, os antepassados dos Shipibo (cerâmica Cumancaya) seriam pressionados rio acima pelos antepassados dos Cocama em torno de $1.300 \mathrm{AD}$, representados pela cerâmica Caimito da Tradição Polícroma da Amazônia (DEBOER, 1981). Na bacia do rio Napo, no Equador, se levanta a hipótese de que mudanças 
climáticas ocorridas em torno do ano mil teriam favorecido a expansão dos grupos da Tradição Polícroma (fase Napo) (ROSTAIN \& DE SAULIEU, 2013).

Essas mudanças culturais não ficam restritas às cerâmicas arqueológicas, sendo observadas na presença e ausência de determinados cultivos. Bush et al. (2016; 2015; 1989), através da palinologia de lagos, registraram a presença constante de milho em diferentes locais da Alta Amazônia, ao longo de 2-3 mil anos. No entanto, as evidências desaparecem em torno de $1.000 \mathrm{DC}$ ou antes. Os autores não possuem uma resposta concreta para esse desaparecimento, mas sugerem algumas hipóteses como: a) mudança do local de cultivo para áreas mais distantes do lago; b) especialização na produção dentro de uma rede de relações comerciais, excluindo a produção de milho em alguns locais e c) possível influência das mudanças climáticas do final do Holoceno, como a Anomalia Climática Medieval (BUSH et al., 2016). Ao contrário do cenário visto na Alta Amazônia, há evidências de milho (fitólitos e carvão), após ano 1.000 DC no médio Solimões (LOPES, 2018; OLIVEIRA, 2016).

Portanto, existem muitas informações arqueológicas relacionada a esse período que antecede a chegada dos colonizadores europeus, e a ideia desse trabalho é esboçar um panorama interligando diferentes regiões e contextos culturais em torno do ano 1.000 DC.

\section{$\underline{1.3 \text { As Tradicões Cerâmicas e seus contextos }}$}

A escolha da categoria Tradição cerâmica nos permite trabalhar em macro escala, correlacionando informações de mesma proporção (espaço e tempo). Mas antes de descrever as diferentes Tradições utilizadas nesse trabalho, é importante contextualizar como esse conceito é incorporado nas discussões desta tese.

Ao contrário da utilização inicial feita pelo PRONAPA e PRONAPABA (CHYMZ, 1966; MEGGERS \& EVANS, 1970; SIMÕES, 1972), entendo a ideia de Tradição como um conjunto de atributos estilísticos e tecnológicos expressos na cerâmica ou outras categorias de objetos (presentes em um conjunto ou região de sítios arqueológicos) e que estariam sendo compartilhados por um grupo de pessoas em determinados períodos, não obrigatoriamente possuindo uma associação com grupos linguísticos ou étnicos. Esse conceito não é inovador e pode ser comparado com a ideia 
de Complexo Cerâmico utilizado por alguns arqueólogos amazônicos (BARRETO, LIMA e BETANCOURT, 2016:589).

Contudo, a utilização do termo Tradição para tratar dos vestígios cerâmicos dá a ela um sentindo amplo e abrangente que qualifica não só a cerâmica, mas o contexto dos sítios onde ocorre (cronologia, estruturas artificiais, solos antrópicos, tamanho dos assentamentos, etc.). Um sentido semelhante, mais simplificado, foi utilizado por Anthony (2007:130-1) ao conceituar cultura arqueológica que, "refere-se a um conjunto recorrente de tipos de artefatos que ocorrem em uma região particular em um período de tempo". Moraes (2013:318) assume que as análises cerâmicas dizem pouco sobre as relações políticas do passado, sendo necessário estuda-las contextualmente em torno de sua espacialidade e distribuição regional. Seguindo a mesma linha de raciocínio, Rapp Py-Daniel (2015) utiliza as características contextuais de cada Tradição cerâmica aliada aos fatores espaciais, temporais, linguísticos, etnografias, além das práticas funerárias identificadas nos contextos arqueológicos. Almeida (2013) faz uma aproximação semelhante analisando os vestígios cerâmicos de modo contextual e utilizando "ferramentas auxiliares" como a linguística, etno-história e etnografia.

De toda forma, não pretendo redefinir, discutir ou propor um novo conceito classificatório ou das análises cerâmicas, pois já existe uma vasta bibliografia que se debruça sobre o assunto (e.g.: SILVA \& NOELLI, 2017; NEVES, 2010; SCHAAN, 2007). No entanto, será mantida a nomenclatura sedimentada na bibliografia (Tradição) de forma a facilitar o entendimento dos leitores.

A seguir serão apresentadas sumariamente as oito Tradições utilizadas nesse estudo. Para maiores detalhes e discussões específicas de cada Tradição, consulte a bibliografia sobre o assunto indicada ao longo do texto. Para a compreensão da localização de cada uma das Tradições, consulte os mapas 3.4.1-1 até 3.4.1-8 (volume II) ou o mapa publicado em Barreto, Lima e Betancourt (2016). 


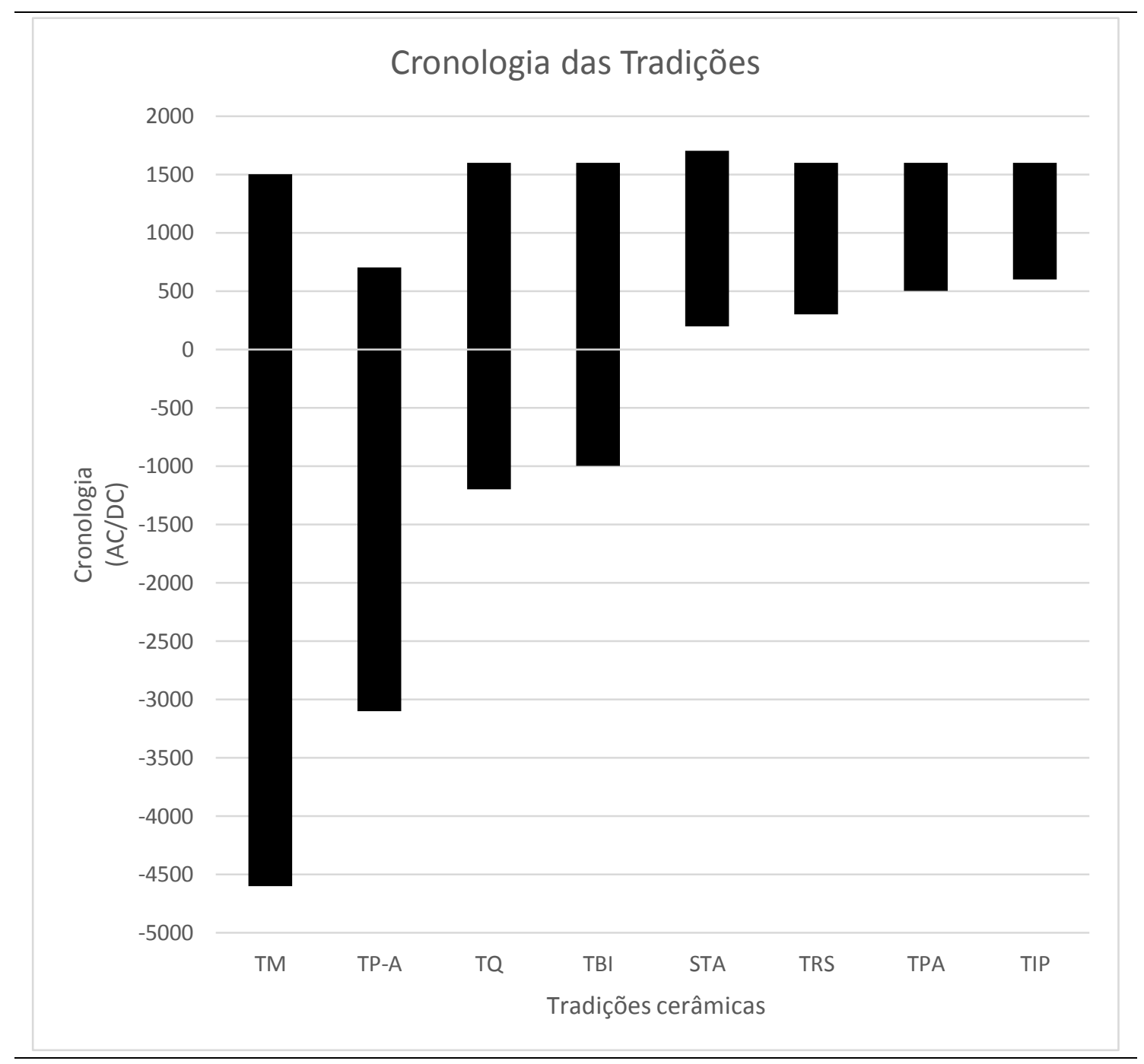

Gráfico 1.3-1: Cronologia das Tradições cerâmicas utilizadas nesse trabalho.

Legenda: TM: Tradição Mina; TP-A: Tradição Pocó-Açutuba; TQ: Tradição Quinari; TBI: Tradição Borda Incisa; STA: Subtradição Tupinambá da Amazônia; TRS: Tradição Regional Saracá; TPA: Tradição Polícroma da Amazônia; TIP: Tradição Inciso-Ponteada. 


\subsubsection{Tradição Mina (TM)}

Período - 4.600 AC - 1.500 DC

Considerada um dos vestígios cerâmicos mais antigos da Amazônia brasileira, a Tradição Mina está associada às ocupações sambaquieiras e não sambaquieiras do litoral atlântico do Pará e Maranhão, ilha de Marajó e baixo rio Xingu, abrangendo os atuais estados do Pará e Maranhão (Ilha de São Luís) (OLIVEIRA \& SILVEIRA, 2016; BANDEIRA, 2012; SILVEIRA \& SCHAAN, 2005).

A tradição foi criada por Mário F. Simões (1981) a partir dos vestígios cerâmicos coletados nos 43 sambaquis no litoral do Salgado, estado do Pará, através do Projeto Salgado entre os anos 1960-1970. Nas décadas de 1980 e 1990, pesquisas conduzidas no baixo rio Xingu (PEROTA, 1992; PEROTA \& BOTELHO, 1994) e no litoral das Guianas (WILLIAMS, 1981) identificaram complexos cerâmicos em sambaquis (litorâneos e fluviais) muito semelhante ao que Simões encontrou no Pará. Mais recentemente, nos anos 2000 em diante, cerâmicas da Tradição Mina já foram evidenciadas em sambaquis do Maranhão (BANDEIRA, 2012) e em sítios de TPI, fora dos sambaquis, no estado do Pará (SILVEIRA et al., 2011).

De início, se pensou que essa tradição poderia ser uma evidência de migrações vindas do litoral do Equador, dos grupos associados à cerâmica Valdívia (SIMÕES, 1981; MEGGERS, 1997). Posteriormente, com o aumento de amostras datadas e a inclusão de outras que haviam sido descartadas para a cerâmica Mina, Roosevelt (1995) e Williams (1981) postulavam que ela teria origem nas terras baixas da América do Sul e Brochado (1984) afirmava que seria a precursora de outras tradições ceramistas.

A cerâmica Mina é caracterizada pelo uso de conchas trituradas como antiplástico, mas pode ocorrer o uso combinado com areia e/ou caraipé. Vasilhas globulares de forma simples (sem carenas ou ombros), com alisamento em ambas as faces, podendo ocorrer engobo vermelho em alguma das faces. A decoração plástica ocorre em forma de escovado, inciso, exciso, acanalado, digitado e ungulado (SIMÕES, 1981; OLIVEIRA \& SILVEIRA, 2016). Bandeira (2016:156) afirma que as vasilhas Mina, reconstruídas nos sambaquis do Maranhão, foram utilizados no preparo, consumo e armazenamento de alimentos e líquidos, associada à subsistência focada na pesca e coleta de frutos do mar.

Para além de sua abrangência geográfica e das particularidades regionais, é interessante notar que sua cronologia começa em 4.600 AC (Sambaqui do Uruá - Litoral 
de Salgado, Pará) até 1.500 DC (Sambaqui do Paço do Lumiar - Ilha de São Luís e Sambaqui Guará I - baixo rio Xingu). No entanto, Oliveira \& Silveira (2016:131) alertam que a cerâmica do Sambaqui Guará é muito semelhante à da Tradição Mina, mas nunca foi incluída nesta Tradição. E apesar das datas recentes, Bandeira (2016:157) afirma que cerâmicas Mina desaparecem do registro arqueológico em torno de 750 DC e nesse período final ocorrem, concomitantemente, com cerâmicas da Tradição Tupi-Guarani. De toda forma, é importante salientar a persistência milenar dessa cerâmica por mais de 5 mil anos.

\subsubsection{Tradição Pocó-Açutuba (TP-A) \\ Período - 3.100 AC - 700 DC}

A cerâmica Pocó foi descrita pela primeira vez por Peter e Klaus Hilbert na década de 1980 em sítios na área dos rios Nhamundá e Trombetas, no Pará (Hilbert \& Hilbert, 1980). Naquele momento, os autores a associaram como uma manifestação local da TBI da foz do Orinoco e que estaria, cronologicamente, na transição entre o AC e DC (Hilbert \& Hilbert, 1980:8-9), descartando uma data de 1.000 AC por não existir nenhum paralelo conhecido na Amazônia. A cerâmica Açutuba foi identificada na área de confluência dos rios Solimões e Negro, possuindo traços muitos semelhantes a Pocó e que na época os pesquisadores chamaram de fase Açutuba (Lima et al., 2006). Mais recentemente Neves et al. (2014) propuseram a unificação desses dois complexos em um único conjunto, denominada Tradição Pocó-Açutuba. Como os autores apontam (ibid:138), essa tradição vai além de um novo conjunto cerâmico: seria um dos marcadores mais antigos e disseminados de antropização da paisagem amazônica, associada à formação dos depósitos mais antigos de terras pretas ao longo da calha do rio Solimões.

Com o avanço das pesquisas, sabemos que ela ocorre desde 3.100 AC (Alto Madeira) até 700 DC (Baixo Amazonas), e que há algumas relações de semelhança com as cerâmicas Saladóide, estilo Ronquín Sombra, identificadas no norte da América do Sul e Caribe (GOMES, 2011; LIMA \& NEVES, 2011; NEVES et al., 2014).

A cerâmica é caracterizada pelo uso da policromia (preto, amarelo, laranja, vermelho e vinho), sendo que não há preferência entre as cores utilizadas em forma de engobos ou pinturas, as quais ocorrem em faixas finas e grossas sobrepostas aos engobos. Os apliques modelados ocorrem muito frequentemente nos vasos, principalmente em 
formas de zoomorfos. Outras decorações plásticas como excisão, ponteado, escovado, corrugado e tracejado também são comuns (Neves et al., 2014). As pastas podem ter o uso isolado ou combinado de cauixi e caraipé, sendo que quando combinado são mais visíveis em determinadas partes dos vasos. Morfologicamente são comuns formas abertas simples (assadores ocorrem com certa frequência), complexas e compostas (vasos carenados), embora o universo fragmentado das amostras tenha permitido poucas reconstituições (HILBERT \& HILBERT, 1980; GUAPINDAIA, 2008; LIMA, 2008; GUAPINDAIA \& AIRES DA FONSECA, 2013).

Em geral, depósitos com cerâmicas da TP-A estão na base das estratigrafias, sendo as primeiras evidências de estabelecimento de ocupações humanas sedentárias, após o hiato cronológico do Holoceno médio (NEVES, 2011), e em áreas previamente não habitadas ou com evidências pouco visíveis de ocupações anteriores. Contudo, esse padrão é questionado quando analisados os dados do alto Madeira (ZUSE, 2014), do médio rio Negro (LIMA, 2014) e do Lago Amanã (COSTA, 2012), onde foram identificadas cerâmicas distintas da TP-A formando a base das sequências, embora essas cerâmicas não sejam evidências de ocupações duradouras. Outra característica é que cerâmicas da TP-A ocorrem em sítios arqueológicos que foram longamente ocupados, seja pelos produtores dessas cerâmicas, seja por grupos que produziram cerâmicas diferentes daquelas, configurando contextos multicomponenciais (NEVES et al., 2014).

Depósitos com cerâmicas Pocó-Açutuba podem ou não estar associados às terras pretas e com uma cronologia diversa, variando para cada região. A partir de $1.000 \mathrm{AC} \mathrm{em}$ sítios do baixo Japurá, Trombetas e Santarém, as terras pretas começaram a se formar, associadas a bolsões e com cerâmicas da TP-A. Entretanto, há também uma série de sítios cujos depósitos associados à TP-A estão matrizes de latossolo, abaixo das terras pretas. Esses contextos estão datados entre os séculos III AC e IV DC (LIMA, 2008).

Em suma, vemos que as características de ocorrência da Tradição Pocó-Açutuba são marcadas por uma ampla variação em um período de mudanças na forma de ocupar os lugares, tendo como característica principal um menor padrão de mobilidade. Nesse cenário, pouco se sabe sobre as diferenças na deposição dessa cerâmica nos sítios, sobre a relação de interação que teriam com produtores de outros conjuntos artefatuais (como aqueles da Tradição Borda Incisa) e ainda menos sobre os significados dessas diferenças no estabelecimento de grupos sedentários na Amazônia (LIMA, 2016). 
1.3.3 Tradição Quinari (TQ)

Período - 1.200 AC - 1.600 DC

A Tradição Quinari foi definida por Ondemar Dias e colegas (2006; LATINI et al.,2001; NíCOLI, 2000) após escavações realizadas no Acre, nas décadas de 1990, em sítios com e sem estruturas de terra (geoglifos). Sua dispersão ocorre de forma localizada e regional, especificamente nos formadores do alto Purus, entre o rio Caeté a oeste e o rio Abunã a leste, podendo estar associada ou não aos geoglifos, tanto aqueles formados por valas quanto os de montículos. A cerâmica é caracterizada por formas cilíndricas, globulares, carenadas, presença de flanges labiais e vasos antropomorfos globulares com pescoço e base cilíndrica. Possui decoração plástica incisa, excisa e pintada em linhas vermelhas ou pretas, podendo estar associada a engobos vermelho, marrom e branco, e antiplástico composto por caraipé, carvão e caco moído (DIAS, 2006; SAUNALUOMA et al., 2018).

Apesar da intensificação das pesquisas no Acre, principalmente nos geoglifos, é interessante notar que esses sítios possuem baixa densidade de vestígios cerâmicos, concentrada nas bases das valetas, nas muretas, nos montículos e em feições (SAUNALUOMA \& SCHAAN, 2012). As áreas mais planas, centrais, cercadas pelas estruturas de terra (valetas) não possuem fragmentos cerâmicos, o que nos leva a pensar como um espaço de circulação de pessoas, constantemente limpo, como uma praça central e/ou uma área para atividades cerimoniais (SAUNALUOMA \& VIRTANEN, 2015; SCHAAN et al., 2012).

Conforme aponta Saunaluoma (2016:419), as cerâmicas da Tradição Quinari necessitam de uma melhor classificação regional aliada à sua cronologia e contexto de deposição. Apesar do esforço em caracterizar esses vestígios através da arqueometria (LATINI et al., 2001; NÍCOLI, 2000), ainda há outros complexos cerâmicos identificados e classificados como "fase a ser designada". Somente com o aprofundamento das pesquisas no leste do Acre é que poderemos ter um melhor quadro cultural para as populações que construíram, ocuparam e reocuparam os diferentes tipos de geoglifos.

\subsubsection{Tradição Borda Incisa (TBI)}

Período - 1.000 AC - 1.600 DC

A Tradição Borda Incisa (TBI) foi definida como um dos complexos mais hipotéticos por Meggers e Evans $(1961 ; 1983)$ para os vestígios encontrados na Ilha de 
Marajó, no Pará, e ao longo da calha do rio Amazonas/Solimões (HILBERT, 1968). Por outro lado, a série Barrancóide foi identificada na bacia do rio Orinoco, na Venezuela, por Howard e Osgood (HOWARD, 1943) e retrabalhada por Rouse e Cruxent (1963). Alguns pesquisadores acreditam que a Tradição Borda Incisa seja uma manifestação meridional e local da série Barrancóide, associada à dispersão de populações de língua Arawak e com possíveis correlações com a Tradição Pocó-Açutuba (NEVES et al., 2014; LIMA \& NEVES, 2011; LIMA et al., 2006; HECKENBERGER, 2002; LATHRAP, 1970).

A cerâmica associada a essa Tradição é caracterizada pela presença de vasos com carena, flange labial, decorações incisas na borda, presença de engobo vermelho e apliques modelados antropomorfo, zoomorfo e antropozoomorfo. Os sítios associados a essas cerâmicas, normalmente multicomponenciais, representam o momento de maior adensamento demográfico, com grandes extensões de TPI e estruturas artificiais de terra (montículos e valas defensivas), aldeias de forma circular e datadas do primeiro milênio DC (LIMA, 2013; MORAES \& NEVES, 2012; LIMA, 2008; GOMES, 2011).

Assim como para a TPA, Lathrap (1970) propôs que a TBI teria seu centro de origem na área de confluência dos rios Solimões e Negro no primeiro milênio $\mathrm{AC}$, representado pela fase Manacapuru, e seria um correlato material dos povos de língua Arawak. Posteriormente, eles teriam migrado para o norte (bacia do Orinoco e Caribe) levando o cultivo de mandioca e a própria língua, onde estes seriam representados pela série Barrancóide. Dados obtidos depois demonstraram, no entanto, a existência datações mais antigas na região do Orinoco ( 1.000 AC) (OLIVER, 2014)

Para a área de confluência, Helena Lima (2008, 2016; LIMA \& NEVES, 2011) estudou uma sequência de estilos cerâmicos e contextos associados à Tradição PocóAçutuba (fase Açutuba - 300 AC-600 DC) e Tradição Borda Incisa (fase Manacapuru 600-1.000 DC; fase Paredão - 800-1.200 DC). Em linhas gerais, a autora afirma ocorrer "uma continuidade cultural colocada em perspectiva a partir de sua inserção em um largo quadro social, econômico e político, de caráter genérico e sistêmico que, por sua materialidade, se torna historicamente datável" (LIMA, 2016). Essa contínua história seria quebrada, de forma belicosa, com a chegada dos grupos produtores da Tradição Polícroma da Amazônia (MORAES \& NEVES, 2012).

Mas se na maior parte dos sítios com cerâmicas TBI há uma apropriação dos espaços por outros grupos culturalmente distintos (e.g. TPA), vê-se no o Alto Xingu outra 
possibilidade. Enquanto toda a calha dos grandes rios, inclusive o próprio médio e baixo Xingu, estavam sendo ocupados por grupos que utilizavam cerâmicas da Tradição Inciso Ponteada ou da Tradição Policroma entre 800 - 1.000 DC, o Alto Xingu começava a ser densamente ocupado por grupos Arawak e que produziam uma cerâmica com traços da TBI misturados aos elementos da Inciso Ponteada (fase Ipavu) (HECKENBERGER 2005; HECKENBERGER et al. 2003, 2008; TONEY, 2016).

Cerâmicas da Tradição Borda Incisa possui uma ampla dispersão pelo território amazônico. No entanto existem poucos estudos comparativos em relação à tecnologia de produção cerâmica, os motivos gráficos, os contextos deposicionais ou sua relação com as demais ocupações (antes e posteriores a ela). Acredito, assim como Moraes (2013), que o período da TBI é marcado por chefias regionais, grandes adensamentos populacionais e possíveis alianças (incorporação?) com grupos vizinhos e/ou culturalmente próximos, criando uma rede multiétnica regional integrada e fluída.

\subsubsection{Subtradição Tupinambá da Amazônia (STA) Período - 200 - 1.700 DC}

Essa subtradição foi recém-definida no trabalho de Almeida (2013; ALMEIDA \& NEVES, 2015) e está localizada no sudeste amazônico, na região dos rios Xingu e Tocantins-Araguaia. Através de dados etnohistóricos, linguísticos e arqueológicos a Subtradição Tupinambá da Amazônia compõe a Tradição Tupi-Guarani juntamente com as Subtradições Tupinambá da Costa e Guarani (ALMEIDA \& NEVES, 2015: 517). Datações radiocarbônicas recuam a STA em 200 DC, para a região do interflúvio XinguTocantins, podendo ser mais antigas (SILVEIRA et al., 2008). As análises cerâmicas demonstraram uma imensa variabilidade, que pode estar atrelada à milenar ocupação desses grupos na região e sua interação com diferentes grupos, como os Arawaks e Caribes do Xingu, Timbira do Maranhão e os Jê do Brasil Central (ALMEIDA \& NEVES, 2015: 518; GARCIA, 2016:195).

A hipótese proposta por Almeida (2013) é que grupos Tupi-Guarani teriam sido incorporados em uma rede de contatos multiétnicos, intermediada por grupos Arawak, onde os Tupi-Guarani teriam adquirido vários elementos estilísticos na cerâmica (possivelmente da Tradição Pocó-Açutuba) observáveis nas tigelas policrômicas da Tradição Tupi-Guarani. 
A cerâmica é caracterizada por pasta com caco moído e/ou mineral como antiplástico, queima redutora, presença de carenas e ombros, base convexa ou ovalada, decorações plásticas externas (corrugado, inciso, ungulado, digitado e escovado) e pintadas (vermelho, preto e branco), que ocorrem tanto na parte interna quanto externa, em forma de banhos, faixas ou motivos geométricos. As urnas funerárias são vasilhas reutilizadas, de grande porte, tampadas por um outro vaso menor (LA SALVIA \& BROCHADO, 1989; ALMEIDA, 2016).

\subsubsection{Tradição Regional Saracá (TRS) \\ Período - 300 - 1.600 DC}

Definida como Tradição Regional por Mário Simões e Ana Lúcia Machado (1984) através de vestígios cerâmicos coletados em sítios arqueológicos localizados em torno do Lago de Silves, no baixo Amazonas. Simões realizou duas excursões a essa região e, conforme citam Lima, Araújo e Moraes (2016:291), a ideia era delimitar a fronteira cultural existente entre duas grandes tradições cerâmicas: Tradição Polícroma da Amazônia e a Tradição Inciso Ponteada, além de identificar as influências dessas duas sobre as cerâmicas regionais.

No entanto, se depararam com características decorativas da cerâmica que não se encaixavam em nenhuma das quatro 4 tradições cerâmicas proposta por Meggers e Evans (1961), o que causou certa confusão classificatória. Os vestígios possuíam elementos decorativos inéditos, como o ponteado estampado, ponteado arrastado e ponteado repuxado (BASSI, 2015). Além disso, havia traços que remetiam a Tradição Polícroma da Amazônia (flanges mesiais, acanalado, pintura policroma e excisão) ou a Tradição Inciso Ponteada (engobo vermelho, inciso fino, inciso ponteado e modelado inciso). Para complicar a situação, o antiplástico preponderante era o cauixí, que o colocava em proximidade com a Tradição Borda Incisa, também presente na região (BASSI, 2015:64). Por fim, com a publicação dos trabalhos realizados na região do Lago de Silves, formalizou-se o termo Tradição Regional Saracá (SIMÕES \& MACHADO, 1987).

Como Filippo Bassi aponta em sua tese de doutorado (2015:65), a criação dessa tradição regional respondeu ao projeto de pesquisa proposto por Simões, ou seja, o conceito de fronteira cultural e a definição dos limites de dois macrossistemas culturais. Um aspecto que corrobora a ideia de fronteira cultural é a ocorrência de vestígios Saracá 
juntamente com as cerâmicas da TPA e da TIP, lembrando que ambas são cronologicamente concomitantes, sendo a TPA ocorrendo mais a oeste e a TIP a leste em relação ao Lago de Silves (LIMA, 2013).

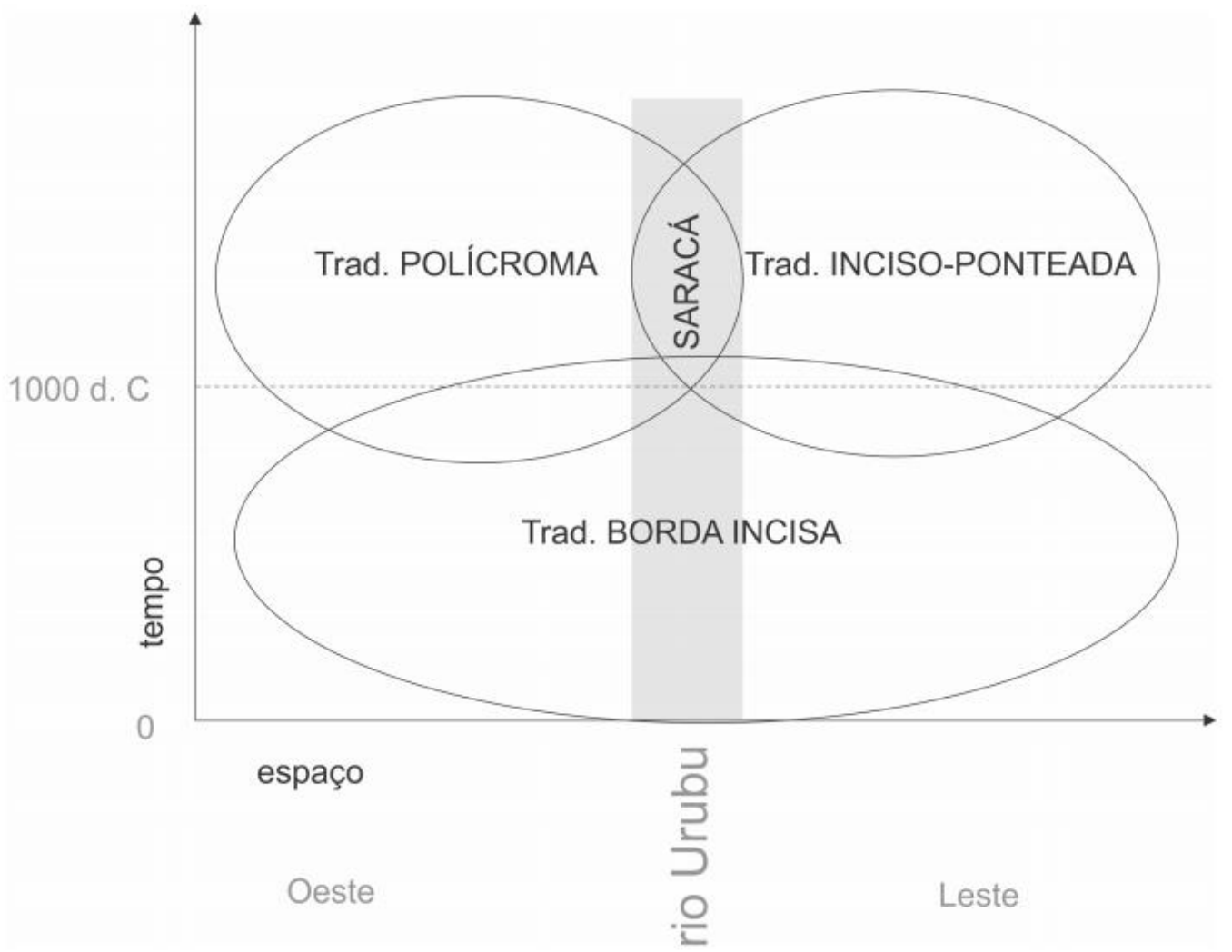

Figura 1.3.6-1: Diagrama representando a hipótese de fronteira cultural no rio Urubu. Extraído de Bassi, 2015.

A cronologia para essas cerâmicas, na época de Simões e Machado, foi obtida através da Fase Uatumã, classificada como TRS, e que estava entre 300 e 900 DC (SIMÕES \& MACHADO, 1987). No entanto, Lima, Araújo e Moraes (2016:301), através do Projeto Baixo Urubu, obtiveram datas que vão de 900 a 1.600 DC, desconsiderando a cronologia obtida por Simões por causa dos contextos datados.

Em suma, a cerâmica Saracá está localizada em uma área de confluência de macrossistemas regionais materializadas nas cerâmicas TPA e TIP que formam formando uma fronteira cultural, entendida como uma fusão regional e localizada (Lago de Silves e arredores) de elementos culturais e sociais distintos. Lima (2013:58) entende essa ideia, de certa maneira, com o conceito de etnogênese pensando na criação de "identidades duradouras em contextos gerais de mudança radical e descontinuidade". 


\subsubsection{Tradição Polícroma da Amazônia (TPA) \\ Período - 500 - 1.600 DC}

Essa tradição cerâmica foi utilizada pela primeira vez, como categoria de classificação, por Howard em 1947 (Polychrome Division of Amazonia) e trabalhado melhor como Tradição Polícroma da Amazônia por J. P. Brochado e D. Lathrap na década de 1980 (BROCHADO, 1989). Ela pode ser caracterizada pela presença da policromia (pintura vermelha, preta e amarela sobre engobo branco), flanges mesiais, rolete reforçado externo nos lábios, decoração plástica acanalada e sepultamentos em urnas antropomorfas (TAMANAHA, 2012; NEVES, 2012; BELLETTI, 2015; OLIVEIRA, 2016; ALMEIDA \& MORAES, 2016). Geralmente, sua ocupação está associada à última camada dos sítios arqueológicos multicomponenciais. Mais raramente pode ocorrer em contextos unicomponenciais, onde é representada por uma camada de até $50 \mathrm{~cm}$ de profundidade com presença de terra preta de índio (TPI) e, ao que tudo indica, sua ocupação possuía forma linear paralela às margens dos rios (REBELLATO, 2007). As datações obtidas para os contextos onde foram identificadas indicam uma faixa temporal entre 500 DC e o período colonial (século XVII) (BELLETTI, 2015).

Sítios com cerâmicas da Tradição Polícroma têm uma ampla distribuição pela Amazônia e podem ser encontrados desde o Alto Rio Napo, no sopé dos Andes equatorianos, e o baixo rio Ucayali, no Peru, até o Lago de Silves, próximo à confluência dos rios Solimões, Negro e Madeira. Após um longo intervalo de ausência (eixo oesteleste), ela volta a aparecer na Ilha de Marajó, na foz do Amazonas, no baixo rio Xingu e na costa litorânea do Amapá (SALDANHA, 2017; OLIVEIRA, 2016; BELLETTI, 2015; TAMANAHA \& NEVES, 2014; ALMEIDA, 2013; SCHAAN, 2008; PEROTA, 1992). Essa ampla distribuição tem sido objeto de estudo desde os anos 1950, por meio da apresentação de hipóteses difusionistas, com perspectivas históricas distintas (BROCHADO, 1989; MEGGERS \& EVANS, 1957, 1961, 1968; LATHRAP, 1970). Tais hipóteses não serão aqui revistas, mas é importante destacar como cerâmicas da Tradição Polícroma - principalmente as produzidas na Amazônia central e Amazônia ocidental — têm uma grande padronização formal e estilística que permite sua fácil identificação, mesmo que tenham sido produzidas em sítios localizados a milhares de quilômetros de distância (MEGGERS \& EVANS, 1968; BOOMERT, 2004; TAMANAHA \& NEVES, 2014). 
Lathrap (1970) e Brochado $(1984,1989)$ propuseram que a ampla dispersão da TPA estaria associada à origem e expansão dos povos de língua Tupi, localizando o seu centro de origem na área de confluência dos rios Solimões e Negro. Lathrap argumentava que o desenvolvimento de uma agricultura de várzea teria impulsionado o crescimento demográfico, sendo essa região central como um coração pulsante (modelo cardíaco) que bombeava esses grupos para outras regiões através dos grandes rios e seus afluentes. Esse fenômeno teria origem em 4.000 AC. No entanto, pesquisas realizadas nos anos 1990 na área de confluência demonstraram que o modelo não se sustentava, pois a TPA ocorria como a última ocupação dos sítios e tinha datações entre 800 e 1.400 DC (NEVES, 2012; TAMANAHA, 2012; HECKENBERGER et al., 1998). Sua vinculação com os povos de língua Tupi ainda é questionada, já que ela ocorre em áreas que histórica e etnograficamente são ocupados por outros grupos, como o rio Negro (povos Arawak) (URBAN, 1992; NIMUENDAJU, 1981).

Por outro lado, Miller (1992) associa a origem da TPA a leste do rio Madeira, por causa de sítios datados de 700 AC. Almeida (2013:349), em sua tese de doutorado, mostrou que essa hipótese não se sustenta e que a TPA do alto Madeira poderia ser o resultado de uma provável rede multiétnica, de matriz Arawak, com a incorporação de diferentes elementos (entre eles, a belicosidade Tupi) e que teriam se expandido pelo médio e baixo Madeira antes de 700 DC.

Outro ponto a ser elencado nessa discussão são as fases cerâmicas da TPA localizadas na região litorânea, como as fases Marajoara e Koriabo. Pesquisas recentes têm reavaliado a inclusão dessas fases na TPA, junto às demais cerâmicas que ocorrem na parte ocidental, por conta dos seus traços estilísticos e contextos arqueológicos particulares (HECKENBERGER \& NEVES, 2009; BARRETO, 2009; NEVES, 2012; ALMEIDA, 2013).

Para nossa discussão é interessante notar como a TPA (em sua parte ocidental) teve uma rápida expansão no primeiro milênio DC, com um aumento expressivo de sítios arqueológicos próximo ao ano mil, em um processo multifacetado que varia entre uma incorporação mais gradual desses elementos estilísticos (BELLETTI, 2015) e uma “entrada" abrupta por meio de guerras (MORAES \& NEVES, 2012). 


\subsubsection{Tradição Inciso Ponteada (TIP)}

Período - 600 - 1.600 DC

As cerâmicas Inciso Ponteada também foram definidas como tradição nos trabalhos de Meggers e Evans $(1961,1983)$, incluindo contextos localizados no rio Orinoco, baixo Amazonas e o litoral atlântico. Segundo os autores, essa Tradição teria se originado nas terras altas da Colômbia, passando pela foz do Orinoco até chegar ao baixo Amazonas (MEGGERS \& EVANS, 1961). Por outro lado, Lathrap (1970) propôs que o centro de origem dessa Tradição seria em algum lugar do médio rio Amazonas e a relacionou com os grupos de língua Karib.

As cerâmicas do baixo Amazonas, representadas pelas fases Tapajônica e Konduri, são as mais conhecidas e estudadas até o momento (ROCHA, 2017, 2012; JÁCOME, 2017; PANACHUK, 2016; TROUFFLARD, 2016; MARTINS, 2012; STENBORG, SCHAAN \& AMARAL, 2012; GUAPINDAIA, 2008; GOMES, 2002), mas existe um representante mais a oeste (médio e baixo rio Madeira) com a fase Curralinho (MORAES, 2013; SIMÕES \& LOPES, 1987) e ao sul (alto rio Xingu) com a fase Ipavu (TONEY, 2016). Simões e Lopes (1987) haviam classificado a fase Axinim como sendo da TIP, no entanto o trabalho de revisão feito por Moraes (2013) demonstrou que essa cerâmica possuía mais traços estilísticos que remetiam a TBI do que a TIP. A fase Ipavu havia sido classificada inicialmente como da TBI e apesar de possuir características dessa Tradição misturados a elementos da TIP, Toney (2016) a considera inclusa nessa última.

As cerâmicas da TIP se caracterizam pelas decorações incisas e ponteadas, muitas vezes associadas a apliques modelados antropomorfos, zoomorfos ou geométricos. Possui uma ampla variedade morfológica, podendo ser um simples vaso globular até com formas de animais ou vasos cariátides, além de estatuetas antropomorfas. Pode estar acompanhado de engobo vermelho, base trípode ou com pedestal e o antiplástico preponderante é o cauixí, mas pode variar bastante (ROCHA, 2017:69; GUAPINDAIA, 2008).

No baixo Amazonas, fragmentos da TIP são encontradas na superfície sobrepondo-se a ocupações da TBI ou Pocó-Açutuba, sempre associada às camadas com Terra Preta (NEVES et al., 2014; GUAPINDAIA, 2008; HILBERT \& HILBERT, 1980). $\mathrm{Na}$ região do baixo rio Madeira ela foi pouco estudada, mas é provável que estivesse na 
mesma situação que as cerâmicas das fases Axinim e Paredão (TBI), ou seja, foram suprimidas pela expansão de produtores de cerâmica da TPA próxima ao ano mil.

Assim como a TIB, a TIP possui um correlato no norte do continente batizado de Arauquinoide por Cruxent \& Rouse (1959), a partir do complexo cerâmico Arauquín encontrado no médio rio Orinoco e datado entre 650 - 1600 DC (ROSTAIN \& VERSTEEG, 2004). Acredita-se que essas cerâmicas, da mesma maneira que a TIP, estariam relacionadas a expansão dos povos de língua Caribe pela região do Orinoco, Guianas e Pequenas Antilhas (LATHRAP, 1970). Seu contexto de deposição nos sítios é muito semelhante ao da TIP, pois é a última camada de ocupação sobrepondo as cerâmicas Pocó-Açutuba ou TBI. Uma grande diferença existente para os contextos amazônicos são os campos elevados e montículos da costa litorânea do Suriname e Guiana Francesa (ROSTAIN \& VERSTEEG, 2004). 


\section{CAPÍTULO 2 - Banco de Dados Georreferenciado}

Como apresentado brevemente no capítulo 1, o banco de dados surgiu em 2007 frente a uma necessidade de compilar os sítios arqueológicos identificados e/ou trabalhados pela equipe do PAC (Projeto Amazônia Central). Inicialmente só foram coletadas duas informações para cada sítio: o seu nome e as coordenadas geográficas. Ao longo dos anos, o banco ficou mais robusto e aumentou a necessidade de incluir mais informações a respeito de cada sítio, pois seria uma forma de categorizar e distinguir sua composição física (e.g.: TPI, estruturas artificiais, profundidade, tamanho, etc.) e temporalidade (e.g.: datação, Tradições cerâmicas, tipo de vestígio, etc.), isto é, de qualificar as informações que o banco compilava.

Atualmente o banco de dados conta com 30 campos para caracterizar cada um dos sítios e a base inicial desses campos foi inspirada no Cadastro Nacional de Sítios Arqueológicos (CNSA) do Instituto do Patrimônio Histórico e Artístico Nacional (IPHAN). Em linhas gerais, os campos definem a identificação, localização, contexto hidrográfico, contexto cultural e cronologia. Hierarquicamente, as informações de identificação e localização são as principais e obrigatórias, pois sem elas não é possível inserir novos sítios arqueológicos no banco de dados. Ou seja, todos os sítios possuem uma coordenada geográfica e (ao menos) uma referência bibliográfica. Em alguns casos, só existem esses dois aspectos e para outros temos informações para os 30 campos. Abaixo serão descritos os campos, de forma geral, conforme demonstrado na figura 2-1.

\section{- Identificação}

Dos três campos, a Referência Bibliográfica é o principal elemento de identificação das informações. Em alguns casos não foi possível obter o nome do sítio arqueológico, referenciando por alguma denominação genérica (e.g. Balbina 01, Balbina 02 , etc.), mas todos possuem alguma referência bibliográfica para que seja possível acessar a fonte de informação.

\section{- Localização}

Da mesma maneira que a referência bibliográfica, as coordenadas geográficas são a base para o banco de dados. Sem elas não é possível georreferenciar as informações arqueológicas. Todas as coordenadas estão em graus decimais e no datum SIRGAS 2000. 
As coordenadas geográficas foram obtidas através de dois métodos: 1) acessando diretamente as coordenadas (longitude-latitude), independente do seu formato e datum; 2) através do georreferenciamento de imagens, mapas e cartas para extrair as coordenadas de um local. Para as coordenadas com outros tipos de Datum (WGS 1984, SAD 1969, etc.) realizou sua conversão através do QuantumGIS ou de conversores gratuitos e online.

Os dados sobre país, estado e município foram extraídos através do cruzamento das coordenadas dos sítios com os polígonos de divisão territorial fornecidos pelo Instituto Brasileiro de Geografia e Estatística (IBGE) ${ }^{2}$.

\section{- Contexto Hidrográfico}

A obtenção de informações a respeito da sub-bacia seguiu o mesmo procedimento que o da localização territorial (país, estado e município). Os polígonos que definem as sub-bacias hidrográficas foram fornecidos pela Agência Nacional de Águas (ANA). Os corpos d'água próximo ao sítio e a classificação das drenagens (de $1^{\circ}$ até $11^{\circ}$ ordem) foram obtidas através da bibliografia ou dos dados georreferenciados fornecidos pela HydroSHEDS ${ }^{3}$ e Águas Amazônicas ${ }^{4}$.

Com esses diferentes níveis de informação, associados à localização dos sítios, é possível mensurar a distância do ponto ao corpo d'água. Somente no caso da implantação (e.g.: topo de colina, área de alagação, etc.) foi necessário recorrer aos dados de campo, quando esse aspecto vinha descrito na bibliografia.

\section{- Contexto Cultural}

Todas as informações referentes ao sítio arqueológico e seus vestígios associados foram levantados através da bibliografia ou do Sistema de Gerenciamento do Patrimônio Arqueológico (SGPA) do IPHAN 5 . Infelizmente, como dito anteriormente, nem todos os sítios identificados possuem todas as informações, pois isso depende do objetivo e andamento do projeto de pesquisa. Em alguns casos há somente a prospecção de sítios através da vistoria de superfícies expostas, por outro lado há casos em que um único sítio

\footnotetext{
${ }^{2}<$ https://mapas.ibge.gov.br/>

$3<$ http://www.hydrosheds.org/ > HydroSHEDS - Hydrological data and maps based on SHuttle Elevation Derivatives at multiple Scales.

${ }^{4}<$ http://pt.aguasamazonicas.org/> - Base dedados hidrológico de toda a bacia amazônica.

${ }^{5}<$ http://portal.iphan.gov.br/pagina/detalhes/236> - Base de dados dos sítios arqueológicos brasileiros cadastrados no IPHAN.
} 
foi escavado exaustivamente ao longo de anos, possuindo uma boa base de informações arqueológicas.

\section{- Cronologia}

Os dados cronológicos são os mais escassos e imprecisos, pois dependem de uma série de fatores como a análise do vestígio arqueológico (e.g. cerâmica colonial vs. cerâmica pré-colonial) ou a datação absoluta. Por conta disso, o foco principal foi obter os dados referentes às datações, principalmente as radiocarbônicas. A preferência por esse método não foi aleatória, já que estas representam a maior parte das datações arqueológicas e são mais fáceis de calibrar através de softwares gratuitos (e.g. Calib ou OxCal).

Para obter um maior controle das informações radiocarbônicas foi utilizada somente a datação convencional com sua variação e calibradas no software $\mathrm{Calib}^{6}$ e a base de dados SHCal 13 (Southern Hemisphere Calibration). Após a calibração, utilizouse o intervalo de 2 sigmas e com área relativa sob distribuição de probabilidade (relative area under probability distribution) próxima ou igual ao valor 1.0. (STUIVER \& REIMER, 1993; HOGG et al., 2013).

\footnotetext{
${ }^{6}<$ http://calib.org/calib/calib.html $>$ - CALIB 7.1, versão HTML
} 


\begin{tabular}{|c|c|c|c|c|}
\hline Identificação & Localização & Contexto Hidrográfico & Contexto Cultural & Cronologia \\
\hline $\begin{array}{l}\text { - Código } \\
\text { - Nome } \\
\text { - Referência Bibliográfica }\end{array}$ & $\begin{array}{l}\text {-Coordenadas } \\
\text { Geográficas } \\
\text {-País/Estado/Município }\end{array}$ & $\begin{array}{l}\text {-Sub-bacia } \\
\text { - Rio mais próximo } \\
\text {-Distância para o rio } \\
\text { mais próximo } \\
\text {-Drenagem } \\
\text {-Implantação }\end{array}$ & $\begin{array}{l}\text {-Tipo de vestígio e } \\
\text { exposição do mesmo } \\
\text {-Solo antrópico } \\
\text { - Tradição/Fase Cultural } \\
\text {-Petróglifo } \\
\text {-Profundidade do sítio } \\
\text {-Dimensão / Área } \\
\text { - Quantidades de } \\
\text { ocupações (líticas e } \\
\text { cerâmicas) } \\
\text { - Estruturas Funerárias } \\
\text { - Atual uso do terreno }\end{array}$ & $\begin{array}{l}\text {-Pré-Colonial / Histórico } \\
\text {-Datação (Relativa e/ou } \\
\text { Absoluta) }\end{array}$ \\
\hline
\end{tabular}

Figura 2-1: Tipos de informações utilizadas no banco de dados georreferenciado. 


\section{$\underline{2.1 \text { - Fontes de informacão }}$}

As informações foram adquiridas em diferentes fontes bibliográficas como relatórios técnicos, planos de gestão de Unidades de Conservação (UC) e Terras Indígenas (TI), teses, dissertações, livros, capítulos de livro e artigos. Soma-se a esse inventário, informações obtidas através do Google Earth (geoglifos), cadernos de campo de outros pesquisadores e o banco de dados do IPHAN. Excluindo esse último e os dados via Google Earth, foram consultadas 303 fontes bibliográficas.

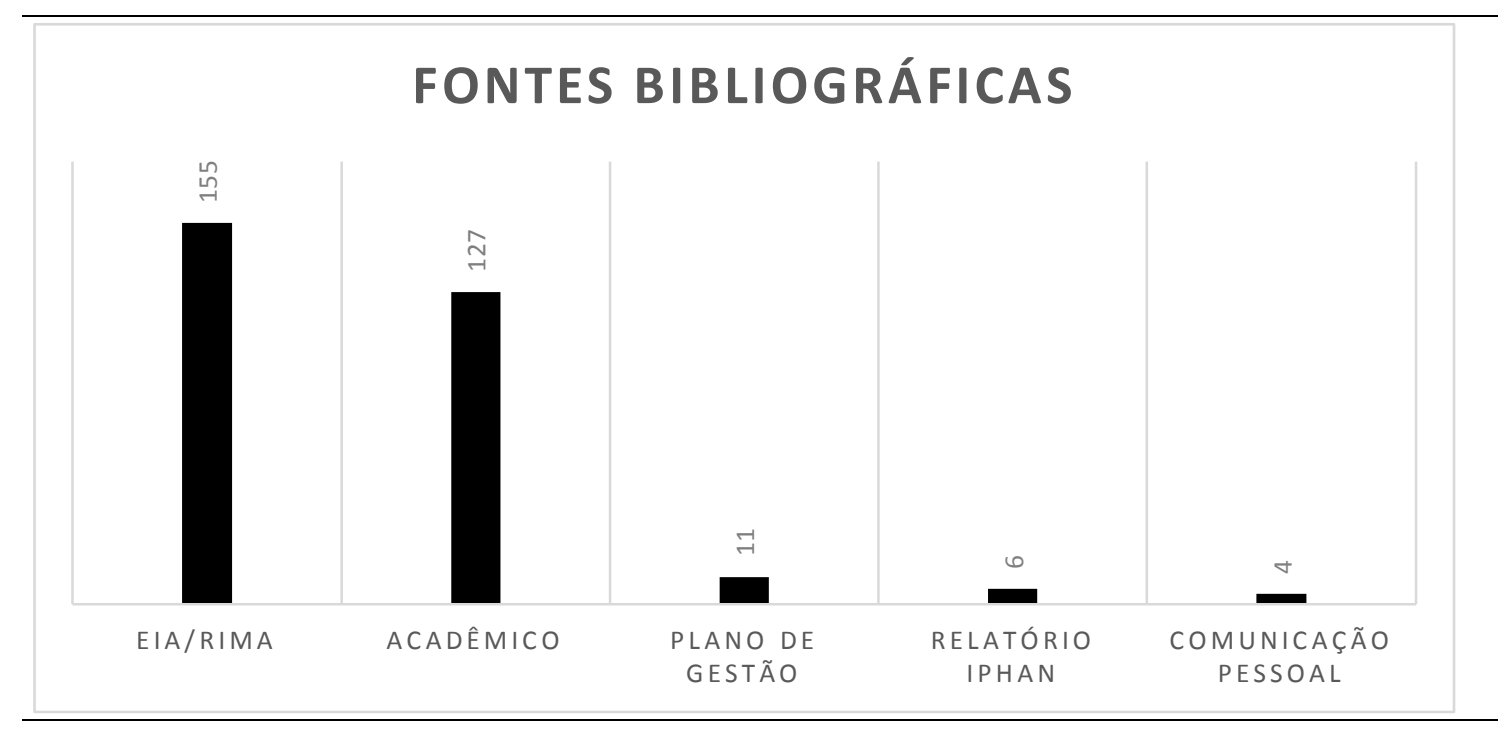

Gráfico 2.1-1: Diferentes fontes consultadas para o banco de dados

O gráfico acima ilustra a quantidade de fontes bibliográficas consultadas, diferenciando principalmente os relatórios técnicos de EIA/RIMA, realizado por empresas de licenciamento, da produção gerada em Universidades (pós-graduação, projetos temáticos, etc.). Ciente de que muitas teses, dissertações e artigos foram geradas a partir de trabalhos de EIA/RIMA, essas duas categorias servem apenas para distinguir a fonte consultada. Grande parte dos relatórios técnicos de EIA/RIMA estão disponíveis na internet e podem ser acessados através do endereço < http://licenciamento.ibama.gov.br/ >.

É interessante apontar que a maioria das fontes consultadas ( $\mathrm{n}=155)$ são dos trabalhos de EIA/RIMA, não se distanciando demasiadamente do acadêmico ( $n=127)$. No entanto, ao longo da construção do banco de dados, percebeu-se uma discrepância na profundidade de informações geradas entre os trabalhos de licenciamento e aqueles desenvolvidos em universidades ou museus. Salvo algumas exceções, a maior parte das 
teses e dissertações listam poucos sítios arqueológicos, mas possuem um alto grau de refinamento das informações. Por outro lado, a maior parte dos relatórios de licenciamento possuem imensas listas de sítios arqueológicos identificados, mas pouco detalhamento sobre os mesmos. Podemos hipotetizar, dedutivamente, que essas diferenças se devem ao cronograma da pesquisa, orçamento disponível, logística, mãode-obra qualificada e metodologia empregada.

Os Planos de Gestão das UC's e TI's foram acessados através dos órgãos públicos responsáveis pela gestão e representam uma pequena parcela do montante de fontes consultadas $(n=11)$. No mesmo sentido que o anterior, alguns trabalhos de pós-graduação foram gerados a partir de pesquisas realizadas para a elaboração do Plano de Gestão, como é o caso da RDS Amanã (COSTA, 2012; GOMES, 2015).

Os relatórios do IPHAN ( $\mathrm{n}=6)$ estavam disponíveis na internet, em diferentes páginas (pessoais ou institucionais), e compõem trabalhos executados pelo próprio corpo técnico do IPHAN, como os relatórios das arqueólogas Maria Lucia Pardi e Maria Clara Migliácio.

As comunicações pessoais $(n=4)$ foram obtidas através de pesquisadores (arqueólogos ou não) que cederam gentilmente as coordenadas, fotos e outras informações pertinentes aos sítios arqueológicos, todos localizados no estado do Amazonas.

As informações georreferenciadas disponibilizadas pelo IPHAN também foram incorporadas ao banco de dados. Foi realizada uma triagem nos mais de 12 mil sítios focando na área de abrangência da Amazônia Legal Brasileira e, posteriormente, foram excluídos os sítios duplicados. No total foram adicionados mais 1.308 sítios arqueológicos à base de dados.

Por fim, alguns sítios do tipo Geoglifo foram encontrados através do Google Earth. Esse tipo de levantamento não é inovador e várias pessoas tiveram a mesma ideia, inclusive para identificar novos sítios Geoglifos na bacia do Alto Purus (RANZI, FERES \& BROWN, 2007). Ao todo foram identificados 80 sítios no sul do Amazonas, leste do Acre e oeste de Rondônia.

Ao analisarmos a quantidade de sítios obtida para cada tipo de fonte de informação, podemos observar que os dados mais expressivos foram gerados nas universidades, correspondendo a $44 \%(n=2.985)$ do total, seguido dos trabalhos de 
licenciamento ambiental $(33 \%, \mathrm{n}=2.240)$ e do banco de dados do IPHAN (19\%, $\mathrm{n}=1.312)$. Os demais representam uma pequena parcela do total (entre $3 \%$ e $0 \%$ ), que somados chegam a 258 sítios arqueológicos.

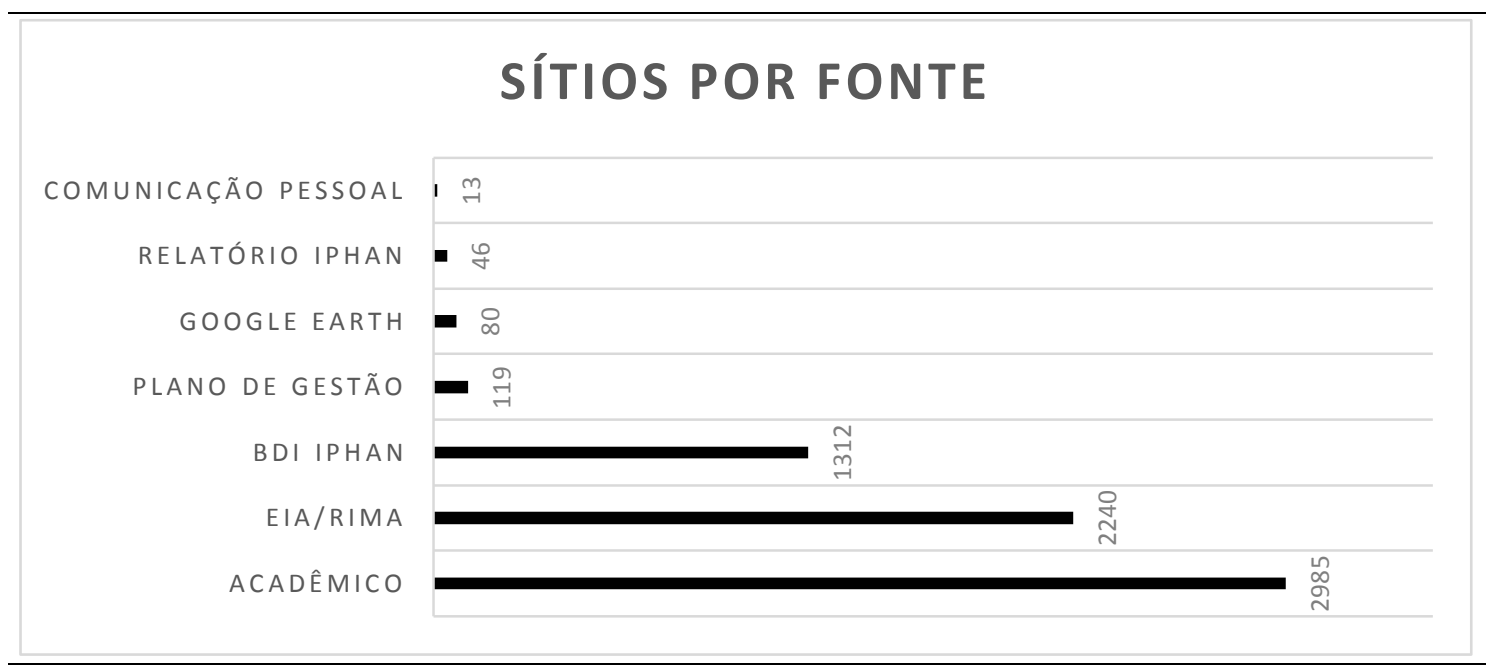

Gráfico 2.1-2: Quantidade de sítios obtidos por fonte consultada

Como dito anteriormente, estou ciente de que muitas teses, dissertações e artigos consultados foram gerados a partir dos trabalhos de EIA/RIMA (e.g.: pesquisas de pósgraduação no alto rio Madeira ou no planalto santareno) e, por essa razão, as pesquisas acadêmicas possuem um maior número de sítios do que os de licenciamento. Embora não seja objetivo dessa tese explorar esse tema é importante reconhecer que somente com uma análise do contexto de pesquisa, para cada sítio, poderíamos chegar a uma reflexão mais acurada sobre as diferentes formas de se fazer a pesquisa arqueológica.

\section{$\underline{2.2}$ - Dificuldades na obtenção de dados e suas limitacões}

No processo de construção do banco de dados me deparei com alguns problemas no acesso e padronização das informações arqueológicas, que contribuíram no alcance analítico desses dados. Os diferentes níveis de informação, o entendimento do contexto arqueológico, conceito utilizados para descrever a cultura material ou a composição do sítio, além de informações publicadas de forma superficial são alguns dos fatores que dificultaram a inclusão de novos dados.

Creio que os casos mais emblemáticos são referentes às pesquisas realizadas durante as décadas de 1950-1970 providas pelo Programa Nacional de Pesquisas 
Arqueológicas da Bacia da Amazônica (PRONAPABA). Entendo que na época o nível do conhecimento arqueológico era escasso e inicial, assim como as tecnologias disponíveis de mapeamento. No entanto, alguns mapas não são precisos ou simplesmente não há nenhuma referência espacial que permita a sua localização de forma precisa. Mesmo que tenham sido cadastrados no SGPA/IPHAN, com escavações, análise do material e datação, o próprio órgão federal só possui as informações do sítio, sem nenhuma coordenada geográfica disponível. São sítios que só poderão ser retrabalhados se alguém for a campo reencontra-los.

Muitos dos relatórios de EIA/RIMA, de uma maneira diferente e oposta aos do PRONAPABA, apresentam uma série de sítios identificados com coordenadas precisas, sendo raras as exceções quando as coordenadas foram digitadas de maneira errada. Por outro lado, as informações sobre o sítio (e.g. tipo de material, profundidade, área, ausência/presença de solos antrópicos, etc.) são muito superficiais. Em alguns casos é perceptível que foram trabalhos realizados por pessoas que não tinham experiência em contextos amazônicos, mas em sua grande maioria está relacionado com o contexto de pesquisa (licenciamento ambiental). Como já foi dito, os objetivos e o cronograma de pesquisa atuam de forma diferente de uma pesquisa de pós-graduação. Sítios que não serão impactados pelos empreendimentos ou que possuem um baixo grau de relevância (conforme a percepção de cada pesquisador ou de um grupo de pessoas) recebem pouca atenção, dificultando a compreensão da ocupação humana em uma escala regional. Há outros fatores de ordem política e econômica que também influenciam nessas decisões, principalmente em empreendimentos governamentais de larga escala (e.g. hidrelétricas) que terão impactos em TI, UC, populações tradicionais, etc. (ROCHA et al., 2013, 2014; PUGLIESE JUNIOR \& VALLE, 2016; 2017).

Independente do contexto de pesquisa, há dois atributos importantes que são apresentados, normalmente, de forma descuidada por muitos pesquisadores: coordenadas geográficas e datação. Correa (2014) também apresenta essa dificuldade para esses dois aspectos durante suas análises bibliográficas.

As coordenadas, geográfica ou UTM, por vezes não correspondem ao local pesquisado, sendo provável que tenha ocorrido algum erro ao digita-las. Isso ocorre, principalmente, quando os pesquisadores apresentam uma extensa lista de sítios arqueológicos. Para além dos erros de digitação, na maior parte dos casos não está especificado que datum está sendo utilizado (e.g. WGS 84, SIRGAS 2000, etc.) e essa 
informação é de extrema importância para sabermos com qual sistema aqueles sítios estão sendo trabalhados.

As datas apresentam outro problema crônico, pois as informações são incompletas e inviabilizam comparações. Há problemas na identificação da datação (TL, C14, Radiométrica, etc.), se está calibrada ou não, a referência cronológica (AP, d.C./a.C.) e, em alguns casos mais graves, o contexto que foi datado.

Em relação ao tamanho do sítio e seu contexto cultural (Tradições cerâmicas) também há algumas implicações que devem ser consideradas. O grau de profundidade dessas informações é bastante variado, pois depende de alguns fatores como:

- Do nível de cada intervenção - levantamento em superfície ou subsuperfície; coleta sistemática ou aleatória; análise estratigráfica através de um perfil de barranco/talude exposto ou de uma unidade de escavação; etc.

- Recorrência das intervenções - uma ou mais etapas de escavação;

- Abrangência intra-sítio - escavações localizadas ou dispersas pelo sítio; escavação de áreas amplas ou pequenas.

Esses aspectos influenciam nos resultados e conhecimento adquirido, até o presente momento, para cada sítio identificado. Existem aqueles que foram delimitados através de linhas de tradagens e outros através da dispersão do material em superfície. Ou seja, conforme a metodologia empregada podemos ter sítios grandes ou pequenos; profundos ou rasos; uni ou multicomponenciais. Não realizei uma triagem nessas informações, sendo utilizado todos os dados possíveis. No entanto, é importante termos em mente que um sítio unicomponencial pode ser multicomponencial ou que a sua área pode aumentar ou diminuir conforme novas intervenções ocorram nos sítios.

Diante dessas dificuldades, ao longo do processo de construção do banco de dados, nem todos os problemas puderam ser sanados. Na maioria dos casos foram consultadas diversas fontes bibliográficas que tratassem do mesmo sítio ou região, esperando a possibilidade de ter informações complementares ou corrigidas. Em outros, as coordenadas erradas ou datações com informação incompleta foram excluídas desse estudo, sendo compiladas em um arquivo separado para que algum dia elas sejam incorporadas aos demais. 


\section{CAPÍTULO 3 - Os sítios arqueológicos e seus contextos}

Após o exaustivo trabalho de levantar informações bibliográficas sobre os sítios arqueológicos e sistematizá-las em um banco de dados, seguimos para a etapa de caracterização e análise de seus atributos. Como foi dito no capítulo anterior, existem diferentes níveis de refinamento das informações disponíveis, podendo ser apenas uma coordenada geográfica com o nome do sítio até detalhadas descrições estratigráficas, com camadas culturais bem definidas e datadas. Por conta dessa discrepância de dados entre os diferentes sítios arqueológicos foram realizadas várias análises quantitativas e correlações entre diferentes características, cada qual com uma amostragem diferente.

Primeiramente será realizada uma breve caracterização do banco dados envolvendo todos os sítios, demonstrando o que existe até o momento a partir das coordenadas geográficas inseridas em limites políticos e hidrográficos.

Em seguida serão analisados 3 atributos específicos de cada sítio: tamanho (área), ausência e presença de TPI (Terra Preta de Índio) e a quantidade de componentes culturais no nível da Tradição (unicomponencial ou multicomponencial). Essas categorias serão apresentadas individualmente e correlacionadas entre si.

O aspecto seguinte são as oito Tradições cerâmicas apresentadas no capítulo 1, analisando-as espacialmente e quantitativamente. As correlações obtidas na análise anterior também serão incorporadas na caracterização das Tradições.

Por último, finalmente, serão apresentados os dados cronológicos do período $1.000 \pm 400 \mathrm{DC}$, principal foco desse trabalho. Após uma breve caracterização das informações adquiridas no banco de dados, os sítios datados serão correlacionados com as Tradições cerâmicas. A proposta é visualizar como esses conjuntos se comportam ao longo do tempo.

Nesse último aspecto não foi possível correlacionar com os três atributos que caracterizam os sítios (tamanho, TPI e Uni - Multicomponencial), pois há variáveis que não tive acesso na bibliografia ou que não foram incorporados no banco de dados, dificultando sua associação com a cronologia. Outra situação é que a informação sobre a área do sítio é baseada em sua totalidade e não aos diferentes períodos de ocupação que, por sua vez, tiveram tamanhos variados. 
Os dados sobre as amostras datadas não contemplam sua associação com o contexto específico na estratigrafia (abaixo ou inserido na TPI), sendo que na maior parte dos casos essa informação não estava disponível na bibliografia. Por último, a cronologia vem associada às camadas culturais (Tradições) tornando a informação de uni ou multicomponencial desnecessária para correlação com as datações.

Após todas essas caracterizações, quantificações e correlações, no capítulo seguinte (capítulo 4) serão realizadas inferências e possíveis cenários de uma Amazônia em torno do ano mil, em uma tentativa de reconstruir a história dos diferentes grupos que conviveram ao longo de 800 anos.

\section{$\underline{\text { 3.1 Caracterização Geral }}$}

A ideia de usar os limites políticos dos municípios e estados se deve à tentativa de mostrar o "estado da arte" da arqueologia amazônica. Obviamente, não sou pretensioso em pensar que esse banco de dados representa a totalidade real de trabalhos executados no bioma amazônico. Mas podemos pensar que pode ser uma ferramenta interessante que permite refletir sobre os contextos das pesquisas, o nível de acesso às informações produzidas e de que maneira podemos gerenciar esse vasto inventário de sítios.

Antes de descrevermos sumariamente a distribuição e adensamento de sítios arqueológicos na Amazônia Brasileira é importante ressaltar que essa quantificação espacial não tem a ver, necessariamente, com as formas de ocupar os espaços no passado, mas sim com os contextos de pesquisa em cada região e o acesso a bibliografia, conforme explicitado no capítulo anterior. Quando correlacionados com a composição dos sítios (item 3.3), Tradições (item 3.4) e cronologia (item 3.5) é que poderemos inferir sobre as escolhas dos lugares ocupados em períodos pré-coloniais. Ciente dessa problemática amostral, serão descritos abaixo os dados arqueológicos espaciais que compõem o banco de dados.

\section{$* * *$}

Dos 6.795 sítios arqueológicos cadastrados no banco de dados, 6.511 estão localizados em território brasileiro, mais especificamente dentro dos limites da Amazônia Legal Brasileira (gráfico 3.1-1), correspondendo a 96\% do total de sítios. 


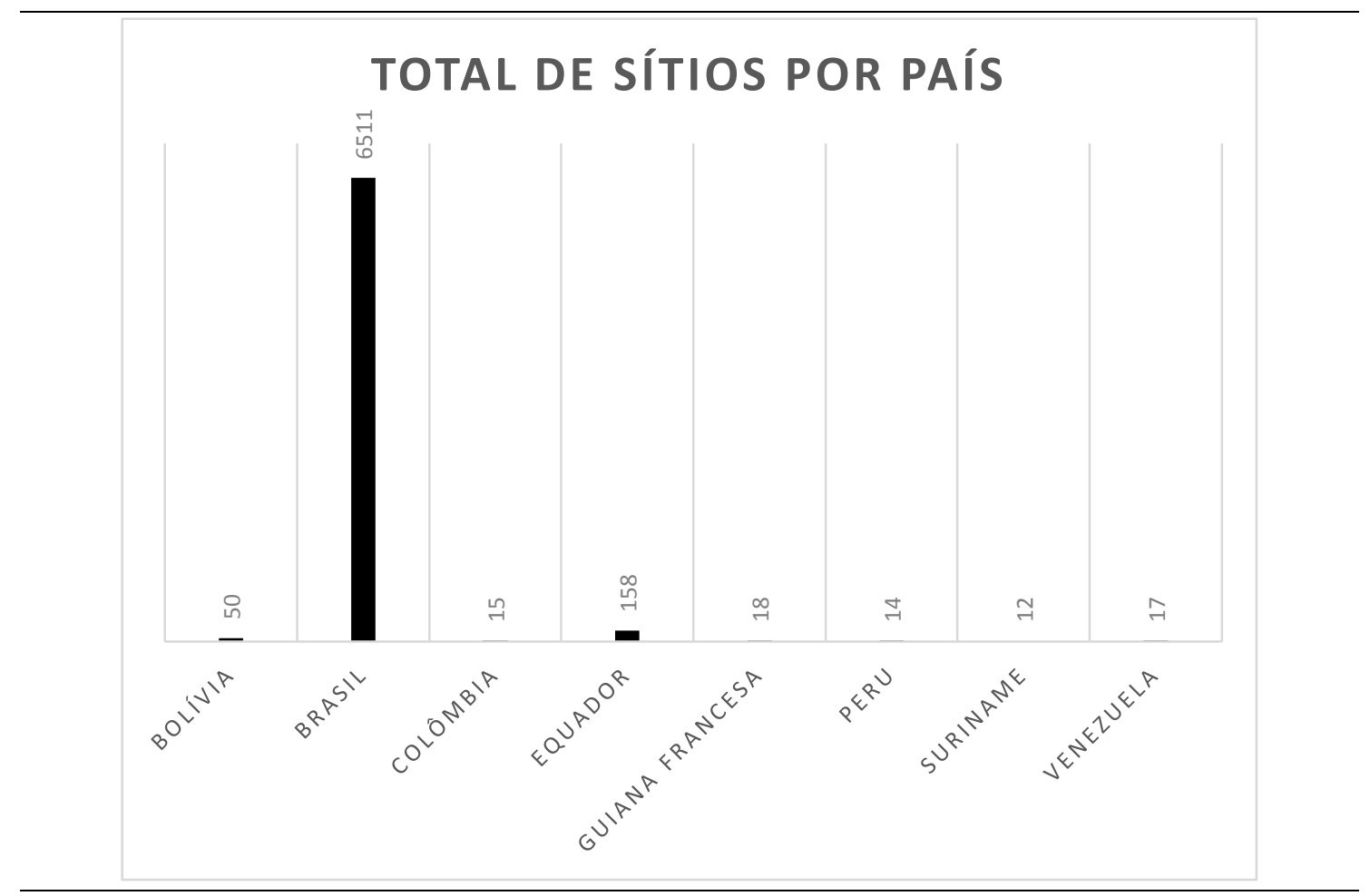

Gráfico 3.1-1: Quantidade total de sítios arqueológicos por país.

Em relação aos estados, podemos ver no gráfico 3.1-2 e no mapa 3.1-1 que o estado do Pará $(n=2.047)$ e do Amazonas $(n=1.256)$ são os que possuem mais sítios arqueológicos identificados. Essa quantidade não é ao acaso, pois são os dois estados que possuem a principal hidrografia cruzando a Amazônia de oeste a leste (SolimõesAmazonas) e os afluentes de maior significância (Nhamundá, Trombetas, Madeira, Xingu, Tapajós, Tocantins, Negro, Japurá, etc.). Por consequência, foram os locais mais pesquisados e desde o século XIX. Soma-se a isso a sua extensão territorial e, no caso do Pará, a quantidade de empreendimentos de grande abrangência (e.g. mineração e hidrelétricas), principalmente na margem sul do rio Amazonas.

O Mato Grosso possui um equilíbrio entre pesquisas etnoarqueológicas e de licenciamento ambiental, ao contrário do Tocantins e de Rondônia onde a maioria dos sítios foi identificada em programas de arqueologia preventiva.

Os vestígios arqueológicos do Amapá são reconhecidos desde o final do século XIX e início do XX, com os trabalhos de Emílio Goeldi e Nimuendajú (MEGGERS \& EVANS, 1957). No entanto, as pesquisas no estado só alavancariam a partir dos anos 2000 através do Instituto de Pesquisas Científicas e Tecnológicas do Estado do Amapá 
(IEPA) e da Universidade Federal do Amapá (UNIFAP). Ambas as instituições trabalharam tanto em contextos acadêmicos quanto no licenciamento ambiental.

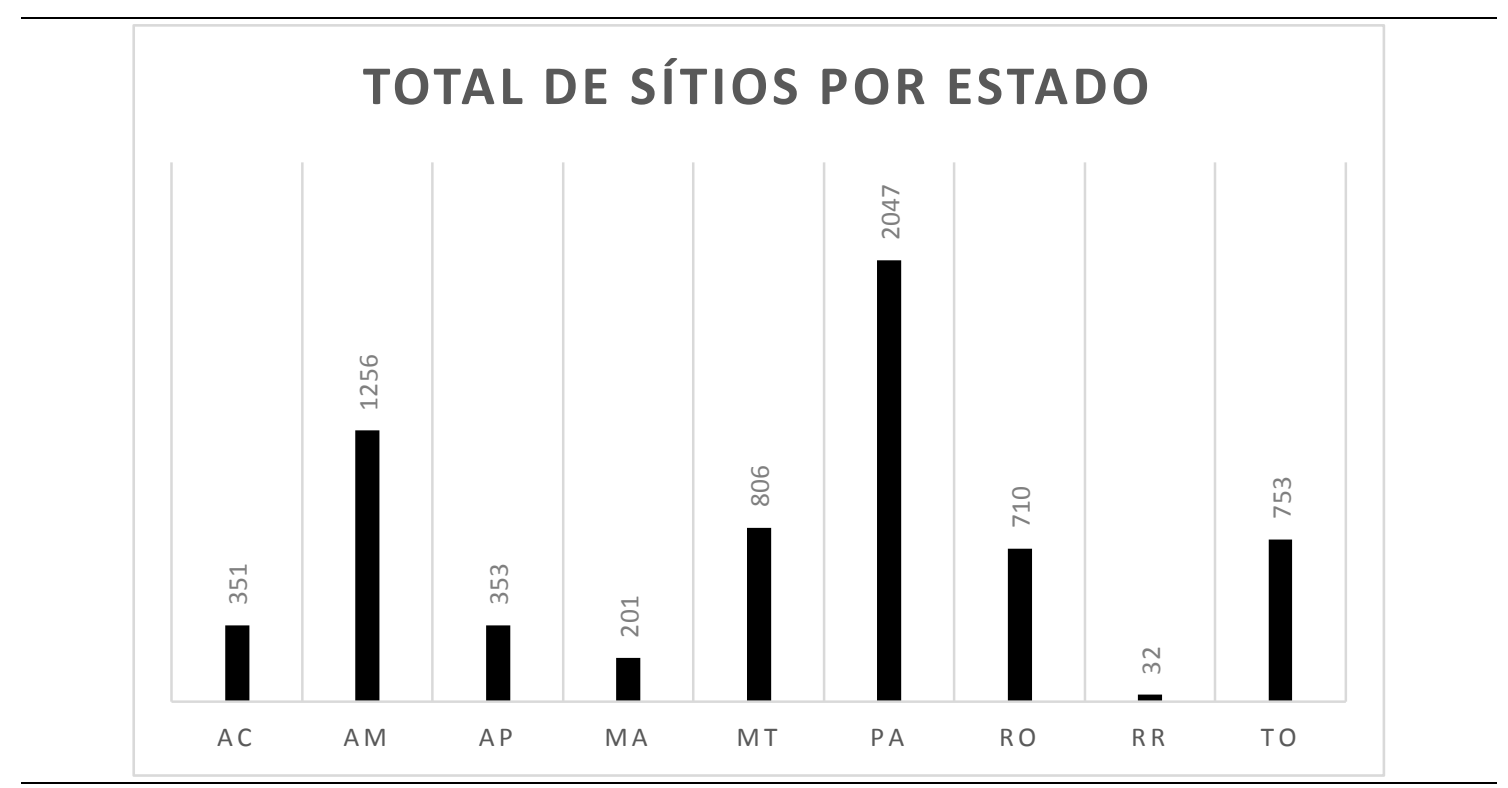

Gráfico 3.1-2: Quantidade total de sítios arqueológicos por estado.

O Acre, por sua vez, possui sua notoriedade quantitativa graças à identificação dos sítios com estruturas de terra. Tais estruturas podem ser reconhecidas através de imagem de satélites, com softwares gratuitos, permitindo uma "prospecção virtual" de baixo custo.

O Maranhão não está, em sua totalidade, dentro da Amazônia Brasileira, sendo que dos seus $332.000 \mathrm{~km}^{2}$ de extensão, $262.280 \mathrm{~km}^{2}$ (79\%) fazem parte da Amazônia Legal. Os sítios estão distribuídos próximos à divisa com o Tocantins e o Piauí, por conta de hidrelétricas, e no entorno de São Luís por causa das Linhas de Transmissão. A própria Ilha de São Luís concentra mais de 50\% $(\mathrm{n}=67)$ dos sítios que constam no banco de dados. Nesse total de sítios não estão inclusas as estearias (NAVARRO, 2016), pois não conseguimos acessar as informações de forma georreferenciada.

O caso de Roraima é complicado, pois não é um estado pequeno e a quantidade de publicações arqueológicas sobre essa região é extremamente escassa, pouco detalhada e/ou pouco divulgada. É importante salientar que até 2008, Roraima estava sob a supervisão da $1^{\circ}$ Superintendência do IPHAN, sediada em Manaus, estado do Amazonas, o que dificultava o gerenciamento do patrimônio arqueológico. Somente a partir de 2009 
o estado passa a ter sua própria Superintendência. É possível que nos próximos anos, assim esperamos, novas informações sejam produzidas através das pesquisas ${ }^{7}$.

Dos 772 municípios que compõem a Amazônia Legal, 385 deles possuem sítios arqueológicos identificados, variando entre 1 e 215 sítios (Mapa 3.1-2, Gráfico 3.1-3) e 378 municípios não possuem sítios identificados. Desse total, somente 7 municípios possuem mais de 100 sítios (Tabela 3.1-1).

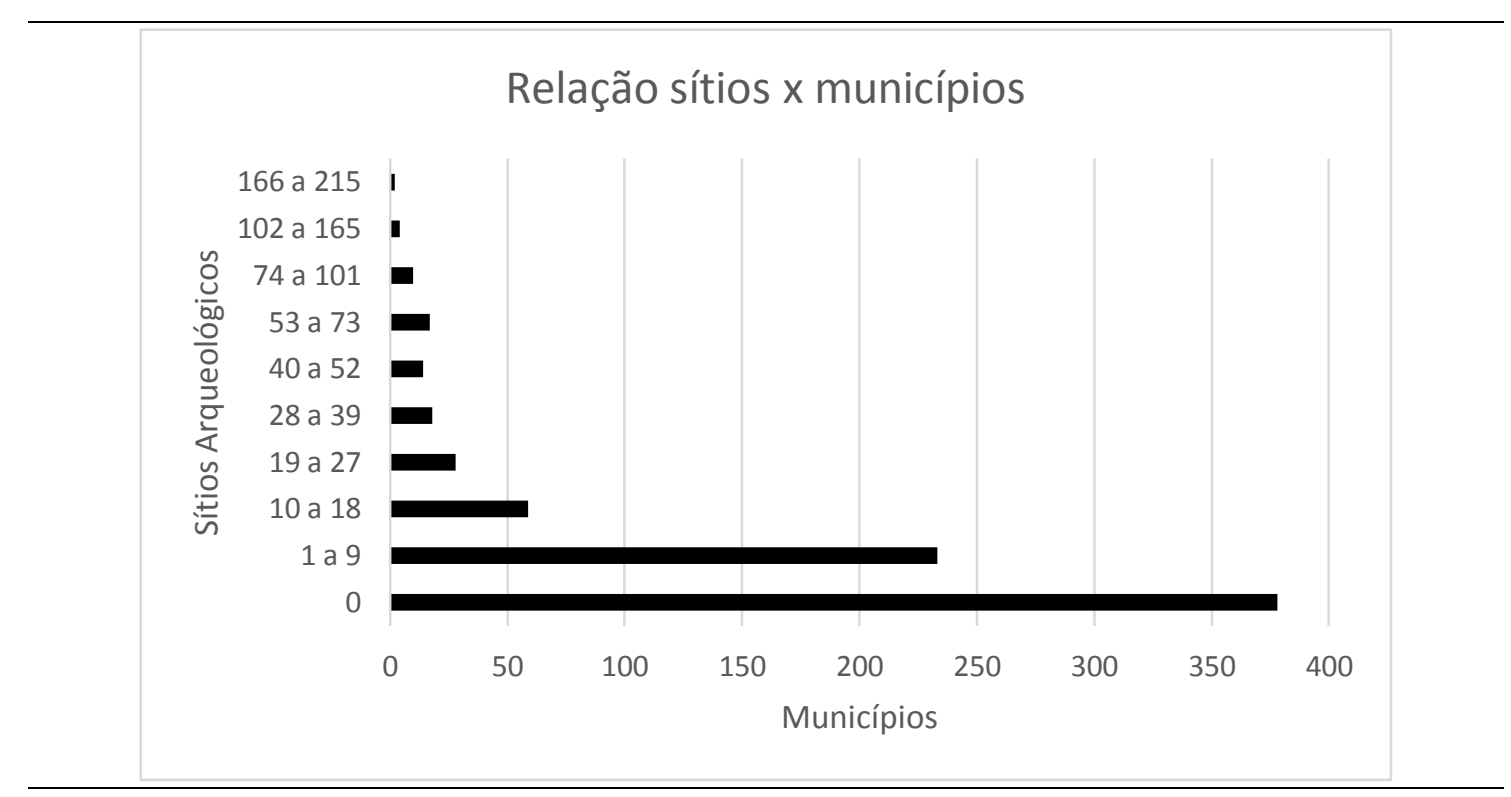

Gráfico 3.1-3: Relação do total de sítios arqueológicos encontrados nos municípios.

\begin{tabular}{|l|c|c|}
\hline \multicolumn{1}{|c|}{ Município } & UF & Sítios \\
\hline RONDONÓPOLIS & MT & 215 \\
\hline SANTARÉM & PA & 197 \\
\hline PORTO VELHO & RO & 165 \\
\hline ORIXIMINÁ & PA & 151 \\
\hline ALTAMIRA & PA & 123 \\
\hline IRANDUBA & AM & 117 \\
\hline ITAITUBA & PA & 101 \\
\hline PRESIDENTE FIGUEIREDO & AM & 99 \\
\hline PRESIDENTE MÉDICI & RO & 96 \\
\hline VITÓRIA DO XINGU & PA & 96 \\
\hline
\end{tabular}

Tabela 3.1-1: Os 10 municípios com maior quantidade de sítios arqueológicos.

\footnotetext{
${ }^{7}$ Segundo matéria publicada em agosto de 2016 na Folha de Boa Vista, a Superintendência do IPHAN em Roraima estava no processo de revisitar os sítios conhecidos e identificar novos locais. < http://www.folhabv.com.br/noticia/RR-ja-registra-151-sitios-arqueologicos-/19548 > acessado em 07/11/2017.
} 
A razão desse baixo número de municípios com mais de 100 sítios está atrelada a três fatores, não excludentes, que tem relação a ver com os diferentes contextos de pesquisa:

- Antiguidade das pesquisas em uma região, remontando ao final do século XIX e início do XX (Santarém e Oriximiná);

- Pesquisas longas com financiamento contínuo (Iranduba e Rondonópolis);

- Vários empreendimentos de grande impacto e abrangência geográfica, principalmente no caso das hidrelétricas (Porto Velho, Altamira e Itaituba);

Outra categoria de análise da distribuição espacial dos sítios, menos arbitrária, são as sub-bacias hidrográficas compreendidas pela Amazônia Legal. São 25 sub-bacias inclusas em quatro grandes bacias hidrográficas, conforme demonstrado na figura 3.1-4. No entanto, elas possuem bastante variações em suas extensões territoriais, que por consequência também afetam a quantidade de sítios inclusos em cada uma delas, conforme demonstrado no Mapa 3.1-3, Gráfico 3.1-4 e Tabela 3.1-2. 


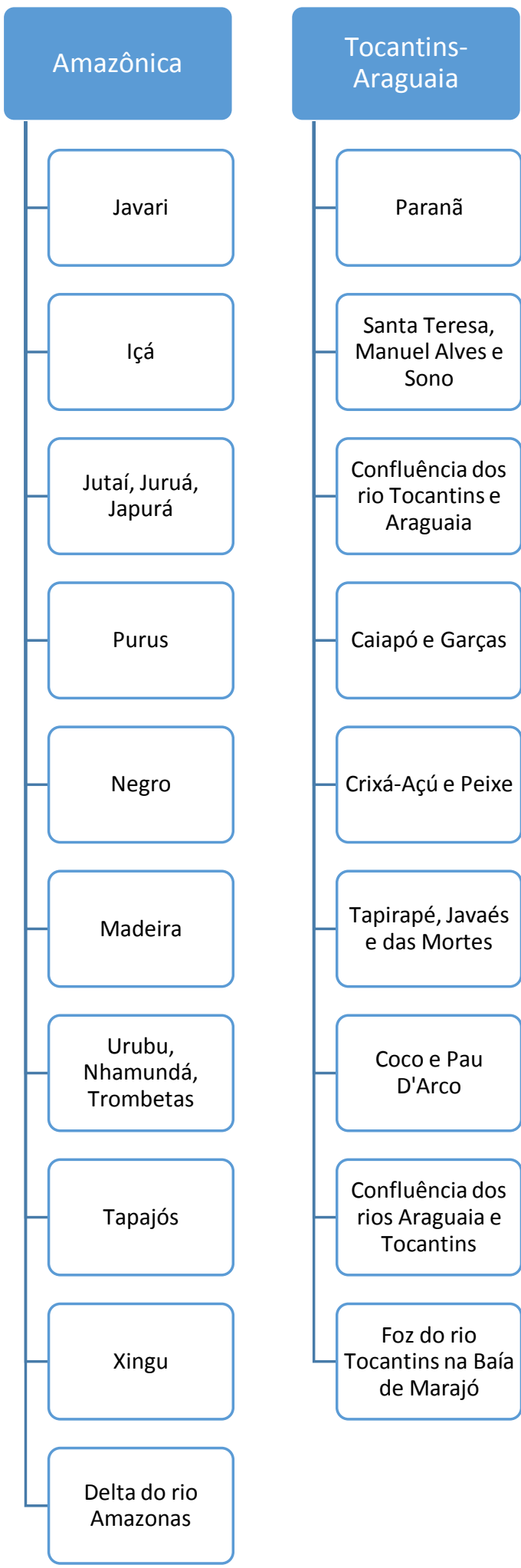

Atlântico

Nordeste

Ocidental

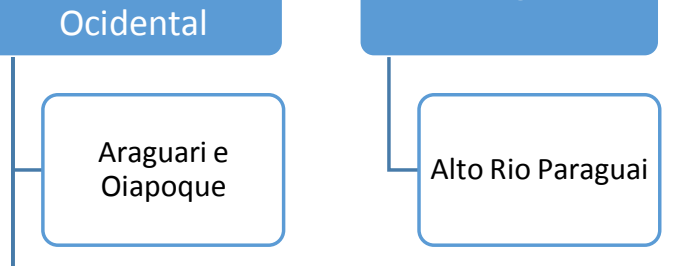

Moju e Guamá

Gurupi e Turiaçú

Mearim e

Itapecuru

Parnaíba
Paraguai 


\begin{tabular}{|l|c|c|}
\hline \multicolumn{1}{|c|}{ Nome bacia } & Sítios & $\begin{array}{c}\text { Área } \\
\left(\mathbf{k m}^{\mathbf{2}}\right)\end{array}$ \\
\hline Rio Javari & 0 & 83.343 \\
\hline Rio Içá & 2 & 44.494 \\
\hline Rios Jutaí, Juruá e Japurá & 173 & 377.542 \\
\hline Rio Purus & 432 & 421.383 \\
\hline Rio Negro & 433 & 598.795 \\
\hline Rio Madeira & 1081 & 598.679 \\
\hline Rios Urubu, Nhamundá e Trombetas & 559 & 330.754 \\
\hline Rio Tapajós & 676 & 525.774 \\
\hline Rio Xingu & 554 & 625.674 \\
\hline Delta do rio Amazonas & 516 & 213.116 \\
\hline Rio Paranã & 110 & 65.736 \\
\hline Rios Santa Teresa, Manuel Alves e Sono & 453 & 111.779 \\
\hline $\begin{array}{l}\text { Confluência dos rios Tocantins e } \\
\text { Araguaia }\end{array}$ & 222 & 70.531 \\
\hline Rios Caiapó e Garças & 38 & 59.857 \\
\hline Rios Crixá-Açú e Peixe & 5 & 55.798 \\
\hline Rios Tapirapé, Javaés e das Mortes & 13 & 162.279 \\
\hline Rios Coco e Pau D'Arco & 17 & 74.865 \\
\hline $\begin{array}{l}\text { Confluência dos rios Araguaia e } \\
\text { Tocantins }\end{array}$ & 85 & 29.328 \\
\hline Foz do rio Tocantins na Baía de Marajó & 309 & 74.368 \\
\hline Rios Araguari e Oiapoque & 208 & 79.901 \\
\hline Rios Moju e Guamá & 34 & 80.157 \\
\hline Rios Gurupi e Turiaçú & 79 & 84.898 \\
\hline Rios Mearim e Itapecuru & 114 & 181.480 \\
\hline Rio Parnaíba & 372 & 329.941 \\
\hline Alto Rio Paraguai & 363.446 \\
\hline
\end{tabular}

Tabela 3.1-2: Quantidade de sítios por cada sub-bacia. 


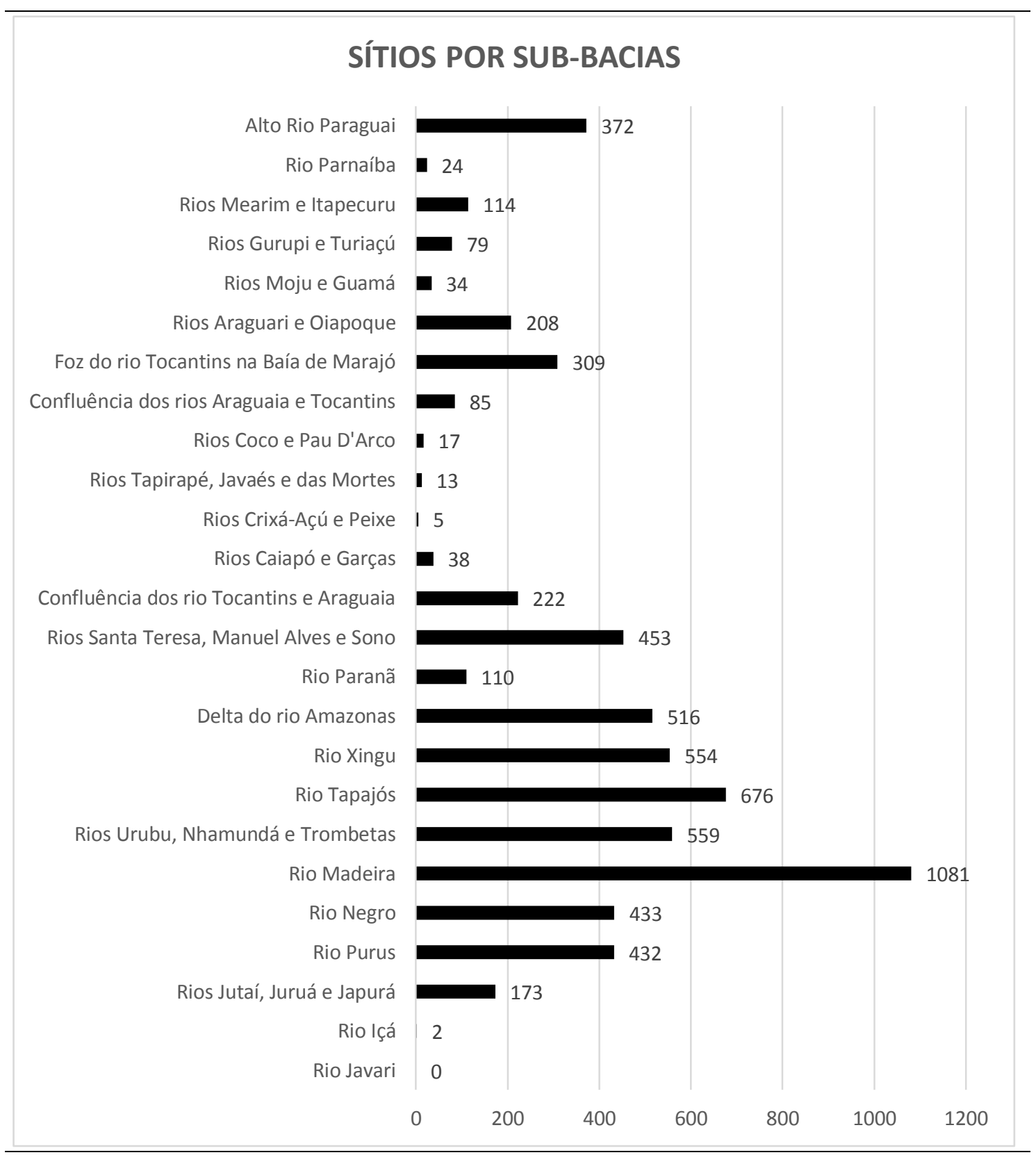

Gráfico 3.1-4: Quantidade de sítios arqueológicos por sub-bacia hidrográfica.

Os três motivos elencados acima, para o caso dos municípios, também se aplicam para as sub-bacias. Se observarmos as 5 sub-bacias com maior quantidade de sítios veremos que são áreas com grande potencial hidrelétrico, com exceção do delta do rio Amazonas e são pesquisadas desde o final do século XIX. 


\section{2 Áreas de Concentracão}

Para além das barreiras políticas atuais ou das delimitações hidrográficas, serão apresentados nos mapas 3.2-1 e 3.2-2 onde estão localizadas as maiores concentrações de sítios arqueológicos. Na tabela 3.2-1 podemos ver a quantidade de sítios e qual a área de cada uma dessas concentrações.

\begin{tabular}{|l|c|c|}
\hline \multicolumn{3}{|c|}{ Maior Concentração } \\
\hline Nome & Sítios & Área $\mathbf{( k m}^{\mathbf{}} \mathbf{)}$ \\
\hline Área 1 & 304 & 36.156 \\
\hline Área 2 & 510 & 50.959 \\
\hline Área 3 & 270 & 25.101 \\
\hline Área 4 & 360 & 33.770 \\
\hline Área 5 & 289 & 25.896 \\
\hline Área 6 & 345 & 34.605 \\
\hline \multicolumn{3}{|c|}{ Menor Concentração } \\
\hline Nome & Sítios & Área $\left.\mathbf{( k m}^{\mathbf{2}}\right)$ \\
\hline Área A & 140 & 8.023 \\
\hline Área B & 180 & 9.062 \\
\hline Área C & 182 & 20.251 \\
\hline Área D & 135 & 14.275 \\
\hline Área E & 144 & 4.803 \\
\hline Área F & 196 & 16.558 \\
\hline Área G & 148 & 12.708 \\
\hline
\end{tabular}

Tabela 3.2-1: Quantidade de sítios arqueológicos por área de concentração.

Ao visualizarmos o mapa de calor (mapa 3.2-2) podemos atribuir seis áreas com grande concentração de sítios arqueológicos (classificadas de 1 a 6), seguida por outras sete áreas de menor intensidade (classificadas de A a G). O mapa possui uma escala 1:14.000.000 e os adensamentos variaram entre 270 e 510 sítios (maiores) e entre 135 e 196 sítios (menores). A seguir serão descritas todas essas áreas e uma breve apresentação contextual (arqueológica e de pesquisa). 


\subsection{1 Áreas com maior concentração}

\section{Área 1: Área de confluência dos rios Solimões, Negro e Madeira.}

A região de confluência, bem como o baixo curso dos três rios, foi alvo de pesquisas durante o PRONAPABA. O rio Solimões, e em torno de Manaus, foi percorrido por Peter Paul Hilbert até o seu alto curso (HILBERT, 1968), enquanto o rio Madeira foi pesquisado por Eurico Miller (MORAES, 2013:234) e Simões (SIMÕES \& LOPES, 1987) e o rio Negro por Simões (SIMÕES, 1974; SIMÕES \& KALKMAN, 1987). Foi a região chave para o modelo cardíaco proposto por Lathrap e Brochado - o centro de origem e da dispersão dos povos de língua Arawak e Tupi (LATHRAP, 1970).

Posteriormente foi a área de atuação, por mais de 15 anos, do Projeto Amazônia Central (PAC), principalmente no município de Iranduba, onde foram inventariados mais de 100 sítios e escavados em torno de 20 (NEVES, 2012). Mais recentemente, outros projetos atuaram na confluência dos rios Solimões, Madeira e Negro, principalmente associados a programas de arqueologia preventiva (COSTA \& LIMA, 2006; UEA, 2012; PRESERVAR, 2012; ARQUEOLÓGIKA, 2014).

Nessa área já foram encontradas evidências pré-cerâmicas em locais de campinarana que recuam em até 6.800 AC. Mas os primeiros registros de ocupações com TPI, associados às cerâmicas TP-A, começam a ocorrer em torno de 360 AC (NEVES et al., 2014). Nos primeiros séculos DC temos evidências de aldeias circulares associados à TBI, chegando ao seu auge próximo ano 1.000 DC com grandes extensões de TPI, dezenas de montículos agrupados em forma circular, valas defensivas e caminhos ligando as ocupações aos corpos d'água (MORAES \& NEVES, 2012; SCHMIDT et al., 2014). Por último, essa enorme área de confluência seria ocupada por grupos associados à TPA (TAMANAHA \& NEVES, 2014; NEVES, 2012).

\section{Área 2: Foz dos rios Nhamundá, Trombetas e Tapajós no rio Amazonas.}

As pesquisas nessa região se iniciaram no final do século XIX com as expedições de João Barbosa Rodrigues (1875) e Frederick Hartt (1885), realizando investigações arqueológicas que marcaram a história da arqueologia amazônica e, cujas descobertas, a colocam até o presente como uma área chave. Hartt realizou escavações no Sambaqui de Taperinha, enquanto Rodrigues fez as primeiras associações das cerâmicas arqueológicas 
com as fontes históricas do período colonial - cerâmica do Nhamundá-Trombetas aos Conduris e a cerâmica de Santarém aos Tapajós.

Já nas décadas de 1920, Curt Nimuendajú identificou uma série de sítios nessa região, com coletas de vestígios e a diferenciação estilística-geográfica das cerâmicas do Nhamundá-Trombetas com as do baixo Tapajós (Santarém) (NIMUENDAJÚ, 2004). Nas décadas seguintes, devido à visibilidade e antiguidade do registro arqueológico, a região seria inclusa em uma série de pesquisas e hipóteses sobre o povoamento da Amazônia em tempos pré-coloniais, bem como sua associação com populações indígenas históricas, variabilidade na cultura material e grupos linguísticos (NORDENSKIÖLD, 1930; PALMATARY, 1939; HILBERT, 1955; MEGGERS \& EVANS, 1961, 1983; LATHRAP, 1970; HILBERT \& HILBERT, 1980; GUAPINDAIA, 2008; GOMES, 2011). No caso mais específico do Nhamundá-Trombetas, três empreendimentos de grande abrangência geraram inúmeras informações arqueológicas na região: UHE Cachoeira Porteira (ARAÚJO-COSTA et al., 1986), o pólo de exploração de bauxita (HILBERT, 1990; GUAPINDAIA, 2008) e a Linha de Transmissão 500 kV Oriximiná (BIODINÂMICA, 2009; SCIENTIA, 2011).

Essa área é caracterizada por antigas ocupações ceramistas (TP-A) na região do Nhamundá-Trombetas datados de 2.600 AC (HILBERT \& HILBERT, 1980; GUAPINDAIA, 2008) e na foz do Tapajós com 1290 AC (GOMES, 2011), alguns poucos sinais de cerâmicas da TBI no Tapajós que começam em 2.300 AC (GOMES, 2008; ALVES, 2012; QUINN, 2004) e por último as cerâmicas da TIP por toda a área, representadas pelas fases Konduri (JÁCOME, 2017; GUAPINDAIA, 2008) e Santarém (GOMES, 2011; MARTINS, 2012) a partir de 700 DC.

\section{Área 3: Volta Grande do rio Xingu (médio-baixo Xingu)}

O médio-baixo curso do rio Xingu tem atraído os olhares de viajantes desde o século XVIII, principalmente em relação às gravuras rupestres localizadas em seus afloramentos rochosos (PEREIRA, 2003). Os vestígios arqueológicos só ganhariam destaque através das coletas de Curt Nimuendajú, no início do século XX, onde ele aponta a existência de gravuras rupestres, urnas funerárias, terra preta e agrupamento de rochas em áreas de lajedo (NIMUENDAJÚ, 1948). 
Com o início das pesquisas do PRONAPABA, nas décadas de 1960-1970, diferentes contextos arqueológicos começaram a ser pesquisados (e.g. sambaquis fluviais e sítios de terra preta), resultando na criação de novas fases cerâmicas associadas às Tradições Inciso Ponteada, Tupiguarani e Polícroma da Amazônia (PEROTA, 1977; SIMÕES \& ARAÚJO-COSTA, 1978). A TPA estaria localizada no baixo rio Xingu, a jusante da Volta Grande, enquanto que as demais Tradições estariam no trecho a montante. Simões, Corrêa e Machado (1973) ao analisarem o material do rio Fresco, afluente da margem direita do Xingu no interflúvio com o rio Tocantins, acreditavam que o médio-baixo Xingu seria um local de fronteira cultural, de contato entre as populações do rio Tocantins (Tradição Tupiguarani) e do rio Tapajós (Tradição Inciso-Ponteada). A cerâmica Tupiguarani (fase Carapanã e Itacaiúnas) possuía traços da cerâmica tupi do litoral misturado a elementos que remetiam a TIP, surgindo uma terceira tradição cerâmica de origem híbrida. A essa questão, Almeida (2013) criou a Subtradição Tupinambá da Amazônia, conforme explicitado no capítulo anterior. De toda forma, essas ocupações estariam no primeiro e segundo milênio DC.

Mais recentemente, a partir da década de 1980, as pesquisas arqueológicas no médio-baixo Xingu começam a ser executadas através do licenciamento ambiental, principalmente por causa da UHE Kararaô (ARAÚJO-COSTA \& CALDARELLI, 1988) e a atual UHE Belo Monte (PEREIRA, 2002; SCIENTIA, 2014; INSIDE, 2014), além das obras na BR-230 e BR-422 nos interflúvios Tapajós-Xingu-Tocantins (MAGALHÃES, 2003; SCHAAN, 2010).

\section{Área 4: Médio/Alto curso do rio Tocantins}

Localizado na transição entre o bioma Amazônico e o Cerrado, no estado do Tocantins, o médio curso do rio Tocantins passou nos últimos anos por sucessivas transformações antrópicas recentes e essas alterações continuam em curso. Devido sua formação geológica, seu potencial hidrelétrico vem sendo explorado continuamente na construção de várias barragens.

Nessa região, há no banco de dados, mais de 200 sítios arqueológicos identificados e todos em contexto do licenciamento ambiental. Foram utilizadas informações da UHE Peixe Angical (THEMAG, 2000), UHE Lajeado (OLIVEIRA, 2005; BUENO, 2005), UHE Estreito (UNITINS-NUTA, 2006), UHE Serra Quebrada (SCIENTIA, 1989), 
Ferrovia do Programa Saltfens (UNITINS-NUTA, 2000a), a Linha de Transmissão Saltimins (UNITINS-NUTA, 2000b), entre outros empreendimentos. No entanto, a maior parte das informações obtidas através dos relatórios foca na antiguidade das ocupações dessa região (transição pleistoceno-holoceno), com poucas referências sobre as ocupações ceramistas ou do primeiro milênio DC - foco dessa tese. As poucas informações obtidas para essa área apontam para ocupações das Tradições Uru e Aratu, todas datadas entre 1.100 e 1.500 DC (OLIVEIRA, 2005:27-28).

\section{Área 5: Sub-bacia do alto rio Paraguai - Rondonópolis}

Os sítios identificados na área de Rondonópolis, ao longo do curso dos rios São Lourenço e Vermelho, são o resultado de dois grandes projetos distintos que começam no início da década de 1980. Um projeto etnoarqueológico coordenado por Irmhild Wüst junto aos Bororo (WÜST, 1990, 1999; WÜST \& BARRETO, 1999) e outro nos sítios em abrigo coordenado por Denis Vialou e Águeda Vilhena Vialou (VIALOU, 2005). As datações obtidas nessas pesquisas demonstram um longo período de ocupação, por diferentes grupos, começando há 25 mil anos até a segunda metade do século XX (VIALOU, 2005; WÜST, 1999). Mais recentemente, a partir dos anos 2000, alguns trabalhos de licenciamento ambiental ocorreram na região levando à identificação de novos sítios, como empreendimentos de Linha de Transmissão (SCIENTIA, 2010; MILDER, 2010), Pequena Central Hidrelétrica (PCH) (LINO, 2010) e Ferrovia (ZANETTINI, 2010).

Nesse caso, em referência ao primeiro e segundo milênio DC, é interessante salientar uma mudança cultural em torno de 900 DC, com o surgimento de aldeias anelares de até 500m de diâmetro associadas aos grupos ceramistas da Tradição Uru (WÜST, 1999). Robrahn-González (1996) hipotetiza uma origem amazônica para esses grupos, mais especificamente no Oeste, nos formadores do rio Guaporé. A partir de 1.400 DC alguns poucos assentamentos com cerâmica Tupiguarani começam a ocorrer na região e permanecem até o período histórico. Essas duas grandes tradições cerâmicas distintas, a partir de 1.700 DC, desaparecem do registro arqueológico e são substituídos (ou parcialmente incorporados) pelos Bororo conhecidos etnograficamente (WÜST, 1999:305-306). 


\section{Área 6: Alto rio Purus}

$\mathrm{O}$ alto rio Purus, abrangendo os estados brasileiros do Acre, Rondônia e Amazonas, é amplamente conhecida pela ocorrência dos geoglifos. São mais de 500 geoglifos cadastrados no banco de dados, entre estruturas com valas e/ou montículos, localizado nos interflúvios dos formadores do rio Purus. É bem provável que exista um grande número de sítios não-geoglifos nessa região, no entanto só consegui acesso as informações dos sítios tipos geoglifos.

Assim como em muitas partes da Amazônia, pesquisas realizadas pelo PRONAPABA foram as primeiras a registrar sítios arqueológicos na região. Arqueólogos do IAB (Instituto de Arqueologia Brasileira), Ondemar Dias e Franklin Levy, cadastraram 80 sítios arqueológicos entre as décadas de 1970 e 1980, percorrendo áreas do Alto Purus e Alto Juruá, no estado do Acre (DIAS \& CARVALHO, 1988). Identificaram tanto os sítios tipo geoglifo, quanto os não-geoglifos, mas com um estreito foco nas cerâmicas que ocorriam nessas áreas. Conforme apontam Schaan et al. (2007:70), havia uma preocupação excessiva no material cerâmico para proporcionar datações relativas, ignorando que as estruturas de terra poderiam ser um marcador cultural e cronológico de ocupação. Nesse sentido, foram criadas diversas fases cerâmicas (divididas geograficamente pelas sub-bacias do Alto Purus) agrupadas em uma tradição regional denominada Quinari, conforme já explicitado no capítulo anterior.

Até o fim dos anos 1990, poucos trabalhos ocorreram na região e os próprios geoglifos, que chegaram a ser escavados por pesquisadores do IAB e da UFAC, tiveram pouca divulgação. No início dos anos 2000, o paleontólogo Alceu Ranzi retoma as pesquisas com os geoglifos do Acre em parceria com arqueólogos da Universidade de Helsinque e da Universidade Federal do Pará, sob a coordenação de Denise Schaan, gerando alguns trabalhos iniciais (PÄRSSINEN et al., 2003; RANZI, 2003). Nessa mesma década, trabalhos de licenciamento ambiental foram conduzidos nessa região produzindo novos dados sobre os geoglifos (SCHAAN \& PLENS, 2005; SCHAAN et al., 2007), assim como a utilização do Google Earth permitiu a localização de novos sítios (RANZI, FERES \& BROWN, 2007).

Ainda não está claro qual é a real extensão geográfica e a variabilidade da Tradição Quinari, necessitando uma maior amostragem e aprofundamento dos estudos 
cerâmicos. No entanto, sabe-se que os geoglifos (valas) ocorrem desde 1.200 AC até 900 DC, sendo que esses sítios do lado boliviano são mais antigos que os brasileiros (SAUNALUOMA, 2014). A partir de 900 DC, sítios com estruturas monticulares de forma circular/elipsoidal começam a ocorrer na região e se estendem até o período do contato, mas sem abandonar os sítios com valas (TAMANAHA, 2015).

\subsection{2 Áreas com menor concentração}

\section{Área A: Margem norte da foz do Amazonas (Amapá)}

A margem norte da foz do Amazonas, atual estado do Amapá, possui uma grande concentração de sítios ao longo de suas margens e afluentes. O potencial arqueológico da região já era conhecido desde a época de Nimuendajú e, posteriormente, com os trabalhos de Meggers e Evans (1957). No entanto, a arqueologia da região só seria alavancada a partir dos anos 2000 através do IEPA e da UNIFAP, conforme descrito anteriormente.

Os sítios identificados nessa área provêm, principalmente, de trabalhos de licenciamento ambiental, como a Linha de Transmissão Santana-Amapá (UNIFAP, 2004), obras na rodovia EAP-070 (IEPA, 2009) e de mineração (IEPA, 2008). No entanto, o trabalho que compilou o maior número de sítios para toda a região do delta vem de um projeto do Ministério do Meio Ambiente, em parceria com várias instituições, no intuito de elaborar Cartas de Sensibilidade a Derramamentos de Óleo (Cartas SAO) ${ }^{8}$. Nesse inventário foram listados 315 sítios arqueológicos distribuídos por toda a área do delta e do litoral atlântico.

Em relação ao contexto arqueológico, existem evidências antigas nos sambaquis fluviais e litorâneos associados à Tradição Mina (Fase Alaka) e ocupações cerâmicas que dialogam com os sítios da Ilha de Marajó (Fases Marajoara, Aruã e Mazagão) e com toda a costa guianense, com datas desde 5.000 AC (pré-cerâmico) até o período colonial (SALDANHA, 2016).

\footnotetext{
${ }^{8}$ Cartas SAO - Foz do Amazonas < http://www.iepa.ap.gov.br/saofza/apresentacao.php>. Acessado em 09/11/2017.
} 


\section{Área B: Margem sul da foz do Amazonas (Baía de Caxiuanã e de Marajó)}

A margem sul da foz, no estado do Pará, tem uma concentração de sítios na Baía de Caxiuanã e na Baía de Marajó (municípios de Abaetetuba e Barcarena). No caso de Caxiuanã, as pesquisas ocorreram dentro da FLONA de Caxiuanã e estavam relacionadas à identificação de áreas com TPI, pensando no plano de manejo madeireiro (KERN, 1996).

Já no caso da Baía de Marajó, nos municípios de Abaetetuba e Barcarena, os sítios foram identificados durante um TAC (Termo de Ajustamento de Conduta), executado pelo Museu Goeldi (SILVEIRA \& MARQUES, 2004). Nesse projeto foram levantados todos os tipos de sítios arqueológicos, incluindo uma grande quantidade de vilarejos e engenhos do período colonial, além de sambaquis, sítios lito-cerâmicos, etc.

Outros projetos abrangeram as duas áreas, como a Linha de Transmissão Marajó (INSIDE, 2012), "Sambaquis do Pará" (SILVEIRA \& SCHAAN, 2005) e "Por Campos e Florestas" (SCHAAN \& MARTINS, 2010). Esses dois últimos foram projetos acadêmicos desenvolvidos em parceria com instituições de pesquisa e ensino. Talvez, essa região, seja um dos poucos casos onde a maioria dos sítios arqueológicos identificados ocorreu fora de licenciamentos ambientais.

Apesar de existir um grande número de sítios identificados, há poucos projetos na área, comprometendo novas informações sobre os seus vestígios ou a composição desses sítios. No entanto, sabemos que essa região possui alta relevância para a arqueologia amazônica desde a primeira metade do século XX (MEGGERS \& EVANS, 1957; NIMUENDAJÚ, 2004). A existência de sambaquis fluviais, datados provavelmente do Holoceno médio (SILVEIRA \& SCHAAN, 2005), e de sítios da fase Ananatuba da Tradição Zonado Hachurada (SIMÕES, 1969) demonstram a antiguidade de ocupações do delta Amazônico. Além desses vestígios, creio que os mais emblemáticos sejam os Tesos Marajoaras (TPA) por terem suscitado toda a discussão sobre sociedades complexas (e.g. Cacicados) na Amazônia pré-colonial (SCHAAN, 2001) ou sobre sua origem exógena e declínio cultural por limitações ambientais (MEGGERS, 1976). 


\section{Área C: Serra dos Carajás}

A região de Carajás, no sudeste do Pará, está localizada na sub-bacia do rio Tocantins, nos vales dos rios Itacaiúnas e Parauapebas. As pesquisas arqueológicas nessa área ocorrem desde o início da década de 1980 e fazem parte do contexto de mineração da região (Projeto Ferro Carajás, Projeto Salobo, Mineração Onça Puma, Mineração Serra do Sossego, entre outros) (SIMÕES, 1986; SILVEIRA et al., 2008, 2009, 2015; GOLDER, 2010; SCHAAN, 2012; SCIENTIA, 2006; MAGALHÃES, 2016).

Esses projetos de mineração acabaram criando outras demandas, que por sua vez incentivaram outros empreendimentos e o levantamento de novos sítios arqueológicos, como a Estrada de Ferro Carajás (AMPLO, 2011), Ramal Ferroviário Sudeste do Pará (SCIENTIA, 2013), Rodovia Municipal de Canaã dos Carajás (SCIENTIA, 2012), as Linhas de Transmissão Tucuruí - Açailândia - Presidente Dutra (SCIENTIA, 2008) e Xingu - Estreito (ORIGEM, 2014).

Os contextos arqueológicos de Carajás estão, em sua maioria, localizados em grutas, abrigos e cavernas contendo material orgânico, cerâmico e lítico com datas de até 8.000 AC (MAGALHÃES, 2016). Essa região possui um importante papel nas discussões sobre o povoamento inicial da Amazônia, como é o caso das Gruta do Gavião (SILVEIRA, 1994), Gruta do Pequiá (MAGALHÃES, 2005) e a Gruta da Capela (MAGALHÃES, 2016), todos associados ao início do Holoceno.

Os sítios cerâmicos a céu aberto, associados ou não com TPI, do primeiro e segundo milênio DC foram identificados e pesquisados durante os licenciamentos do Projeto Salobo, Mineração Onça Puma (GARCIA, 2012) e Linha de Transmissão Tucuruí-Açaílândia (ALMEIDA, 2008). Na maior parte dos contextos foi evidenciado que se tratava de ocupações da Subtradição Tupinambá da Amazônia (ALMEIDA \& NEVES, 2015), e em dois sítios observou-se ocupações da TBI anteriores à Tupinambá (GARCIA, 2012:161).

\section{Área D: Médio/Baixo rio Tocantins}

Essa concentração é uma influência dos empreendimentos que ocorreram na Área 4 e no baixo rio Araguaia. Há poucas informações disponíveis sobre os vestígios e sítios arqueológicos identificados, mas em linha gerais são caracterizadas por sítios em abrigo 
e a céu aberto, em sua maioria com presença de material lítico lascado e, em poucos casos, com gravuras rupestres. Não encontramos publicações com datações para esses sítios e, os poucos casos em que há uma menção mais detalhada do material cerâmico, estes são associados à Subtradição Tupinambá da Amazônia (GESAI, 2010).

Com exceção dos sítios identificados pela Fundação Casa de Cultura de Marabá (ATZINGEN, 1999), todos os outros fazem parte do licenciamento ambiental da UHE Estreito (UNITINS-NUTA, 2006), UHE Serra Quebrada (SCIENTIA, 1989) e Ferrovia do Programa Saltfens (UNITINS-NUTA, 2000a), na bacia do rio Tocantins, e da UHE Santa Isabel no baixo rio Araguaia (GESAI, 2010).

\section{$\underline{\text { Área E: Rio Teles Pires }}$}

Área localizada na divisa entre os estados do Mato Grosso e Pará, no baixo curso do rio Teles Pires, formador do rio Tapajós. As pesquisas arqueológicas na região são recentes e, inicialmente, focaram em uma perspectiva etnoarqueológica junto aos povos Kaiabi, da família linguística Tupi-Guarani (GASPAR, 2014; STUCHI, 2010; SILVA et al., 2010). Alguns anos depois, a região passaria pelo licenciamento de duas hidrelétricas - a UHE Teles Pires (DOCUMENTO, 2014) e UHE São Manoel (EPE, 2010; BORNAL, 2014). No momento há poucos dados publicados sobre os sítios e os vestígios encontrados no âmbito do licenciamento. Mas é fato que a arqueologia, enquanto ferramenta para legitimar esses empreendimentos e os impactos nos territórios tradicionais, não tem sido vista com bons olhos por muito arqueólogos e moradores da região (PUGLIESE JR \& VALLE, 2016).

Por outro lado, as pesquisas etnoarqueológicas têm trazido contribuições substanciais sobre as ocupações pré-coloniais no baixo Teles Pires. Os vestígios cerâmicos apontam para traços estilísticos das Tradições Inciso-Ponteada, Borda Incisa e Tupinambá da Amazônia, com uma cronologia que se inicia em 300 DC e se estende até o período inicial da colonização (GASPAR, 2014).

\section{Área F: Médio/Alto rio Ji-Paraná}

O médio e alto cursos do rio Ji-Paraná (ou rio Machado) vêem sendo estudado sistematicamente desde a década de 1970, através das pesquisas realizadas por Eurico 
Miller no âmbito do PRONAPABA (MILLER, 1987a), de empreendimentos hidrelétrico (MILLER, 1987B; MILLER \& CALDARELLI, 1987) e rodoviário (MILLER, 1987c).

Essas atividades identificaram 97 sítios arqueológicos e os vestígios coletados subsidiaram a criação de 13 fases cerâmicas e 3 pré-cerâmicas (Miller, 1987a, 1987b). Dos conjuntos cerâmicos, sete foram vinculadas à Subtradição Tupinambá da Amazônia, cinco como "não-tupi" e três como "a ser definida" (SUÑER, 2016:52-53), demonstrando existir uma imensa variabilidade observada na cerâmica e que recua em 550 AC. Essas categorias necessitam de revisão e devem ser comparadas à medida que novos sítios forem sendo escavados, uma vez que elas foram criadas conforme as classificações cronotipológicas do PRONAPABA.

Nas décadas dos anos 2000, pesquisas realizadas no licenciamento do Sistema de Transmissão Acre-Rondônia comprovaram a antiguidade dos assentamentos cerâmicos na região associados à TPI e à Subtradição Tupinambá da Amazônia, com uma datação de 2.500 AC (ZIMPEL NETO, 2009). Outros trabalhos de licenciamento ocorreram na região, mas até o momento os dados sobre os vestígios arqueológicos não foram encontrados nas fontes consultadas (PELLINI \& TELLES, 2011; SCIENTIA, 2010).

É importante ressaltar que a criação do Centro de Pesquisa e Museu Regional de Arqueologia de Rondônia, na cidade de Presidente Médici, médio rio Ji-Paraná, teve um importante papel nos últimos anos na identificação de sítios arqueológicos, salvaguarda de seus vestígios, trabalhos de extensão junto à população local e apoio às pesquisas acadêmicas (SUÑER, 2016; OLIVEIRA, 2013)

\section{Área G: Alto rio Madeira/Baixo rio Jamari}

Assim como a região do médio-alto Ji-Paraná, as pesquisas arqueológicas na área G iniciaram-se nas décadas de 1970, alavancando na década seguinte com os trabalhos de salvamento arqueológico para a construção da UHE Samuel, coordenado por Eurico Miller (MILLER et al., 1992).

A essa região do alto rio Madeira foi atribuído uma grande significância para as hipóteses de ocupação da Amazônia, explorado em vários projetos de pós-graduação (TIZUKA, 2012; ALMEIDA, 2013; ZUSE, 2014; MONGELÓ, 2015). É o local com as TPI mais antigas associadas a possíveis grupos pré-cerâmicos, o possível centro de 
dispersão dos grupos Proto-Tupi e de domesticação da mandioca (Manihot esculenta) e da pupunha (Bactris gasipaes) (NEVES, 2012).

Todos os sítios identificados nessa área de concentração estão atrelados aos trabalhos de licenciamento ambiental. Além da citada UHE Samuel, nas décadas de 2000 ocorreu a construção das UHE Santo Antônio e Jirau, gerando um enorme acervo arqueológico que foi explorado em diversos projetos acadêmicos (graduação e pósgraduação). Tais informações aumentaram expressivamente o conhecimento pré-colonial da região (ZUSE, 2014) e testaram as hipóteses elaboradas por Miller e colegas, além de revisar algumas das fases cerâmicas propostas pelos mesmos (ALMEIDA, 2013).

Os vestígios cerâmicos encontrados, até o momento, são associados às ocupações da TP-A, TBI e TPA, com uma cronologia de 7.520 AC para o período pré-cerâmico e de 3.100 AC para os primeiros vestígios cerâmicos (TP-A).

\subsubsection{Considerações sobre as áreas}

Conforme exposto acima, o banco de dados possui 6.511 sítios arqueológicos distribuídos por toda Amazônia Legal Brasileira, mas existem áreas de maior concentração. Esses aglomerados de sítios, a princípio, não estão associados com a forma de ocupar os espaços, com um período ou cultura específica. Não podemos descartar essas possibilidades, mas a maior parte desses sítios foi somente identificada e não necessariamente escavados, o que inviabiliza fazermos maiores inferências numa perspectiva regional inter-sítios.

Portanto, analisar a localização e agrupamento desses sítios sob a ótica do contexto de pesquisa se torna mais viável e interessante para entendermos a trajetória das pesquisas arqueológicas em determinados locais. Isso está longe de ser o foco principal dessa tese, mas retomando a ideia inicial penso que esse esforço pode servir para futuros projetos de gerenciamento do patrimônio arqueológico.

Nesse sentido, analisar quantitativamente os sítios dentro dos limites estaduais, municipais e das sub-bacias hidrográficas nos permite realizar projetos de extensão em relação à extroversão e preservação do patrimônio arqueológico. Ou então, simplesmente realizar planejamentos estratégicos de forma a mitigar os impactos físicos nos sítios arqueológicos. É uma tarefa difícil, que não cativa muitos gestores públicos e podemos 
usar o município de Iranduba como exemplo. Área com mais de 100 sítios arqueológicos identificados e hoje, após a construção da ponte sobre o rio Negro, grande parte já foi destruída por centenas de empreendimentos, pela especulação imobiliária, retirada para matéria-prima, etc.

Para além dos limites políticos ou hidrográficos, as concentrações de sítios em uma região variaram entre 50 mil e 4 mil km² de área, ocorrendo de 510 a 140 sítios arqueológicos identificados. Apesar da antiguidade das pesquisas arqueológicas em algumas áreas, como a margem norte da foz do Amazonas (área A) e a foz dos rios Nhamundá, Trombetas e Tapajós (área 2), a maior parte dos sítios foi identificada durante os trabalhos de licenciamento ambiental.

Conforme Saldanha (2016), as pesquisas no âmbito do licenciamento aumentam continuamente o nosso conhecimento sobre os contextos culturais e particulares dos sítios, bem como a diversidade estilística das cerâmicas, nos últimos dois milênios que antecederam a colonização europeia. Mas, a meu ver, isso só será possível se essas informações arqueológicas forem incorporadas em projetos de pós-graduação. Não estou minimizando os trabalhos de licenciamento, mas o tempo e dedicação exigida ao tema na pós-graduação não se compara ao do meio empresarial, cujo cronograma está atrelado à execução do empreendimento. Por outro lado, o licenciamento possui uma grande vantagem sobre as pesquisas de pós-graduação: financiamento!

Os subitens relacionados às Tradições cerâmicas e cronologias de ocupação serão abordados de forma detalhada mais adiante.

\subsection{Composicão dos Sítios}

Nesse item será realizada a caracterização através de três atributos dos sítios arqueológicos: tamanho (área), presença ou ausência de solos antrópicos (Terra Preta de Índio) e quantidade de componentes culturais no nível das Tradições cerâmicas (uni ou multicomponencial). Essas características foram escolhidas por retratarem os sítios enquanto assentamentos, podendo representar questões ligadas à densidade demográfica, reocupações ou transformações culturais.

Nem todos os sítios possuem essas três informações, portanto houve variação no total amostrado para cada atributo. Vale ressaltar que nessa amostragem não foram 
inclusos os sítios que continham somente gravuras rupestres e bacias de polimento (ou afiadores), pois a princípio eles não trariam maiores informações sobre os assentamentos.

A seguir será apresentado cada um dos atributos individualmente. Em seguida esses atributos serão correlacionados.

\subsubsection{Dimensão dos sítios}

Dos 6.511 sítios arqueológicos somente uma pequena parcela $(n=1.723,26,46 \%)$ possui informações sobre dimensão (comprimento x largura e/ou área total). A área que é definida como um sítio arqueológico, em alguns casos, pode ser o resultado de um palimpsesto de diferentes tipos de ocupações - funcional, cultural ou temporal - com diferentes tipos de evidências distribuídos em um determinado local, como aqueles observados na área de confluência dos rios Solimões-Negro (NEVES, 2012) ou na foz do Tapajós (STENBORG et al., 2014).

Os sítios possuem bastante variações em seu tamanho, desde 0,0002 ha (ou $2 \mathrm{~m}^{2}$ ) até 150 ha (ou $1.500 .000 \mathrm{~m}^{2}$ ). Por conta dessa grande variedade de dimensões, optou-se por quantificar os sítios como maiores ou menores que 10 hectares. Intervalos menores trariam informações interessantes, principalmente em uma escala regional, mas para esse estudo optou-se em reduzir o número de categorias classificatórias por conta da área amostrada (Amazônia Legal Brasileira).

\begin{tabular}{|c|c|}
\hline \multicolumn{1}{|c|}{ Tamanho } & Quantidade \\
\hline Sítios $<10$ ha. & 1.520 \\
\hline Sítios $>10$ ha. Total & 210 \\
\hline \multicolumn{2}{|c|}{ Tot30 } \\
\hline
\end{tabular}

Tabela 3.3.1-1: Quantidade de sítios arqueológicos maiores e menores que 10 hectares de área.

Como podemos ver na tabela 3.3.1-1, a maior parte dos sítios (87\% de 1.730) possui menos de 10 ha de área. Vale ressaltar que existem três tipos de sítios que possuem pequenas dimensões, cuja delimitação está restrita às estruturas artificiais. Esse é o caso dos geoglifos no sudoeste amazônico $(n=479)$ e dos sambaquis litorâneos e fluviais $(n=69)$. Outro tipo de sítio que possui pequenas dimensões são aqueles restritos aos ambientes naturais, como as grutas $(n=49)$, abrigos $(n=133)$ e cavernas $(n=15)$. 
Até o momento não foi encontrado um padrão de ocorrência desses sítios em relação a sua localização geográfica, como a margem de grandes rios, interflúvios, lagos, costa litorânea, etc. (Mapa 3.3.1-1). O que podemos notar é que existem áreas onde só ocorrem sítios menores que 10 ha, mas não há registro da situação inversa.

No entanto, os sítios maiores que 10 ha ocorrem em meio a uma série de sítios menores (Mapa 3.3.1-2), em uma proporção de aproximadamente 80\% (sítios menores) e 20\% (sítios maiores), variando conforme cada região (Tabela 3.3.1-2). Foram utilizadas as áreas com maior concentração de sítios (áreas de 1-6, Mapa 3.2-2) para avaliar essa proporção.

\begin{tabular}{|l|c|c|}
\hline \multicolumn{3}{|c|}{ Área 1 } \\
\hline \multicolumn{1}{|c|}{ Tipo } & Quantidade & $\begin{array}{c}\text { Proporção } \\
\text { (\%) }\end{array}$ \\
\hline Sítios < 10 ha. & 76 & 85,39 \\
\hline Sítios >10 ha. & 13 & 14,61 \\
\hline Total & $\mathbf{8 9}$ & $\mathbf{1 0 0}$ \\
\hline
\end{tabular}

\begin{tabular}{|l|c|c|}
\hline \multicolumn{3}{|c|}{ Área 2 } \\
\hline \multicolumn{1}{|c|}{ Tipo } & Quantidade & $\begin{array}{c}\text { Proporção } \\
(\%)\end{array}$ \\
\hline Sítios < 10 ha. & 89 & 80,18 \\
\hline Sítios >10 ha. & 22 & 19,82 \\
\hline Total & $\mathbf{1 1 1}$ & $\mathbf{1 0 0}$ \\
\hline
\end{tabular}

\begin{tabular}{|l|c|c|}
\hline \multicolumn{3}{|c|}{ Área 3 } \\
\hline \multicolumn{1}{|c|}{ Tipo } & Quantidade & $\begin{array}{c}\text { Proporção } \\
\text { (\%) }\end{array}$ \\
\hline Sítios < 10 ha. & 132 & 88,59 \\
\hline Sítios >10 ha. & 17 & 11,41 \\
\hline Total & $\mathbf{1 4 9}$ & $\mathbf{1 0 0}$ \\
\hline
\end{tabular}

\begin{tabular}{|l|c|c|}
\hline \multicolumn{3}{|c|}{ Área 4 } \\
\hline \multicolumn{1}{|c|}{ Tipo } & Quantidade & $\begin{array}{c}\text { Proporção } \\
\mathbf{( \% )}\end{array}$ \\
\hline Sítios < 10 ha. & 69 & 95,83 \\
\hline Sítios > 10 ha. & 3 & 4,17 \\
\hline Total & $\mathbf{7 2}$ & $\mathbf{1 0 0}$ \\
\hline
\end{tabular}

\begin{tabular}{|l|c|c|}
\hline \multicolumn{3}{|c|}{ Área 5 } \\
\hline \multicolumn{1}{|c|}{ Tipo } & Quantidade & $\begin{array}{c}\text { Proporção } \\
\mathbf{( \% )}\end{array}$ \\
\hline Sítios < 10 ha. & 7 & 87,5 \\
\hline Sítios >10 ha. & 1 & 12,5 \\
\hline Total & $\mathbf{8}$ & $\mathbf{1 0 0}$ \\
\hline
\end{tabular}

\begin{tabular}{|l|c|c|}
\hline \multicolumn{3}{|c|}{ Área 6 } \\
\hline \multicolumn{1}{|c|}{ Tipo } & Quantidade & $\begin{array}{c}\text { Proporção } \\
(\%)\end{array}$ \\
\hline Sítios < 10 ha. & 22 & 100 \\
\hline Sítios >10 ha. & 0 & 0 \\
\hline Total & $\mathbf{2 2}$ & $\mathbf{1 0 0}$ \\
\hline
\end{tabular}

Tabela 3.3.1-2: Relação entre os sítios maiores e menores que 10 hectares conforme as áreas com maior concentração.

Outras áreas também foram amostradas para testar esse padrão, utilizando os locais de maior ocorrência de sítios $>10$ ha, conforme demonstrado abaixo.

\begin{tabular}{|l|c|c|}
\hline \multicolumn{3}{|c|}{ Área C } \\
\hline \multicolumn{1}{|c|}{ Tipo } & Quantidade & $\begin{array}{c}\text { Proporção } \\
\text { (\%) }\end{array}$ \\
\hline Sítios < 10 ha. & 42 & 76,36 \\
\hline Sítios > 10 ha. & 13 & 23,64 \\
\hline Total & $\mathbf{5 5}$ & $\mathbf{1 0 0}$ \\
\hline
\end{tabular}

\begin{tabular}{|l|c|c|}
\hline \multicolumn{3}{|c|}{ Área G } \\
\hline \multicolumn{1}{|c|}{ Tipo } & Quantidade & $\begin{array}{c}\text { Proporção } \\
\text { (\%) }\end{array}$ \\
\hline Sítios < 10 ha. & 110 & 91,67 \\
\hline Sítios > 10 ha. & 10 & 8,33 \\
\hline Total & $\mathbf{1 2 0}$ & $\mathbf{1 0 0}$ \\
\hline
\end{tabular}




\begin{tabular}{|l|c|c|}
\hline \multicolumn{3}{|c|}{ Área E } \\
\hline \multicolumn{1}{|c|}{ Tipo } & Quantidade & $\begin{array}{c}\text { Proporção } \\
(\%)\end{array}$ \\
\hline Sítios < 10 ha. & 82 & 85,42 \\
\hline Sítios >10 ha. & 14 & 14,58 \\
\hline Total & $\mathbf{9 6}$ & $\mathbf{1 0 0}$ \\
\hline
\end{tabular}

\begin{tabular}{|l|c|c|}
\hline \multicolumn{3}{|c|}{ Médio-Baixo rio Madeira } \\
\hline \multicolumn{1}{|c|}{ Tipo } & Quantidade & $\begin{array}{c}\text { Proporção } \\
\text { (\%) }\end{array}$ \\
\hline Sítios $<\mathbf{1 0}$ ha. & 20 & 62,5 \\
\hline Sítios $>\mathbf{1 0}$ ha. & 12 & 37,5 \\
\hline Total & $\mathbf{3 2}$ & $\mathbf{1 0 0}$ \\
\hline
\end{tabular}

Tabela 3.3.1-2: Outras áreas amostradas na relação de sítios maiores ou menores que 10 hectares.

É importante ressaltar que por uma questão amostral, até o momento, não há como afirmar que em uma região todos esses sítios estavam sendo ocupados concomitantemente e nem que o seu tamanho é o resultado de um único componente cultural.

Porém, os dados aqui reunidos nos permitem hipotetizar que essa configuração espacial do registro arqueológico é o resultado de ocupações concomitantes dentro de um mesmo sistema sócio-político regional. Se isso estiver correto, poderíamos supor que houvesse locais de uso/ocupação mais intensa rodeado por locais de uso/ocupação menos intensa, como uma espécie de "aldeia satélite" rodeado por aldeias menores, com diferentes funções e hierarquias dentro de uma organização sociopolítica regional. Contextos semelhantes já foram identificados no Alto rio Xingu com os seus "aglomerados galácticos", com assentamentos de diferentes tamanhos e funcionalidades, conectados por estradas e acessando diferentes recursos naturais (HECKENBERGER et al., 2008). Na Ilha de Marajó, Schaan (2004) identifica essas diferentes espacialidades a partir dos diferentes tamanhos e localizações dos tesos, diferenciando-os entre áreas habitacionais e cerimoniais.

É bem provável que outras regiões da Amazônia possuam padrões de organizações sociopolíticas semelhantes, cada qual com os seus critérios de elegibilidade, permitindo um maior controle territorial e acesso aos diferentes recursos naturais, levando a importantes distinções sociais internas. Nesse sentido, pesquisas em escala regional são importantes para testar esse modelo, identificando padrões localizados, refinando sua cronologia e construindo uma história indígena de longa duração. 


\subsection{2 "Terra Preta Índio" (TPI)}

A “Terra Preta de Índio” (TPI) ou Terra Preta Antropogênica é um bom indicador de sítios arqueológicos pré-coloniais devido a sua alta visibilidade no solo e associação com grandes quantidades de vestígios cerâmicos. Sua ocorrência é restrita a determinados locais e contrasta com a coloração de outros solos amazônicos (vermelho ou amarelo, por exemplo) que abrangem grandes áreas.

Em algumas regiões, como no baixo Amazonas ou próximo à Manaus, esses solos são utilizados para a agricultura ou extraídos para serem comercializados (HIRAOKA et al., 2003; JUNQUEIRA, 2015). No entanto, muitos desses sítios com TPI estão em áreas ocupadas por residências, desde pequenas propriedades familiares até os grandes centros urbanos. E isso nos traz uma noção sobre a sua localização: o comportamento de reocuparmos os mesmos locais. Em alguns casos temos uma continuidade ininterrupta de ocupações, como os centros urbanos que surgiram dos aldeamentos do período colonial (PORRO, 1996), e em outros eles voltam a ser ocupados centenas de anos após o abandono, como é o caso de algumas comunidades ribeirinhas da Amazônia.

Nos últimos anos, com os avanços das tecnologias de SIG e a criação de extensos bancos de dados, diversos modelos preditivos foram elaborados de forma a otimizar os trabalhos de campo ou ampliar as discussões sobre o grau de impacto humano na floresta amazônica, e suas possíveis alterações no solo e na flora (PALACE et al., 2017; SÖDERSTRÖM et al., 2016; MCMICHAEL et al., 2014; AIRES DA FONSECA, 2013; THAYN et al., 2011; RUSSEL, 2005). Por consequência, isso nos leva aos locais com maior potencial para a ocorrência de sítios arqueológicos com TPI.

Para muitos sítios não foi possível obter na bibliografia a informação sobre tipo de solo ( $\mathrm{n}=2.436)$, o que reduz os sítios analisados nesse tópico a uma amostra de 3.803, correspondendo a 58,40\% dos 6.511 sítios arqueológicos (Mapa 3.3.2-1). 


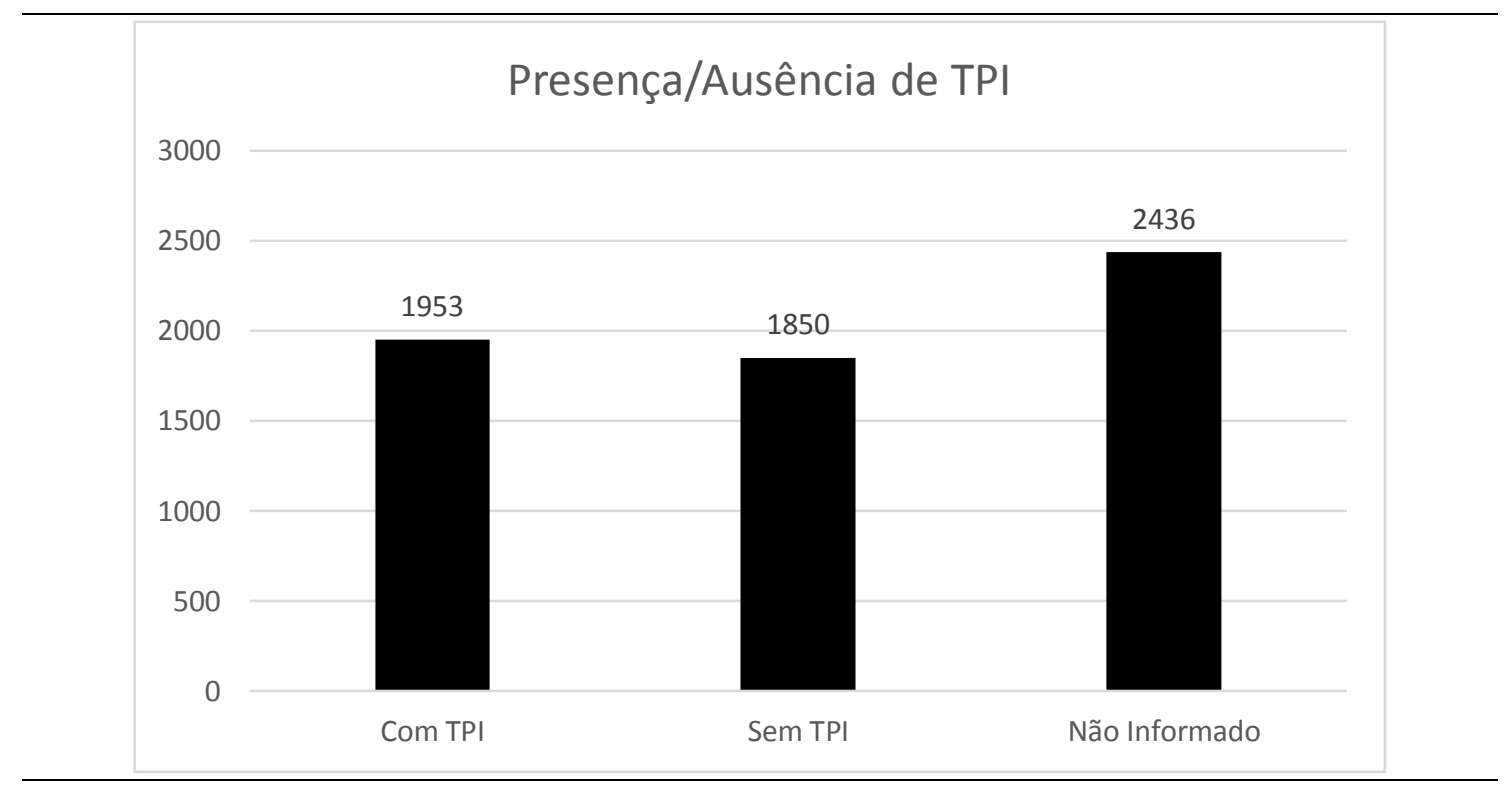

Gráfico 3.3.2-1: Sítios arqueológicos com TPI, sem TPI e os sem informações.

Os sítios com TPI ocorrem, de maneira geral, no eixo leste-oeste ao longo da calha do Amazonas, Solimões, Negro e no médio-baixo curso dos seus principais afluentes. A sub-bacia do rio Madeira é um dos poucos locais onde ocorre TPI desde a sua foz até os seus formadores, como o rio Guaporé, sendo que no baixo e médio curso não há informações de sítios sem TPI (Mapa 3.3.2-2).

Os sítios sem TPI ocorrem nas mesmas áreas que os sítios com TPI, mas em menor quantidade. Por outro lado, existem regiões onde só há sítios sem TPI, como o sudoeste amazônico, nos formadores do alto rio Purus, associados aos geoglifos. A região dos rios Tocantins e Araguaia, acima da confluência de ambos também não há registros de TPI, bem como algumas partes da Amazônia meridional. Ou seja, a maioria dos sítios sem TPI ocorrem nas extremidades da Amazônia brasileira, formando uma espécie de arco em torno das áreas de sítios com TPI (Mapa 3.3.2-3).

Apesar de sua reconhecida fertilidade para a agricultura devemos levar em consideração que a formação desses solos está associada ao depósito de grandes quantidades de matéria orgânica (FALCÃO et al., 2008), e o registro arqueológico demonstra que poderiam ser locais residenciais. Nesse sentido, a distribuição de sítios com TPI pela Amazônia, associada a uma cronologia refinada, pode nos dar indicativos a respeito da densidade demográfica em um mesmo local.

Isso quer dizer que sítios sem TPI representam baixa densidade demográfica? Se pensarmos localmente (o sítio arqueológico), pode ser que sim. No entanto, uma 
concentração de sítios sem TPI em uma mesma região também pode representar um adensamento demográfico (menos intenso do que as regiões com TPI), porém com formas diferentes de descarte do material orgânico, mobilidade ou menor concentração populacional em escala local. Podemos estar diante de um padrão ocupacional que ocorreu de forma mais abrangente em uma vasta área, ao ponto de não ocupar de maneira intensa um mesmo local, mas ao contrário, de forma frequente vários locais. Isso tem relação com a faixa temporal no qual esses sítios foram ocupados.

\subsubsection{Unicomponencial e Multicomponencial}

Nessa caracterização serão utilizadas as classificações de uni e multicomponencial do sítio arqueológico. Essa categoria está relacionada à presença de uma (uni) ou mais (multi) camadas culturais. As camadas, em linhas gerais, tendem a ser definidas de acordo com os vestígios cerâmicos, utilizando a classificação de fases cerâmicas para definir a presença de um ou mais elementos culturais no mesmo sítio.

Para esse tópico serão utilizadas as Tradições cerâmicas para definir a quantidade de camadas culturais de cada sítio. No entanto, uma grande parte dos sítios não possui essa informação $(n=5.154)$, totalizando uma amostra de 1.085, correspondendo a $16,64 \%$ do total de sítios (Gráfico 3.3.3-1; Mapa 3.3.3-1).

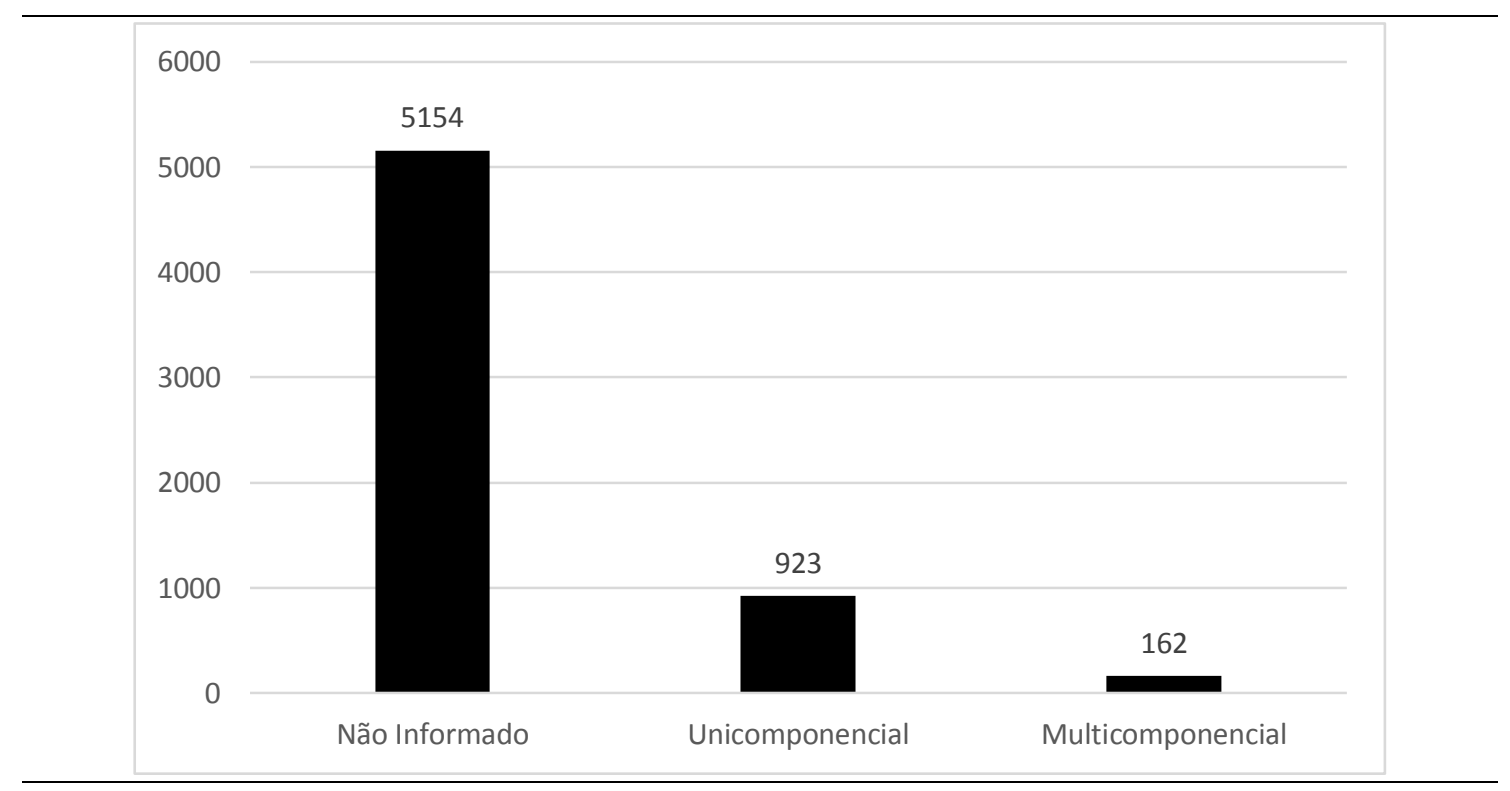

Gráfico 3.3.3-1: Quantidade de sítios arqueológicos unicomponenciais, multicomponenciais e sem informação. 
Como trabalhamos no nível das Tradições cerâmicas, ao invés das fases, a quantidade de sítios multicomponenciais ficou reduzida (162 de 1.085 sítios). A maior concentração desse tipo de sítio está na área de confluência entre os rios Solimões e Negro, com algumas ocorrências na confluência do rio Madeira com o Amazonas, no baixo curso do rio Madeira e no baixo curso do rio Jamari, onde está a UHE Samuel (Mapa 3.3.3-2). Por outro lado, os sítios unicomponenciais não possuem uma área de ocorrência específica, estando distribuídos em todos os locais.

Ainda não está claro porque alguns locais foram reocupados e outros apenas abandonados. De toda forma, os sítios unicomponenciais com longo período de ocupação (e.g.: geoglifos do sudoeste amazônico) podem representar um forte domínio territorial ou um status diferenciado dentro de um sistema político regional. Ou seja, uma população que perdurou por centenas de anos em um mesmo local, mantendo sua base estrutural (nesse caso representada culturalmente na cerâmica), demonstra a habilidade em manter seu território por meio de diferentes relações com outros grupos.

Por outro lado, os sítios multicomponenciais podem representar dois aspectos distintos: a significância de um determinado local que o torna importante para ser reocupado (NEVES, 2012) e/ou a incorporação de diferentes elementos culturais exógenos (LOPES, 2018). A área de confluência dos rios Solimões-Negro-Madeira, como já foi dito, foi reocupada em seu último período através de conflitos bélicos. Em contrapartida, no médio Solimões, a população local optou por incorporar novos aspectos em sua expressão cultural, marcando uma área onde não há rupturas claras entre um estilo expresso na cerâmica e outro.

No caso de reocupações onde existe um intervalo de tempo entre uma ocupação e outra, temos que ter em mente que a primeira irá transformar a paisagem, tanto o local do assentamento como o seu entorno, e as demais poderão alterar, potencializar ou se aproveitar dessas transformações. Em alguns casos, isso pode ter facilitado processos de reocupação por um mesmo grupo ou outro, após o abandono do local. Uma explicação mais simplista para as reocupações pode estar associada à existência de florestas secundárias com plantas úteis (ou "capoeiras") associadas ou não aos solos antrópicos (TPI), que se formam em locais previamente ocupados. Tais práticas não são exclusivas de períodos pré-coloniais, tendo sido documentado em diversas populações atuais da Amazônia (BALÉE, 1989; POLITIS, 1999; MACHADO, 2009). 
De toda forma, os processos que levaram a formação desses contextos podem variar de sítio para sítio, de região para região, sendo necessária uma análise contextual local e pormenorizada para compreender sua trajetória histórica.

\subsubsection{Correlacionando informações dos sítios}

Conforme demonstrado nos três itens anteriores temos um total de amostragem diferenciado para cada aspecto quantificado, devido às informações disponíveis para cada sítio arqueológico compilado no banco de dados. Em linhas gerais, para cada um dos itens, conclui-se que a maior parte dos sítios possui menos que 10 hectares de áreas $(\mathrm{n}=1.511)$; presença de TPI $(\mathrm{n}=1.953)$; e a presença de um único componente no nível das Tradições ( $\mathrm{n}=923)$. A tabela a seguir sintetiza essas informações.

\begin{tabular}{|l|c|c|c|}
\cline { 2 - 4 } \multicolumn{1}{c|}{} & Sítios $<\mathbf{1 0 h a}$ & Sítios $>\mathbf{1 0 h a}$ & Total \\
\hline Área & 1.511 & 212 & 1.723 \\
\cline { 2 - 4 } \multicolumn{1}{c|}{ Com TPI } & Sem TPI & Total \\
\hline Tipo de Solo & 1.953 & 1.850 & 3.803 \\
\hline \multicolumn{4}{|c|}{} \\
\cline { 2 - 4 } \multicolumn{1}{c|}{ Unicompon. } & Multicompon. & Total \\
\hline Componentes & 923 & 162 & 1.085 \\
\hline
\end{tabular}

Tabela 3.3.4-1: Quantidade de sítios arqueológicos por características analisadas.

A partir desses três atributos foram realizados outros cruzamentos correlacionando cada um deles. Da mesma forma que as outras análises, o número amostral variou para cada caso:

1. Sítios que possuem as dimensões e informações sobre os componentes ( $n=633)$;

2. Sítios que possuem as dimensões e informações com o tipo de solo $(n=1.515)$;

3. Sítios que possuem informações sobre o tipo de solo e componentes $(n=1.008)$.

Em cada correlação foram geradas 4 combinações diferentes, conforme demonstrado na tabela a seguir. As áreas selecionadas devem possuir uma amostra mínima de 30 sítios arqueológicos. Para classificar os resultados por área amostrada foram utilizados os seguintes parâmetros: 
a) Presença de 1 combinação - uniformidade;

b) Presença de 2 combinações - menor variabilidade;

c) Presença de 3 ou 4 combinações - maior variabilidade;

Nos casos de menor ou maior variabilidade, só foram consideradas as combinações que possuem mais de $10 \%$ de representatividade em relação ao total de sítios da área amostrada. No caso da uniformidade, somente quando ocorre uma única combinação com mais de $10 \%$ de representação. Foram utilizadas as mesmas áreas de maior (1-6) ou menor concentração (A-G), mas em alguns casos foram exploradas outras regiões por conta de sua variabilidade. Esses parâmetros foram escolhidos de forma a aproveitar o máximo do número amostral das informações para cada sítio e região e ao mesmo tempo, de oferecer certo refinamento às analises. A seguir estão os resultados gerais de cada correlação.

\begin{tabular}{|l|c|c|c|}
\cline { 2 - 4 } \multicolumn{1}{c|}{} & Unicomponencial & Multicomponencial & Total \\
\hline Sítios $<$ 10ha & $481(86,98 \%)$ & $72(13,02 \%)$ & $\mathbf{5 5 3}$ \\
\hline Sítios $>$ 10ha & $55(68,75 \%)$ & $25(31,25 \%)$ & $\mathbf{8 0}$ \\
\hline Total & $\mathbf{5 3 6}$ & $\mathbf{9 7}$ & $\mathbf{6 3 3}$ \\
\hline
\end{tabular}

\begin{tabular}{|l|c|c|c|}
\cline { 2 - 4 } \multicolumn{1}{c|}{} & Com TPI & Sem TPI & Total \\
\hline Sítios $<$ 10ha & $611(46,26 \%)$ & $710(53,74 \%)$ & $\mathbf{1 . 3 2 1}$ \\
\hline Sítios $>$ 10ha & $130(67,01 \%)$ & $64(32,99 \%)$ & $\mathbf{1 9 4}$ \\
\hline Total & $\mathbf{7 4 1}$ & $\mathbf{7 7 4}$ & $\mathbf{1 . 5 1 5}$ \\
\hline
\end{tabular}

\begin{tabular}{|l|c|c|c|}
\cline { 2 - 4 } \multicolumn{1}{c|}{} & Com TPI & Sem TPI & Total \\
\hline Unicomponencial & $552(65,01 \%)$ & $297(34,99 \%)$ & $\mathbf{8 4 9}$ \\
\hline Multicomponencial & $146(91,82 \%)$ & $13(8,18 \%)$ & $\mathbf{1 5 9}$ \\
\hline Total & $\mathbf{6 9 8}$ & $\mathbf{3 1 0}$ & $\mathbf{1 . 0 0 8}$ \\
\hline
\end{tabular}

Tabela 3.3.4-2: Quantidade de sítios arqueológicos para cada tipo de correlação.

A única região que apresentou alta variabilidade para as três correlações foi a área de confluência entre os rios Solimões e Negro (área 1).

$\mathrm{Na}$ primeira análise (componentes + dimensão), a área que apresentou maior variabilidade é o baixo rio Jamari (área G). Essa área é caracterizada por sítios unicomponenciais menores que $10 \mathrm{ha}$, com baixa representação das outras combinações (Mapa 3.3.4-1). 


\begin{tabular}{|c|c|}
\hline \multicolumn{2}{|c|}{ Área 1 - Confluência Negro-Solimões } \\
\hline Combinação & Quantidade (\%) \\
\hline Uni e $<10$ ha & $18(29,04 \%)$ \\
\hline Uni e $>10$ ha & $0(0 \%)$ \\
\hline Multi e $<10$ ha & $32(51,61 \%)$ \\
\hline Multi e $>10$ ha & $12(19,35)$ \\
\hline Total & $\mathbf{6 2}$ \\
\hline
\end{tabular}

\begin{tabular}{|c|c|}
\hline \multicolumn{2}{|c|}{ Área G - Baixo Jamari } \\
\hline Combinação & Quantidade (\%) \\
\hline Uni e $<10$ ha & $24(61,54 \%)$ \\
\hline Uni e $>10$ ha & $5(12,82 \%)$ \\
\hline Multi e $<10$ ha & $9(23,07 \%)$ \\
\hline Multi e $>10$ ha & $1(2,56 \%)$ \\
\hline Total & $\mathbf{3 9}$ \\
\hline
\end{tabular}

Tabela 3.3.4-3: Quantidade de sítios arqueológicos com maior variabilidade na correlação de componentes com dimensão.

Com menor variabilidade temos duas variações:

- Sítios unicomponenciais maiores e menores que 10ha

\begin{tabular}{|c|c|}
\hline \multicolumn{2}{|c|}{ Baixo-Médio Madeira } \\
\hline Combinação & Quantidade (\%) \\
\hline Uni e $<10$ ha & $17(53,13 \%)$ \\
\hline Uni e $>10$ ha & $10(31,25 \%)$ \\
\hline Multi e $<10$ ha & $3(9,37 \%)$ \\
\hline Multi e $>10$ ha & $2(6,25 \%)$ \\
\hline Total & 32 \\
\hline
\end{tabular}

\begin{tabular}{|l|c|}
\hline \multicolumn{2}{|c|}{ Baixo Rio Tapajós } \\
\hline Combinação & Quantidade (\%) \\
\hline Uni e $<10$ ha & $50(79,36 \%)$ \\
\hline Uni e $>10$ ha & $12(19,04 \%)$ \\
\hline Multi e $<10$ ha & 0 \\
\hline Multi e $>10$ ha & $1(1,60 \%)$ \\
\hline Total & $\mathbf{6 3}$ \\
\hline
\end{tabular}

Tabela 3.3.4-4: Quantidade de sítios arqueológicos com menor variabilidade na correlação de componentes com dimensão (unicomponenciais maiores e menores que 10 hectares).

- Sítios menores que 10ha uni e multicomponenciais

\begin{tabular}{|l|c|}
\hline \multicolumn{2}{|c|}{ Baixo rio Urubu-Uatumã } \\
\hline Combinação & Quantidade (\%) \\
\hline Uni e $<10$ ha & $35(77,78 \%)$ \\
\hline Uni e $>10$ ha & $2(4,45 \%)$ \\
\hline Multi e $<10$ ha & $8(17,77 \%)$ \\
\hline Multi e $>10$ ha & 0 \\
\hline Total & $\mathbf{4 5}$ \\
\hline
\end{tabular}

Tabela 3.3.4-5: Quantidade de sítios arqueológicos com menor variabilidade na correlação de componentes com dimensão (uni e multicomponenciais menores que 10 hectares).

De maneira uniforme temos o litoral salgado representado pelos sambaquis unicomponenciais menores que 10ha $(n=32)$.

Na segunda análise (tipo de solo + dimensão) a variabilidade está concentrada na confluência dos rios Tocantins e Araguaia, Serra dos Carajás (área C) e o baixo rio Jamari (área $\mathrm{G})$. A duas áreas a leste ( $\mathrm{C}$ e confluência Tocantins-Araguaia) apresentaram uma 
maior quantidade de sítios sem TPI e menores que 10ha, enquanto que as outras duas possuem sítios com TPI menores que 10ha (Mapa 3.3.4-2).

\begin{tabular}{|c|c|}
\hline \multicolumn{2}{|c|}{ Confluência Tocantins-Araguaia } \\
\hline Combinação & Quantidade (\%) \\
\hline$<10$ ha com TPI & $7(12,28 \%)$ \\
\hline$<10$ ha sem TPI & $37(64,91 \%)$ \\
\hline$>10$ ha com TPI & $2(3,50 \%)$ \\
\hline$>10$ ha sem TPI & $11(19,29 \%)$ \\
\hline Total & $\mathbf{5 7}$ \\
\hline
\end{tabular}

\begin{tabular}{|c|c|}
\hline \multicolumn{2}{|c|}{ Área C - Serra dos Carajás } \\
\hline Combinação & Quantidade (\%) \\
\hline$<10$ ha com TPI & $7(17,08 \%)$ \\
\hline$<10$ ha sem TPI & $28(68,29 \%)$ \\
\hline$>10$ ha com TPI & $1(2,44 \%)$ \\
\hline$>10$ ha sem TPI & $5(12,19 \%)$ \\
\hline Total & $\mathbf{4 1}$ \\
\hline
\end{tabular}

\begin{tabular}{|c|c|}
\hline \multicolumn{2}{|c|}{ Área G - Baixo Jamari } \\
\hline Combinação & Quantidade (\%) \\
\hline$<10$ ha com TPI & $33(63,46 \%)$ \\
\hline$<10$ ha sem TPI & $12(23,07 \%)$ \\
\hline$>10$ ha com TPI & $7(13,47 \%)$ \\
\hline$>10$ ha sem TPI & $0(0 \%)$ \\
\hline Total & $\mathbf{5 2}$ \\
\hline
\end{tabular}

\begin{tabular}{|c|c|}
\hline \multicolumn{2}{|c|}{ Área 1 - Confluência Negro-Solimões } \\
\hline Combinação & Quantidade (\%) \\
\hline$<10$ ha com TPI & $42(62,68 \%)$ \\
\hline$<10$ ha sem TPI & $13(19,40 \%)$ \\
\hline$>10$ ha com TPI & $12(17,92 \%)$ \\
\hline$>10$ ha sem TPI & $0(0 \%)$ \\
\hline Total & $\mathbf{6 7}$ \\
\hline
\end{tabular}

Tabela 3.3.4-6: Quantidade de sítios arqueológicos com maior variabilidade na correlação da dimensão com o tipo de solo.

Para a menor variabilidade temos três tipos de ocorrências para diferentes áreas:

- Sítios com TPI maiores e menores que 10ha

\begin{tabular}{|c|c|}
\hline \multicolumn{2}{|c|}{ Baixo rio Tapajós } \\
\hline Combinação & Quantidade (\%) \\
\hline$<10$ ha com TPI & $54(75 \%)$ \\
\hline$<10$ ha sem TPI & $5(6,94 \%)$ \\
\hline$>10$ ha com TPI & $13(18,06 \%)$ \\
\hline$>10$ ha sem TPI & 0 \\
\hline Total & $\mathbf{7 2}$ \\
\hline
\end{tabular}

\begin{tabular}{|c|c|}
\hline \multicolumn{2}{|c|}{ Médio-Baixo rio Madeira } \\
\hline Combinação & Quantidade (\%) \\
\hline$<10$ ha com TPI & $20(62,5 \%)$ \\
\hline$<10$ ha sem TPI & 0 \\
\hline$>10$ ha com TPI & $12(37,5 \%)$ \\
\hline$>10$ ha sem TPI & 0 \\
\hline Total & $\mathbf{3 2}$ \\
\hline
\end{tabular}

Tabela 3.3.4-7: Quantidade de sítios arqueológicos com menor variabilidade na correlação da dimensão com o tipo de solo (com TPI maiores ou menores que 10 hectares). 
- Sítios sem TPI maiores e menores que 10ha

\begin{tabular}{|c|c|}
\hline \multicolumn{2}{|c|}{ Rio Teles Pires } \\
\hline Combinação & Quantidade (\%) \\
\hline$<10$ ha com TPI & 0 \\
\hline$<10$ ha sem TPI & $51(83,60 \%)$ \\
\hline$>10$ ha com TPI & 0 \\
\hline$>10$ ha sem TPI & $10(16,40 \%)$ \\
\hline Total & $\mathbf{6 1}$ \\
\hline
\end{tabular}

Tabela 3.3.4-7: Quantidade de sítios arqueológicos com menor variabilidade na correlação da dimensão com o tipo de solo (sem TPI maiores ou menores que 10 hectares).

- Sítios menores que 10ha com e sem TPI

\begin{tabular}{|c|c|}
\hline \multicolumn{2}{|c|}{ Volta Grande do Xingu } \\
\hline Combinação & Quantidade (\%) \\
\hline$<10$ ha com TPI & $65(43,33 \%)$ \\
\hline$<10$ ha sem TPI & $68(45,34 \%)$ \\
\hline$>10$ ha com TPI & $13(8,66 \%)$ \\
\hline$>10$ ha sem TPI & $4(2,67 \%)$ \\
\hline Total & $\mathbf{1 5 0}$ \\
\hline
\end{tabular}

\begin{tabular}{|c|c|}
\hline \multicolumn{2}{|c|}{ Litoral do Salgado } \\
\hline Combinação & Quantidade (\%) \\
\hline$<10$ ha com TPI & $7(15,55 \%)$ \\
\hline$<10$ ha sem TPI & $38(84,45)$ \\
\hline$>10$ ha com TPI & 0 \\
\hline$>10$ ha sem TPI & 0 \\
\hline Total & $\mathbf{4 5}$ \\
\hline
\end{tabular}

Tabela 3.3.4-8: Quantidade de sítios arqueológicos com menor variabilidade na correlação da dimensão com o tipo de solo (menores que 10 hectares com e sem TPI).

Entre as ocorrências uniformes, temos dois tipos:

- Sítios menores que 10ha sem TPI

\begin{tabular}{|c|c|}
\hline \multicolumn{2}{|c|}{ Médio-Alto rio Machado } \\
\hline Combinação & Quantidade (\%) \\
\hline$<10$ ha com TPI & $2(2,95 \%)$ \\
\hline$<10$ ha sem TPI & $61(89,70 \%)$ \\
\hline$>10$ ha com TPI & 0 \\
\hline$>10$ ha sem TPI & $5(7,35 \%)$ \\
\hline Total & $\mathbf{6 8}$ \\
\hline
\end{tabular}

\begin{tabular}{|c|c|}
\hline \multicolumn{2}{|c|}{ Médio-Alto rio Tocantins } \\
\hline Combinação & Quantidade (\%) \\
\hline$<10$ ha com TPI & 0 \\
\hline$<10$ ha sem TPI & $69(95,84 \%)$ \\
\hline$>10$ ha com TPI & 0 \\
\hline$>10$ ha sem TPI & $3(4,16 \%)$ \\
\hline Total & $\mathbf{7 2}$ \\
\hline
\end{tabular}

Tabela 3.3.4-9: Quantidade de sítios arqueológicos na correlação da dimensão com o tipo de solo (menores que 10 hectares sem TPI). 
- Sítios menores que 10ha com TPI

\begin{tabular}{|c|c|}
\hline \multicolumn{2}{|c|}{ Baixo rio Urubu-Uatumã } \\
\hline Combinação & Quantidade (\%) \\
\hline$<10$ ha com TPI & $61(89,70)$ \\
\hline$<10$ ha sem TPI & $2(2,94 \%)$ \\
\hline$>10$ ha com TPI & $3(4,41 \%)$ \\
\hline$>10$ ha sem TPI & $2(2,95 \%)$ \\
\hline Total & $\mathbf{6 8}$ \\
\hline
\end{tabular}

\begin{tabular}{|c|c|}
\hline \multicolumn{2}{|c|}{ Lago Amanã (médio Solimões) } \\
\hline Combinação & Quantidade (\%) \\
\hline$<10$ ha com TPI & $29(93,54 \%)$ \\
\hline$<10$ ha sem TPI & $1(3,23 \%)$ \\
\hline$>10$ ha com TPI & $1(3,23 \%)$ \\
\hline$>10$ ha sem TPI & 0 \\
\hline Total & $\mathbf{3 1}$ \\
\hline
\end{tabular}

Tabela 3.3.4-10: Quantidade de sítios arqueológicos na correlação da dimensão com o tipo de solo (menores que 10 hectares com TPI).

$\mathrm{Na}$ terceira análise (tipo de solo + componentes) a única região com alta variabilidade que se encaixou aos parâmetros pré-definidos foi a área de confluência entre os rios Solimões e Negro (área 1), com maior presença de sítios multicomponenciais com TPI (Mapa 3.3.4-3). Fora dos parâmetros (menos que 30 sítios) tivemos a T.I. Koatinemo no baixo Xingu, o rio Teles Pires (área E) e o médio-alto Ji-Paraná (área F). Com exceção da T.I. Koatinemo, que apresentou uma distribuição mais homogênea, as outras duas áreas são caracterizadas por sítios unicomponenciais sem TPI.

\begin{tabular}{|c|c|}
\hline \multicolumn{2}{|c|}{ Área 1 - Confluência Negro-Solimões } \\
\hline Combinação & Quantidade (\%) \\
\hline Uni com TPI & $20(22,22 \%)$ \\
\hline Uni sem TPI & $10(11,11 \%)$ \\
\hline Multi com TPI & $54(60 \%)$ \\
\hline Multi sem TPI & $6(6,67 \%)$ \\
\hline Total & 90 \\
\hline
\end{tabular}

\begin{tabular}{|c|c|}
\hline \multicolumn{2}{|c|}{ Área F - Médio-Alto Ji-Paraná } \\
\hline Combinação & Quantidade (\%) \\
\hline Uni com TPI & $4(22,22 \%)$ \\
\hline Uni sem TPI & $12(66,66 \%)$ \\
\hline Multi com TPI & $2(11,12 \%)$ \\
\hline Multi sem TPI & $0(0 \%)$ \\
\hline Total & 18 \\
\hline
\end{tabular}

\begin{tabular}{|c|c|}
\hline \multicolumn{2}{|c|}{ Área E - Teles Pires } \\
\hline Combinação & Quantidade (\%) \\
\hline Uni com TPI & $3(12 \%)$ \\
\hline Uni sem TPI & $17(68 \%)$ \\
\hline Multi com TPI & $5(20 \%)$ \\
\hline Multi sem TPI & $0(0 \%)$ \\
\hline Total & 25 \\
\hline
\end{tabular}

\begin{tabular}{|c|c|}
\hline \multicolumn{2}{|c|}{ TI Koatinemo } \\
\hline Combinação & Quantidade (\%) \\
\hline Uni com TPI & $6(37,50 \%)$ \\
\hline Uni sem TPI & $4(25 \%)$ \\
\hline Multi com TPI & $6(37,50 \%)$ \\
\hline Multi sem TPI & $0(0 \%)$ \\
\hline Total & 16 \\
\hline
\end{tabular}

Tabela 3.3.4-11: Quantidade de sítios arqueológicos com maior variabilidade na correlação dos componentes com o tipo de solo.

Sítios com menor variabilidade ocorrem na região do rio Urubu-Uatumã e no baixo-médio rio madeira, caracterizados por sítios com TPI e variando entre maiores ou menores que 10ha. 


\begin{tabular}{|c|c|}
\hline \multicolumn{2}{|c|}{ Baixo rio Urubu-Uatumã } \\
\hline Combinação & Quantidade (\%) \\
\hline Uni com TPI & $37(80,43 \%)$ \\
\hline Uni sem TPI & 0 \\
\hline Multi com TPI & $9(19,57 \%)$ \\
\hline Multi sem TPI & 0 \\
\hline Total & 46 \\
\hline
\end{tabular}

\begin{tabular}{|l|c|}
\hline \multicolumn{2}{|c|}{ Médio-Baixo rio Madeira } \\
\hline \multicolumn{1}{|c|}{ Combinação } & Quantidade (\%) \\
\hline Uni com TPI & $48(78,68 \%)$ \\
\hline Uni sem TPI & 0 \\
\hline Multi com TPI & $13(21,32 \%)$ \\
\hline Multi sem TPI & 0 \\
\hline \multicolumn{1}{|c|}{ Total } & $\mathbf{6 1}$ \\
\hline
\end{tabular}

\begin{tabular}{|c|c|}
\hline \multicolumn{2}{|c|}{ Baixo Jamari } \\
\hline Combinação & Quantidade (\%) \\
\hline Uni com TPI & $34(77,27 \%)$ \\
\hline Uni sem TPI & $2(4,55 \%)$ \\
\hline Multi com TPI & $8(18,18 \%)$ \\
\hline Multi sem TPI & 0 \\
\hline Total & 44 \\
\hline
\end{tabular}

Tabela 3.3.4-12: Quantidade de sítios arqueológicos com menor variabilidade na correlação dos componentes com o tipo de solo.

Entre as ocorrências uniformes, temos dois tipos:

- Sítios unicomponenciais com TPI

\begin{tabular}{|l|c|}
\hline \multicolumn{2}{|c|}{ Baixo rio Tapajós } \\
\hline \multicolumn{1}{|c|}{ Combinação } & Quantidade (\%) \\
\hline Uni com TPI & $95(88,78 \%)$ \\
\hline Uni sem TPI & $10(9,35 \%)$ \\
\hline Multi com TPI & $2(1,87 \%)$ \\
\hline Multi sem TPI & 0 \\
\hline \multicolumn{1}{|c|}{ Total } & $\mathbf{1 0 7}$ \\
\hline
\end{tabular}

\begin{tabular}{|c|c|}
\hline \multicolumn{2}{|c|}{ Volta Grande do Xingu } \\
\hline Combinação & Quantidade (\%) \\
\hline Uni com TPI & $31(88,57 \%)$ \\
\hline Uni sem TPI & $3(8,58 \%)$ \\
\hline Multi com TPI & $1(2,85 \%)$ \\
\hline Multi sem TPI & 0 \\
\hline Total & 35 \\
\hline
\end{tabular}

\begin{tabular}{|l|c|}
\hline \multicolumn{2}{|c|}{ Baixo rio Tocantins } \\
\hline \multicolumn{1}{|c|}{ Combinação } & Quantidade (\%) \\
\hline Uni com TPI & $29(93,55 \%)$ \\
\hline Uni sem TPI & 0 \\
\hline Multi com TPI & $2(6,45 \%)$ \\
\hline Multi sem TPI & 0 \\
\hline Total & $\mathbf{3 1}$ \\
\hline
\end{tabular}

Tabela 3.3.4-12: Quantidade de sítios arqueológicos na correlação dos componentes com o tipo de solo (unicomponenciais com TPI). 
- Sítios unicomponenciais sem TPI

\begin{tabular}{|c|c|}
\hline \multicolumn{2}{|c|}{ Litoral Salgado } \\
\hline Combinação & Quantidade (\%) \\
\hline Uni com TPI & $1(2,05 \%)$ \\
\hline Uni sem TPI & $48(97,95 \%)$ \\
\hline Multi com TPI & 0 \\
\hline Multi sem TPI & 0 \\
\hline Total & 49 \\
\hline
\end{tabular}

Tabela 3.3.4-13: Quantidade de sítios arqueológicos na correlação dos componentes com o tipo de solo (unicomponenciais sem TPI).

Por fim, analisaram-se os sítios que possuíam informações sobre esses três aspectos, reduzindo a amostra para 585 sítios arqueológicos. Para essa etapa foi utilizado os seguintes parâmetros:

a) Presença de 1 combinação - uniformidade;

b) Presença de 2 ou 3 combinações - menor variabilidade;

c) Presença de 4 ou mais combinações - maior variabilidade;

O resultado final não foi diferente das análises anteriores, com a maioria dos sítios sendo menores que 10 ha e unicomponenciais.

\begin{tabular}{|c|c|}
\hline Combinações & Quantidade (\%) \\
\hline Sítios $<10$ ha + Com TPI + Uni & $269(45,99 \%)$ \\
\hline Sítios $<10$ ha + Com TPI + Multi & $62(10,59 \%)$ \\
\hline Sítios $<10$ ha + Sem TPI + Uni & $169(28,89 \%)$ \\
\hline Sítios $<10$ ha + Sem TPI + Multi & $7(1,19 \%)$ \\
\hline Sítios $>10$ ha + Com TPI + Uni & $49(8,37 \%)$ \\
\hline Sítios $>10$ ha + Com TPI + Multi & $24(4,10 \%)$ \\
\hline Sítios $>$ 10ha + Sem TPI + Uni & $4(0,69 \%)$ \\
\hline Sítios $>$ 10ha + Sem TPI + Multi & $1(0,18 \%)$ \\
\hline TOTAL & 585 \\
\hline
\end{tabular}

Tabela 3.3.4-14: Quantidade de sítios arqueológicos na correlação do tipo de solo, componentes e dimensão.

Apesar de existirem 8 combinações diferentes, somente na área de confluência entre os rios Solimões e Negro (área 1) e na confluência do baixo rio Jamari com Alto rio Madeira (área $\mathrm{G}$ ) obtivemos uma maior variabilidade de combinações (mínimo de 10\% de representação), conforme demonstrado a seguir e no Mapa 3.3.4-4: 


\begin{tabular}{|c|c|}
\hline \multicolumn{2}{|c|}{ Área de confluência Solimões-Negro } \\
\hline Combinação & Quantidade (\%) \\
\hline Sítios $<10$ ha + Com TPI + Uni & $11(17,75 \%)$ \\
\hline Sítios $<10$ ha + Com TPI + Multi & $29(46,77 \%)$ \\
\hline Sítios $<10$ ha + Sem TPI + Uni & $7(11,30 \%)$ \\
\hline Sítios $<10$ ha + Sem TPI + Multi & $3(4,83 \%)$ \\
\hline Sítios $>$ 10ha + Com TPI + Uni & 0 \\
\hline Sítios $>10$ ha + Com TPI + Multi & $12(19,35 \%)$ \\
\hline Sítios $>$ 10ha + Sem TPI + Uni & 0 \\
\hline Sítios $>$ 10ha + Sem TPI + Multi & 0 \\
\hline Total & 62 \\
\hline
\end{tabular}

\begin{tabular}{|c|c|}
\hline \multicolumn{2}{|c|}{ Baixo Jamari e Alto Madeira } \\
\hline Combinação & Quantidade (\%) \\
\hline Sítios $<10$ ha + Com TPI + Uni & $15(41,67 \%)$ \\
\hline Sítios $<10$ ha + Com TPI + Multi & $8(22,23 \%)$ \\
\hline Sítios $<10$ ha + Sem TPI + Uni & $5(13,88 \%)$ \\
\hline Sítios $<10$ ha + Sem TPI + Multi & 0 \\
\hline Sítios $>10$ ha + Com TPI + Uni & $7(19,45 \%)$ \\
\hline Sítios $>10$ ha + Com TPI + Multi & $1(2,77 \%)$ \\
\hline Sítios $>10$ ha + Sem TPI + Uni & 0 \\
\hline Sítios $>$ 10ha + Sem TPI + Multi & 0 \\
\hline Total & 36 \\
\hline
\end{tabular}

Tabela 3.3.4-15: Quantidade de sítios arqueológicos com maior variabilidade na correlação do tipo de solo, componentes e dimensão.

De menor variabilidade temos a representação de três áreas, sendo duas delas com características bem semelhantes, representadas por sítios unicomponenciais, com TPI e maiores ou menores que 10ha.

\begin{tabular}{|c|c|}
\hline \multicolumn{2}{|c|}{ Baixo Tapajós } \\
\hline Combinação & Quantidade (\%) \\
\hline Sítios $<10$ ha + Com TPI + Uni & $46(74,20 \%)$ \\
\hline Sítios $<10$ ha + Com TPI + Multi & 0 \\
\hline Sítios $<10$ ha + Sem TPI + Uni & $3(4,83 \%)$ \\
\hline Sítios $<10$ ha + Sem TPI + Multi & 0 \\
\hline Sítios $>10$ ha + Com TPI + Uni & $12(19,35 \%)$ \\
\hline Sítios $>10$ ha + Com TPI + Multi & $1(1,62 \%)$ \\
\hline Sítios $>10$ ha + Sem TPI + Uni & 0 \\
\hline Sítios $>$ 10ha + Sem TPI + Multi & 0 \\
\hline Total & 62 \\
\hline
\end{tabular}




\begin{tabular}{|c|c|}
\hline \multicolumn{2}{|c|}{ Baixo-Médio Madeira } \\
\hline Combinação & Quantidade (\%) \\
\hline Sítios $<10$ ha + Com TPI + Uni & $17(53,13 \%)$ \\
\hline Sítios $<10$ ha + Com TPI + Multi & $3(9,37 \%)$ \\
\hline Sítios $<10$ ha + Sem TPI + Uni & 0 \\
\hline Sítios $<10$ ha + Sem TPI + Multi & 0 \\
\hline Sítios $>10$ ha + Com TPI + Uni & $10(31,25 \%)$ \\
\hline Sítios $>10$ ha + Com TPI + Multi & $2(6,25 \%)$ \\
\hline Sítios $>10$ ha + Sem TPI + Uni & 0 \\
\hline Sítios $>$ 10ha + Sem TPI + Multi & 0 \\
\hline Total & 32 \\
\hline
\end{tabular}

Tabela 3.3.4-16: Quantidade de sítios arqueológicos com menor variabilidade na correlação do tipo de solo, componentes e dimensão (unicomponenciais, com TPI, maiores ou menores que 10 hectares).

A terceira área, no interflúvio Xingu-Tocantins, na Serra dos Carajás, temos sítios unicomponenciais menores que 10ha, com variações na presença de TPI.

\begin{tabular}{|c|c|}
\hline \multicolumn{2}{|c|}{ Serra dos Carajás } \\
\hline Combinação & Quantidade (\%) \\
\hline Sítios $<10$ ha + Com TPI + Uni & $19(37,25 \%)$ \\
\hline Sítios $<10$ ha + Com TPI + Multi & $1(1,96 \%)$ \\
\hline Sítios $<10$ ha + Sem TPI + Uni & $24(47,05 \%)$ \\
\hline Sítios $<10$ ha + Sem TPI + Multi & $1(1,96 \%)$ \\
\hline Sítios $>10$ ha + Com TPI + Uni & $4(7,85 \%)$ \\
\hline Sítios $>10$ ha + Com TPI + Multi & 0 \\
\hline Sítios $>$ 10ha + Sem TPI + Uni & $2(3,93 \%)$ \\
\hline Sítios $>$ 10ha + Sem TPI + Multi & 0 \\
\hline Total & 51 \\
\hline
\end{tabular}

Tabela 3.3.4-17: Quantidade de sítios arqueológicos com menor variabilidade na correlação do tipo de solo, componentes e dimensão (unicomponenciais, menores que 10 hectares, com ou sem TPI).

De maneira uniforme, assim como nos outros casos, temos a presença majoritária de uma combinação (mais de 10\%) e menor das demais na região dos rios Urubu-Uatumã. O único caso onde ocorreu $100 \%$ de uma mesma combinação foi no Litoral do Salgado, com sítios unicomponenciais, menores que 10 ha e sem TPI $(n=32)$. 


\begin{tabular}{|l|c|}
\hline \multicolumn{2}{|c|}{ Rios Urubu-Uatumã } \\
\hline \multicolumn{1}{|c|}{ Combinação } & Quantidade (\%) \\
\hline Sítios $<10$ ha + Com TPI + Uni & $35(85,37 \%)$ \\
\hline Sítios $<10$ ha + Com TPI + Multi & $4(9,75 \%)$ \\
\hline Sítios $<10 \mathrm{ha}+$ Sem TPI + Uni & 0 \\
\hline Sítios $<10 \mathrm{ha}+$ Sem TPI + Multi & 0 \\
\hline Sítios $>10 \mathrm{ha}+$ Com TPI + Uni & $2(4,88 \%)$ \\
\hline Sítios $>10 \mathrm{ha}+$ Com TPI + Multi & 0 \\
\hline Sítios $>10 \mathrm{ha}+$ Sem TPI + Uni & 0 \\
\hline Sítios $>10 \mathrm{ha}+$ Sem TPI + Multi & 0 \\
\hline Total & 41 \\
\hline
\end{tabular}

Tabela 3.3.4-18: Quantidade de sítios arqueológicos na correlação do tipo de solo, componentes e dimensão (unicomponenciais, menores que 10 hectares e sem TPI).

\subsubsection{Considerações sobre a composição dos sítios}

O sítio arqueológico é a representação material de diferentes atividades ao longo do tempo quando observado em sua totalidade, resultando em dimensões variadas (área), transformações no solo (ausência e presença de TPI) e ocupações (uni ou multicomponentes). A quantificação desses atributos, em escala regional, de forma individual e relacional, permitiu localizar áreas que apresentam uma alta variabilidade de sítios ou uniformidade em suas ocorrências.

Em relação aos atributos utilizados e combinações realizadas é interessante notar que não há, em princípio, uma correlação direta entre tamanho de sítio, presença ou ausência de TPI e componentes em uma escala pan-amazônica. Quando avaliamos na escala macro observamos uma grande variabilidade e que está associada a diferentes fatores, principalmente nos processos históricos que cada local passou. Através das três correlações realizadas (componentes + dimensão; tipo de solo + dimensão; tipo de solo + componentes) e dos parâmetros utilizados (maior ou menor variabilidade e uniformidade) observamos três áreas que são constantes nas três correlações:

- Confluência dos rios Solimões e Negro - Maior Variabilidade;

- Médio e Baixo rio Madeira - Menor Variabilidade;

- Litoral do Salgado - Uniformidade. 


\begin{tabular}{|l|l|l|l|}
\hline \multicolumn{1}{|c|}{ Região } & $\begin{array}{c}\text { Comp. }+ \\
\text { Área }\end{array}$ & $\begin{array}{c}\text { Solo }+ \\
\text { Comp. }\end{array}$ & Solo + Área \\
\hline Confluência Solimões-Negro & & & \\
\hline Baixo rio Jamari & & & \\
\hline Litoral Salgado & & & \\
\hline Médio-Baixo Madeira & & & \\
\hline Baixo Tapajós & & & \\
\hline Baixo rio Urubu-Uatumã & & & \\
\hline Volta Grande do Xingu & & & \\
\hline Rio Teles Pires & & & \\
\hline $\begin{array}{l}\text { Confluência Tocantins- } \\
\text { Araguaia }\end{array}$ & & & \\
\hline Serra dos Carajás & & & \\
\hline Médio-Alto rio Machado & & & \\
\hline Médio-Alto rio Tocantins & & & \\
\hline $\begin{array}{l}\text { Lago Amanã (médio } \\
\text { Solimões) }\end{array}$ & & & \\
\hline Baixo rio Tocantins & & & \\
\hline
\end{tabular}

\begin{tabular}{|l|}
\hline Maior Variabilidade \\
\hline Menor Variabilidade \\
\hline Uniformidade \\
\hline Não há \\
\hline
\end{tabular}

Tabela 3.3.5-1: Regiões com maior e menor variabilidade ou uniformidade, separadas de acordo com o tipo de correlação utilizado.

Com exceção do Litoral do Salgado, a presença de sítios com TPI e maiores que 10ha é constante e majoritário nas duas outras áreas. O aspecto multicomponencial é marcante na área de confluência, menos presente no rio Madeira e inexistente no Litoral do Salgado.

Outro aspecto interessante é a localização dos sítios maiores que 10ha, pois são sítios bem extensos e pouco comuns na amostragem (210 de 1.730 sítios - 12\%). Desse total, os que possuem TPI estão localizados majoritariamente na calha do rio Amazonas e no baixo curso dos seus principais afluentes, com exceção da bacia do rio Madeira que ocorre em toda a sua extensão. Por outro lado, os sítios sem TPI estão, em sua maioria, nos formadores dos principais afluentes do Amazonas (e.g.: alto rio Machado, rio Teles Pires, etc.) e na porção oriental, na fronteira entre o bioma Amazônico e o Cerrado. Refinando essa caracterização, os sítios sem TPI e maiores que 10ha ocorrem como uni 
e multicomponentes (uni $=4$; multi $=1$ ). O único sítio multicomponencial está localizado no médio curso do rio Mearim, no estado do Maranhão, em área de Cerrado.

Em relação aos unicomponenciais existem:

- 2 na Serra dos Carajás (interflúvio entre sub-bacia);

- 1 na confluência dos rios Tocantins e Araguaia (fronteira do bioma Amazônico com o Cerrado);

- 1 na ilha de São Luiz do Maranhão (ambiente insular).

A maior parte dos sítios maiores que 10 hectares possuem TPI, estão localizados nas margens dos grandes rios e dentro do bioma amazônico. Por outro lado, o extenso tamanho, a ausência de TPI e a localização desses quatro sítios o tornam interessantes para compreendermos as diferentes formas e intensidades de ocupar os espaços.

Sobre a correlação das três características que compõem o sítio (área, tipo de solo e quantidade de componentes) na região dos rios Urubu e Uatumã, a presença de sítios unicomponenciais traz um contexto interessante. Estamos em uma área de fronteira cultural entre duas Tradições diferentes, com baixa quantidade de sítios multicomponenciais. Ou seja, é provável que cada grupo estivesse ocupando um local diferente, mantendo seus estilos cerâmicos como uma forma de reforçar sua identidade e espaços.

No baixo rio Tapajós e no médio-baixo rio Madeira há poucos sítios multicomponenciais, com predominância de sítios unicomponenciais com TPI e variando somente o seu tamanho. Por outro lado, na Serra dos Carajás, local de interflúvio entre duas grandes bacias (Xingu e Tocantins), a predominância são de sítios unicomponenciais, menores que 10ha, sem TPI.

Em relação a área com maior variabilidade, temos a região de confluência dos rios Solimões-Negro e o baixo rio Jamari com o alto rio Madeira. Apesar de ainda não termos correlacionado com a cronologia de cada sítio arqueológico, podemos inferir que essas duas regiões foram intensamente ocupadas, por diferentes culturas cerâmicas, formando extensos locais antropizados com mais de 10ha. Da mesma maneira, essas duas regiões sempre tiveram grande importância nas hipóteses sobre a origem e expansão de grupos linguísticos e estilos cerâmicos (LATHRAP, 1970; BROCHADO \& LATHRAP, 1982; MILLER, 1992; HECKENBERGER, NEVES \& PETERSEN, 1998; MORAES \& NEVES, 2012; NEVES, 2012; ZUSE, 2014; ALMEIDA, 2013, 2016). 
Independente das hipóteses, que já foram testadas, não podemos ignorar que essa variabilidade de sítios arqueológicos, principalmente na área de confluência, demonstra uma persistência em reocupar os locais, independente do grupo cultural e de sua relação com os demais grupos. Não é à toa, que em torno do ano $1.000 \mathrm{DC}$, temos a construção de valas defensivas e o aparecimento de um novo componente cultural na área de confluência Solimões-Negro, substituindo o anterior de forma abrupta (MORAES \& NEVES, 2012).

\subsection{As Tradicõos Cerâmicas na Amazônia}

\subsubsection{Localização e Quantificação}

As Tradições cerâmicas, como detalhado no capítulo 1, representam um conjunto de elementos estilísticos associados a diferentes contextos deposicionais e paisagísticos. Podem estar vinculados a questões linguísticas e/ou de regionalidades, passando por uniformização ou variação ao longo do tempo e da sua localização (fases cerâmicas).

Dos 6.511 sítios arqueológicos, 810 possuem informações das Tradições cerâmicas que estão presentes nos sítios, representando $12,44 \%$ do total. Foram identificadas 8 Tradições presentes, sendo a TPA $(n=341)$ e a TIP $(n=261)$ com maior representatividade.

\begin{tabular}{|c|c|}
\hline Tradição & Quantidade (\%) \\
\hline Polícroma da Amazônia (TPA) & $341(42,09 \%)$ \\
\hline Inciso-Ponteada (TIP) & $261(32,22 \%)$ \\
\hline Borda Incisa (TBI) & $176(21,72 \%)$ \\
\hline Tupinambá da Amazônia (STA) & $118(14,56 \%)$ \\
\hline Mina (TM) & $55(6,79 \%)$ \\
\hline Saracá (TRS) & $26(3,20 \%)$ \\
\hline Pocó-Açutuba (TP-A) & $21(2,59 \%)$ \\
\hline Quinari (TQ) & $9(1,11 \%)$ \\
\hline
\end{tabular}

Tabela 3.4.1-1: Quantidade de sítios arqueológicos, separados por Tradições, utilizados nas análises.

Com base nas informações sobre a presença dessas Tradições e da localização desses sítios foi elaborado um mapa para cada uma das Tradições, com um raio de $30 \mathrm{~km}$ em torno de cada sítio (Mapa 3.4.1-1 até 3.4.1-8). A ideia é ilustrar e extrapolar uma possível área de atuação (caça, pesca, extrativismo, comércio, etc.) para cada sítio 
arqueológico. Estou ciente que cada local pode ter diferentes funcionalidades em diferentes períodos e, portanto, tamanhos de atuação diferentes. Mas como não temos essas informações até o momento, optou-se por padronizar essa simulação e ver em que áreas essas diferentes Tradições se distanciam ou entrecruzam. Da mesma maneira, para uma melhor caracterização de cada Tradição, os dados serão cruzados com as correlações realizadas anteriormente (tamanho de sítios, TPI e componentes).

A TPA (Mapa 3.4.1-1) é a mais representativa da amostra e está dispersa, principalmente, no eixo oeste-leste do rio Solimões-Amazonas e partes da região litorânea do Amapá, havendo apenas um "hiato" entre a região dos rios Urubu-Uatumã e a foz do rio Xingu. Para o cruzamento dos dados com as combinações a amostra ficou reduzida a 156 sítios.

\begin{tabular}{|c|c|}
\hline \multicolumn{2}{|c|}{ T. Polícroma da Amazônia } \\
\hline Combinações & Quantidade (\%) \\
\hline Sítios $<10$ ha + TPI + Uni & $42(26,92 \%)$ \\
\hline Sítios $<10$ ha + TPI + Multi & $37(23,72 \%)$ \\
\hline Sítios $<10$ ha + Sem TPI + Uni & $48(30,77 \%)$ \\
\hline Sítios $<10$ ha + Sem TPI + Multi & $2(1,28 \%)$ \\
\hline Sítios $>10$ ha + TPI + Uni & $10(6,41 \%)$ \\
\hline Sítios $>$ 10ha + TPI + Multi & $17(10,90 \%)$ \\
\hline Sítios $>10$ ha + Sem TPI + Uni & 0 \\
\hline Sítios $>10$ ha + Sem TPI + Multi & 0 \\
\hline Total & 156 \\
\hline
\end{tabular}

Tabela 3.4.1-2: Quantidade de sítios arqueológicos associados à TPA de acordo com as correlações dimensão, tipo de solo e componentes.

Da amostragem total da TPA, 260 sítios estão localizados na parte ocidental (continental) e 81 na parte oriental (litorânea). Se utilizarmos as combinações para a TPA $(\mathrm{n}=156)$ teremos 48 no oriente e 108 no ocidente. 


\begin{tabular}{|l|c|}
\hline \multicolumn{2}{|c|}{ T. Polícroma da Amazônia (oriental) } \\
\hline \multicolumn{1}{|c|}{ Combinações } & Quantidade (\%) \\
\hline Sítios $<10 \mathrm{ha}+$ TPI + Uni & $9(18,75 \%)$ \\
\hline Sítios $<10 \mathrm{ha}+$ TPI + Multi & 0 \\
\hline Sítios $<10 \mathrm{ha}+$ Sem TPI + Uni & $39(81,25 \%)$ \\
\hline Sítios $<10 \mathrm{ha}+$ Sem TPI + Multi & 0 \\
\hline Sítios $>10 \mathrm{ha}+$ TPI + Uni & 0 \\
\hline Sítios $>10 \mathrm{ha}+$ TPI + Multi & 0 \\
\hline Sítios $>10 \mathrm{ha}+$ Sem TPI + Uni & 0 \\
\hline Sítios $>10 \mathrm{ha}+$ Sem TPI + Multi & 0 \\
\hline Total & $\mathbf{4 8}$ \\
\hline
\end{tabular}

\begin{tabular}{|c|c|}
\hline \multicolumn{2}{|c|}{ T. Polícroma da Amazônia (ocidental) } \\
\hline Combinações & Quantidade (\%) \\
\hline Sítios $<10$ ha + TPI + Uni & $33(30,56 \%)$ \\
\hline Sítios $<10$ ha + TPI + Multi & $37(34,25 \%)$ \\
\hline Sítios $<10$ ha + Sem TPI + Uni & $9(8,34 \%)$ \\
\hline Sítios $<10$ ha + Sem TPI + Multi & $2(1,85 \%)$ \\
\hline Sítios $>10$ ha + TPI + Uni & $10(9,25 \%)$ \\
\hline Sítios $>10$ ha + TPI + Multi & $17(15,75 \%)$ \\
\hline Sítios $>10$ ha + Sem TPI + Uni & 0 \\
\hline Sítios $>10 \mathrm{ha}+$ Sem TPI + Multi & 0 \\
\hline Total & 108 \\
\hline
\end{tabular}

Tabela 3.4.1-3: Quantidade de sítios arqueológicos associados à TPA de acordo com as correlações dimensão, tipo de solo e componentes, divididos entre oriental e ocidental.

A parte ocidental possui uma variabilidade muito maior de sítios com representação majoritária de sítios menores que 10ha e com presença de TPI. Apesar da grande quantidade de sítios identificados, a maior parte dos locais escavados estão em contexto multicomponencial, o que dificulta uma melhor caracterização dos assentamentos. De toda forma, a TPA em sítios multicomponenciais $(n=56)$ ocorre junto com TBI, TIP, TP-A, TRS e contextos pré-cerâmicos do início do Holoceno localizados na área de confluência dos rios Solimões-Negro (COSTA, 2009).

Por outro lado, a porção oriental possui baixa variabilidade e com presença de sítios menores que 10 ha, sem TPI e unicomponencial $(81,25 \%)$. Se adicionarmos características como a presença de tesos e lagoas artificiais (Marajó), Megalitos (Oiapoque - norte do Amapá) e poços funerários selados por laterita (Estuário Amazônico - sul do Amapá), esses aspectos podem auxiliar numa melhor caracterização dessa área oriental, permitindo a divisão da TPA nos dois blocos (oriental e ocidental). Assim como 
outros arqueólogos (HECKENBERGER \& NEVES, 2009; BARRETO, 2009; NEVES, 2012; ALMEIDA, 2013), acredito que a TPA presente na região litorânea deveria ser reavaliada e separada da TPA que ocorre na Amazônia ocidental, por conta dos contextos arqueológicos em que se encontram e do seu estilo possuir elementos que não ocorrem rio acima. Os atributos cerâmicos não serão discutidos aqui, mas as características contextuais dos sítios, conforme apresentado acima, já deixam claro a necessidade de uma divisão classificatória no nível das Tradições.

A $\underline{\text { TIP }}$ (Mapa 3.4.1-2) também está dispersa no eixo leste-oeste do rio Amazonas e no baixo curso dos seus afluentes. A leste está na foz do Amazonas e a oeste próximo a Manaus e no baixo rio Madeira. Dos 261 sítios dessa Tradição, quase 40\% (n=103) é representada por sítios unicomponenciais da cultura Santarém, na foz do rio Tapajós. No cruzamento das informações, a amostragem ficou reduzida para 136 sítios, conforme demonstrada na tabela abaixo.

\begin{tabular}{|c|c|}
\hline \multicolumn{2}{|c|}{ T. Inciso-Ponteada } \\
\hline Combinações & Quantidade (\%) \\
\hline Sítios $<10$ ha + TPI + Uni & $92(67,65 \%)$ \\
\hline Sítios $<10$ ha + TPI + Multi & $10(7,35 \%)$ \\
\hline Sítios $<10$ ha + Sem TPI + Uni & $11(8,08 \%)$ \\
\hline Sítios $<10$ ha + Sem TPI + Multi & $1(0,73 \%)$ \\
\hline Sítios $>10$ ha + TPI + Uni & $18(13,24 \%)$ \\
\hline Sítios $>10$ ha + TPI + Multi & $4(2,95 \%)$ \\
\hline Sítios $>10$ ha + Sem TPI + Uni & 0 \\
\hline Sítios $>10$ ha + Sem TPI + Multi & 0 \\
\hline Total & 136 \\
\hline
\end{tabular}

Tabela 3.4.1-4: Quantidade de sítios arqueológicos associados à TIP de acordo com as correlações dimensão, tipo de solo e componentes.

A grande maioria dos sítios é caracterizada por ser unicomponencial com presença de TPI. Os multicomponenciais $(n=15)$ estão relacionados com vestígios da TPA, TBI, TP-A e STA.

A TBI (Mapa 3.4.1-3), apesar de menos numerosa que as duas anteriores e estar estratigraficamente abaixo das mesmas, possui uma grande amplitude de dispersão. Sua maior concentração está localizada na área de confluência entre os rios Solimões-NegroMadeira, mas possui evidências no alto rio Madeira, médio rio Solimões e Negro, baixo rio Tapajós, foz do rio Amazonas, alto rio Xingu, Serra dos Carajás e médio rio Mearim. Para a correlação com as combinações a amostra utilizada foi de 94 sítios. 


\begin{tabular}{|c|c|}
\hline \multicolumn{2}{|c|}{ T. Borda Incisa } \\
\hline Combinações & Quantidade (\%) \\
\hline Sítios $<$ 10ha + TPI + Uni & $21(22,35 \%)$ \\
\hline Sítios $<10$ ha + TPI + Multi & $39(41,49 \%)$ \\
\hline Sítios $<10$ ha + Sem TPI + Uni & $6(6,39 \%)$ \\
\hline Sítios $<10$ ha + Sem TPI + Multi & $2(2,12 \%)$ \\
\hline Sítios $>$ 10ha + TPI + Uni & $9(9,57 \%)$ \\
\hline Sítios $>10$ ha + TPI + Multi & $16(17,02 \%)$ \\
\hline Sítios $>$ 10ha + Sem TPI + Uni & 0 \\
\hline Sítios $>$ 10ha + Sem TPI + Multi & $1(1,06 \%)$ \\
\hline Total & 94 \\
\hline
\end{tabular}

Tabela 3.4.1-5: Quantidade de sítios arqueológicos associados à TBI de acordo com as correlações dimensão, tipo de solo e componentes.

A maioria dos sítios TBI são multicomponenciais $(n=58)$ e se sobrepõem, principalmente, algumas áreas de ocorrência da TIP e TPA. Por ser uma ocupação "mais antiga" em relação a essas duas, alguns assentamentos TBI foram transformados ou reocupados por essas duas Tradições. Como já foi citado anteriormente, há evidências dessas transições de forma gradual (médio Solimões) e abrupta (área de confluência Solimões-Negro).

Suas ocupações antropizaram de forma intensa o ambiente, pois é nesse período em que temos as maiores extensões e profundidade de TPI. Essas transformações na paisagem, relacionado ao uso e manejo dos recursos naturais, podem ter favorecido a sua incorporação em novas redes de relações ou tornado o local mais atraente para que grupos exógenos o reocupassem. Os sítios multicomponenciais TBI estão associados às TPA, TIP, TP-A, TRS, STA e contextos pré-cerâmicos.

A $\underline{\text { STA }}$ (Mapa 3.4.1-4) está dispersa no leste-sudeste da Amazônia Legal, abrangendo o bioma Amazônico e de Cerrado, no baixo rio Xingu, em vários trechos do rio Tocantins e Araguaia, Serra dos Carajás e na Ilha de São Luís. A maior concentração dos sítios está localizada na Serra dos Carajás (interflúvio Xingu-Tocantins), seguido do baixo rio Tocantins nas imediações da Cachoeira de Tucuruí. Para a análise com as combinações a amostral total foi de 97 sítios. 


\begin{tabular}{|c|c|}
\hline \multicolumn{2}{|c|}{ S. Tupinambá da Amazônia } \\
\hline Combinações & Quantidade (\%) \\
\hline Sítios $<$ 10ha + TPI + Uni & $55(56,70 \%)$ \\
\hline Sítios $<10$ ha + TPI + Multi & $2(2,06 \%)$ \\
\hline Sítios $<10$ ha + Sem TPI + Uni & $30(30,93 \%)$ \\
\hline Sítios $<10$ ha + Sem TPI + Multi & $1(1,03 \%)$ \\
\hline Sítios $>10$ ha + TPI + Uni & $5(5,15 \%)$ \\
\hline Sítios $>10$ ha + TPI + Multi & 0 \\
\hline Sítios $>10$ ha + Sem TPI + Uni & $4(4,13 \%)$ \\
\hline Sítios $>$ 10ha + Sem TPI + Multi & 0 \\
\hline Total & 97 \\
\hline
\end{tabular}

Tabela 3.4.1-6: Quantidade de sítios arqueológicos associados à STA de acordo com as correlações dimensão, tipo de solo e componentes.

Apesar da antiguidade das ocupações da STA, iniciadas no século III DC (ALMEIDA \& NEVES, 2015), é interessante notar que os locais ocupados por esses grupos não se sobrepõem de outras populações ceramistas, demonstrado pela existência de 94 sítios unicomponenciais, tanto com TPI como sem. Há somente 3 sítios multicomponenciais, sendo 2 na Serra dos Carajás e 1 na Ilha de São Luís. Nesses 3 casos cada um se sobrepôs a uma Tradição diferente: TIP, TBI e TM. Ao que tudo indica, os dados corroboram o sudeste amazônico como área de dispersão da STA (Op. Cit.).

A TM (Mapa 3.4.1-5) está associada, principalmente, aos contextos sambaquieiros do baixo Amazonas e costa litorânea amazônica. Sua presença é registrada desde o baixo rio Xingu até a Ilha de São Luís, mas sua maior concentração está no Litoral do Salgado, no Pará. É considerada uma das cerâmicas mais antigas da Amazônia, depois da cerâmica de Taperinha, com uma cronologia que se estende até o segundo milênio DC (BANDEIRA, 2016). Foram utilizados 38 sítios para as análises com as combinações. 


\begin{tabular}{|c|c|}
\hline \multicolumn{2}{|c|}{ T. Mina } \\
\hline Combinações & Quantidade (\%) \\
\hline Sítios $<$ 10ha + TPI + Uni & $5(13,15 \%)$ \\
\hline Sítios $<10$ ha + TPI + Multi & $1(2,63 \%)$ \\
\hline Sítios $<10$ ha + Sem TPI + Uni & $32(84,22 \%)$ \\
\hline Sítios $<10$ ha + Sem TPI + Multi & 0 \\
\hline Sítios $>10$ ha + TPI + Uni & 0 \\
\hline Sítios $>10$ ha + TPI + Multi & 0 \\
\hline Sítios $>10$ ha + Sem TPI + Uni & 0 \\
\hline Sítios $>10$ ha + Sem TPI + Multi & 0 \\
\hline Total & 38 \\
\hline
\end{tabular}

Tabela 3.4.1-7: Quantidade de sítios arqueológicos associados à TM de acordo com as correlações dimensão, tipo de solo e componentes.

As combinações são bem localizadas e possuem pouca variação local. Os sambaquis unicomponenciais sem TPI estão todos localizados no Litoral do Salgado, enquanto que o único multicomponencial (TM e STA) está na Ilha de São Luís, assim como os sítios com TPI.

A TRS (Mapa 3.4.1-6) é uma manifestação regional, localizada na região dos rios Urubu-Uatumã, e um possível correlato da fronteira cultural existente entre a expansão da TPA (oeste) e a TIP (leste) (LIMA, 2013). Para a análise foram utilizados 25 sítios, sendo que somente um único sítio ficou de fora por ser de gravura rupestre (BASSI \& CAVALLINI, 2015).

\begin{tabular}{|c|c|}
\hline \multicolumn{2}{|c|}{ T. Regional Saracá } \\
\hline Combinações & Quantidade (\%) \\
\hline Sítios $<$ 10ha + TPI + Uni & $18(72 \%)$ \\
\hline Sítios $<10$ ha + TPI + Multi & $4(16 \%)$ \\
\hline Sítios $<10$ ha + Sem TPI + Uni & 0 \\
\hline Sítios $<10$ ha + Sem TPI + Multi & 0 \\
\hline Sítios $>$ 10ha + TPI + Uni & $2(8 \%)$ \\
\hline Sítios $>10$ ha + TPI + Multi & $1(4 \%)$ \\
\hline Sítios $>10$ ha + Sem TPI + Uni & 0 \\
\hline Sítios $>$ 10ha + Sem TPI + Multi & 0 \\
\hline Total & 25 \\
\hline
\end{tabular}

Tabela 3.4.1-8: Quantidade de sítios arqueológicos associados à TRS de acordo com as correlações dimensão, tipo de solo e componentes. 
Há pouca variabilidade na ocorrência dos sítios, sendo a maioria unicomponencial com TPI. Os poucos multicomponenciais $(n=5)$ ocorrem com vestígios da TPA, TBI e TP-A.

A TP-A (Mapa 3.4.1-7) é uma das primeiras manifestações visíveis de antropização da paisagem, através da formação de TPI, e da expansão de um estilo cerâmico por várias regiões da Amazônia (NEVES et al., 2014). Sítios com seus vestígios são encontrados desde o médio Solimões (oeste) até o baixo rio Xingu (leste) e do médio rio negro (norte) até o alto rio Madeira (sul). Se considerarmos sua vinculação com a série Saladóide, sua ocorrência se expande para a foz do rio Orinoco, litoral guianense e o Caribe (Op. Cit.). Apesar da sua antiguidade, há contextos com datas que chegam até 600 DC (NEVES et al., 2014). Nas análises foram utilizados 15 sítios arqueológicos.

\begin{tabular}{|c|c|}
\hline \multicolumn{2}{|c|}{ T. Pocó-Açutuba } \\
\hline Combinações & Quantidade (\%) \\
\hline Sítios $<10$ ha + TPI + Uni & 0 \\
\hline Sítios $<10$ ha + TPI + Multi & $6(40 \%)$ \\
\hline Sítios $<10$ ha + Sem TPI + Uni & $1(6,67 \%)$ \\
\hline Sítios $<10$ ha + Sem TPI + Multi & 0 \\
\hline Sítios $>$ 10ha + TPI + Uni & 0 \\
\hline Sítios $>10$ ha + TPI + Multi & $8(53,33)$ \\
\hline Sítios $>10$ ha + Sem TPI + Uni & 0 \\
\hline Sítios $>10$ ha + Sem TPI + Multi & 0 \\
\hline Total & 15 \\
\hline
\end{tabular}

Tabela 3.4.1-9: Quantidade de sítios arqueológicos associados à TP-A de acordo com as correlações dimensão, tipo de solo e componentes.

Por se tratar de ocupações mais antigas e, na maior parte dos casos, a primeira de muitos sítios arqueológicos, sua identificação e mapeamento da dispersão dos vestígios intra-sítio ficam comprometidas. No entanto, assim como a TBI, os sítios tendem a ser multicomponenciais e ocorrem com a TBI, TPA, TIP e TRS.

A TQ (Mapa 3.4.1-8) está associada aos contextos dos geoglifos acreanos, no sudoeste amazônico, mas há poucos estudos sobre os seus vestígios cerâmicos. Sua dispersão foi estimada para toda a região do alto rio Purus e Juruá (DIAS, 2006), mas até o momento as pesquisas focaram mais nos geoglifos em si, enquanto estruturas artificiais, do que nos vestígios cerâmicos. A partir da bibliografia foram utilizados somente os sítios em que os pesquisadores vincularam os vestígios e seus contextos à TQ, ou seja, apesar de existirem mais de 400 geoglifos no banco de dados, somente 9 são identificados como 
pertencentes à TQ. Esses estão localizados no interflúvio do rio Abunã, afluente do rio Madeira, e dos rios Iquiri e Acre, afluentes do rio Purus. Para a análise a amostra ficou reduzida a 5 sítios, todos menores que 10ha, unicomponenciais e sem TPI.

\subsubsection{Sobreposições espaciais}

Independente do período analisado é evidente que cada Tradição possui uma área de ocorrência contínua ou segmentada, muitas vezes se sobrepondo às outras ou formando fronteiras, resultando na formação de novos estilos cerâmicos. As Tradições Borda Incisa, Polícroma da Amazônia, Inciso-Ponteada e, em menor representatividade, a PocóAçutuba são as que possuem maior dispersão pela Amazônia. Da mesma maneira, essas Tradições são as mais expressivas do eixo Solimões-Amazonas (leste-oeste), ocupando a principal e maior via de trânsito e comunicação entre diferentes regiões.

Se expormos todas as Tradições analisadas anteriormente em um mesmo mapa (Mapa 3.4.2-1) veremos que algumas áreas são dominadas unicamente por uma única Tradição (e.g.: TQ no sudoeste amazônico e TM no Litoral do Salgado), mas em sua maioria há ocorrência de mais de uma Tradição na mesma região, como o baixo curso dos principais afluentes do Amazonas (e.g.: baixo rio Tapajós, baixo rio Xingu, etc.). O resultado exibido no mapa é semelhante daqueles apresentados em Barreto, Lima e Betancourt (2016), onde as autoras compilam e apresentam em um mapa todos os dados publicados no livro, apesar das extrapolações dos limites de cada ocorrência (Mapa 3.4.22).

No entanto, nada se compara a região de confluência dos rios Solimões-NegroMadeira-Amazonas, incluso o baixo curso dos rios Solimões, Negro e Madeira, abrangendo uma área aproximada de $140 \mathrm{mil} \mathrm{km}^{2}$. Essa área possui 245 sítios arqueológicos e a presença de 5 Tradições: TP-A, TBI, TIP, TPA e TRS, sendo a TPA $(n=149)$ e a TBI ( $n=130)$ com maior número de ocorrências por sítio. 


\begin{tabular}{|l|c|c|c|}
\hline \multicolumn{4}{|c|}{ Área de confluência dos rios Solimões-Negro-Madeira- } \\
Amazonas \\
\hline Tradição & Multicomponencial & Unicomponencial & Total \\
\hline TP-A & 9 & 1 & 10 \\
\hline TRS & 6 & 20 & 26 \\
\hline TIP & 11 & 22 & 33 \\
\hline TBI & 88 & 42 & 130 \\
\hline TPA & 83 & 66 & 149 \\
\hline
\end{tabular}

Tabela 3.4.2-1: Quantidade de sítios arqueológicos conforme a Tradição e quantidade componentes na área de confluência dos rios Solimões-Negro-Madeira-Amazonas.

Em relação à quantidade e quais componentes ocorrem por sítio, a TP-A é a que possui menos contextos unicomponenciais, podendo estar atrelado ao fato de ser uma das ocupações ceramistas mais antigas da região e, por consequência, com registros mais discretos que as ocupações tardias, dificultando sua localização. A tabela abaixo demonstra todas as combinações de ocorrências das Tradições, em sítios multicomponenciais, da área de confluências dos rios Solimões-Negro-MadeiraAmazonas.

\begin{tabular}{|c|c|}
\hline Combinação & Total \\
\hline TPA + TBI & 71 \\
\hline TIP + TBI & 5 \\
\hline TPA + TIP & 4 \\
\hline TPA + TRS & 1 \\
\hline TBI + TRS & 4 \\
\hline TIP + TP-A & 1 \\
\hline TP-A + TRS & 1 \\
\hline TPA + TBI + TP-A & 6 \\
\hline TBI + TP-A & 1 \\
\hline TPA + TBI + TIP & 1 \\
\hline Total & $\mathbf{9 5}$ \\
\hline
\end{tabular}

Tabela 3.4.2-2: Combinações de Tradições para os sítios multicomponencias da área de confluência dos rios Solimões-Negro-Madeira-Amazonas.

A área de confluência é caracterizada por sítios, majoritariamente, com ocupações TPA sobrepondo as da TBI. Como já foi dito, nesse caso específico os dados parecem indicar um momento de reocupações através da guerra. Por outro lado, a TIP e a TRS deram preferência para locais que, a princípio, não possuíam ocupações anteriores ou que deixaram pouco/nenhum registro material de sua presença. Esse resultado será melhor discutido no capítulo seguinte. 
No entorno da área de confluência, em linhas gerais, temos a TIP sobrepondo ocupações da TP-A (leste) e a TPA sobrepondo ocupações da TBI (oeste e sudoeste).

A STA também ocorre em contextos multicomponenciais na parte sul e leste da Amazônia. No rio Xingu e no interflúvio Xingu-Tocantins foram encontrados vestígios da STA sobrepondo ocupações da TIP. Na Ilha de São Luís há um único sítio (sambaqui) da TM com material da STA.

Nesse estudo, com exceção da TRS, não foram consideradas outras Tradições regionais, como aquelas definidas por Simões e colegas (Simões et al., 1987) devido à sua baixa representatividade em escala espacial e quantitativa. Isso não tira a sua importância dentro do quadro de ocupações da Amazônia e caso tivessem sido inclusas, teríamos um panorama muito mais diversificado e com mais sobreposições.

\section{$\underline{3.5 \text { Cronologia }}$}

\subsubsection{Caracterização geral}

As informações cronológicas foram obtidas através de 755 datações radiocarbônicas, correspondendo a 189 sítios arqueológicos e abrangendo um período que vai de 11.500 AC até 1.870 DC. Para uma melhor visualização da concentração dessas datações, em uma escala temporal, foi realizada uma média aritmética para cada data (média = data calibrada mínima + data calibrada máxima / 2) e quantificada em escala de mil anos, conforme demonstrado a seguir e no mapa 3.5.1-1.

\begin{tabular}{|c|c|c|}
\hline $\begin{array}{c}\text { Período } \\
\text { (AC/DC) }\end{array}$ & Datações & Sítios \\
\hline $\mathbf{1 2 k}-\mathbf{1 1 k}$ & 2 & 1 \\
\hline $\mathbf{1 1 k}-\mathbf{1 0 k}$ & 33 & 1 \\
\hline $\mathbf{1 0 k}-\mathbf{9 k}$ & 21 & 1 \\
\hline $\mathbf{9 k}-\mathbf{8 k}$ & 4 & 4 \\
\hline $\mathbf{8 k}-\mathbf{7 k}$ & 14 & 10 \\
\hline $\mathbf{7 k}-\mathbf{6 k}$ & 17 & 10 \\
\hline $\mathbf{6 k}-\mathbf{5 k}$ & 15 & 5 \\
\hline
\end{tabular}

\begin{tabular}{|c|c|c|}
\hline $\begin{array}{c}\text { Período } \\
\text { (AC/DC) }\end{array}$ & Datações & Sítios \\
\hline $\mathbf{5 k}-\mathbf{4 k}$ & 10 & 9 \\
\hline $\mathbf{4 k}-\mathbf{3 k}$ & 16 & 8 \\
\hline $\mathbf{3 k}-\mathbf{2 k}$ & 12 & 16 \\
\hline $\mathbf{2 k}-\mathbf{1 k}$ & 29 & 21 \\
\hline $\mathbf{1 k}-\mathbf{0}$ & 44 & 32 \\
\hline $\mathbf{0}-\mathbf{1 k}$ & 216 & 82 \\
\hline $\mathbf{1 k}-\mathbf{2 k}$ & 315 & 118 \\
\hline
\end{tabular}

Tabela 3.5.1-1: Quantidade de sítios e datações divididos por intervalos de 1000 anos. 


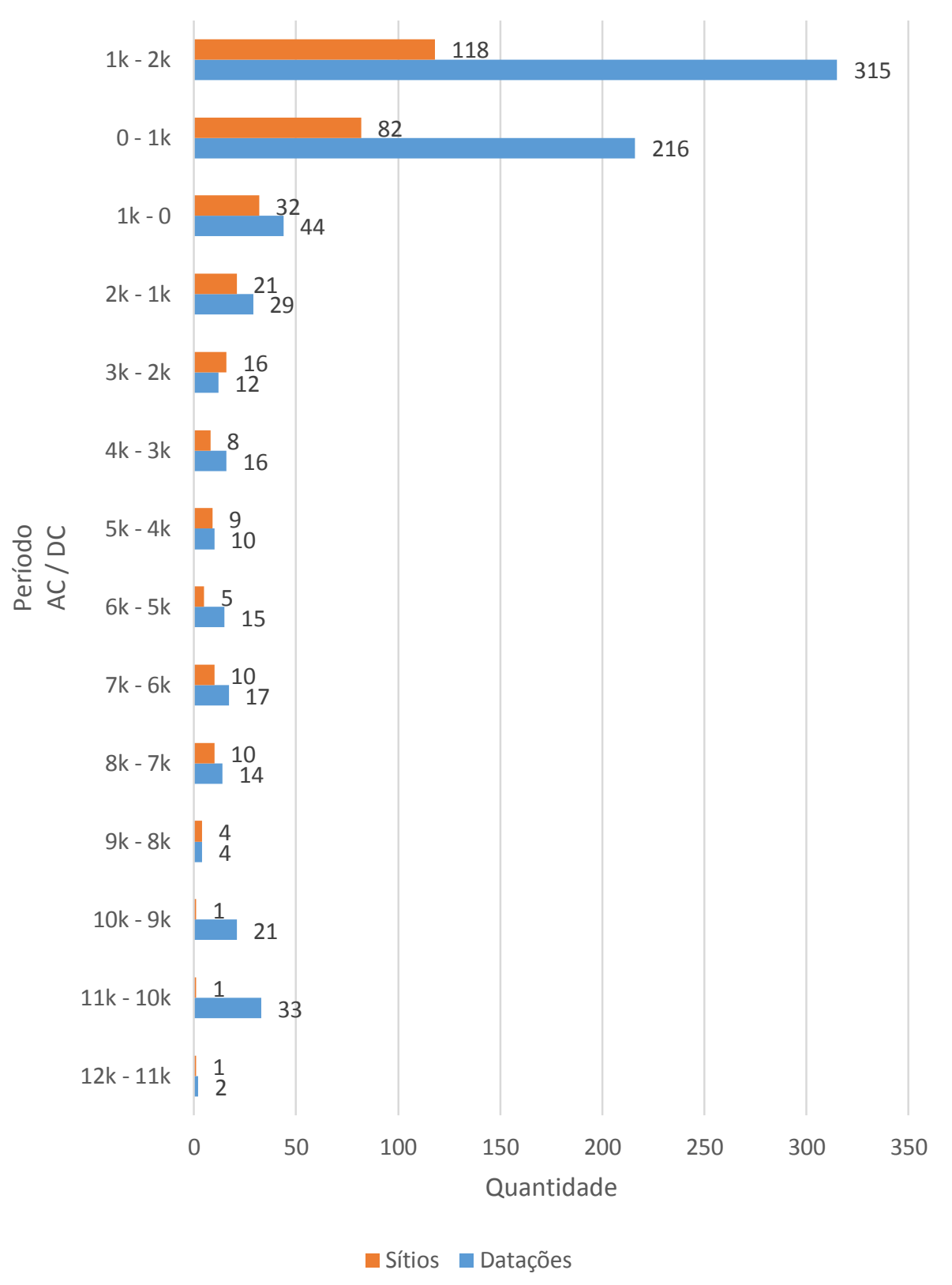

Gráfico 3.5.1-1: Quantidade de sítios arqueológicos e datações divididas por intervalos de mil anos. 
Na distribuição dessas informações em uma escala espacial, averiguou-se que 535 datas de 111 sítios estão concentradas em 7 diferentes áreas (áreas 1, 2, 3, 6, B, C e G), conforme demonstrado no mapa 3.5.1-2 e na tabela abaixo. As demais datações estão dispersas pela Amazônia Legal, com pequenas concentrações no Litoral do Salgado e na Ilha de São Luís do Maranhão.

\begin{tabular}{|c|c|c|}
\hline Área & Total Datas & Total Sítios \\
\hline Área 1 & 111 & 13 \\
\hline Área 2 & 162 & 20 \\
\hline Área 3 & 51 & 10 \\
\hline Área 6 & 25 & 7 \\
\hline Área B & 40 & 8 \\
\hline Área C & 112 & 38 \\
\hline Área G & 34 & 15 \\
\hline TOTAL & $\mathbf{5 3 5}$ & $\mathbf{1 1 1}$ \\
\hline
\end{tabular}

Tabela 3.5.1-2: Quantidade de sítios e datações divididos nas áreas de maior e menor concentração.

Para a quantificação dessas datações, e dos respectivos sítios, foi utilizado todo o período da datação calibrada em 2 sigma (e.g.: 770 à $880 \mathrm{DC}=$ período de 110 anos), utilizando intervalos de 200 anos para a contabilização (Tabela 3.5.1-3). Se olharmos para o primeiro e segundo milênio DC $(0-1.600 \mathrm{DC})$, observamos que o recorte cronológico proposto nessa pesquisa $(600-1.400$ DC) é o período de maior visibilidade no registro arqueológico, seja pela quantidade de sítios ou pela quantidade de datações realizadas. 


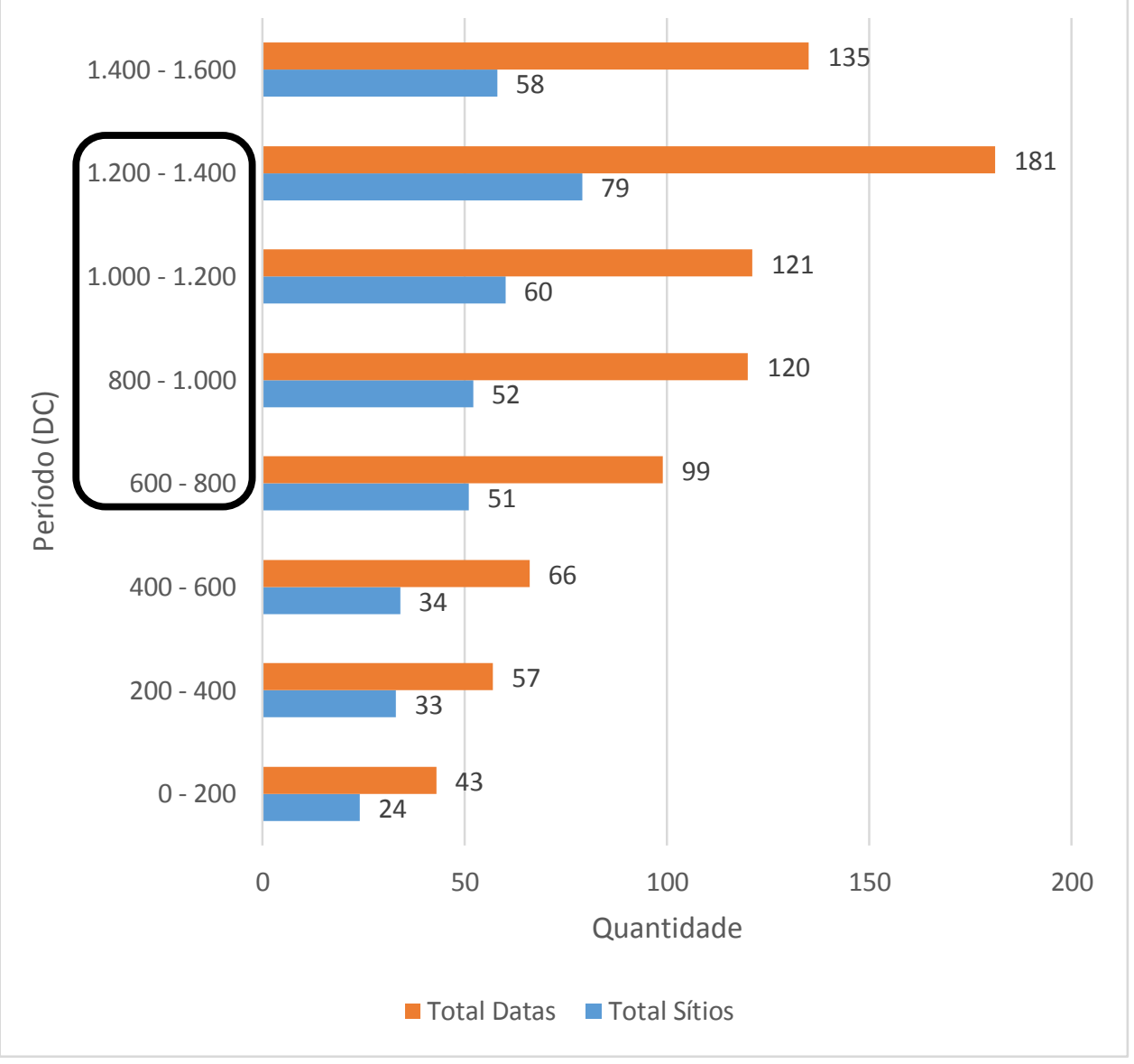

Gráfico 3.5.1-2: Quantidade de sítios e datações do primeiro e segundo milênio DC, divididos em intervalos de 200 anos. Destaque para o período entre 600 e 1.400 DC.

\begin{tabular}{|c|c|c|}
\hline Período (DC) & Total Sítios & Total Datas \\
\hline $0-200$ & 24 & 43 \\
\hline $200-400$ & 33 & 57 \\
\hline $400-600$ & 34 & 66 \\
\hline $600-800$ & 51 & 99 \\
\hline $800-1.000$ & 52 & 120 \\
\hline $1.000-1.200$ & 60 & 121 \\
\hline $1.200-1.400$ & 79 & 181 \\
\hline $1.400-1.600$ & 58 & 135 \\
\hline
\end{tabular}

Tabela 3.5.1-3: Quantidade de sítios e datações do primeiro e segundo milênio DC, divididos em intervalos de 200 anos.

Essa maior visibilidade do registro arqueológico também nos indica o período de maior crescimento, adensamento e expansão dos diferentes grupos humanos pela Amazônia. Com um período inicial e gradativo (600 - 1.00 DC), auge (1.000 - 1.400 DC) e o colapso populacional com a colonização europeia (1.492 em diante). 


\subsubsection{Tradições e cronologia}

Para o intervalo entre 600 e 1.400 DC foram utilizadas somente as datações que possuíam clara associação com as camadas culturais (Tradições), resultando em uma amostra de 337 datas que envolvem 118 sítios arqueológicos (Mapa 3.5.1-3 e Tabela 3.5.2-1) e as 8 Tradições cerâmicas, conforme demonstrado no gráfico 3.5.2. Para a espacialização das informações cronológicas foram gerados 4 mapas (Mapas 3.5.2-1 a 3.5.2-4) mantendo os intervalos de 200 anos.

\begin{tabular}{|c|c|c|}
\hline Período (DC) & Sítios & Datas \\
\hline $600-800$ & 51 & 99 \\
\hline $800-1.000$ & 52 & 120 \\
\hline $1.000-1.200$ & 60 & 121 \\
\hline $1.200-1.400$ & 79 & 181 \\
\hline
\end{tabular}

Tabela 3.5.2-1: Quantidade de sítios e datações entre 600 e 1.400 DC, divididos em intervalos de 200 anos.

É interessante notar como as ocorrências de algumas Tradições vão diminuindo ao longo do tempo, enquanto outras se tornam majoritárias em relação as outras. Se em um primeiro momento (600-800 DC) temos a dominância da TBI, essa se mantém presente até o último período (1.200-1.400 DC) em vários pontos da Amazônia, competindo com a rápida ascensão da TIP a leste e da TPA a oeste, que reocupam parte de suas áreas e formam uma fronteira cultural, representado pela TRS.

A TP-A tem as suas últimas evidências registradas, em diferentes locais, entre 600 e 800 DC. A STA se mantém constante no rio Tocantins (confluência AraguaiaTocantins) e no interflúvio Xingu-Tocantins (Serra dos Carajás), chegando até o cerrado maranhense entre 1.200-1.400 DC, aumentando sua presença a partir do ano 1.000 DC. A TQ e TM possuem antiguidade superior a todas as outras Tradições, sempre associadas às estruturas artificiais (geoglifos e sambaquis, respectivamente) e se mantém presentes ao longo de todo período nas mesmas regiões, com exceção do período $1.000-1.200$ DC em que não há datas para a TQ, podendo ser uma questão amostral. 


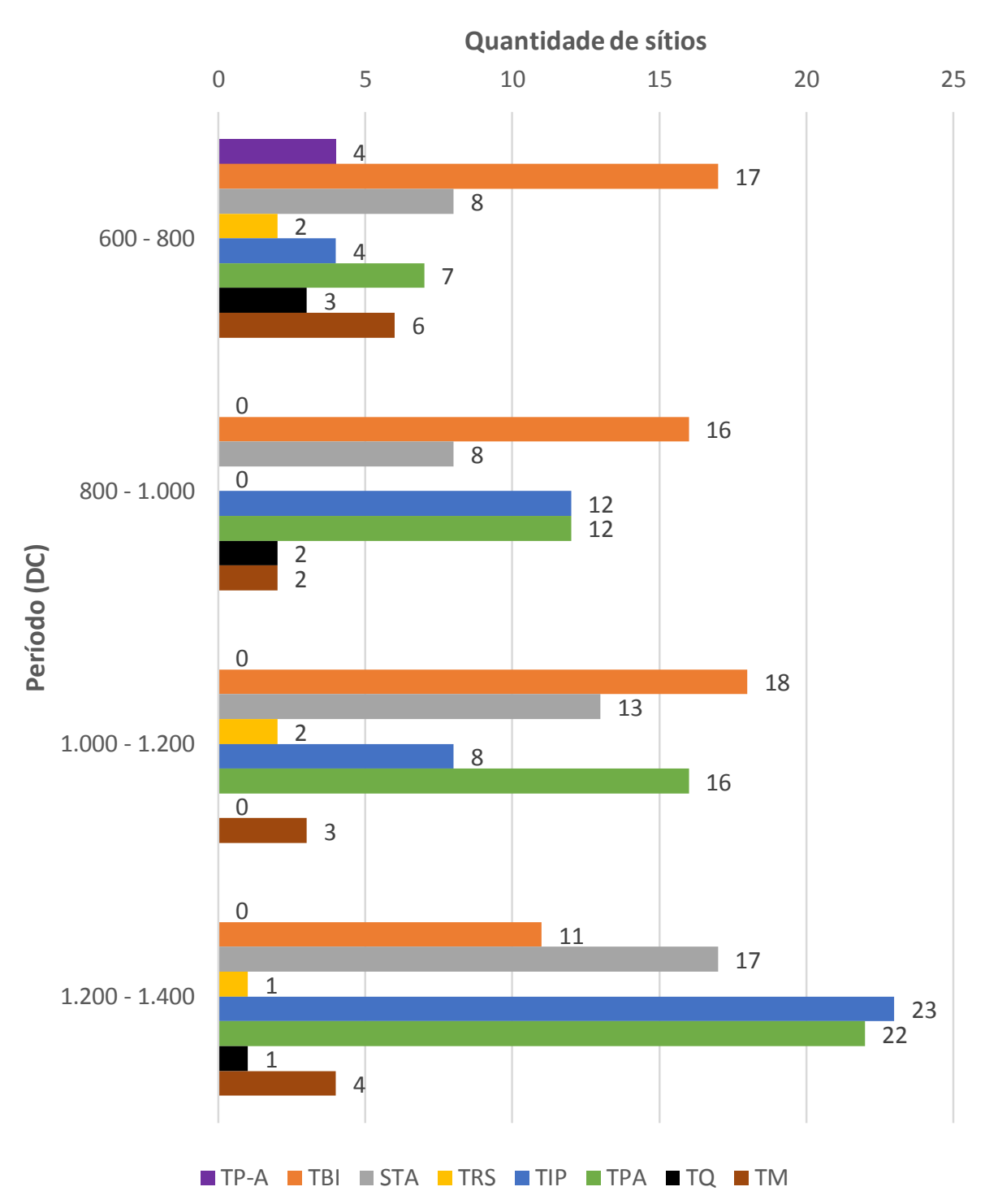

Gráfico 3.5.2: Quantidade de sítios arqueológicos com suas respectivas Tradições associadas entre 600 e 1.400 DC.

Dentre os contextos mais locais, no período de 600 - 800 DC, o alto rio Madeira, próximo a Cachoeira do Teotônio, temos pelo menos a ocorrência de três Tradições concomitantes: TP-A, TBI e TPA. A TP-A e a TPA estão em margens opostas, um defronte ao outro, e ambos estão distantes da TBI em torno de $13 \mathrm{~km}$ em linha reta.

Ainda nesse mesmo período, no baixo rio Urubu temos a presença de sítios TBI e um único sítio da TP-A. Mais a jusante, no baixo rio Uatumã, temos dois sítios da TRS. No entanto, é importante ter cautela em relação a essas datas, pois existem poucos sítios datados referente à TRS. No período seguinte $(800-1.000 \mathrm{DC})$, essa Tradição está 
ausente nessa área. E se ela é consequência de uma fronteira entre a TPA e a TIP, ambas ainda não aparecem no entorno dessa região.

No período de 800 - 1.000 DC se inicia um rápido aumento no número de sítios da TPA e TIP. Enquanto a TPA surge no baixo rio Xingu e se intensifica na Ilha de Marajó e no médio rio Solimões, a TIP parece se expandir a montante no rio Amazonas, adentrando no baixo curso do rio Madeira. E apesar da diferença na quantidade de datações para o período posterior (1.000 - 1.200 DC), a presença de sítios da TIP diminui enquanto que a TPA alcança a área de confluência dos rios Solimões-Negro e no litoral do Amapá.

Por fim, no período de 1.200 - 1.400 DC temos a TPA (oeste e litoral) e TIP (leste) presente na calha do Amazonas e ao longo dos principais afluentes. A TBI não desaparece totalmente, mas se mantém presente em vários locais lado a lado com outras Tradições. No baixo rio Xingu existe um contexto interessante com a ocorrência de sítios da TM, TPA e TIP, com distâncias aproximadas entre 6 km e 10 km entre si. 


\section{CAPÍTULO 4 - Conclusão}

Ao longo desta tese foram utilizados diferentes aspectos de análise relacionados aos sítios arqueológicos localizado na Amazônia Legal Brasileira. Para facilitar a discussão, a partir daqui retomarei sucintamente os resultados e reflexões feitos através das análises quantitativas e correlações entre os atributos:

- Os diferentes níveis de detalhamento das informações arqueológicas inviabilizam analises com maior grau de refinamento. No entanto, o fato de termos a localização dos sítios e o seu contexto de pesquisa nos dá uma ferramenta para pensarmos uma gestão do patrimônio arqueológico em várias instâncias, planejamentos de projetos científicos, a criação de modelos preditivos ou sua correlação com outras informações (e.g.: paleoambientais);

- O tamanho dos sítios demonstra um padrão de ocorrência de poucos sítios maiores que 10 hectares em meio a vários sítios menores que 10 hectares, numa proporção de 1:4 (capítulo 3.3.1). Considerando que todos esses locais estavam sendo ocupados em um mesmo período, podemos hipotetizar que cada local (sítio) possuía diferentes papéis dentro de um sistema político regional, semelhante ao identificado no Alto rio Xingu (HECKENBERGER et al., 2008);

- Os dados de ausência e presença de TPI demonstraram que as margens dos rios Amazonas, Negro, Solimões e Madeira, e o baixo curso de seus principais afluentes (Tapajós, Xingu, Tocantins, etc.) foram densamente ocupados, ao contrário das áreas interfluviais ou alto curso dos afluentes. No entanto, em algumas áreas existem grandes concentrações de sítios sem TPI (e.g.: alto rio Purus e Serra dos Carajás) e, caso eles tenham sido ocupados em um mesmo período, por mais que não haja a presença de TPI, poderíamos supor que foram áreas densamente ocupadas, mas com um diferente grau de mobilidade em relação aos grupos da calha principal. É necessário maior investimento em escavações e datações em sítios sem TPI, numa escala regional, para que possamos compreender melhor essas dinâmicas e as diferentes formas de ocupar os espaços. É interessante notar que um aspecto negligenciado ou pouco comentado nas análises que envolvem esse tipo de solo pode marcar um padrão de ocupação diferente dos principais modelos amazônicos e que tende a formas mais dinâmicas de ocupação; 
- Os sítios uni ou multicomponenciais demonstraram áreas com maior persistência e hegemonia de ocupação de um único grupo (unicomponenciais), e áreas com maior ocorrência de reocupações ou transformações culturais (multicomponenciais). Os sítios unicomponenciais são a maioria e ocorrem por toda a Amazônia, ao contrário dos multicomponenciais que ocorreram, principalmente, na área de confluência dos rios Solimões-Negro-MadeiraAmazonas. Essa mesma área apresentou uma grande variabilidade nas ocorrências das Tradições cerâmicas;

- E, se por um lado, a área de confluência dos rios Solimões-Negro-MadeiraAmazonas apresentou grande variabilidade de ocorrência das Tradições e na composição dos sítios, o Litoral do Salgado (TM) e o alto rio Purus (TQ) demonstraram o domínio de uma única Tradição, com a presença de estruturas artificiais, sítios menores que 10 hectares e um longo período de ocupação. A bacia do rio Tocantins e seu entorno também apresentaram uma relativa homogeneidade, com a presença da STA e corroborando com a proposta de Almeida \& Neves (2015);

- Em relação à cronologia, os dados demonstraram que o período entre 600 e 1.400 DC foi o momento de maior crescimento, adensamento e expansão dos diferentes grupos, observado na quantidade de sítios arqueológicos e sua associação com as Tradições cerâmicas. Nesse recorte temporal é possível observamos o domínio territorial da TBI sendo reduzido rapidamente pelo aumento de sítios da TIP e TPA, formando posteriormente uma fronteira cultural entre ambas (TRS). A TQ e a TM permanecem presentes em suas respectivas regiões por todos os períodos, enquanto que STA começa a se expandir da bacia do Tocantins para regiões adjacentes;

O ano $1.000 \pm 400 \mathrm{DC}$ foi um período em que diferentes sociedades deixaram de existir, se expandiram ou se mantiveram frente a uma série de mudanças culturais, sociais ou políticas. Seja através das Tradições cerâmicas, da composição dos sítios, construção de estruturas artificiais, modificações paisagísticas ou da cronologia, contextualizado para cada região, pode-se averiguar que tais transformações foram frequentes e ocorreram 
de forma rápida. Através do registro arqueológico, em uma escala temporal de 800 anos, observamos o desaparecimento de vestígios associados à TP-A, diminuição da TBI, permanência localizada da TQ e TM, expansão da TPA e da TIP e o surgimento da TRS. Inseridos nesses diferentes episódios da história indígena pré-colonial da Amazônia, alguns locais registraram uma maior intensidade de eventos do que outros.

Ainda não está clara a razão de algumas regiões possuírem um intenso trânsito de pessoas e culturas, em um curto espaço de tempo (800 anos), e visível no registro arqueológico através dos vestígios cerâmicos ou na paisagem. No caso dos sítios arqueológicos, utilizados nesse trabalho como unidade analítica, estes fazem parte de uma paisagem construída historicamente, como uma marca visível da agência humana do passado (NEVES \& PETERSEN, 2006:279). Nesse sentido de paisagem temos uma série de indícios que nos demonstram diferentes relações sociais e distintas culturas transitando por um mesmo local ou região, em diversos períodos. Como resultado final temos a formação dos sítios arqueológicos multicomponenciais e essa heterogeneidade observada no registro arqueológico, demonstra a persistência dos diferentes grupos humanos em se apropriar de uma determinada região, dando a ela diferentes sentidos. Esses sentidos são expressos nas relações que esses grupos humanos tiveram com as paisagens e as pessoas que moram ou passaram por ali ao longo do tempo, tanto com o meio natural, social e sobrenatural.

Essa ideia se encaixa no que Zedeño e Bownser (2009) conceituaram como lugares significativos e persistentes. Em linhas gerais, um lugar significativo pode ser uma estrutura artificial (e.g.: geoglifos, tesos, montículos, sambaquis, etc.), uma modificação no meio natural (e.g.: terra preta, florestas antrópicas, gravuras rupestres, etc.) ou a ressignificação do próprio ambiente (e.g.: cachoeiras, cavernas, lagos, serras, montanhas, confluências de rios ou lagos, etc.). Esses locais possuem diferentes significados e conhecimentos sobre o mundo, elaborados através das interações entre os humanos e meio ambiente, ganhando reconhecimento e importância ao indivíduo ou coletivo, influenciando em suas ações e estão ligados à sua história, memória, território e identidade. A continuidade do uso desses locais, mesmo que resignificados e transformados em diferentes momentos, o torna como um lugar persistente (ZEDEÑO \& BOWNSER, 2009; SCHLANGER, 1992). Segundo Thompson (2010), existem três características que definem a persistência de um lugar: concentração de recursos naturais 
que o tornam atrativo, elementos culturais que estruturam sua reutilização e as suas práticas por um longo período de tempo.

O conceito de lugares significativos e persistentes é atualmente utilizado amplamente em diferentes contextos de pesquisas arqueológicas na Amazônia, seja olhando apenas para o passado pré-colonial (LOPES, 2018; ALMEIDA \& KATER, 2017; SALDANHA, 2016; BARRETO et al., 2016; ALMEIDA, 2013; entre outros) ou estendendo até o presente (PUGLIESE JR. \& VALLE, 2016; GOMES, 2015; SILVA \& GARCIA, 2015; MACHADO, 2012; entre outros).

Seguindo essa noção de lugar, conforme apresentado no mapa 3.4.2-1, a área de confluência entre os rios Solimões-Negro-Madeira-Amazonas parece ter sido uma região de intensas sobreposições culturais, observadas principalmente nos vestígios cerâmicos, mas que também podem ser associadas a presença/ausência de TPI, estruturas artificiais (montículos e valas defensivas) e na forma de ocupar os locais (aldeias lineares ou circulares). Isso fica claro quando olhamos a quantidade de sítios multicomponenciais concentrados nessa área de confluência que, ao que parece, não conflui apenas os grandes rios amazônicos, mas ideias, pessoas e suas diferentes interações. Se em um primeiro momento na história da arqueologia amazônica esse local pareceu propício para a emergência e dispersão de grandes culturas (LATHRAP, 1970), agora ela pende mais para um local importante que precisa ser incorporado por diferentes grupos, seja ela através da guerra ou de uma expansão cultural gradual, através de bens de prestígio, especialização na produção dentro de uma esfera de interação ou a inclusão de seus habitantes em organizações sociopolíticas regionais multiétnicas (HECKENBERGER \& NEVES, 2009). Essa hipótese já havia sido levantada anteriormente por Neves (2012:218) e Almeida (2013:289) e os dados apresentados apenas corroboram suas ideias.

A área de confluência deveria possuir tamanha importância e complexidade nas articulações sociopolíticas, já que é a única região em que há evidências de um nome representando um coletivo. A crônica de Cristóbal de Acuña, no século XVII, registra a denominação Carabuyana para as diferentes nações que habitavam o baixo curso do rio Negro e Solimões, ao contrário dos demais locais que eram chamados de "províncias", mas constituída de uma única "nação". Era um dos poucos locais que, em pleno século XVII, possuía ferramentas europeias vindas dos Holandeses da Guiana, através de uma extensa rede comercial (PORRO, 1996). 
Almeida e Kater (2017) atribuem ao elemento da cachoeira como lugares persistentes e significativos, imbuído por diferentes componentes (ideológicos, históricos, econômicos e territoriais), tornando-se um entroncamento das redes de relações ao longo de centenas de anos e formando diferentes contextos arqueológicos, como repletos de diferentes Tradições cerâmicas, cemitérios, grafismos rupestres, etc. Entre as regiões que eles apresentam está a Cachoeira do Teotônio, no alto rio Madeira, e a Cachoeira de Tucuruí e seus arredores, no baixo rio Tocantins, expandindo até a Serra dos Carajás. Ambos os locais também apareceram nas análises desse trabalho como um local de grande variabilidade cultural e na composição dos sítios. Além desses dois locais, eu acrescentaria ainda a Cachoeira de Samuel, no baixo rio Jamari, e a Cachoeira da Volta Grande, no rio Xingu. A persistência desses locais me parece tão significativa que até o presente, todas elas, possuem grandes hidrelétricas.

A Cachoeira Porteira, localizado próximo da confluência entre os rios Trombetas e Mapuera, possui diversos sítios identificados, mas que não passaram por grandes intervenções. Até o momento, sabe-se que os sítios possuem TPI, são pouco profundos, variam entre 1 a 8 hectares e são constituídos por cerâmica da TIP. Segundo Jácome (2017:224) os diferentes povos de língua Caribe que habitam a região do NhamundáTrombetas procuram evitar os locais de cachoeiras, pois são locais perigosos, onde mora a Cobra Grande e podem causar muitos malefícios às pessoas. Nesse sentido, se um significado semelhante existiu no passado pré-colonial, pode ser que o contexto arqueológico no entorno de Cachoeira Porteira seja diferente daqueles apresentados por Almeida e Kater (2017).

Lopes (2018), Gomes (2015) e Lima (2016) ao trabalharem nos lagos de água preta do médio rio Solimões, atribuíram esses locais como lugares persistentes e significativos. Nesses contextos podem ser encontrados sítios multicomponenciais com mais de 2 mil anos de ocupação, de grandes extensões e repleto de urnas funerárias. Os locais com maior ou menor significância e persistência dentro de um lago podem ter variado conforme o período, sua localização e acesso aos diferentes recursos. Entre essas localidades, como exposto por Lopes (2018), a foz dos lagos com o rio Solimões possui esse privilégio devido ao seu controle de acesso fluvial e piscosidade anual. Por outro lado, Gomes (2015) identifica uma série de sítios cemitérios e habitacionais-cemitérios espalhados ao longo do lago, refletindo uma possível paisagem repleta de memória e identidade. Lima (2016) observa uma relação intensa entre áreas que são hoje grandes 
comunidades com sítios arqueológicos de maior densidade, sugerindo uma persistência e significância na longa história de ocupação de um lago. No banco de dados existe uma série de sítios identificados dentro desses contextos de lagos, mas poucos foram efetivamente escavados. No entanto, os trabalhos de Gomes, Lopes e Lima nos dão uma possibilidade que pode ser testada em futuros projetos.

Outro local onde se atribui esse aspecto de persistência é a região de Monte Alegre, no baixo rio Amazonas, defronte a foz do rio Tapajós. Barreto, Nascimento e Pereira (2016) identificam a persistência de identidades locais através dos estilos cerâmicos, paisagens construídas e lugares ocupados em torno de 1.200 DC, se distinguindo dos seus vizinhos Tapajônicos e Konduri. Esses aspectos seriam o resultado das extensas redes de relações, que passavam por ressignificações conforme as relações sócio-políticas regionais se alteravam. As autoras atribuem a persistência desse local pela presença das serras de arenito que se destacam na paisagem da várzea amazônica e a proximidade de diferentes ambientes, como a floresta, cerrado, campos e várzea (Op. Cit.). Infelizmente, as análises realizadas nesse trabalho não identificaram esse contexto descrito pelas autoras, mas isso tem relação com os atributos utilizados nas correlações e na escala macro que utilizei, que por consequência acabaram dissolvendo aspectos de escala local.

Para além da variabilidade artefatual do registro arqueológico, a persistência e significância de algum lugar podem estar associadas a contextos unicomponenciais. Esse parece ser o caso da Tradição Quinari (TQ), no sudoeste Amazônico, e da Tradição Mina (TM) no leste da Amazônia. Ambas as Tradições possuem pouca pesquisa e necessitam de maiores aprofundamentos, principalmente na análise cerâmica e cronologia. No entanto, os poucos dados disponíveis, apontam para uma longa duração de sua existência e sempre associadas a grandes estruturas artificiais, ou seja, dois fatores para serem lugares significativos e persistentes.

Em relação à TQ, sabe-se que ela ocorre desde 1.200 AC até o 1.600 DC e que há mudanças substanciais em torno do ano 1.000 DC na forma de ocupar os espaços, deixando de construírem os geoglifos (valas) para construírem sítios de montículos de forma anelar. Não sabemos até onde sua influência se expande espacialmente, principalmente em relação ao norte e a leste. Os mapas 3.5.2-1 a 3.5.2-4 mostram como a TQ se mantém presente na região do alto rio Purus enquanto no alto rio Madeira, em torno de $100 \mathrm{~km}$ em linha reta, uma série de mudanças e Tradições estão presente entre 
600 e 1.400 DC. Em seu interflúvio (alto Purus-alto Madeira) e ao longo do rio Abunã, afluente do alto rio Madeira, é possível encontrar uma série de geoglifos, mas pouco estudados. Ao norte existe um vazio de pesquisas arqueológicas e pouco sabemos sobre os rios Juruá e Purus.

A TM possui uma antiguidade superior a todas as outras Tradições cerâmicas mencionadas nesse trabalho (4.600 AC), sendo considerada uma das primeiras evidências na fabricação de vasilhames cerâmicos da Amazônia brasileira e perdurando até o segundo milênio DC. Sua presença está associada tanto aos contextos sambaquieiros litorâneos quanto os fluviais, e também em sítio com TPI fora dos sambaquis. Mesmo com a expansão da TPA, TIP e STA, é possível que esse estilo continuo sendo fabricado e utilizado concomitante a essas Tradições, convivendo lado a lado, como demonstrado no mapa 3.5.2-4. Em alguns casos, ela deixou de existir nos sambaquis e evidências da STA são encontradas sobrepostas a ela.

Uma hipótese para essa permanência, mesmo que em escala regional, é que ambas as Tradições estivessem associadas a uma distinção social e/ou prestígio dentro de uma rede de relações. Sua associação com estruturas que se destacam na paisagem (geoglifos e sambaquis), entre outros fatores simbólicos que desconhecemos até o momento, podem ter auxiliado para o seu na sua manutenção e evitado o seu desaparecimento.

Outro exemplo observado na correlação Tradição e cronologia está localizado no baixo rio Tapajós, área muito bem conhecida pela cerâmica Tapajônica (ou Santarém) e os muiraquitãs. Essa cerâmica, associada à TIP, estava dispersa pela margem direita do baixo rio Tapajós e sua foz com o rio Amazonas, abrangendo tanto as áreas de várzea quanto o planalto. Possui sítios de grandes dimensões, como aquele localizado na atual cidade de Santarém (mais de 100 ha), muitos deles com densos pacotes de TPI e outros com reservatórios artificiais de água. Suas ocupações se iniciam em torno de 700 DC e se estendem até o período de contato com os europeus, quando ganham a fama de ser uma tribo das Amazonas (QUINN, 2004; PORRO, 1996). Apesar de sua dominância local, observado no registro arqueológico, na margem oposta temos a permanente presença de grandes assentamentos ( $>10 \mathrm{ha})$ associados à TBI e esses se estabelecem antes do surgimento da cerâmica Santarém e perduram até 1.400 DC (GOMES, 2008), conforme demonstrado nos mapas 3.5.2-1 a 3.5.2-4. Não sabemos o que levou a sua continuidade e/ou resistência, mas assim como a TM no baixo rio Xingu eles conseguiram se manter de forma distinta frente a expansão de seus vizinhos. 
Ao que tudo indica, não existe um padrão nas relações existentes entre as diferentes culturas que conviveram lado a lado, sendo estas pacíficas ou bélicas. Contudo, existe uma recorrência de locais que devem ter sido cobiçados por diferentes sistemas sócio-políticos regionais, em diferentes momentos, como a área de confluência dos rios Solimões-Negro-Madeira-Amazonas. De toda forma, o período entre 600 e 1.400 DC foi de intensas transformações culturais, expansão de alguns grupos e resistência de outros.

Ao longo deste trabalho busquei esboçar, com base nos dados disponíveis, uma pequena parcela da longa história indígena na Amazônia. O refinamento dessa trajetória histórica será continuando à medida que novas informações arqueológicas forem incorporadas ao banco de dados, correlacionando com dados de outras ciências (e.g.: paleoecologia e etnohistória) e na constante busca de parceiros que queiram entrar nessa empreitada. Para além dos dados científicos, transformados em números e categorias classificatórias, é importante termos em mente três perguntas: para quem estamos reconstruindo o passado? Quais são as visões de mundo utilizadas para interpretar esses contextos? E, principalmente, o que iremos legitimar através da arqueologia? Para essa última pergunta, a resposta deverá ser sempre a favor dos verdadeiros protagonistas dessa longa história amazônica: indígenas e ribeirinhos. 


\section{BIBLIOGRAFIA}

AB'SABER, A. Os domínios de natureza no Brasil - Potencialidades paisagísticas. São Paulo: Ateliê Editora, 2003.

AIRES DA FONSECA, J. Levantamento regional na arqueologia amazônica: o uso de sistema de informação geográfica e sensoriamento remoto. Boletim do Museu Paraense Emílio Goeldi. Ciências Humanas 8(3): 675-690, 2013.

ALMEIDA, F. O. O complexo Tupi na Amazônia Oriental. Dissertação de Mestrado. São Paulo: Museu de Arqueologia e Etnologia da Universidade de São Paulo, 2008.

AlmeIdA, F. O. A Tradição Polícroma no Alto Rio Madeira. Tese de Doutorado. São Paulo: Museu de Arqueologia e Etnologia da Universidade de São Paulo, 2013.

ALMEIDA, F. O. Arqueologia dos Tupi-Guarani no baixo Amazonas. IN.: BARRETO, C.; LiMA, H. P. \& BETANCOURT, C. J. (orgs.) Cerâmicas Arqueológicas da Amazônia: rumo a uma nova síntese. Belém: IPHAN/MinC, p.171-182, 2016.

ALMEIDA, F. O.; NEVES, E. G. Evidências arqueológicas para a origem dos TupiGuarani no leste da Amazônia. MANA 21(3): 499-525, 2015.

ALMEIDA, F. O.; MORAES, C. P. A cerâmica policroma do rio Madeira. IN.: BARRETO, C.; LIMA, H. P. \& BETANCOURT, C. J. (orgs.) Cerâmicas Arqueológicas da Amazônia: rumo a uma nova síntese. Belém: IPHAN/MinC, p.402-413, 2016.

ALMEIDA, F. O.; KATER, T. As cachoeiras como bolsões de histórias dos grupos indígenas das terras baixas sul-americanas. Revista Brasileira de História 37(75): 3967, 2017.

ALVES, D. T. A ocupação indígena na foz do rio Tapajós (3260-960 AP): estudo do sítio Porto de Santarém, Baixo Amazonas. Dissertação de Mestrado. Belém: Universidade Federal do Pará, 2012.

AMPLO Engenharia e Gestão de Projetos. Duplicação da Estrada de Ferro Carajás EFC. Relatório de Estudo Ambiental e Plano Básico Ambiental (EA/PBA). Belo Horizonte, 2011.

ANTHONY, D. W. The horse, the wheel and language. New Jersey: Princenton University Press, 2007. 
ARAÚJO-COSTA, F.; CALDARELli, S. B. Programa de estudos arqueológicos na área do reservatório de Kararaô (PA). Belém: MPEG, 1988.

ARAUJO-COSTA, F., SENNA, C. S.; PEREIRA, E.; KERN, D. C. Levantamento arqueológico na área da UHE Cachoeira-Porteira. Relatório Final. 1986.

ARQUEOLOGIKA - Programa de Gestão Arqueológica: Potássio Amazonas Autazes/AM. Jundiaí/Belo Horizonte: Arqueológika/Potássio do Brasil, 2015.

ARROYO-KALIN, M. The Amazonian Formative: Crop Domestication and Anthropogenic Soils. Diversity 2, p. 473-504, 2010.

ATZINGEN, N. V. et al. O Núcleo Arqueológico de Marabá. Boletim Informativo da Fundação Casa da Cultura de Marabá. Edição Comemorativa. Marabá, 1999.

BALEÉ, W. The culture of Amazonian forests. Advances in economic botany 7(1):1$21,1989$.

BALÉE, W. Contingent diversity on anthropic landscapes. Diversity 2:163-181, 2010.

BANDEIRA, A. M. Ocupações humanas pré-coloniais na Ilha de São Luís-MA: inserção dos sítios arqueológicos na paisagem, cronologia e cultura material cerâmica. Tese de Doutorado. São Paulo: Museu de Arqueologia e Etnologia, Universidade de São Paulo, 2012.

BANDEIRA, A. M. A cerâmica Mina no Maranhão. IN. BARRETO, C.; LIMA, H. P. \& BETANCOURT, C. J. (orgs.) Cerâmicas Arqueológicas da Amazônia: rumo a uma nova síntese. Belém: IPHAN/MinC, p.147-157, 2016.

BARLOW, J.; GARDNER, T. A.; LEES, A. C.; PARRY, LINDA; PERES, C. A. How pristine are tropical forests? An ecological perspective on the pre-Columbian human footprint in Amazonia and implications for contemporary conservation. Biological Conservation 151:45-49, 2012.

BARRETO, C. Meios místicos de reprodução social: arte e estilo na cerâmica funerária da Amazônia Antiga. Tese de Doutorado. São Paulo: Museu de Arqueologia e Etnologia da Universidade de São Paulo, 2009.

BARRETO, C.; LIMA, H. P. \& BETANCOURT, C. J. (orgs.) Cerâmicas Arqueológicas da Amazônia: rumo a uma nova síntese. Belém: IPHAN/MinC, 2016. 
BARRETO, C.; NASCIMENTO, H. F.; PEREIRA, E. Lugares persistentes e identidades distribuídas no baixo Amazonas: complexos cerâmicos pré-coloniais de Monte Alegre, Pará. Revista de Arqueologia 29(1): 55-85, 2016.

BASSI, F. S. A Maloca Saracá: uma fronteira cultural no médio Amazonas pré-colonial, vista da perspectiva de uma casa. Tese de Doutorado. São Paulo: Museu de Arqueologia e Etnologia da Universidade de São Paulo, 2015.

BASSI, F. S.; CAVALLINI, M. As gravuras rupestres do baixo rio Urubu (Amazônia central) e a formação de uma fronteira cultural persistente no final do I milênio DC. Revista do Museu de Arqueologia e Etnologia, São Paulo, Supl. 20, p.101-108, 2015.

BELLETTI, J. S. Arqueologia do Lago Tefé e a expansão polícroma. Dissertação de Mestrado. São Paulo: Museu de Arqueologia e Etnologia da Universidade de São Paulo, 2015.

BIODINAMICA RIO. Estudo de Impacto Ambiental (EIA) da Linha de Transmissão 500kV Oriximiná-Cariri. Manaus: Manaus Transmissora de Energia S.A. Relatório técnico. 2009.

BOOMERT, A. Koriabo and the Polychrome Tradition: the Late-Prehistoric Era between the Orinoco and Amazon mouths. IN.: DELPUECH, A.; HOFFMAN, C. L. (Eds.). Late ceramic age societies in the Eastern Caribbean. Paris: BAR International, 2004.

BORnAl, W. G. Programa de Gestão do Patrimônio Arqueológico, Histórico e Cultural - Etapa de Resgate e Ações de Monitoramento Arqueológico para a implantação da UHE São Manoel. Relatório técnico final. 2014.

BROCHADO, J. J. J. P. An ecological model of the spread of pottery and agriculture into Eastern South America. Dissertação de Mestrado. Urbana-Champaign: University of Illinois, 1984.

BROCHADO, J. J. J. P. A expansão dos Tupis e da cerâmica da tradição policrômica da Amazônia. Dédalo, São Paulo, v. 9, p. 17-18, 1989.

BROCHADO, J. P.; LATHRAP, D. W. Chronologies in the new world. Manuscrito não publicado, 1982.

BUENO, L. M. R. Variabilidade tecnológica nos sítios líticos da região do Lajeado, médio rio Tocantins. Tese de Doutorado. São Paulo: PPGA/MAE-USP, 2005. 
BUSH, M. B.; CORREA-METRIO, A.; MCMICHAEL, C. H.; SULLY; S.; SHADIK; C. R.; VALENCIA, B. G.; GUILDERSON, T.; STEINITZ-KANNAN, M.; OVERPECK, J. T. A 6900-year history of landscape modification by humans in lowland Amazonia. Quaternary Science Reviews 141:52-64, 2016.

BUSH, M.B.; MCMICHAEL, C.H.; PIPERNO, D.R.; SILMAN, M.R.; BARLOW, J.; PERES, C.A.; POWER, M.; PALACE, M.W. Anthropogenic influence on Amazonian forests in pre-history: an ecological perspective. Journal of Biogeography 42:22772288, 2015.

BUSH, M.B., PIPERNO, D.R., COLINVAUX, P.A. A 6000 year history of Amazonian maize cultivation. Nature 340:303-305, 1989.

CABRAL, M. P.; SALDANHA, J. D. M. Paisagens megalíticas na costa norte do Amapá. Revista de Arqueologia 21:09-26, 2008.

CABRAL, M. P. Juntando cacos: uma reflexão sobre a classificação da fase Koriabo no Amapá. Amazônica 3 (1):88-106, 2011.

CARSON, J. F.; WHITNEY, B. S.; MAYLE, F. E.; IRIARTE, J.; PRÜMERS, H.; SOTO, J. D.; WATLING, J. Environmental impact of geometric earthwork construction in preColumbian Amazonia. PNAS 111 (29):10497-10502, 2014.

CHMYZ, I. Terminologia arqueológica brasileira para a cerâmica. Curitiba: CEPA/ UFPR, 1966.

CHURCH, W. B.; HAGEN, A. V. Chachapoyas: cultural development at an andean cloud forest crossroads. IN. SILVERMAN, H; ISBELL, W. H. (orgs). The Handbook of South American Archaeology. New York: Springer, pp. 903-926, 2008.

CLEMENT, C. R.; JUNQUEIRA, A. B. Between a pristine myth and an impoverished future. Biotropica 42:534-536, 2010

CLEMENT, C. R.; DENEVAN, W. M.; HECKENBERGER, M. J.; JUNQUEIRA, A. B.; NEVES, E. G.; TEIXEIRA, W. G.; WOODS, W. I. The domestication of Amazonia before European conquest. Proceedings of Royal Society B 282:1-9, 2015.

CORRÊA, A. A. Pindorama de Mboia e Iakaré: continuidade e mudança na trajetória das populações Tupi. Tese de Doutorado. São Paulo: Museu de Arqueologia e Etnologia da Universidade de São Paulo, 2014. 
COSTA, B. L. Levantamento Arqueológico na Reserva de Desenvolvimento Sustentável (RDS) Amanã. Estado do Amazonas. São Paulo: Dissertação de Mestrado. Museu de Arqueologia e Etnologia da Universidade de São Paulo, 2012.

COSTA, F. W. S. Arqueologia das Campinaranas do Baixo Rio Negro: em busca dos pré-ceramistas nos areais da Amazônia Central. Tese de Doutorado. São Paulo: Museu de Arqueologia e Etnologia da Universidade de São Paulo, 2009.

COSTA, F.; LIMA, H. Levantamento Arqueológico no Município de Manaus. Relatório encaminhado ao IPHAN, $1^{\text {a }}$ Superintendência Regional - Manaus. 2006.

CRUXENT, J. M.; ROUSE, I. An archaeological chronology of Venezuela. Washington, D.C.: Pan America Union, 1959.

DEBOER, W. R. Buffer Zones in the Cultural Ecology of Aboriginal Amazonia: An Ethnohistorical Approach. American Antiquity, v. 46, n. 2, p. 364-377, 1981.

DENEVAN, W. The Pristine Myth: the landscape of the Americas in 1492. Annals of the association of American Geographers 82(3) The Americas before and after 1492: Current Geographical Research, p. 368-385, 1992.

DENEVAN, W. A Bluff Model of Riverine Settlement in Prehistoric Amazônia. Annals of the Association of American Geographers 86(4):654-681, 1996.

DENEVAN, W. Estimating Amazonian Indian Numbers in 1492. Journal of Latin American Geography, 13 (2): 207-221, 2014

DIAS, O. As estruturas arqueológicas de terra no estado do Acre - Amazônia Ocidental, Brasil. Um caso de resiliência? In: DIAS, O.; CARVALHO, E.; ZIMMERMANN, M. Estudos contemporâneos de Arqueologia. Palmas: Unitins-IAB, 2006. p. 59-168.

DIAS, O.; CARVALHO, E. As Estruturas de Terra na Arqueologia do Acre. Arqueologia-IAB, Rio de Janeiro, p. 29-35, 1988.

DOCUMENTO Arqueologia. Programa de Gestão do Patrimônio Arqueológico, Histórico e Cultural UHE Teles Pires /MT. Relatório técnico. São Paulo, 2014.

ERIKSEN, L. Nature and culture in prehistoric Amazonia: using G.I.S. to reconstruct ancient ethnogenetic processes from archaeology, linguistics, geography, and ethnohistory. Tese de Doutorado. Lund: Lund University, 2011. 
EPE - Empresa de Pesquisa Energética. Estudo de Impacto Ambiental (EIA) da Usina Hidrelétrica de São Manoel. Relatório técnico. Volume 4, capítulo V, 2010.

EVANS, C.; MEGGERS, B. Archaeological investigations on the rio Napo, eastern Ecuador. Washington: Smithsonian Institution Press, 1968.

FALCÃO, N. P. S.; CLEMENT, C. R.; TSAI, S. M.; COMERFORD, N. B. Pedology, Fertility, and Biology of Central Amazonian Dark Earths. IN: WOODS, W.; TEIXEIRA, W.; LEHMANN, J.; STEINER, C.; WINKLERPRINS, A.; REBELLATO, L. (orgs) Amazonian Dark Earths: Wim Sombroek's Vision. Berlim: Springer, p. 213-228, 2008. FRASER, J. A.; JUNQUEIRA, A. B.; CLEMENT, C. R. Homegardens on Amazonian Dark Earths, Non-anthropogenic Upland, and Floodplain Soils along the Brazilian Middle Madeira River Exhibit Diverging Agrobiodiversity. Economic Botany 65(1), p. 1-12, 2011.

GARCIA, L. Arqueologia na região dos interflúvios Xingu-Tocantins: a ocupação Tupi no Cateté. Dissertação de Mestrado. São Paulo: Museu de Arqueologia e Etnologia da Universidade de São Paulo, 2012.

GARCIA, L. Cerâmicas e histórias indígenas no médio-baixo Xingu. IN. BARRETO, C.; LIMA, H. P. \& BETANCOURT, C. J. (orgs.) Cerâmicas Arqueológicas da Amazônia: rumo a uma nova síntese. Belém: IPHAN/MinC, p. 183-195, 2016.

GASPAR, M. V. A cerâmica arqueológica na Terra Indígena Kaiabi (MT/PA). Dissertação de Mestrado. São Paulo: Museu de Arqueologia e Etnologia da Universidade de São Paulo, 2014.

GESAI. Estudos de Impacto Ambiental (EIA) da UHE Santa Isabel. Relatório técnico de diagnóstico ambiental. 2010.

GOLDER ASSOCIATES BRASIL. Projeto Ferro Carajás S11D. Estudo de Impacto Ambiental - EIA. Volume IV-A. Belo Horizonte, 2010.

GOMES, J. Cronologia e Mudança Cultural na RDS Amanã (Amazonas): um estudo sobre a fase Caiambé da Tradição Borda Incisa. Dissertação de Mestrado. São Paulo: Museu de Arqueologia e Etnologia da Universidade de São Paulo, 2015.

GOMES, D. M. C. Cerâmica arqueológica da Amazônia: vasilhas da coleção tapajônica MAE-USP. São Paulo: EDUSP/FAPESP/Imprensa Oficial, 2002. 
GOMES, D. M. C. Cotidiano e Poder na Amazônia Pré-Colonial. São Paulo: EDUSP, 2008.

GOMES, D.M.C. Cronologia e Conexões Culturais na Amazônia: as sociedades Formativas da região de Santarém, PA. Revista de Antropologia 54(1): 269-314, 2011.

GUAPINDAIA, V. L. C. Além da margem do rio - a ocupação Konduri e Pocó na região de Porto-Trombetas, PA. Tese de Doutorado. São Paulo: Museu de Arqueologia e Etnologia da Universidade de São Paulo, 2008.

GUAPINDAIA, V. L. C., FONSECA JÚNIOR, J. A. A. Metodologia de delimitação no sítio arqueológico Cipoal do Araticum na região do rio Trombetas, Pará, Brasil. Boletim do Museu Paraense Emilio Goeldi - Ciências Humanas 8(3): 657-673, 2013.

HARTT, C. F. Contribuições para a ethnologia do Valle do Amazonas. Archivos do Museu Nacional 6:1-174, 1885.

HECKENBERGER, M. J. Estrutura, História e Transformação: a cultura xinguano na long duree. IN. FRANCHETTO, B.; HECKENBERGER, M. J. Os Povos do Alto Xingu: História e Cultura. Rio de Janeiro: UFRJ, 2001, p. 21-62.

HECKENBERGER, M. J. Rethinking the Arawakan Diaspora: Hierarchy, Regionality, and Amazonian Formative. In: HILL, J.; SANTOS-GRANERO, F. Comparative Arawakan Histories: Rethinking Languag, Family and Culture Area in Amazonia. Urbana/Chicago: University of Illinois Press, 2002. p. 99-122.

HECKENBERGER, M. J. The Ecology of Power: culture, place, and personhood in the southern Amazon, A.D. 1000-2000. New York: Routledge, 2005.

HECKENBERGER, M J.; NEVES, E. G. Amazonian Archaeology. Annual Review of Anthropology, 38:251-266, 2009.

HECKENBERGER, M.; NEVES, E. G.; PETERSEN, J. De onde vem os modelos? A arqueologia da origem Tupi e Guarani. Revista de Antropologia, São Paulo: Universidade de São Paulo, v. 41, n. 1, 1998.

HECKENBERGER, M. J.; KUIKURO, A.; KUIKURO, U. T.; RUSSEL, J. C.; SCHMIDT, M. J.; FAUSTO, C.; FRANCHETTO, B. Amazonia 1492: Pristine Forest or Cultural Parkland? Science 301:1710-1714, 2003. 
HECKENBERGER, M. J.; RUSSEL, J. C.; FAUSTO, C.; TONEY, J. R.; SCHMIDT, M. J.; PEREIRA, E.; FRANCHETTO, B.; KUIKURO, A. Pre-Columbian Urbanism, Anthropogenic Landscapes, and the Future of the Amazon. Science 29:1214-1217, 2008. HILBERT, K. Salvamento arqueologico na regipo de Porto Trombetas (Pará). Relatório final. Belém: Museu Paraense Emílio Goeldi, 1990.

HILBERT, P. P. Archäologische Untersuchungen Am Mittlern Amazonas. Berlim: Dietrich Reimer Verlag, 1968.

HILBERT, P. P. A cerâmica arqueológica da região de Oriximiná. Publicação do Instituto de Antropologia e Etnologia do Pará 9, 1955.

HILBERT P. P.; HILBERT, K. Resultados Preliminares da Pesquisa Arqueológica nos rios Nhamundá e Trombetas, baixo Amazonas. Boletim do Museu Paraense Emilio Goeldi - Antropologia 75: 1-15, 1980.

HIRAOKA, M.; YAMAMOTO, S.; MATSUMOTO, E.; NAKAMURA, S.; FALESI, I. C.; BAENA, A.R.C. Contemporary use and management of Amazonian Dark Earths. In.: Lehmann, J.; Kern, D.; Glaser, B.; Woods, W. Amazonian Dark Eaths: Origin, Properties and Management. Dordrecht, The Netherlands: Kluwer Academic Publishers, pp. 387-406, 2003.

HOGG, A. G.; HUA, Q.; BLACKWELL, P. G.; BUCK, C. E.; GUILDERSON, T. P.; HEATON, T. J.; NIU, M.; PALMER, J. G.; REIMER, P. J.; REIMER, R. W.; TURNEY, C. S. M.; ZIMMERMAN, S. R. H. SHCal13 Southern Hemisphere Calibration, 0-50,000 Years cal BP. Radiocarbon 55(4):1889-1903, 2013.

HOWARD, G. D. Excavations at Ronquin. New Haven, Conn: Yale University Press, 1943.

IBGE - Instituto Brasileiro de Geografia e Estatística. Amazônia Legal Brasileira. < https://ww2.ibge.gov.br/home/geociencias/geografia/amazonialegal.shtm >. Acessado em 06/11/2017.

IEPA. Resgate Arqueologico e educaçao Patrimonial ao Longo da Rodovia EAP-070. Relatório Técnico Final. Macapá, 2009.

IEPA. Levantamento e Resgate Arqueológico na Área de Implantação do Projeto Ferro Santa Maria - Mineração Amapari S/A. Relatório Técnico Final. Macapá, 2008. 
INSIDE CONSULTORIA. Programa de Arqueologia e Educação Patrimonial nas áreas de influência direta e indireta do empreendimento LT Marajó. Belém, 2012

INSIDE CONSULTORIA. Estudos Arqueológicos e Educação Patrimonial do Projeto Volta Grande. Belém, 2014.

JÁCOME, C. P. Dos Waiwai aos Pooco - Fragmentos de história e arqueologia das gentes dos rios Mapuera (Mawtohrî), Cachorro (Katxuru) e Trombetas (Kahu). Tese de Doutorado. São Paulo: Museu de Arqueologia e Etnologia da Universidade de São Paulo, 2017.

JUNQUEIRA, A. B. Anthropogenic soils in central Amazonia: farmers practices, agrobiodiversity and land-usepatterns. Tese de Doutorado. Wageningen: Wageningen University, 2015.

JUNQUEIRA, A. B.; SHEPARD, G. H.; CLEMENT, C. R. Secondary forests on anthropogenic soils in Brazilian Amazonia conserve agrobiodiversity. Biodiversity Conservation 19:1933-1961, 2010.

KERN, D.C. Geoquímica e pedogeoquímica de sítios arqueológicos com Terra Preta na Floresta Nacional de Caxiuanã (Portel-Pará). Tese de Doutorado. Belém: Universidade Federal do Pará, 1996.

LA SALVIA, F.; BROCHADO, J. P. Cerâmica guarani. Porto Alegre: Posenato Arte e Cultura, 1989.

LATHRAP, D. W. The Upper Amazon. London: Praeger, 1970.

LATINI, R.; BELliDO, A.; VASCONCELlOS, M.; DIAS, O. Classificação de Cerâmicas Arqueológicas da Bacia Amazônica. Química Nova 24(6):724-729, 2001.

LEHMANN, J.; KERN, D. C.; GERMAN, L.; MCCANN, J.; MARTINS, G. C.; MOREIRA, A. Soil fertility and production potential. IN: LEHMANN, J.; KERN, D. C.; GLASER, B.; WOODS, W. I. (orgs) Amazonian Dark Earths: Origin, Properties, Management. The Netherlands: Kluwer Academic Publishers, p. 105-124, 2003.

LEVIS, C.; SOUZA, P. F.; SCHIETTI, J.; EMILIO, T.; PINTO, J. L. P. V.; CLEMENT, C. R.; COSTA, F. R. C. Historical human footprint on modern tree species composition in the Purus-Madeira interfluve, central Amazonia. PloS one 7(11):e48559, 2012. 
LEVIS, C. et al. Persistent effects of pre-Columbian plant domestication on Amazonian forest composition. Science 355:925-931, 2017.

LEVIS, C.; FLORES, B. M.; MOREIRA, P. A.; LUIZE, B. G.; ALVES, R. P.; FRANCOMORAES, J.; LINS, J.; KONINGS, E.; PEÑA-CLAROS, M.; BONGERS, F.; COSTA, F.; CLEMENT, C. R. How people domesticated Amazonian forests. Frontiers in Ecology and Evolution 5, 2017.

LIMA, H. P. História das Caretas: A Tradição Borda Incisa da Amazônia Central. Tese de Doutorado. São Paulo: Museu de Arqueologia e Etnologia da Universidade de São Paulo, 2008.

LIMA, H. P. Variabilidade arqueológica e o estudo de fronteiras culturais na região do baixo rio Urubu. IN.: LIMA, H. P. (org.) Fronteiras do Passado: aportes interdisciplinares sobre a arqueologia do baixo rio Urubu, médio Amazonas, Brasil. Manaus: EDUA, p.35-61, 2013.

LIMA, H. P. As cerâmicas Açutuba e Manacapuru da Amazônia Central. IN.: BARRETO, C.; LIMA, H. P. \& BETANCOURT, C. J. (orgs.) Cerâmicas Arqueológicas da Amazônia: rumo a uma nova síntese. Belém: IPHAN/MinC, p. 303-320, 2016.

LIMA, H. P., NEVES, E. G. Cerâmicas da Tradição Borda Incisa/Barrancóide na Amazônia Central. Revista do Museu de Arqueologia e Etnologia 21: 205-230, 2011.

LIMA, H. P.; ARAUJO, L. S.; MORAES, B. M. As cerâmicas Saracá e a cronologia regional do rio Urubu. IN.: BARRETO, C.; LIMA, H. P. \& BETANCOURT, C. J. (orgs.) Cerâmicas Arqueológicas da Amazônia: rumo a uma nova síntese. Belém: IPHAN/MinC, p. 289-302, 2016.

LIMA, H. P.; NEVES, E. G.; PETERSEN, J. B. A fase Açutuba: Um novo complexo cerâmico na Amazônia central. Arqueologia Sul-Americana, v. 2, n. 1, p. 26-52, 2006.

LIMA, M. N. O rio Unini na arqueologia do baixo rio Negro, Amazonas. Dissertação de Mestrado. São Paulo: Museu de Arqueologia e Etnologia da Universidade de São Paulo, 2014.

LIMA, M. N. O início de ocupações sedentárias na Amazônia: A Tradição PocóAçutuba no médio Solimões/baixo Japurá. Projeto de doutorado submetido ao Programa 
de Pós-Graduação em Arqueologia do Museu de Arqueologia e Etnologia da Universidade de São Paulo. 2016.

LINO, J. T. Levantamento Arqueológico Sistemático Prospectivo na PCH Europa. Relatório Técnico Final. Içara: Arqueosul, 2010.

LINS, J.; LIMA, H. P.; BACCARO, F. B.; KINUPP, V. F.; SHEPARD, G. H.; CLEMENT, C. R. Pre-Columbian Floristic Legacies in Modern Homegardens of Central Amazonia. PLoS ONE 10(6):1-10, 2015.

LOPES, R. C. A. A Tradição Polícroma da Amazônia no contexto do médio rio Solimões (AM). Dissertação de Mestrado. Aracaju: Universidade Federal de Sergipe, 2018.

LOWIE, R. H. The Tropical Forest: An Introduction. In: STEWARD, J. Handbook of South American Indians. Washington: Bureau of American Ethnology, Smithsonian Institution, v. III, 1948. p. 1-56.

MACHADO, J. S. Arqueologia e história nas construções de continuidade na Amazônia. Bol. Mus. Para. Emílio Goeldi. Ciências Humanas 4(1): 57-70, 2009.

MACHADO, J. S. Lugares de gente: mulheres, plantas e redes de troca no delta amazônico.Tese de Doutorado. Rio de Janeiro: Universidade Federal do Rio de Janeiro, 2012.

MAGAlHÃES, M. P. Levantamento Arqueológico ao longo das BRs (PA) 230 e 422 (Novo Repartimento/Tucuruí). Relatório final. Belém: Museu Paraense Emílio Goeldi, 2003.

MAgalhães, M. P. A phýsis da origem. Belém: Museu Paraense Emílio Goeldi, 2005.

MAGAlHÃES, M. P. Amazônia Antropogênica (org.). Belém: Museu Paraense Emílio Goeldi, 2016.

MARTINS, C. Sobre contatos e fronteiras: um enfoque arqueológico. Amazônica 4(1): 150-184, 2012. 
MCMICHAEL, C. H.; PIPERNO, D. R.; BUSH, M. B.; SILMAN, M. R.; ZIMMERMAN, A. R.; RACZKA, M. F.; LOBATO, L. C. Sparse Pre-Columbian Human Habitation in Western Amazonia. Science 336:1429-1431, 2012.

MCMICHAEL, C. H.; PALACE, M. W.; BUSH, M. B.; BRASWELL, B.; HAGEN, S.; NEVES, E. G.; SILMAN, M. R.; TAMANAHA, E. K.; CZARNECKI, C. Predicting preColumbian anthropogenic soils in Amazonia. Proceedings of Royal Society B 281: $20132475,2014$.

MEGGERS, B. J. Environmental Limitation on the Development of Culture. American Anthropologist 56:801-823, 1954

MEGGERS, B. J. Amazônia: A Ilusão de um Paraíso. Belo Horizonte: Itatiaia, 1976.

MEGGERS, B. J. Prehistoric Population Density in the Amazon Basin. IN.: VERANO, J. W.; UBELAKER, D. H. (eds.). Disease and Demography in the Americas. Washington, D. C.: Smithsonian Institution Press, p. 197-205, 1992.

MEGGERS, B. J. La cerámica temprana en América Del Sur. Invención independiente o difusión? Revista de Arqueologia Americana 13:7-40, 1997.

MEGGERS, B. J.; EVANS, C. Archaeological investigations at the mouth of the Amazon. Washington: Smithsonian Institution Press, v. Smithsonian Institution Bulletin No 167, 1957.

MEGGERS, B. J.; EVANS, C. An experimental formulation of horizon styles in the tropical forest area of South America. In: LOTHROP, S. Essays in Precolumbian Art and Archaeology. Cambridge: Harvard University Press, 1961. p. 372-388.

MEGGERS, B. J. \& EVANS, C. Como interpretar a linguagem da cerâmica: Manual para arqueólogos. Washington: Smithsonian Institution, 1970.

MEGGERS, B. J. \& EVANS, C. Lowland South America and the Antilles. Ancient South America. IN.: JENNINGS, J. D. (Ed.). Ancient South Americans. San Francisco: W. H. Freeman and Company, 1983. p. 286-335.

MILDER, S. E. S. Salvamento Arqueológico e Educação Patrimonial da área abrangida pela LT 500 kV - Cuiabá - Ribeirãozinho e LT 500 kV Ribeirãozinho Rio Verde Norte (MT/GO). Relatório Técnico Final. 2010. 
MILLER, E. T. Inventário Arqueológico da Bacia e Sub-Bacias do Rio Madeira 1974

- 1987. São Paulo: CNEC, 1987a.

MILLER, E. T. Relatório das pesquisas arqueológicas efetuadas na área de abrangência da UHE-Ji-Paraná (1986-87). São Paulo: CNEC, 1987b.

MILLER, E. T. Projeto de Avaliação do potencial arqueológico na área de influência da rodovia BR-429 - Presidente Médici a Costa Marques. Porto Velho: Gov. Estado de Rondônia, SEPLAN, 1987c.

MILLER, E. T. Adaptação agrícola pré-histórica no alto rio Madeira. In: MEGGERS, B. J. Prehistoria Sudamericana: Nuevas Perspectivas. Washington: Taraxacum, 1992. p. 219-229.

MILLER, E. T.; CALDARELLI, S. B. Estudos de viabilidade arqueológica nas áreas de inundação e de influência da UHE Ji-Paraná. Relatório de Atividades. Belém: Museu Paraense Emílio Goeldi, 1987.

MONGELÓ, G. Z. O formativo e os modos de produção: ocupações pré-ceramistas no Alto Rio Madeira-RO. Dissertação de Mestrado. São Paulo: Museu de Arqueologia e Etnologia da Universidade de São Paulo, 2015.

MORAES, C. P. Amazônia ano 1000: territorialidade e conflito no tempo das chefias regionais. Tese de Doutorado. São Paulo: Museu de Arqueologia e Etnologia da Universidade de São Paulo, 2013.

MORAES, C. P.; NEVES, E. G. O Ano 1000: Adensamento populacional, interação e conflito na Amazônia Central. Amazônica 4(1): 122-148, 2012

NAVARRO, A. G. O complexo cerâmico das estearias do Maranhão. IN.: BARRETO, C.; LIMA, H. P. \& BETANCOURT, C. J. (orgs.) Cerâmicas Arqueológicas da Amazônia: rumo a uma nova síntese. Belém: IPHAN/MinC, p. 158-168, 2016.

NEVES, E. G. A Arqueologia da Amazônia Central e as classificações na Arqueologia Amazônica. IN. PEREIRA. E.; GUAPINDAIA, V. (orgs). Arqueologia Amazônica. Belém: MPEG; IPHAN; SECULT, 2010. Volume 2. p. 53-71.

NEVES, E.G. Archaeological Cultures and Past Identities in Precolonial Central Amazon. IN.: Hornborg, A. \& Hill, J. (Org.). Ethnicity in Ancient Amazonia: Reconstructing Past 
Identities from Archaeology, Linguistics and Ethnohistory. Boulder. University of Colorado Press. p. 31-56, 2011.

NEVES, E. G. Sob os tempos do equinócio: oito mil anos de história na Amazônia Central (6.500 AC - 1500 DC). Tese de Livre Docência. São Paulo: Museu de Arqueologia e Etnologia da Universidade de São Paulo, 2012.

NEVES, E. G.; PETERSEN, J. Political economy and pre-columbian: landscape transformation in Central Amazonia. IN: BALÉE, W.; ERICKSON, C. Time and Complexity in Historical Ecology: Studies in the Neotropical Lowlands. New York: Columbia Press University, p. 279-309, 2006.

NEVES, E. G.; GUAPINDAIA, V. L. C.; LIMA, H. P.; COSTA, B. L. S.; GOMES, J. A tradição Pocó-Açutuba e os primeiros sinais visíveis de modificações de paisagens na calha do Amazonas. In: RÓSTAIN, S. Antes de Orellana: Actas del 3er Encuentro Internacional de Arqueología Amazónica. Quito: IFEA, 2014. p. 137-158.

NÍCOLI, I. Estudo de Cerâmicas de Sitios Arqueológicos Circulares da Bacia Amazônica por Meio de Métodos Geoquímicos: Datação e Caracterização. Dissertação de Mestrado. Rio de Janeiro: Departamento de Geoquímica, Universidade Federal Fluminense, 2000.

NIMUENDAJÚ, C. Tribes of the lower and middle Xingú river. IN.: STEWARD, J. H. (Ed.). Handbook of South American Indians: the tropical forest tribes, v. 3. Washington: Smithsonian Institution, p. 213-243, 1948.

NIMUENDAJÚ, C. Mapa etnohistórico. Rio de Janeiro: IBGE, 1981.

NIMUENDAJÚ, C. Comments on the Archaeological Finds. IN.: STENBORG, P. (Ed.). Pursuit of a Past Amazon. Archaeological Researches in the Brazilian Guyana and in the Amazon Region. Götenborg: Etnologiska Studier, 45, 2004.

NORDENSKIÖLD, E. L'Archaéologie du bassin de l'Amazone. Paris: G. Van Oest, 1930.

OLIVEIRA, E. Potes que encantam: estilo e agência na cerâmica polícroma da Amazônia Central. Dissertação de Mestrado. São Paulo: Museu de Arqueologia e Etnologia da Universidade de São Paulo, 2016. 
OLIVEIRA, E. R. Aspectos da interação cultural entre os grupos ceramistas précoloniais do médio curso do rio Tocantins. Dissertação de Mestrado. São Paulo: PPGA/MAE-USP, 2005.

OLIVEIRA, E. R.; SILVEIRA, M. I. A cerâmica Mina no estado do Pará: oleiras das águas salobras da Amazônia. IN. BARRETO, C.; LIMA, H. P. \& BETANCOURT, C. J. (orgs.) Cerâmicas Arqueológicas da Amazônia: rumo a uma nova síntese. Belém: IPHAN/MinC, p. 125-146, 2016.

OLIVEIRA, M.C. Arte Rupestre de Rondônia. Presidente Médici, RO, 2013.

OLIVER, J. The Archaeology of Agriculture in Ancient Amazonia. IN. SILVERMAN, H; ISBELL, W. H. (orgs). The Handbook of South American Archaeology. New York: Springer, pp. 185-216, 2008.

OLIVER, J. Nuevos aportes a la arqueología del sitio El Saladero, bajo Orinoco, Venezuela. IN. ROSTAIN, S. (org.). Antes de Orellana: Actas del 3er Encuentro Internacional de Arqueología Amazónica. Quito: IFEA, p. 97-112, 2014.

ORIGEM ARQUEOlogiA. Programa de Gestão do Patrimônio Arqueológico, Histórico e Cultural LT 800 kV Xingu - Estreito e Instalações Associadas Etapa de Diagnóstico Interventivo. Relatório técnico. 2014.

PALACE, M. W.; MCMICHAEL, C. N. H.; BRASWELL, B. H.; HAGEN, S. C.; BUSH, M. B.; NEVES, E. G.; TAMANAHA, E. K.; HERRICK, C.; FROLKING, S. Ancient Amazonian populations left lasting impacts on forest structure. Ecosphere 8(12):e02035, 2017.

PALMATARY, H. C. Tapajo Pottery. Etnologiska studier 8: 1-136, 1939.

PANACHUCK, L. Cerâmicas Pocó e Konduri no baixo Amazonas. IN.: BARRETO, C.; LIMA, H. P. \& BETANCOURT, C. J. (orgs.) Cerâmicas Arqueológicas da Amazônia: rumo a uma nova síntese. Belém: IPHAN/MinC, p. 279-287, 2016.

PÄRSSINEN, M.; RANZI, A.; SAUNALUOMA, S.; SIIRIÄNEN, A. Geometrically patterned ancient earthworks in the rio Branco region of Acre, Brazil. IN.: PÄRSSINEN, M.; KORPISAARI, A. (Ed.). Western Amazonia - Amazônia ocidental (Renvall Institute Publications 14): 97-133. Helsinki: Renvall Institute for Area and Cultural Studeis, University of Helsinki, 2003. 
PELlini, J. R., TELleS, M. Primeiro relatório parcial do Projeto de Resgate Arqueológico da área afetada pelas obras de Adequação e Pavimentação da Rodovia BR-429. Relatório técnico. Goiânia, 2011.

PEREIRA, E. Levantamento arqueológico na área da UHE Belo Monte, rio Xingu (PA). Relatório Final. Belém: Museu Paraense Emílio Goeldi, 3 volumes, 2002.

PEREIRA, E. Arte Rupestre na Amazônia - Pará. Belém: MPEG; São Paulo: UNESP, 2003.

PEROTA, C. Relatório de trabalho de campo realizado no rio Xingu, durante o mês de julho de 1977, para o Programa Nacional de Pesquisas Arqueológicas na Bacia Amazônica (PRONAPABA). Vitória: UFES, 1977.

PEROTA, C. Adaptação agrícola no baixo Xingu. IN: MEGGERS, B. (org.) Prehistoria Sudamericana: Nuevas Perspectivas. Washington, Taraxacum, pp. 211-218, 1992.

PEROTA, C.; BOTELHO, W. C. Os sambaquis do Guará e as variações climáticas no Holoceno. Revista do Departamento de Geografia 7:49-59, 1994.

PETERSEN, J. B.; NEVES, E. G.; HECKENBERGER, M. J. Gift from the past: terra preta and prehistoric occupation in Amazonia. In: MCEWAN, C.; BARRETO, C.; NEVES, E. G. Unknown Amazon. Culture in Nature in Ancient Brazil. London: British Museum Press, p. 86-107, 2001.

PIPERNO, D.; MCMICHAEL, C.; BUSH, M. B. Amazonia and the Anthropocene: What was the spatial extent and intensity of human landscape modification in the Amazon Basin at the end of prehistory? The Holocene, p. 1-10, 2015.

POLITIS, G. Plant exploitation among the Nukak hunter-gatherers of Amazonia: between ecology and ideology. In: GOSDEN, C.; HATHER, J. (Ed.). The Prehistory of Food: Appetites for Change. London: Routledge, 1999. p. 99-126

POLITIS, G. Moving to produce: Nukak mobility and settlement patterns in Amazonia. World Archaeology 27:492-211, 1996.

PORRO, A. O Povo das Águas: Ensaios de Etno-história Amazônica. Petrópolis: Vozes, 1996 
PRESERVAR Arqueologia e Patrimônio. Linha de Transmissão 500 kV Manaus - Boa Vista, Subestação Lechuga (AM), Subestação Equador (RR) e Subestação Boa Vista (RR), Estado do Amazonas e Roraima. Relatório final do diagnóstico arqueológico. Curitiba, 2012.

PUGLIESE JUNIOR, F. A.; VALLE, R. B. M. A gestão do patrimônio arqueológico em territórios indígenas. Revista de Arqueologia 28(1): 30-51, 2017.

PUGLIESE JUNIOR, F. A.; VALLE, R. B. M. Sobre sítios arqueológicos e lugares significativos: impactos socioambientais e violações dos direitos culturais dos povos indígenas e tradicionais pelos projetos de usinas hidrelétricas na bacia do rio Tapajós. IN.: ALARCON, D. F.; Millikan, B.; TORRES, M. Ocekadi: hidrelétricas, conflitos socioambientais e resistência na bacia do Tapajós. Brasília, DF: International Rivers Brasil; Santarém, PA: Programa de Antropologia e Arqueologia da Universidade Federal do Oeste do Pará, p. 417-436, 2016.

QUINN, E. R. Excavating "Tapajó" ceramics at Santarém: their age and archaeological context. Tese de Doutorado. Chicago: University of Illinois, 2004.

RANZI, A. Geoglifos: Patrimônio cultural do Acre. IN.: PÄRSSINEN, M.; KORPISAARI, A. (Ed.). Western Amazonia - Amazônia ocidental (Renvall Institute Publications 14): 135-172. Helsinki: Renvall Institute for Area and Cultural Studeis, University of Helsinki, 2003.

RANZI, A., FERES, R. \& BROWN, F. Internet Software Programs Aid in Search for Amazonian Geoglyphs. American Geophysical Union - EOS (88) 21:226-229, 2007.

RAPP PY-DANIEL, A. Os contextos funerários na arqueologia da calha do rio Amazonas. Tese de Doutorado. São Paulo: Museu de Arqueologia e Etnologia da Universidade de São Paulo, 2015.

REBELLATO, L. Interpretando a variabilidade cerâmica e as assinaturas químicas e físicas do solo no sítio arqueológico Hatahara. Dissertação de Mestrado. São Paulo: Museu de Arqueologia e Etnologia da Universidade de São Paulo, 2007.

ROBERTS, P.; HUNT, C.; ARROYO-KALIN, M.; EVANS, D.; BOIVIN, N. The deep human prehistory of global tropical forests and its relevance for modern conservation. Nature Plants 3, 17093, 2017. 
ROBRAHN GONZALEZ, E.M. Os grupos ceramistas pré-coloniais do Centro-Oeste brasileiro. Revista do Museu de Arqueologia e Etnologia 6: 83-121, 1996.

ROCHA, B. C. Ipi Ocemumuge: a regional archaeology of the upper Tapajós river. Tese de Doutorado. Londres: Institute of Archaeology, University College London, 2017.

ROCHA, B. C.; JACOME, C.; STUCHI, F. F.; MONGELO, G. Z.; VALLE, R. B. M. Arqueologia pelas Gentes: um manifesto. Constatações e posicionamentos críticos sobre a arqueologia brasileira em tempos de PAC. Revista de Arqueologia 26:130-140, 2013.

ROCHA, B. C.; BELETTI, J.; PY-DANIEL, A. R.; MORAES, C. P.; Oliveira, V.E.H. $\mathrm{Na}$ Margem e à Margem: Arqueologia Amazônica em Territórios Tradicionalmente Ocupados. Amazônica 6: 358-384, 2014.

RODRIGUES, J. B. Exploração e estudo do Valle do Amazonas. O rio Tapajós. Rio de Janeiro: Typographia Nacional, 1875.

ROOSEVELT, A. C. Early pottery in the Amazon: twenty years of scholarly obscurity. IN: BARNETT, W. K.; HOOPES, J. (Eds.). The emergence of pottery. Technology and innovation in ancient societies. Washington, D.C.: Smithsonian Institution Press, 1995. p. 115-131.

ROOSEVELT, A. C. The Amazon and the Anthropocene: 13,000 years of human influence in a tropical rainforest. Anthropocene 4: 69-87, 2014.

ROSTAIN, S. Etnoarqueología de las casas Huapula y Jíbaro. Bulletin de l'Institut français d'études andines 35 (3): 337-346, 2006.

ROStain, S.; SAUlieU, G. Antes. Arqueología de la Amazonía ecuatoriana. Quito: IFEA/IPGH/IRD, 2013.

ROSTAIN, S.; VERSTEEG, A. The Arauquinoid tradition in the Guianas. IN.: DELPUECH, A.; HOFFMAN, C. L. (Eds.). Late ceramic age societies in the Eastern Caribbean. Paris: BAR International, p. 233-250, 2004.

ROUSE, I.; CRUXENT, J. M. Arqueología Venezolana. Altos de Pipe (Miranda): Instituto Venezolano de Investigaciones Científicas, 1963. 
RUSSELL, J.C. Integrated approach to predictive modeling: a case study from the Upper Xingu (Mato Grosso, Brazil). Dissertação de Mestrado. Florida: Department of Anthropology, University of Florida, 2005.

SAldanha, J. D. M. Poços, Potes e Pedras: uma longa história indígena na costa da Guayana. Tese de Doutorado. São Paulo: Museu de Arqueologia e Etnologia da Universidade de São Paulo, 2016.

SAUNALUOMA, S. Os sítios pré-colombianos com estruturas de terra na região de fronteira entre o Acre, Brasil, e Riberalta, Bolívia, Amazônia sul-ocidental. Revista de Arqueologia 27(2):125-149, 2014.

SAUNALUOMA, S. Cerâmicas do Acre. IN. BARRETO, C.; LIMA, H. P. \& BETANCOURT, C. J. (orgs.) Cerâmicas Arqueológicas da Amazônia: rumo a uma nova síntese. Belém: IPHAN/MinC, p. 414-419, 2016.

SAUNALUOMA, S.; SCHAAN, D. Monumentality in Western Amazonian formative societies: geometric ditched enclosures in the Brazilian state of Acre. Antiqua 2(1): 1$11,2012$.

SAUNALUOMA, S.; VIRTANEN, P. K. Variable model for organization of earthworking communities in Upper Purus, Southwestern Amazonia: archaeological and ethnographic perspectives. Tipití: Journal of the Society for the Anthropology of Lowland South America 13(1): 23-43, 2015.

SAUNALUOMA, S.; PÄRSSINEN, M.; SCHAAN, D. Diversity of Pre-colonial Earthworks in the Brazilian State of Acre, Southwestern Amazonia. Journal of Field Archaeology (no prelo), 2018.

SCHAAN, D. Into the labyrinths of Marajoara pottery: Status and cultural identity in prehistoric Amazonia. IN: MCEWAN, C.; BARRETO, C.; NEVES, E. G. Unknown Amazon: Culture in nature in Ancient Brazil. London: The British Museum, 2001.

SCHAAN, D. P. The Camutins chiefdom: rise and development of social complexity on Marajó Island, Brazilian Amazon. Tese de Doutorado. Pittsburgh: University of Pittsburgh, 2004. 
SCHAAN, D. P. Uma janela para a história pré-colonial da Amazônia: olhando além - e apesar - das fases e tradições. Bol. Mus. Para. Emílio Goeldi. Ciências Humanas 2(1):77-89, 2007.

SCHAAN, D. P. The Non-agricultural chiefdoms of Marajo Island. In: SILVERMAN, H.; ISBELL, W. (Orgs). Handbook of South American Archaeology. New York: Springer, p. 339-357, 2008.

SCHAAN, D. P. Programa de Prospecções BR-230: Primeiro Relatório Parcial. Belém: NPEA/UFPA, 2010.

SCHAAN, D. P. Programa de Prospecção e Educação Patrimonial na Serra Leste. Belém: UFPA, 2012.

SCHAAN, D. P. \& PLENS, C. R. Diagnóstico sobre a situação do Patrimônio Arqueológico na Área de Implantação das Linhas de Transmissão LT 138 kv Epitaciolância/ Rio Branco e LT 69 kv Rio Branco/ Sena Madureira (incluindo áreas das subestações). Relatório técnico. Belém: Museu Paraense Emílio Goeldi, 2005.

SCHAAN, D. P.; MARTINS, C. Muito além dos campos: arqueologia e história na Amazônia Marajoara. Belém: GKNORONHA, 2010.

SCHAAN, D. P.; PÄRSSINEN, M.; RANZI, A.; PICCOLI, J. C. Geoglifos da Amazônia ocidental: evidência de complexidade social entre povos da terra firme. Revista de Arqueologia (20): 67-82, 2007.

SCHAAN, D. P.; PÄRSSINEN, M.; SAUNALUOMA, S.; RANZI, A.; BUENO, M.; BARBOSA, A. New radiometric dates for precolumbian (2000-700 B.P.) earthworks in western Amazonia, Brazil. Journal of Field Archaeology, v. 37, n. 2, p. 132-142, 2012.

SCHLANGER, S. H. Recognizing persistent places in Anasazi settlement systems. IN: ROSSIGNOL, J. \& WANDSNIDER, L. (eds.), Space, Time, and Archaeological Landscapes. New York: Plenum Press, p. 91-112, 1992.

SCHMIDT, M. J.; RAPP PY-DANIEL, A.; MORAES, C. P.; VALLE, R. B. M.; CAROMANO, C. F.; TEXEIRA, W. G.; BARBOSA, C. A.; FONSECA, J. A.; MAGAlHÃES, M. P.; SANTOS, D. S. C.; SILVA, R. S.; GUAPINDAIA, V. L.; MORAES, B.; LIMA, H. P.; NEVES, E. G.; HECKENBERGER, M. J. Dark earths and 
the human built landscape in Amazonia: a widespread pattern of anthrosol formation. Journal of Archaeological Science 42(1): 152-165, 2014.

SCIENTIA CONSULTORIA. Diagnóstico Arqueológico da UHE Serra Quebrada MA/TO. Relatório Técnico Final. São Paulo: THEMAG/Eletronorte, 1989.

SCIENTIA CONSUlTORIA. Arqueologia Preventiva na Área de Intervenção da Mineração Onça Puma e Linha de Transmissão Associada, Sudeste do Pará. Relatório técnico. São Paulo, 2006.

SCIENTIA CONSULTORIA. Salvamento dos sítios arqueológicos localizados na área diretamente afetada da linha de transmissão Tucuruí/PA - Presidente Dutra/MA ( $3^{\circ}$ Circuito). Relatório técnico final. São Paulo, 2008.

SCIENTIA CONSULTORIA. Estudo de Impacto Ambiental (EIA) da LT 600kV CC Coletora Porto Velho - Araraquara 2. Relatório Técnico Final. São Paulo, 2010.

SCIENTIA CONSUlTORIA. Arqueologia Preventiva na Área de Intervenção da Linha de Transmissão 230 kV Oriximiná (PA) - Mineração Rio do Norte - Etapa de Prospecção. Relatório técnico. São Paulo, 2011.

SCIENTIA CONSUlTORIA. Arqueologia Preventiva da Rodovia Municipal de Canaã dos Carajás. Relatório técnico. São Paulo, 2012.

SCIENTIA CONSUlTORIA. Ramal Ferroviário Sudeste do Pará. Estudo de Impacto Ambiental. Relatório Técnico. São Paulo, 2013.

SCIENTIA CONSULTORIA. Estudo de Impacto Ambiental da UHE Belo Monte. $6^{\circ}$ Relatório Técnico. São Paulo, 2014.

SHEPARD, G. H.; RAMIREZ, H. "Made in Brazil": Human dispersal of the brazil nut (Bertholletia excelsa, Lecythidaceae) in ancient Amazônia. Economic Botany 65: 44-65, 2011.

SILVA, F. A.; STUCHI, F. F.; BESPALEZ, E.; POUGET, F. C. Arqueologia em terra indígena: uma reflexão teórico-metodológica sobre as experiências de pesquisa na Aldeia Lalima (MS) e na Terra Indígena Kaiabi (MT $\backslash$ PA). In: PEREIRA, E. \& GUAPINDAIA, V. (Org.). Arqueologia Amazônica (2). Belém: MPEG; IPHAN; SECULT. 2010 
SILVA, F. A.; GARCIA, L. Território e memória dos Asurini do Xingu: arqueologia colaborativa na T. I. Kuatinemu, Pará. Amazônica 7(1): 74-99, 2015.

SILVA, F. A.; NOELLI, F. S. Arqueologia e Linguística: construindo as trajetórias histórico-culturais dos povos Tupi. Crítica e Sociedade 7(1):55-87, 2017.

SILVEIRA, M.I. Estudo sobre estratégias de subsistência de caçadores coletores préhistóricos do sítio Gruta do Gavião, Carajás (Pará). Tese de Doutorado. São Paulo: Universidade de São Paulo, 1994.

SILVEIRA, M. I.; MARQUES, F. L.T. Levantamento de potencialidades arqueológicas e históricas na área dos municípios de Barcarena e Abaetetuba, PA. Relatório técnico final. Belém: Museu Paraense Emílio Goeldi, 2004.

SILVEIRA, M. I.; RODRIGUES, M. C. L. F.; OLIVEIRA, E. R.; LOSIER, L. M. Sequência cronológica de ocupação na área do Salobo (Pará). Revista de Arqueologia, 21(1):61-84, 2008.

SILVEIRA, M. I.; RODRIGUES, M. C. L. F.; MACHADO, C. L.; OLIVEIRA, E. R.; LOSIER, L. M. Prospecção arqueológica em áreas de floresta - contribuição metodológica da pesquisa na área do Projeto Salobo (Pará). Revista do Museu de Arqueologia e Etnologia 19: 155-178, 2009.

SILVEIRA, M. I.; RODRIGUES, M. C. L. F.; OLIVEIRA, E. R.; LOSIER, L. M. Arqueologia na floresta: contribuição metodológica da pesquisa na Floresta Nacional Tapirapé-Aquiri - FLONATA, área do Salobo, Pará. Revista do Museu de Arqueologia e Etnologia 25: 133-167, 2015

SILVEIRA, M. I.; OLIVEIRA, E. R.; KERN, D. C.; COSTA, M. L.; RODRIGUES, S. F. S. O sítio Jabuti, em Bragança, Pará, no cenário arqueológico do litoral amazônico. Boletim do Museu Paraense Emílio Goeldi - Ciências Humanas 6(2):335-345, 2011. SILVEIRA, M. I.; SCHAAN, D. P. Onde a Amazônia encontra o mar: estudando os sambaquis do Pará. Revista de Arqueologia 18:67-79, 2005.

SIMÕES, M. F. Salvamento arqueológico. IN: ALMEIDA JR., J. M. G. Carajás: desafio político, ecologia e desenvolvimento. São Paulo: Brasiliense; Brasília: Conselho Nacional de Desenvolvimento Científico e Tecnológico. p. 535-559, 1986. 
SIMÕES, M. F. The Castanheira Site: new evidence of the antiquity and history of the Ananatuba phase (Marajo Island, Brazil). American Antiquity 34(4): 402-410, 1969.

SIMÕES, M. F. Índice das fases arqueológicas brasileiras: 1950 - 1971. Belém: Publicações avulsas do Museu Paraense Emílio Goeldi, n. 18, 1972.

SIMÕES, M. Contribuição à arqueologia dos arredores do baixo Rio Negro. Programa Nacional de Pesquisas Arqueológicas 5. Belém. Publicações Avulsas do Museu Paraense Emilio Goeldi 26: 165-188, 1974.

SIMÕES, M. F. Coletores-pescadores ceramistas do litoral do Salgado (Pará). Nota Preliminar. Boletim do Museu Paraense Emílio Goeldi. Série Antropologia (78), 1981. SIMÕES, M. F.; ARAÚJO-COSTA, F. Áreas da Amazônia Legal Brasileira para pesquisa e cadastro de sítios arqueológicos. Publicações Avulsas do Museu Paraense Emílio Goeldi 30. Belém: MPEG, 1978.

SIMÕES, M. F.; MACHADO, A. L. A tradição regional Saracá: uma nova tradição ceramista da Bacia Amazônica. In: Resumos da 36a Reunião Anual da Sociedade Brasileira para o Progresso da Ciência (36). Anais: comunicações. São Paulo: SBPC, 1984. p. 133-13.

SIMÕES, M. F.; KALKMANN, A. Pesquisas arqueológicas no médio rio Negro (Amazonas). Revista de Arqueologia 4(1):83-116, 1987.

SIMÕES, M. F.; CORREA, C. G.; MACHADO, A. L. Achados arqueológicos no baixo rio Fresco (Pará). Publicações Avulsas do Museu Paraense Emílio Goeldi 20:113-141. Belém: MPEG, 1973.

SIMÕES, M. F.; LOPES, D. Pesquisas arqueológicas no baixo/médio rio Madeira (Amazonas). Revista de Arqueologia 4(1):117-133, 1987.

SMITH, N. The Amazon River Forest: A Natural History of Plants, Animals, and People. Oxford: Oxford University Press, 1999.

SÖDERSTRÖM, M.; ERIKSSON, J.; ISENDAHL, C.; SCHAAN, D. P.; STENBORG, P.; REBELLATO, L.; PIIKKI, K. Sensor mapping of Amazonian Dark Earths in deforested croplands. Geoderma 281:58-68, 2016. 
STENBORG, P.; SCHAAN, D.; AMARAL, M. Precolumbian land use and settlement pattern in the Santarem region, Lower Amazon. Amazônica 4(1):222-250, 2012.

STEWARD, J. Culture areas of the tropical rainforest. In: STEWARD, J. Handbook of South American Indias. Washington: Bureau of American Ethnology, Smithsonian Institution, v. III, 1948. p. 883-903.

STEWARD, J. H. The Native Population of South America. IN.: STEWARD, J. H. (eds). Handbook of South American Indians, vol. 5. Bureau of American Ethnology Bulletin 143. Washington, D. C.: Smithsonian Institution, pp. 655-668, 1949.

STUCHI, F. F. A ocupação da Terra Indígena Kaiabi (MT/PA): História indígena e etnoarqueologia. Dissertação de Mestrado. São Paulo: Museu de Arqueologia e Etnologia da Universidade de São Paulo, 2010.

STUIVER, M.; REIMER, P. J. Extended 14C data base and revised CALIB 3.0 14C age calibration program. Radiocarbon 35 (1):215-230, 1993.

SUÑER, R. A. Arqueologia Tupi no Médio Ji-Paraná (RO): teoria do não-equilíbrio dinâmico e abordagem multifocal dos processos de mobilidade populacional no Sudoeste Amazônico. Tese de Doutorado. São Paulo: Museu de Arqueologia e Etnologia da Universidade de São Paulo, 2015.

TAMANAHA, E. K. Ocupação Polícroma no baixo e médio rio Solimões, estado do Amazonas. Dissertação de Mestrado. São Paulo: Museu de Arqueologia e Etnologia da Universidade de São Paulo, 2012.

TAMANAHA, E. K. Cerâmicas e Montículos: o sítio Sol de Campinas do Acre. Projeto de Doutorado. São Paulo: Museu de Arqueologia e Etnologia da Universidade de São Paulo, 2015.

TAMANAHA, E. K.; NEVES, E. G. 800 anos de ocupação da Tradição Polícroma da Amazônia: um panorama histórico no Baixo Rio Solimões. Anuário Antropológico, Brasília, UnB, v. 39, n. 2, p. 45-67, 2014.

TAMANAHA, E. K.; FURQUIM, L. P.; LOPES, R. A.; FERNANDO, V. L. Levantamento de sítios arqueológicos nos lagos Jutica e Caiambé, município de Tefé/AM. Cadernos do LEPAARQ, 12 (23):190-221, 2015. 
TER STEEGE, H., PITMAN, N. C. A., SABATIER, D., BARAlOTO, C., SALOMÃO, R. P., GUEVARA, J. E., et al. Hyperdominance in the Amazonian tree flora. Science 342:1243092, 2013.

THAYN, J.; PRICE, K.P.; WOODS, W.I. Locating Amazonian Dark Earths (ADE) using vegetation vigour as a surrogate for soil type. Int. J. Remote Sens. 32, 6713-6729, 2011. THEMAG Engenharia e Gerenciamento. Estudos de Impacto Ambiental (EIA), aproveitamento hidrelétrico Peixe (UHE Peixe Angical). Diagnóstico SócioEconômico, Volume IV. Novembro, 2000.

THOMPSON, V. D. The rhythms of space-time and the making of monuments and places during the Archaic. IN: THOMAS, D.; SANGER, M. (eds) Trend, Tradition, and Turmoil: What Happened to the Southeastern Archaic? New York: American Museum of Natural History, pp 217-228, 2010.

TIZUKA, M. M. Geoarqueologia e paleohidrologia da planície aluvial Holocênica do rio Madeira entre Porto Velho e Abunã. Dissertação de Mestrado. Departamento de Geologia, UNESP-Rio Claro, 2013.

TONEY, J. R. Cerâmica e história indígena do Alto Xingu. IN.: BARRETO, C.; LIMA, H. P. \& BETANCOURT, C. J. (orgs.) Cerâmicas Arqueológicas da Amazônia: rumo a uma nova síntese. Belém: IPHAN/MinC, p. 224-236, 2016.

TRINDADE, T. B. Geoglifos, zanjas ou earthworks? Levantamento geral dos sítios arqueológicos com estruturas de terra em vala no médio rio Guaporé (RO) e análise comparada com os demais sítios no Sudoeste da Bacia Amazônica. Dissertação de Mestrado. São Paulo: Museu de Arqueologia e Etnologia da Universidade de São Paulo, 2015.

TROUFFLARD, J. Cerâmicas da cultura Santarém, baixo Tapajós. IN.: BARRETO, C.; LIMA, H. P. \& BETANCOURT, C. J. (orgs.) Cerâmicas Arqueológicas da Amazônia: rumo a uma nova síntese. Belém: IPHAN/MinC, p. 237-252, 2016.

UEA - UNIVERSIDADE ESTADUAL DO AMAZONAS. Estudo prévio de impacto ambiental: diagnóstico arqueológico. Manaus: UEA/MURAKI, 2012.

UNIFAP. Levantamento Arqueológico na Linha de Transmissão de 138 KV Central/Santana - C2/Amapá. Relatório Técnico Final. Macapá, 2004. 
UNITINS-NUTA. Programa Saltfens: Salvamento e Monitoramento do Patrimônio Histórico, Cultural, Paisagístico e Arqueológico, na extensão do traçado do eixo da Ferrovia Norte/Sul, de Aguiarnópolis a Talismã, no Estado do Tocantins. Relatório Técnico Final. Palmas: UNITINS-NUTA, 2000a.

UNITINS-NUTA. Programa Saltimins: Salvamento Arqueológico no Trecho da Linha de Transmissão de Imperatriz/MA à Miracema do Tocantins/TO, Interligação Norte/Sul. Relatório Técnico Final. Palmas: UNITINS-NUTA, 2000 b.

UNITINS-NUTA. Programa Saltestreito: Levantamento e Salvamento Arqueológico, Cultural, Histórico e paisagístico da UHE Estreito, MA/TO. Relatório Técnico Final. Palmas: UNITINS-NUTA, 2006.

URBAN, G. A história da cultura brasileira segundo línguas nativas. In: CUNHA, M. C. História dos índios no brasil. São Paulo: FAPESP/SMC/Cia. das Letras, 1992.

VIALOU, A. V. Apresentação. IN.: Vialou, A. V. (org.). Pré-História do Mato Grosso, Volume 1: Santa Elina. São Paulo: EDUSP, p.9-13, 2005.

WILLIAMS, D. Excavation of the Barambina shell mound northwest district: na interim report. Archaeology and Anthropology 4(1-2):13-38, 1981.

WÜST, I. Continuidade e mudança: para uma interpretação dos grupos pré-coloniais da bacia do rio Vermelho, Mato Grosso. Tese de Doutorado. São Paulo: Departamento de Ciências Sociais da Universidade de São Paulo, 1990.

WÜST, I. Etnicidade e tradições ceramistas: algumas reflexões a partir das antigas aldeias Bororo do Mato Grosso. Revista do Museu de Arqueologia e Etnologia, Suplemento 3: 303-317, 1999.

WÜST, I.; BARRETO, C. The rinf villages of Central Brazil: a challenge for Amazonian Archaeology. Latin American Antiquity 10 (1): 3-23, 1999.

ZANETTINI Arqueologia. Diagnóstico Arqueológico Não Interventivo Ferrovia Ferronorte. Relatório Técnico Final. São Paulo, 2010.

ZEDEÑO, M. N.; BOWSER, B. J. The Archaeology of Meaningful Places. IN: BOWSER, B. J.; ZEDEÑO, M. N. (Ed.) The Archaeology of Meaningful Places. Salt Lake City: University of Utah Press, 2009. p.1-15. 
ZIMPEL NETO, C. A. Na direção das periferias extremas da Amazônia: arqueologia na bacia do rio Ji-Paraná, Rondônia. Dissertação de Mestrado. São Paulo: Museu de Arqueologia e Etnologia da Universidade de São Paulo, 2009.

ZUSE, S. Variabilidade cerâmica e diversidade cultural no alto rio Madeira, Rondônia. Tese de Doutorado. São Paulo: Museu de Arqueologia e Etnologia da Universidade de São Paulo, 2014. 
UNIVERSIDADE DE SÃO PAULO

MUSEU DE ARQUEOLOGIA E ETNOLOGIA

PROGRAMA DE PÓS-GRADUAÇÃO EM ARQUEOLOGIA

EDUARDO KAZUO TAMANAHA

\section{Um panorama comparativo da Amazônia no ano 1.000}

VOLUME II

SÃO PAULO

2018 


\section{Um panorama comparativo da Amazônia no ano 1.000}

Tese apresentada ao Programa de PósGraduação em Arqueologia do Museu de Arqueologia e Etnologia da Universidade de São Paulo para obtenção do título de Doutor em Arqueologia

Área de Concentração: Arqueologia

Orientador: Prof. Dr. Eduardo Góes Neves

Linha de Pesquisa: Arqueologia e Identidade

Durante o desenvolvimento deste trabalho o autor recebeu auxílio financeiro da CAPES.

VOLUME II

São Paulo 2018 


\section{SUMÁRIO}

Mapa 1.1-1: Mapa hidrográfico da Amazônia Legal com os nomes dos principais rios mencionados no texto.

Mapa 1.1-2: Mapa hidrográfico da Amazônia Legal com os nomes dos principais rios mencionados no texto. 6

Mapa 3.1-1: Quantidade de sítios arqueológicos por estado 7

Mapa 3.1-2: Quantidade de sítios arqueológicos por município 8

Mapa 3.1-3: Quantidade de sítios arqueológicos por subbacia hidrográfica

Mapa 3.2-1: Localização dos sítios arqueológicos inseridos na Amazônia Legal Brasileira.

Mapa 3.2-2: Localização das áreas com maior concentração (1-6) e menor concentração (A-G) de sítios arqueológicos.

Mapa 3.3.1-1: Localização dos sítios arqueológicos maiores e menores que 10 hectares.

Mapa 3.3.1-2: Detalhe da área de confluências dos rios Solimões-Negro, foz do rio Tapajós e da Serra dos Carajás

Mapa 3.3.2-1: Localização dos sítios arqueológicos a partir das informações de ausência e presença de Terra Preta Antropogênica

Mapa 3.3.2-2: Concentração de sítios com Terra Preta de Índio

Mapa 3.3.2-3: Concentração de sítios sem Terra Preta de Índio

Mapa 3.3.3-1: Localização dos sítios arqueológicos unicomponenciais e multicomponenciais.

Mapa 3.3.3-2: Detalhe da área de confluência dos rios Solimões-Negro, baixo rio madeira e baixo rio Jamari.

Mapa 3.3.4-1: Localização dos sítios a partir da relação entre área e quantidade de componentes culturais. Detalhe para as duas regiões com maior variabilidade.

Mapa 3.3.4-2: Localização dos sítios a partir da relação entre área e o tipo de solo (TPI). Detalhe para as quatro regiões com maior variabilidade.

Mapa 3.3.4-3: Localização dos sítios a partir da relação entre o tipo de solo (TPI) e quantidade de componentes culturais. Detalhe para a região com maior variabilidade. 
Mapa 3.3.4-4: Localização dos sítios a partir da relação entre a área, tipo de solo (TPI) e quantidade de componentes culturais. Detalhe para as duas regiões com maior variabilidade.

Mapa 3.4.1-1: Localização dos sítios arqueológicos com vestígios da Tradição Polícroma da Amazônia (TPA).

Mapa 3.4.1-2: Localização dos sítios arqueológicos com vestígios da Tradição Inciso Ponteada (TIP).

Mapa 3.4.1-3: Localização dos sítios arqueológicos com vestígios da Tradição Borda Incisa (TBI).

Mapa 3.4.1-4: Localização dos sítios arqueológicos com vestígios da Subtradição Tupinambá da Amazônia (STA).

Mapa 3.4.1-5: Localização dos sítios arqueológicos com vestígios da Tradição Mina (TM).

Mapa 3.4.1-6: Localização dos sítios arqueológicos com vestígios da Tradição Regional Saracá (TRS).

Mapa 3.4.1-7: Localização dos sítios arqueológicos com vestígios da Tradição Pocó-Açutuba (TP-A).

Mapa 3.4.1-8: Localização dos sítios arqueológicos com vestígios da Tradição Quinari (TQ).

Mapa 3.4.2-1: Localização de todos os sítios arqueológicos e suas respectivas Tradições associadas.

Mapa 3.4.2-1: Dispersão aproximada dos principais complexos cerâmicos. Extraído de Barreto, Lima e Betancourt (2016).

Mapa 3.5.1-1: Localização de todos os sítios arqueológicos com datações radiocarbônicas.

Mapa 3.5.1-2: Concentração das áreas com maior quantidade de sítios datados.

Mapa 3.5.1-3: Localização dos sítios arqueológicos com datas calibradas entre 600 e 1.400 DC.

Mapa 3.5.2-1: Localização dos sítios arqueológicos e suas respectivas Tradições cerâmicas entre 600 e 800 DC.

Mapa 3.5.2-2: Localização dos sítios arqueológicos e suas respectivas Tradições cerâmicas entre 800 e 1.000 DC.

Mapa 3.5.2-3: Localização dos sítios arqueológicos e suas respectivas Tradições cerâmicas entre 1.000 e 1.200 DC.

Mapa 3.5.2-4: Localização dos sítios arqueológicos e suas respectivas Tradições cerâmicas entre 1.200 e 1.400 DC. 


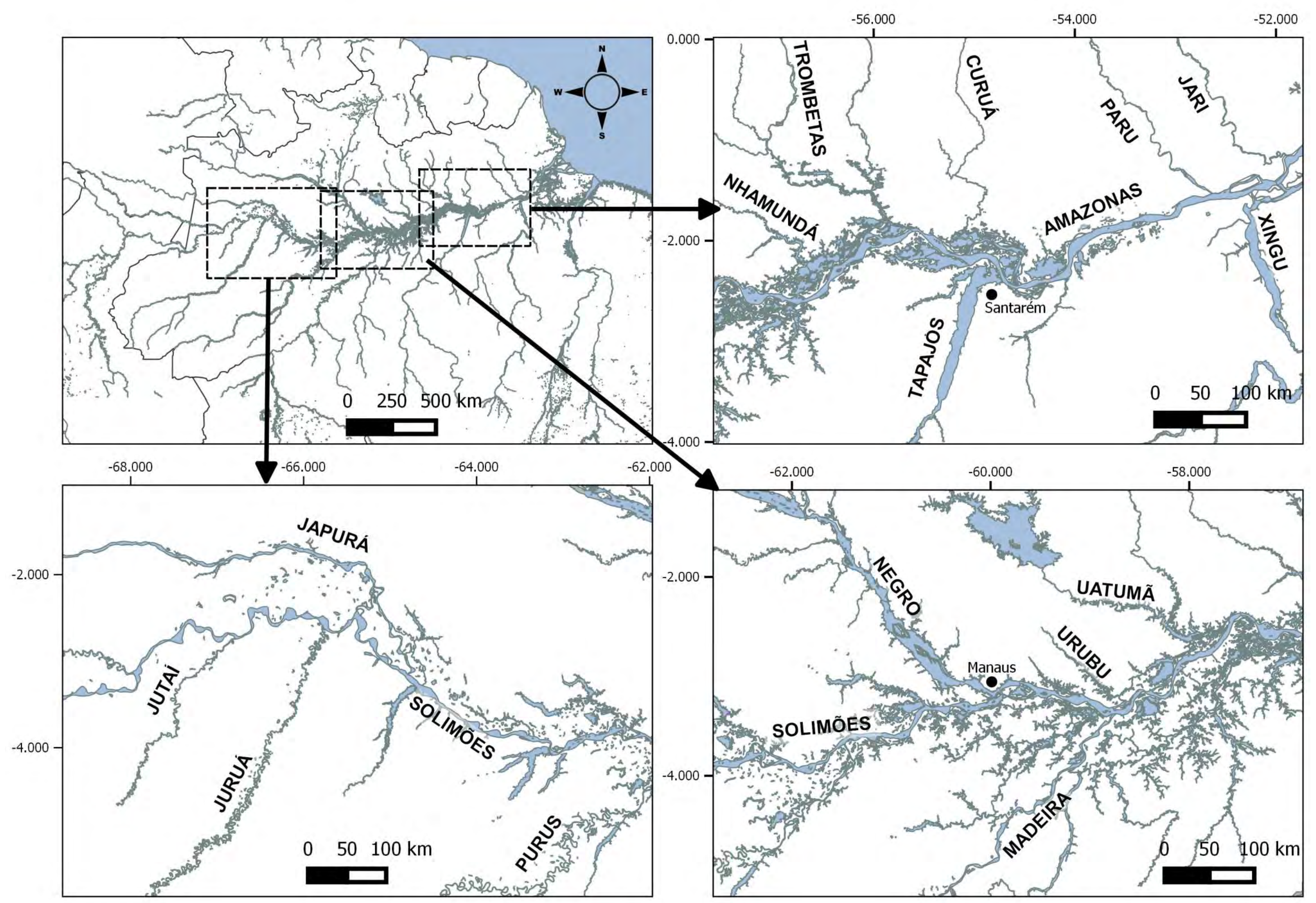

Mapa 1.1-1: Mapa hidrográfico da Amazônia Legal com os nomes dos principais rios mencionados no texto. 


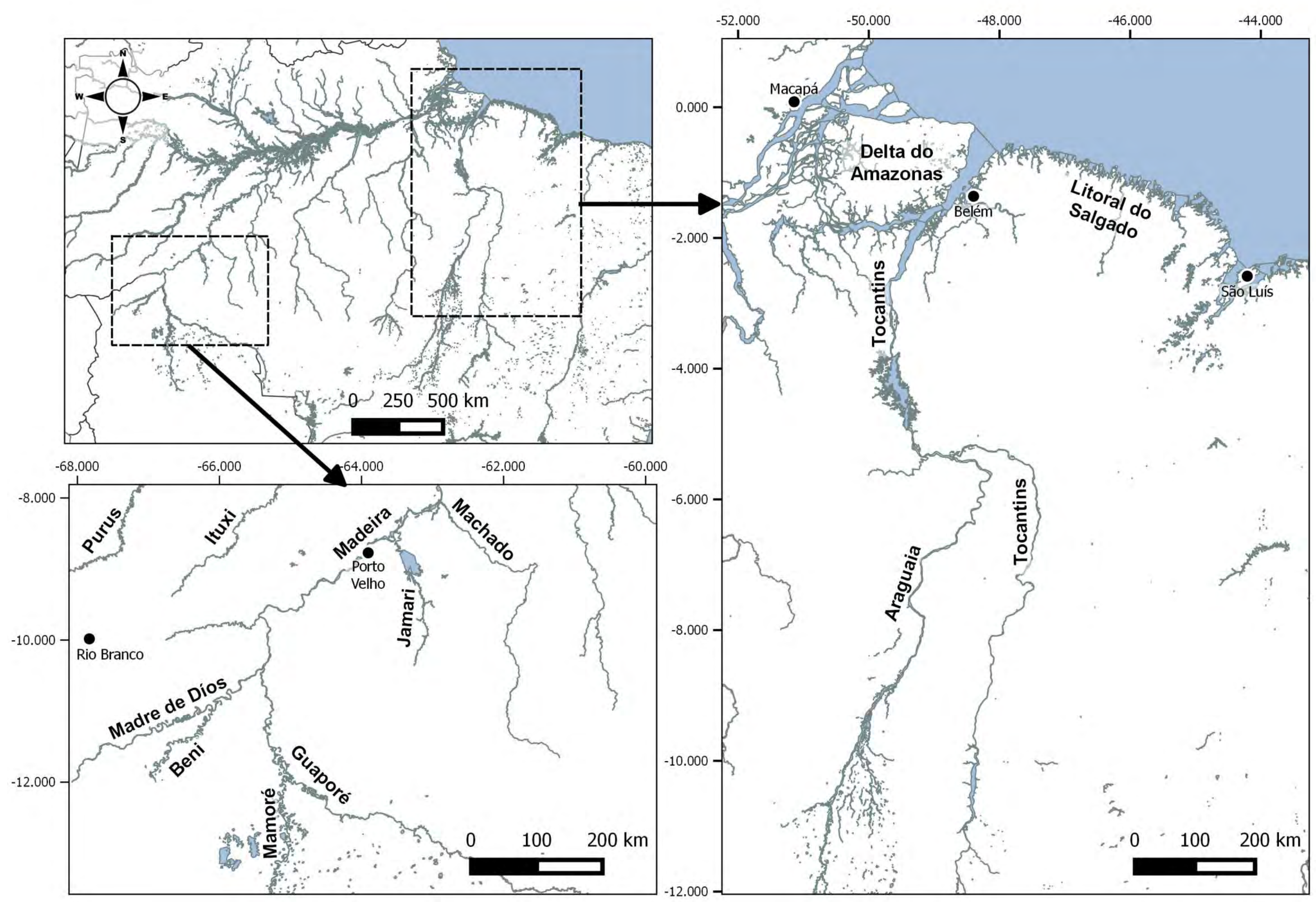

Mapa 1.1-2: Mapa hidrográfico da Amazônia Legal com os nomes dos principais rios mencionados no texto. 


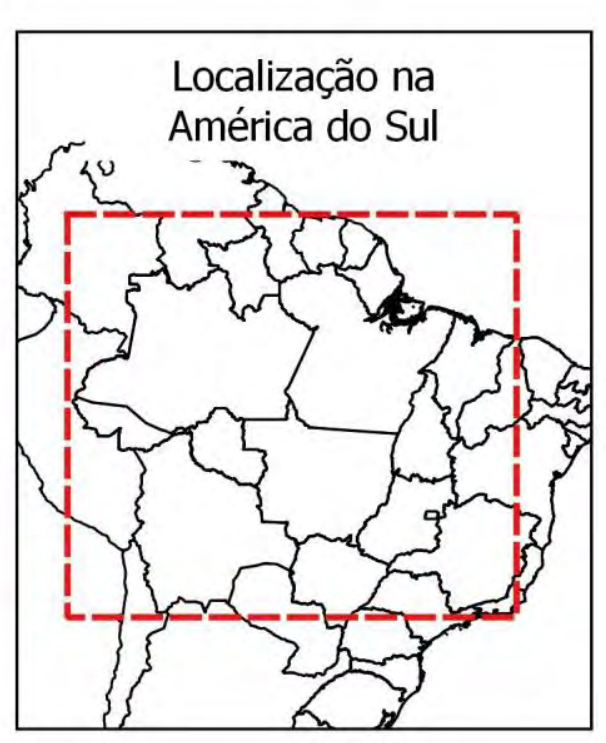

\begin{tabular}{|l|}
\multicolumn{1}{c|}{$\begin{array}{c}\text { Quantidade de sítios } \\
\text { arqueológicos por estado }\end{array}$} \\
Escala - 1:16.000.000 \\
Datum - SIRGAS 2000 \\
Fonte - IBGE \\
Autor - E. Tamanaha \\
\hline
\end{tabular}
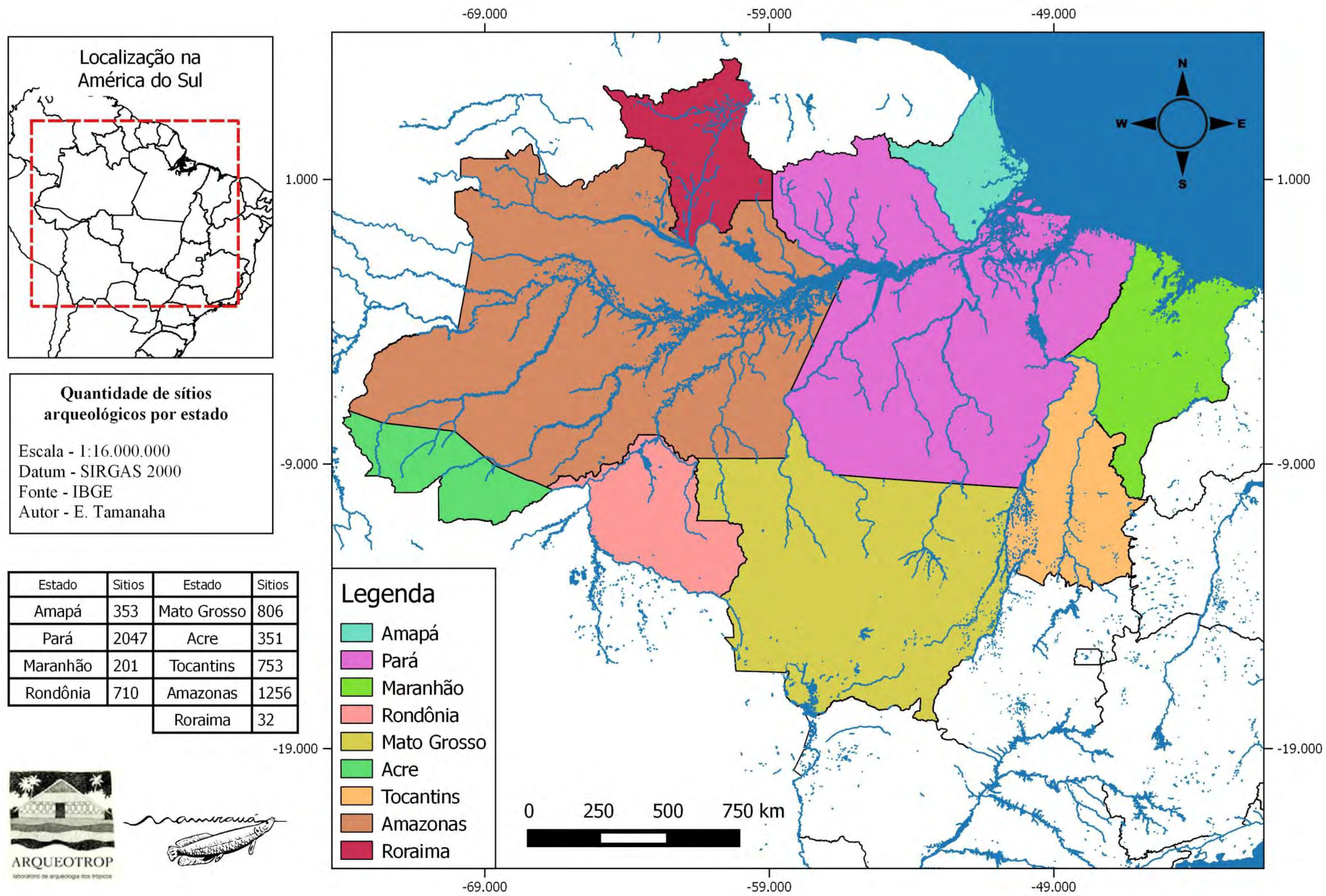

Mapa 3.1-1: Quantidade de sítios arqueológicos por estado 


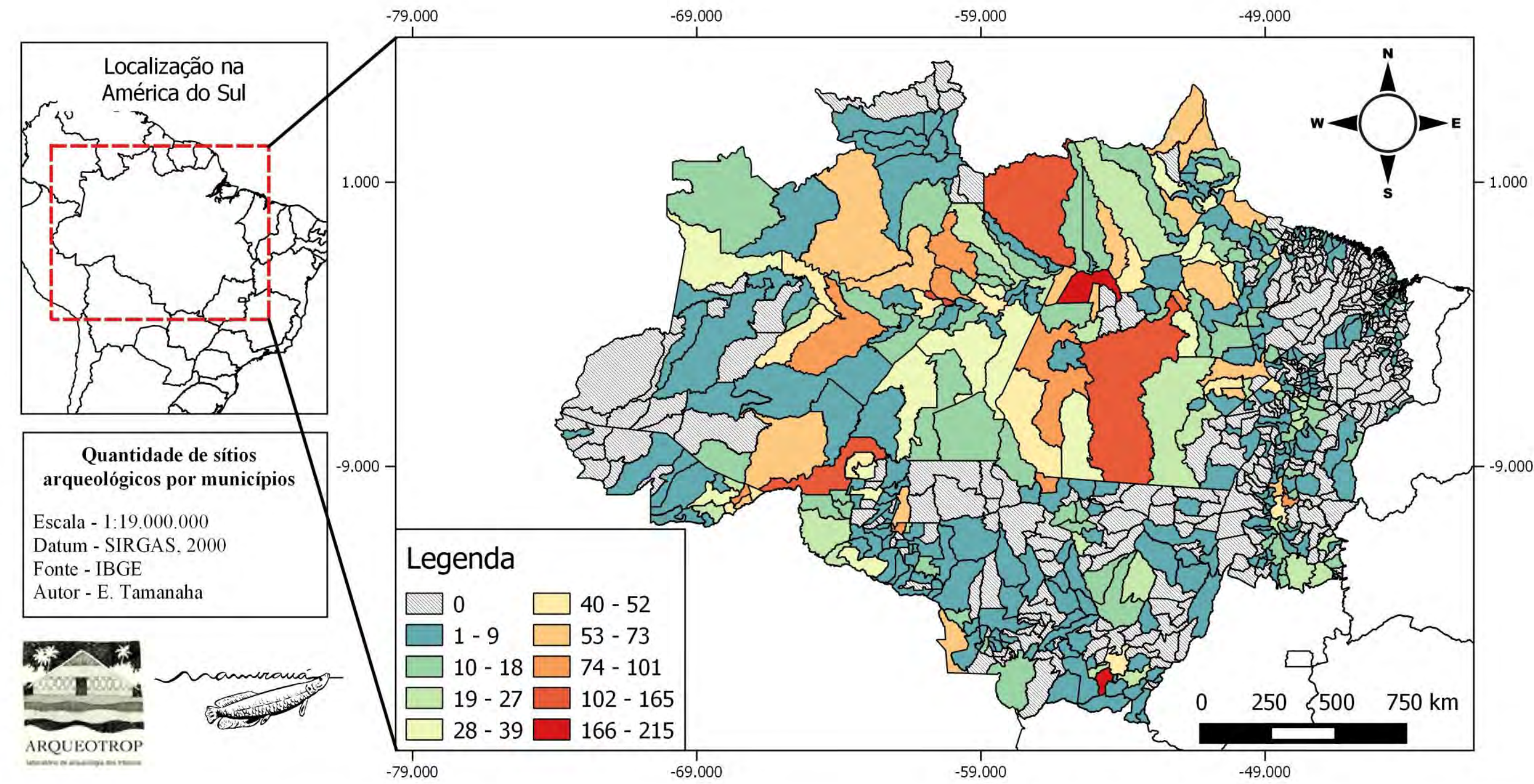

\begin{tabular}{|c|c|c|c|c|c|c|c|c|c|c|c|}
\hline Município & Estado & Sitios & Município & Estado & Sitios & Município & Estado & Sitios & Município & Estado & Sitios \\
\hline RONDONÓPOLIS & MT & 215 & PRESIDENTE FIGUEIREDO & AM & 99 & LAJEADO & TO & 79 & PORTEL & PA & 65 \\
\hline SANTARÉM & PA & 197 & VITÓRIA DO XINGU & PA & 96 & MANAUS & AM & 79 & CHAVES & PA & 64 \\
\hline PORTO VELHO & RO & 165 & PRESIDENTE MÉDICI & RO & 96 & MAZAGÃO & $A P$ & 73 & MARABÁ & PA & 63 \\
\hline ORIXIMINÃ & PA & 151 & PARANá́tA & MT & 91 & MONTE ALEGRE & PA & 71 & PLÁCIDO DE CASTRO & $A C$ & 62 \\
\hline ALTAMIRA & PA & 123 & PALMAS & TO & 90 & OIAPOQUE & AP & 68 & LÁBREA & AM & 61 \\
\hline IRANDUBA & AM & 117 & SENADOR GUIOMARD & $A C$ & 87 & MIRACEMA DO TOCANTINS & TO & 66 & CALÇOENE & AP & 60 \\
\hline ITATUUA & PA & 101 & COARI & AM & 83 & VILA BELA DA SANTÍSSIMA TRINDADE & MT & 65 & CANAÃ DOS CARAJÁS & PA & 60 \\
\hline
\end{tabular}




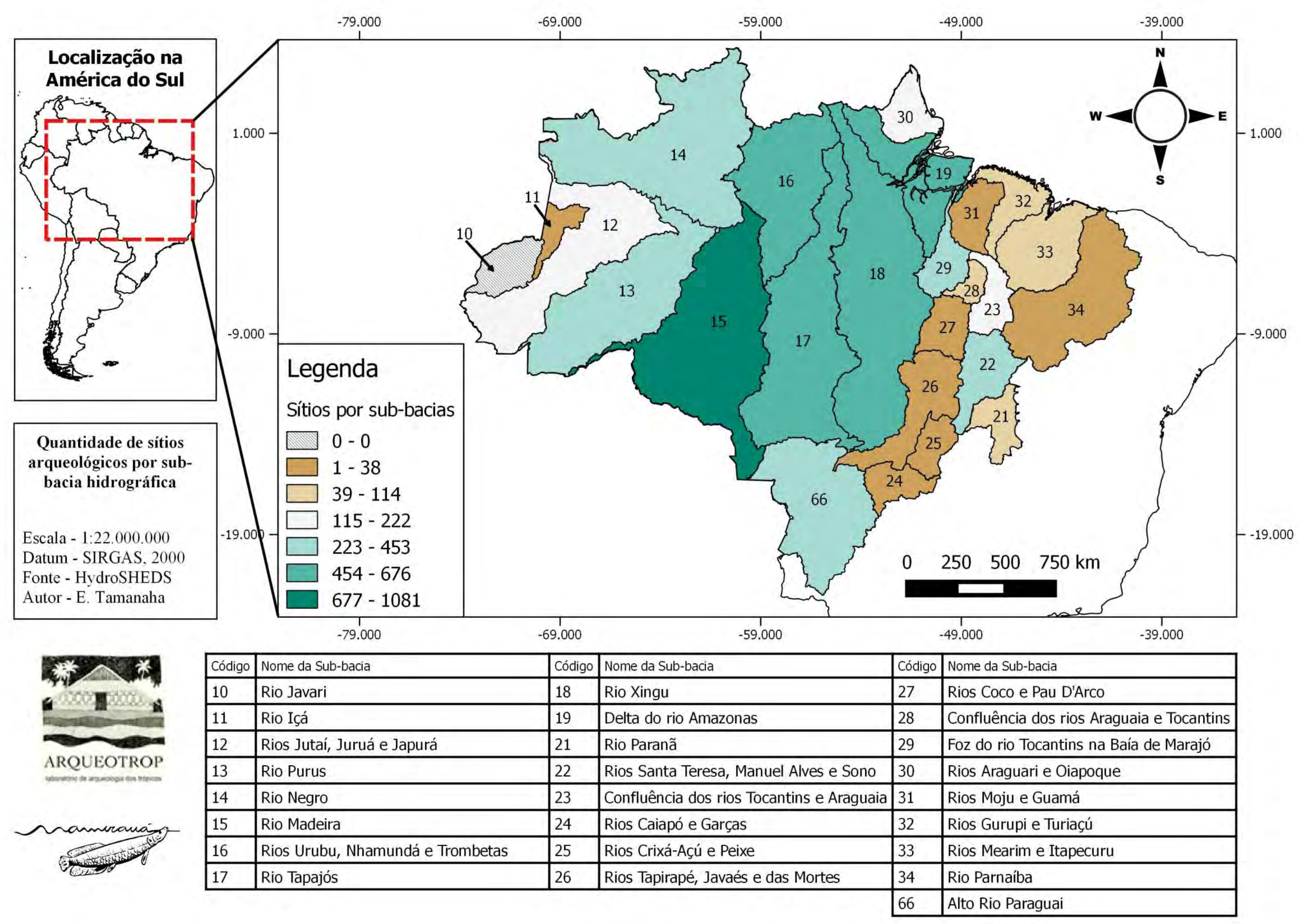

Mapa 3.1-3: Quantidade de sítios arqueológicos por sub-bacia hidrográfica 


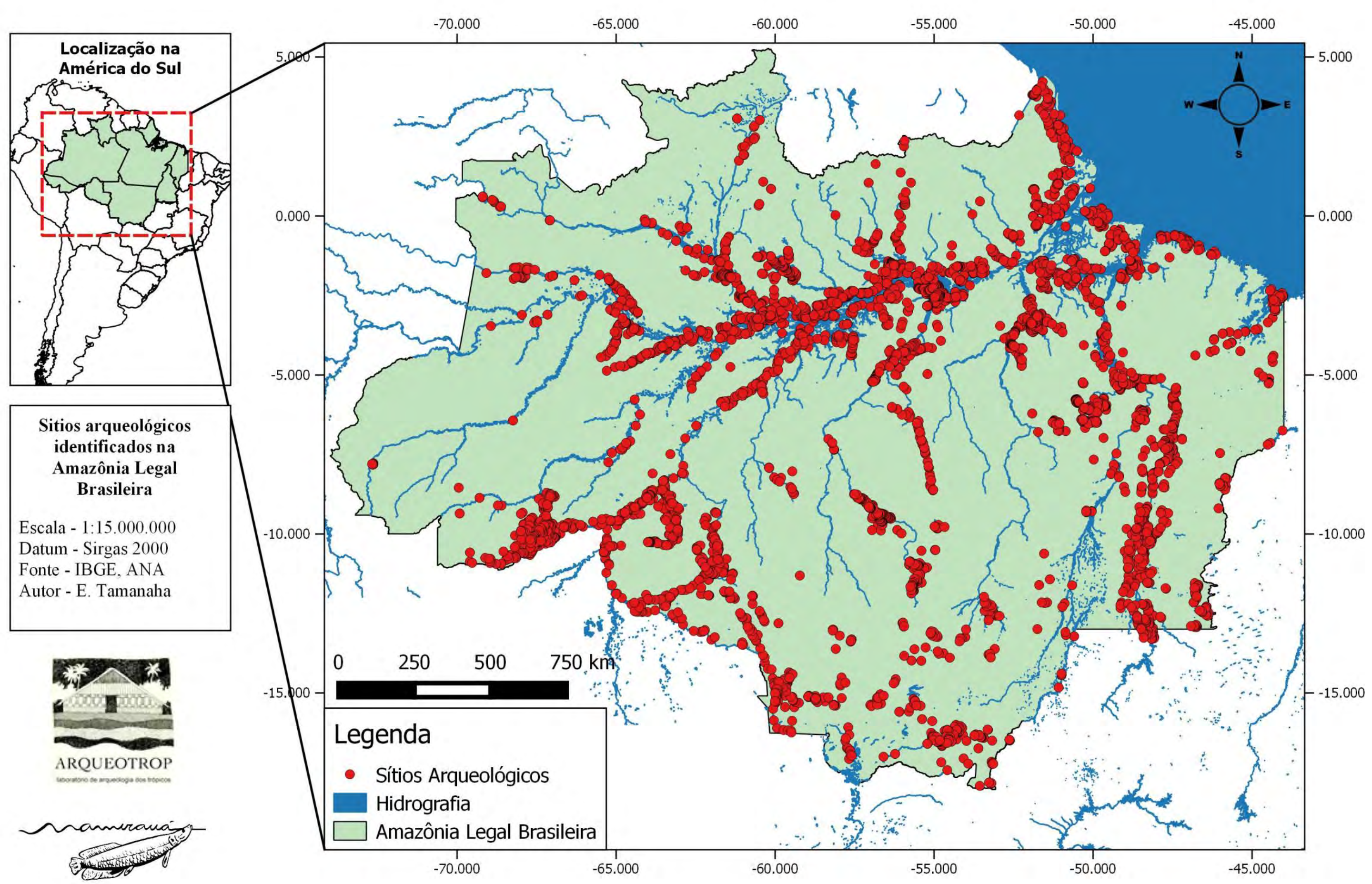

Mapa 3.2-1: Localização dos sítios arqueológicos inseridos na Amazônia Legal Brasileira. 


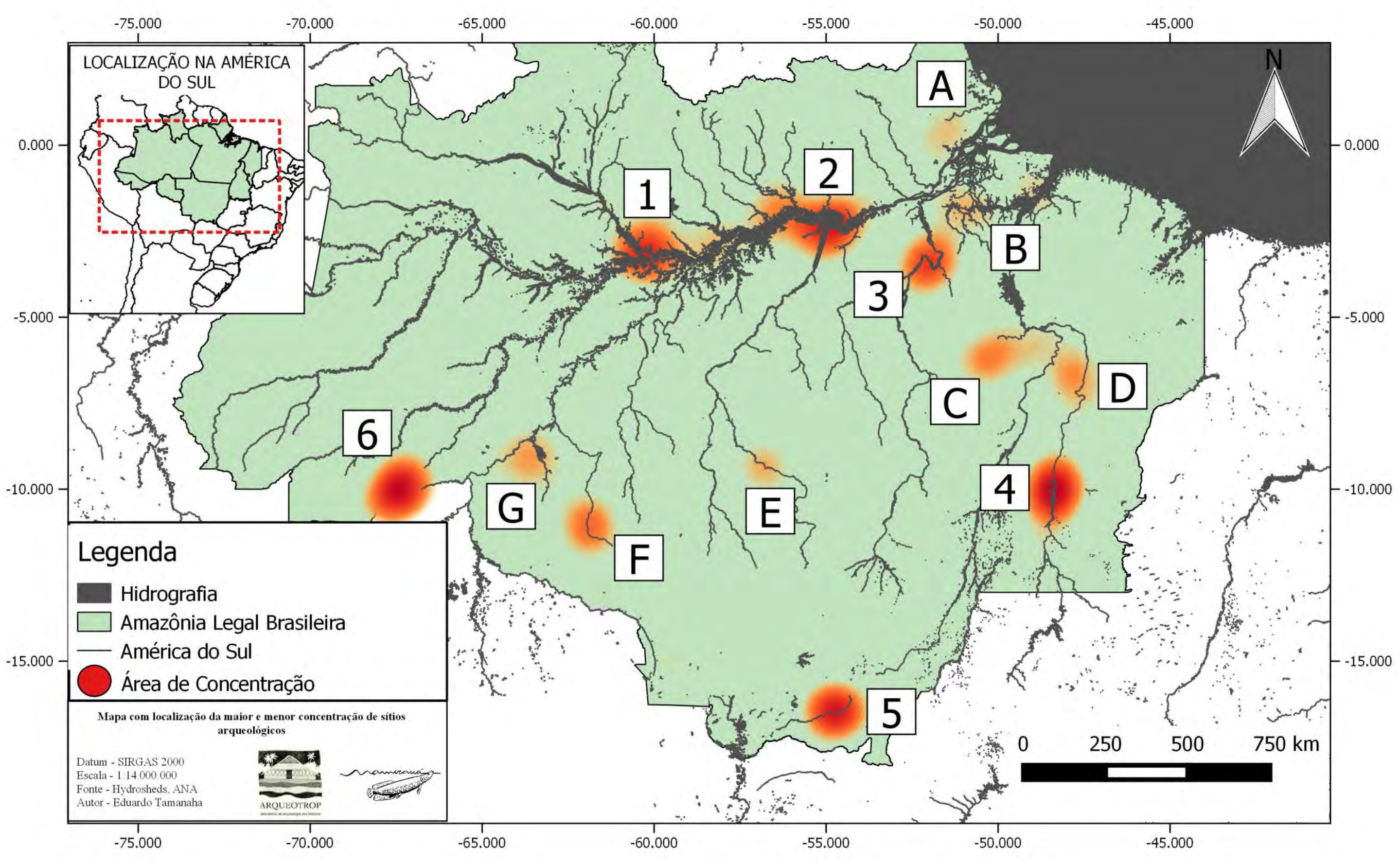




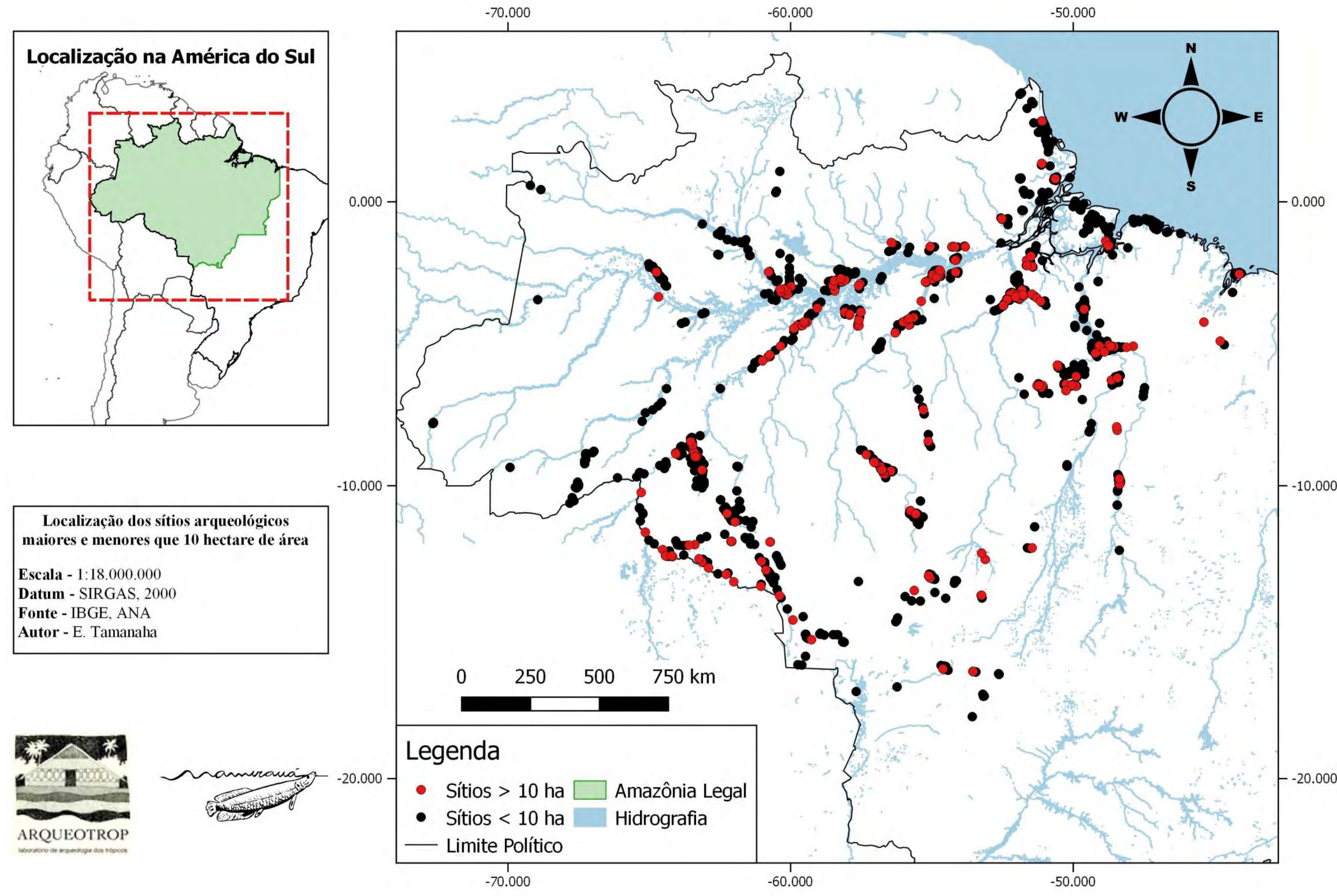

Mapa 3.3.1-1: Localização dos sítios arqueológicos maiores e menores que 10 hectares. 


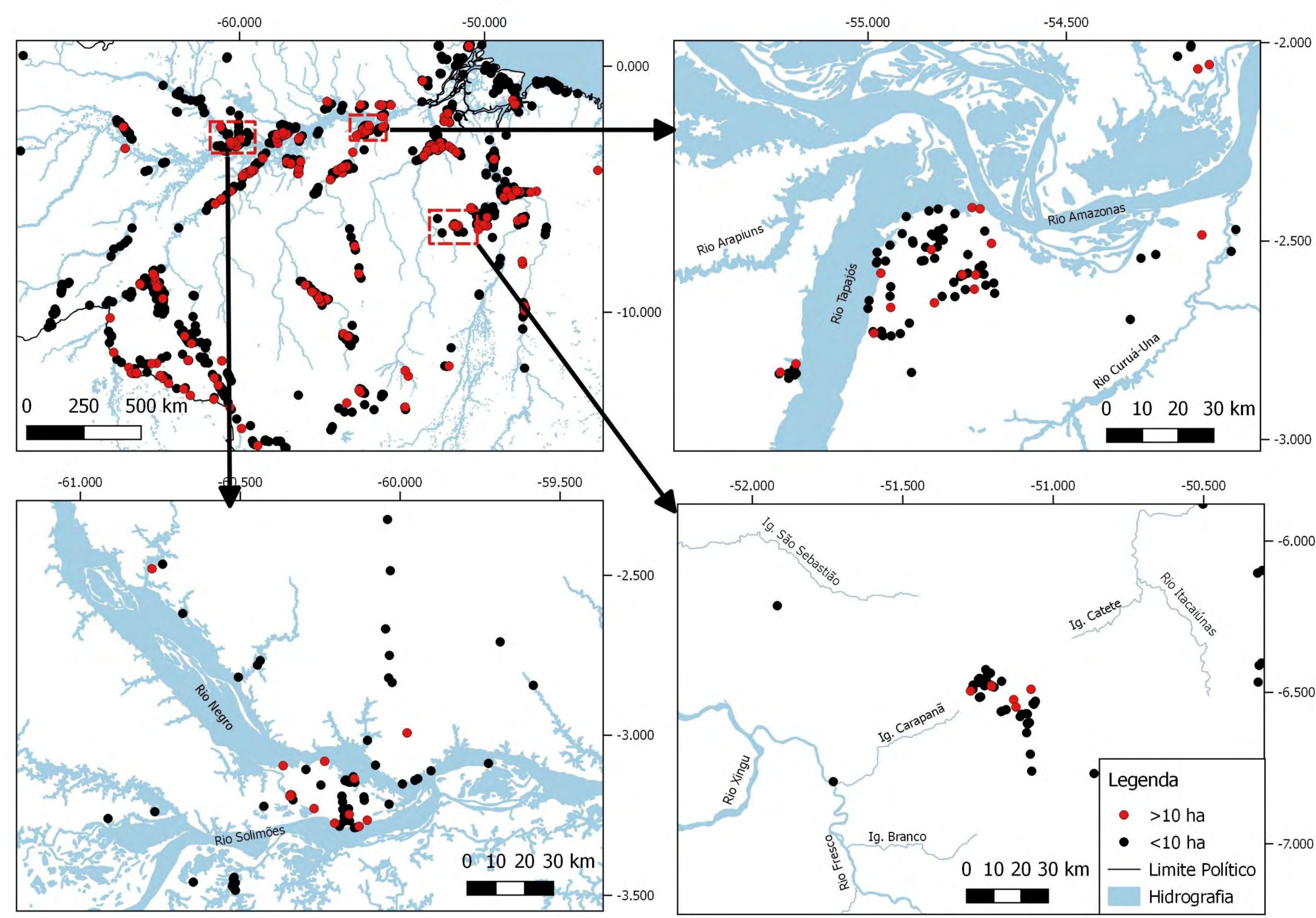

Mapa 3.3.1-2: Detalhe da área de confluências dos rios Solimões-Negro, foz do rio Tapajós e da Serra dos Carajás 


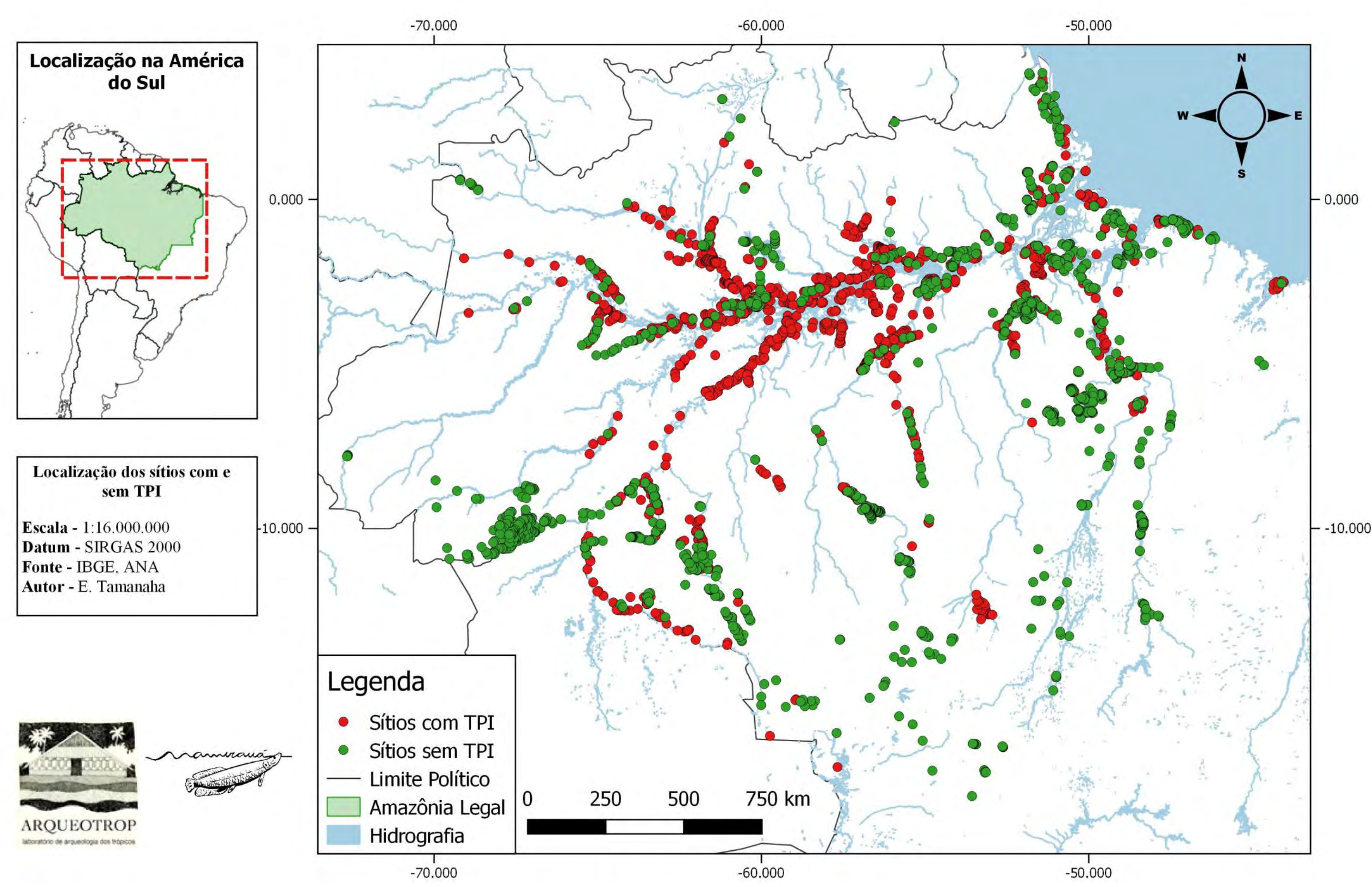

Mapa 3.3.2-1: Localização dos sítios arqueológicos a partir das informações de ausência e presença de Terra Preta de Índio 


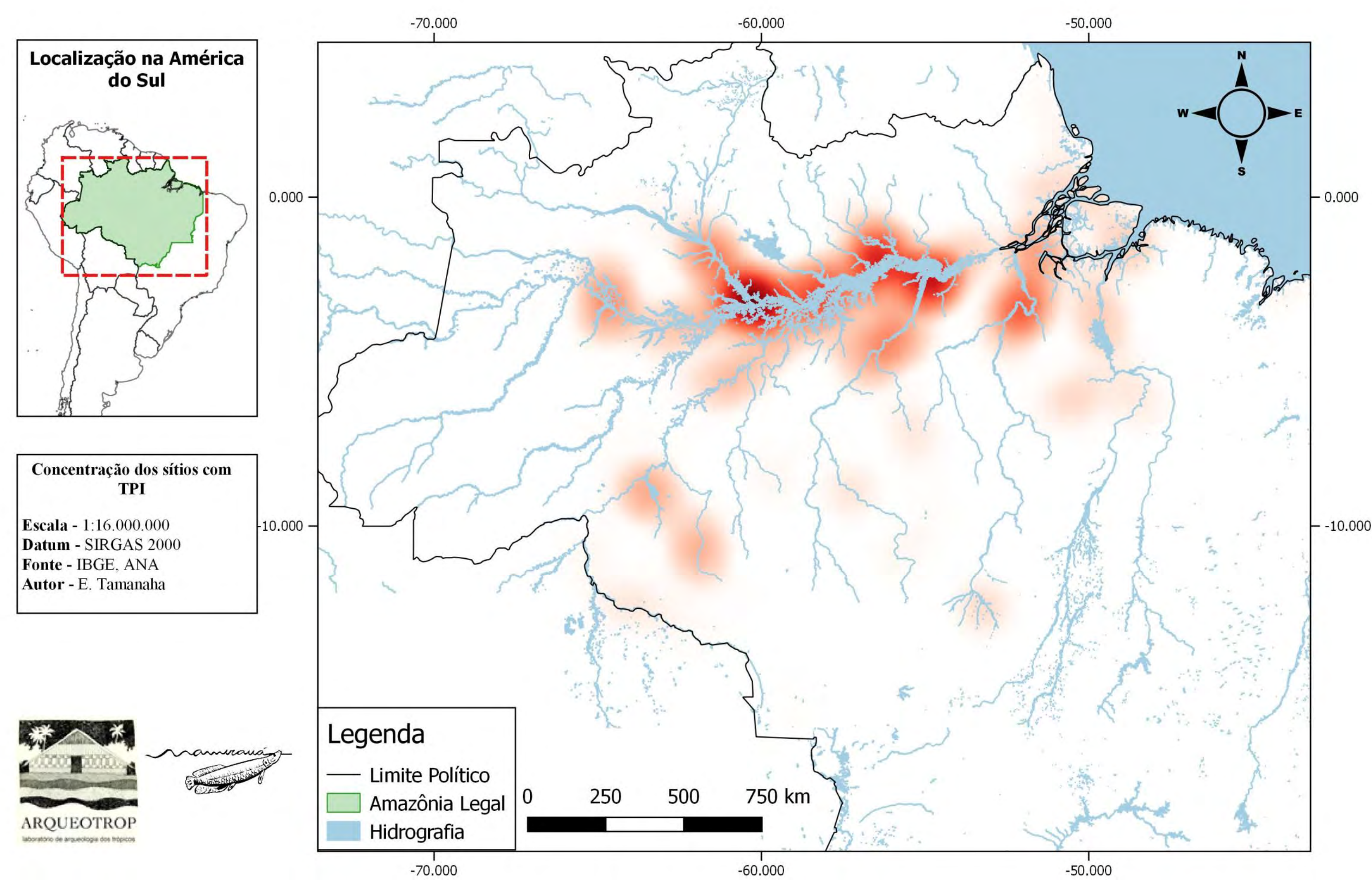

Mapa 3.3.2-2: Concentração de sítios com Terra Preta de Índio 


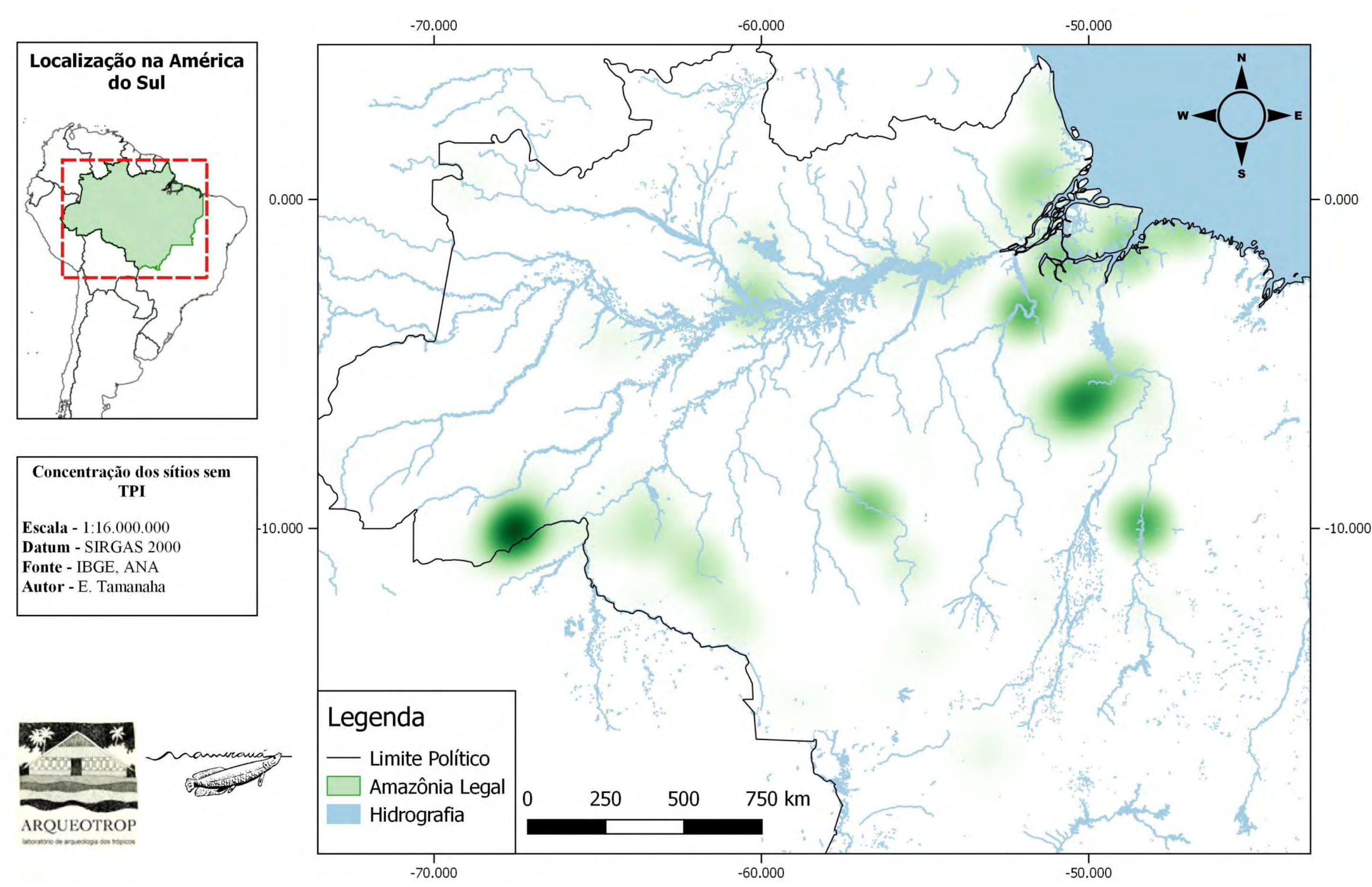

Mapa 3.3.2-3: Concentração de sítios sem Terra Preta de Índio 

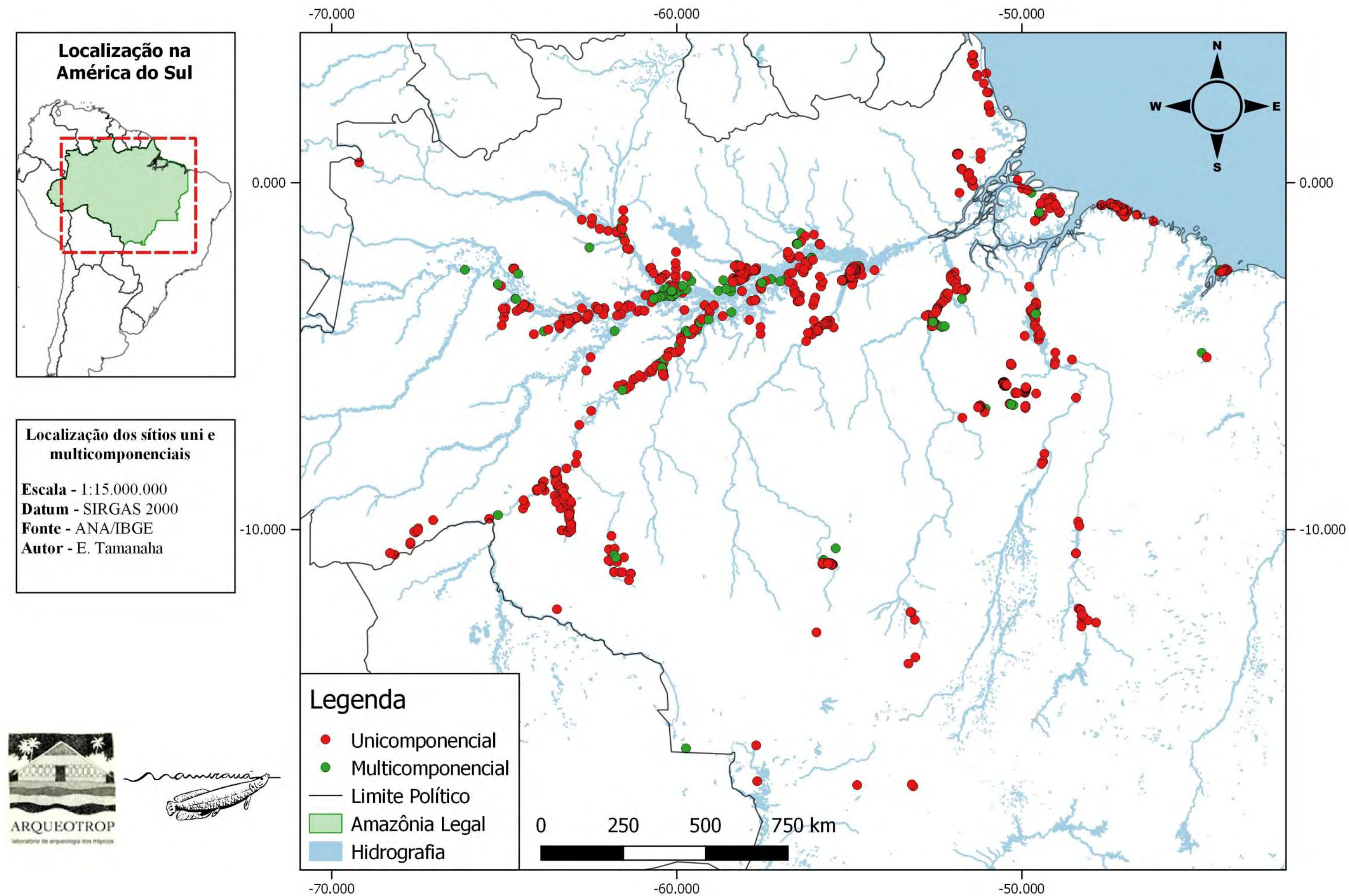

Mapa 3.3.3-1: Localização dos sítios arqueológicos unicomponenciais e multicomponenciais. 


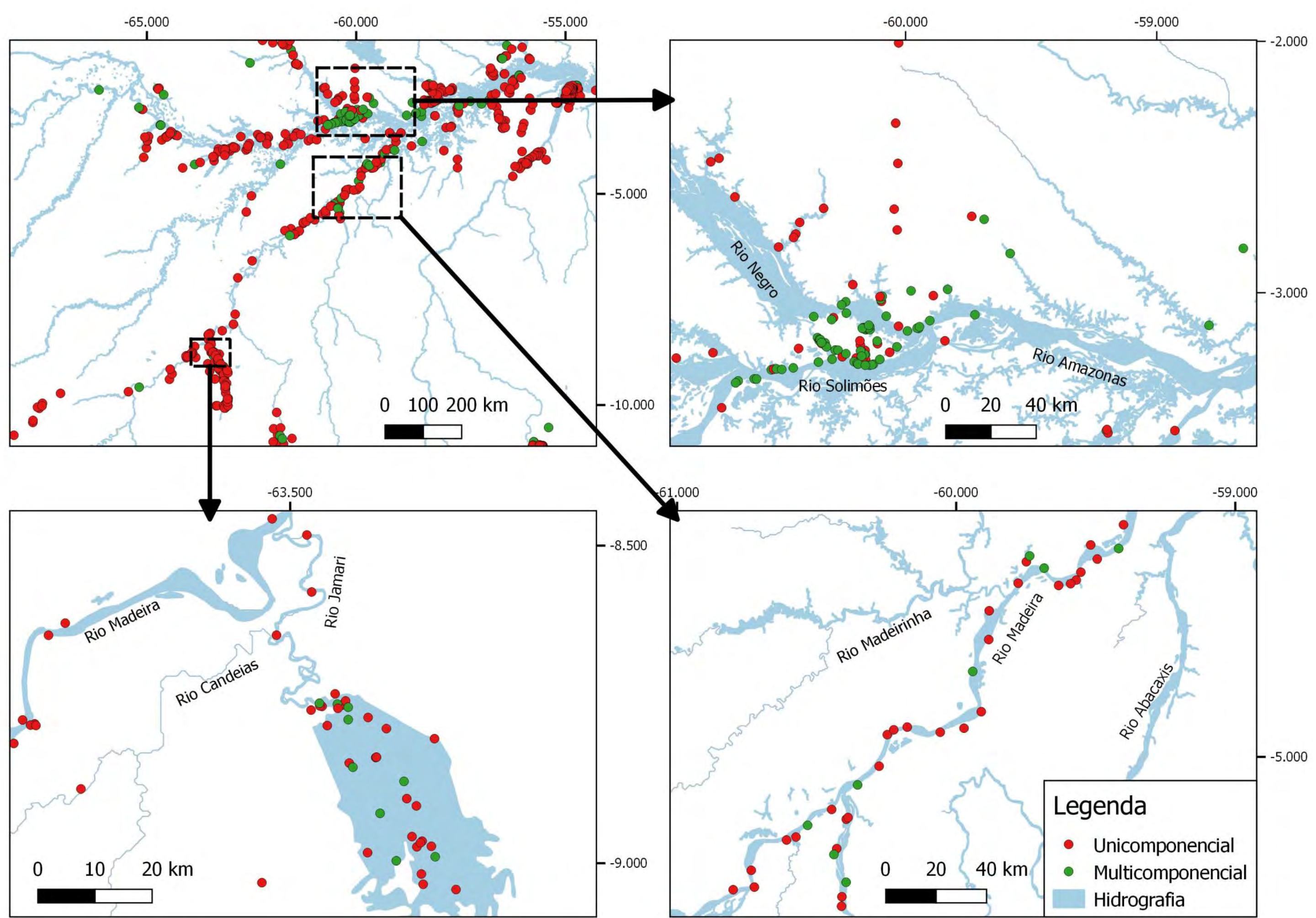

Mapa 3.3.3-2: Detalhe da área de confluência dos rios Solimões-Negro, baixo rio madeira e baixo rio Jamari. 


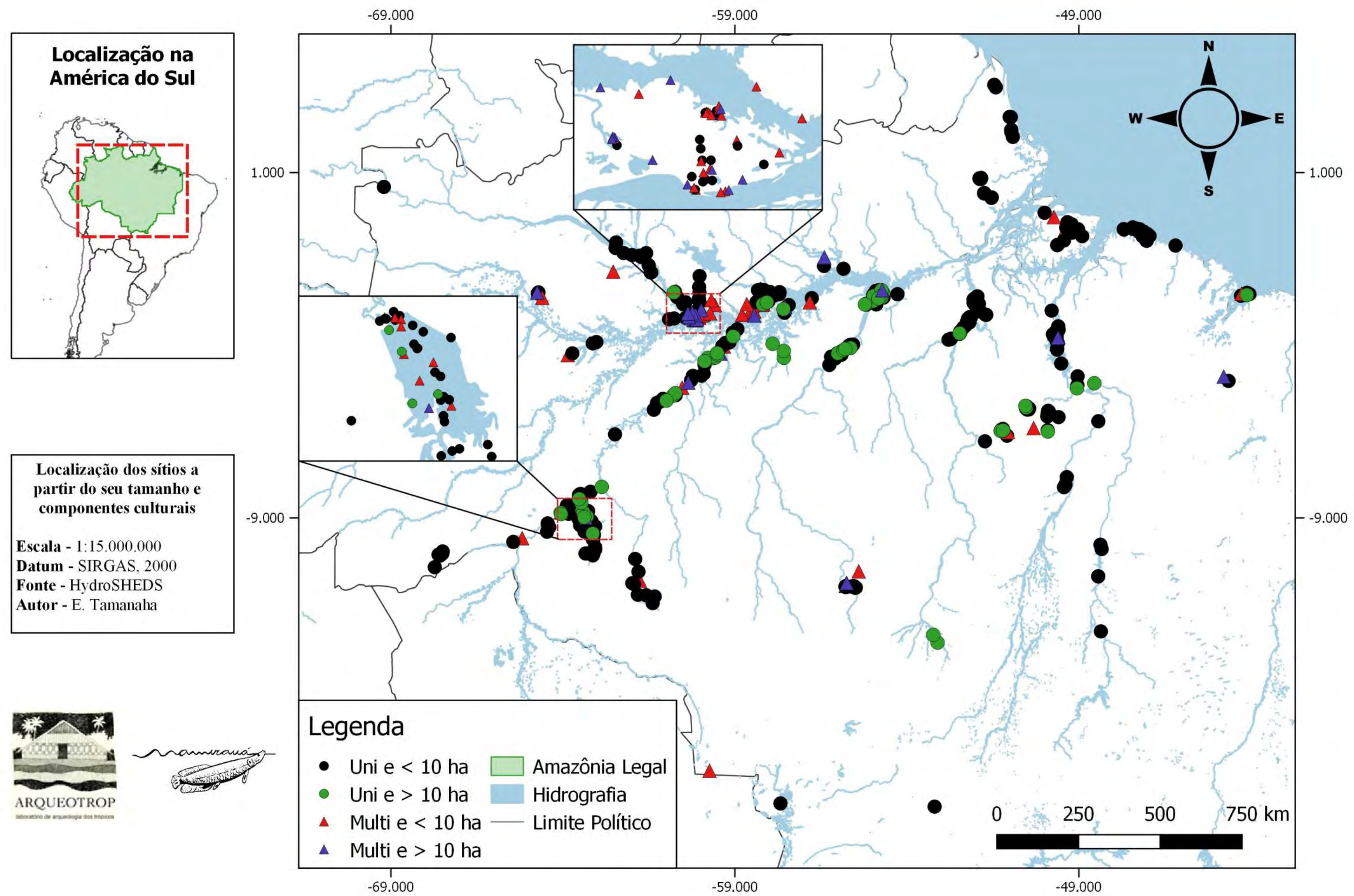

Mapa 3.3.4-1: Localização dos sítios a partir da relação entre área e quantidade de componentes culturais. Detalhe para as duas regiões com maior variabilidade. 




Mapa 3.3.4-2: Localização dos sítios a partir da relação entre área e o tipo de solo (TPI). Detalhe para as quatro regiões com maior variabilidade. 


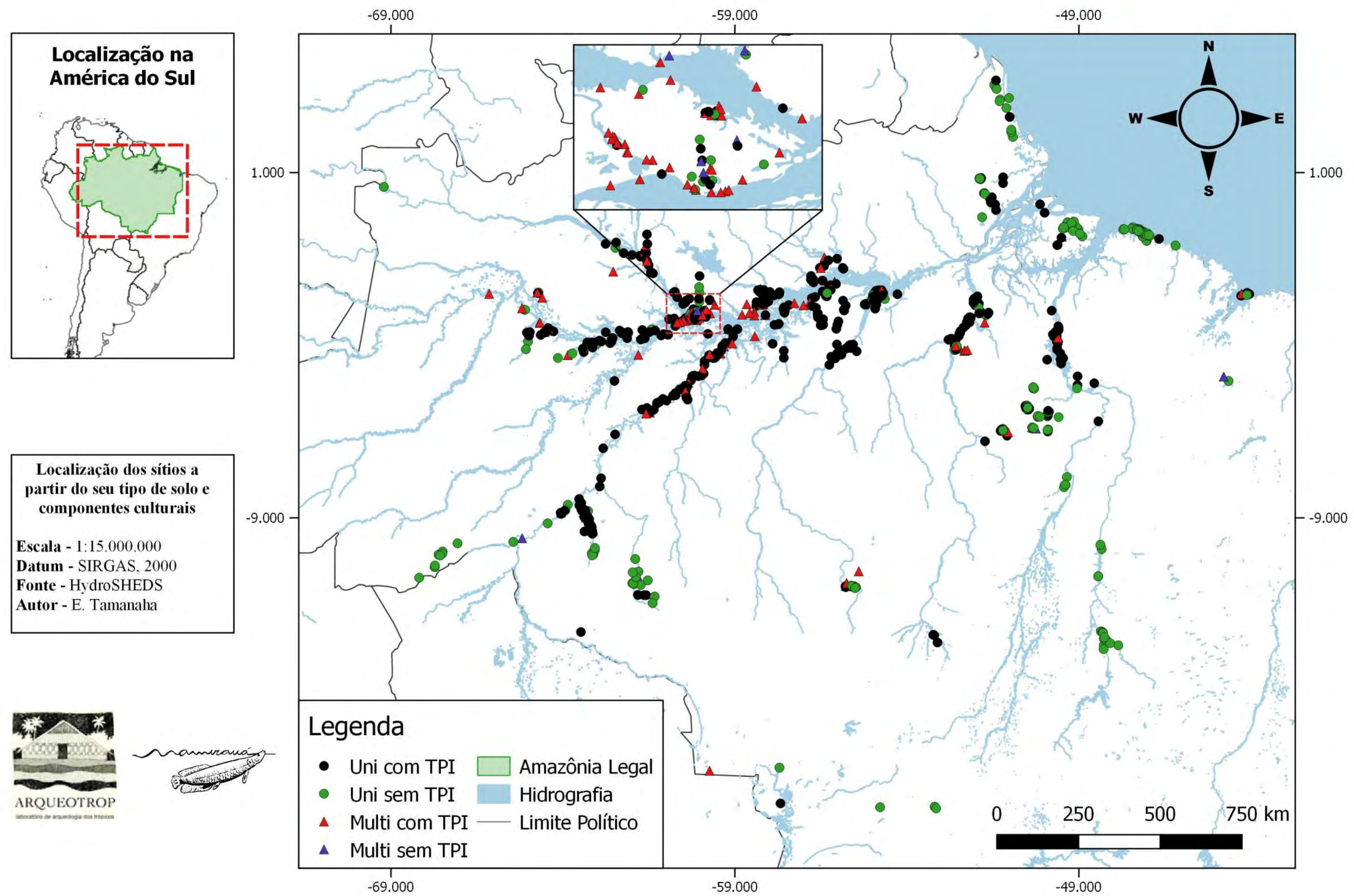

Mapa 3.3.4-3: Localização dos sítios a partir da relação entre o tipo de solo (TPI) e quantidade de componentes culturais. Detalhe para a região com maior variabilidade. 


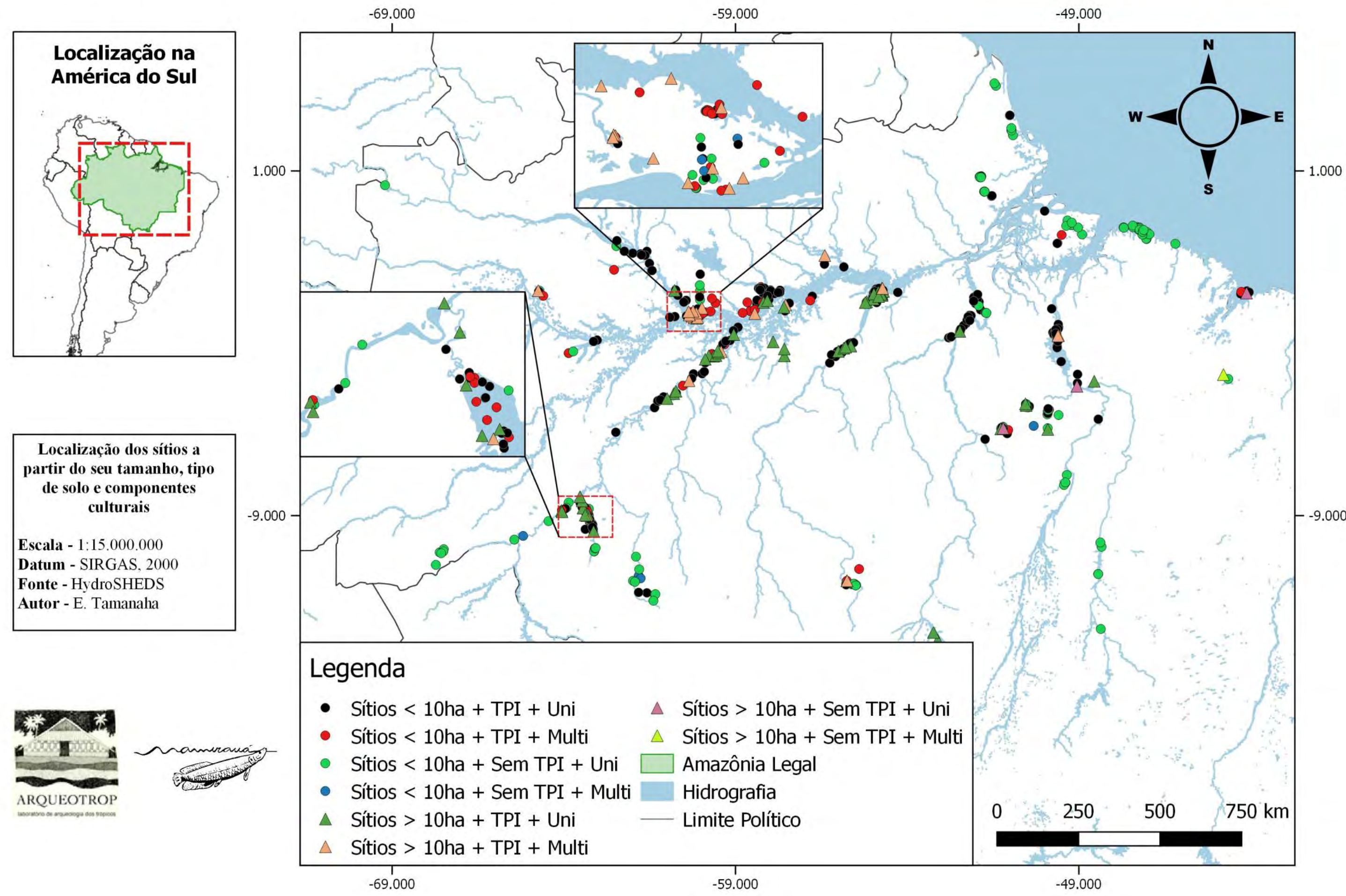

Mapa 3.3.4-4: Localização dos sítios a partir da relação entre a área, tipo de solo (TPI) e quantidade de componentes culturais. Detalhe para as duas regiões com maior variabilidade. 

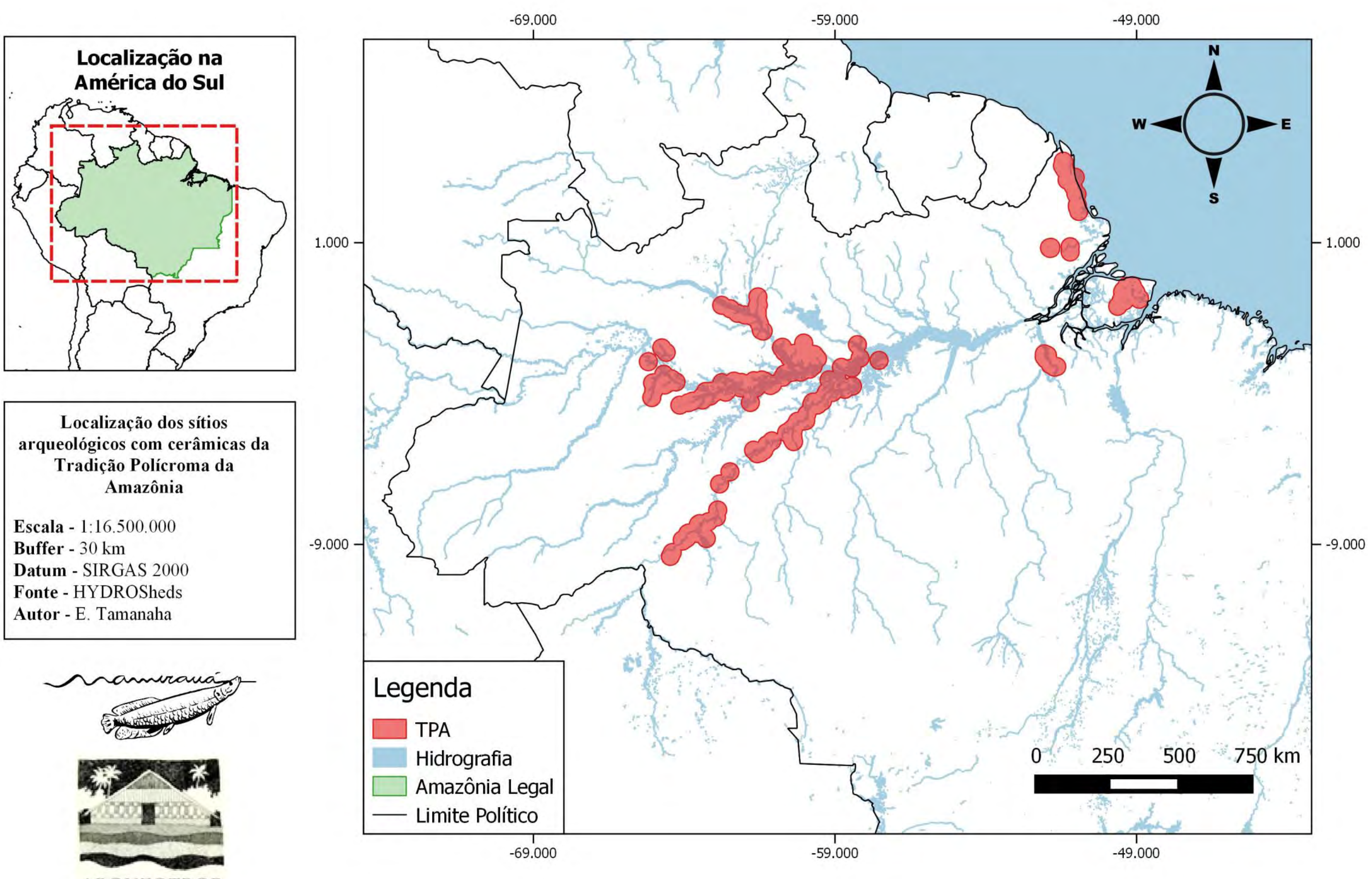

Mapa 3.4.1-1: Localização dos sítios arqueológicos com vestígios da Tradição Polícroma da Amazônia (TPA). 

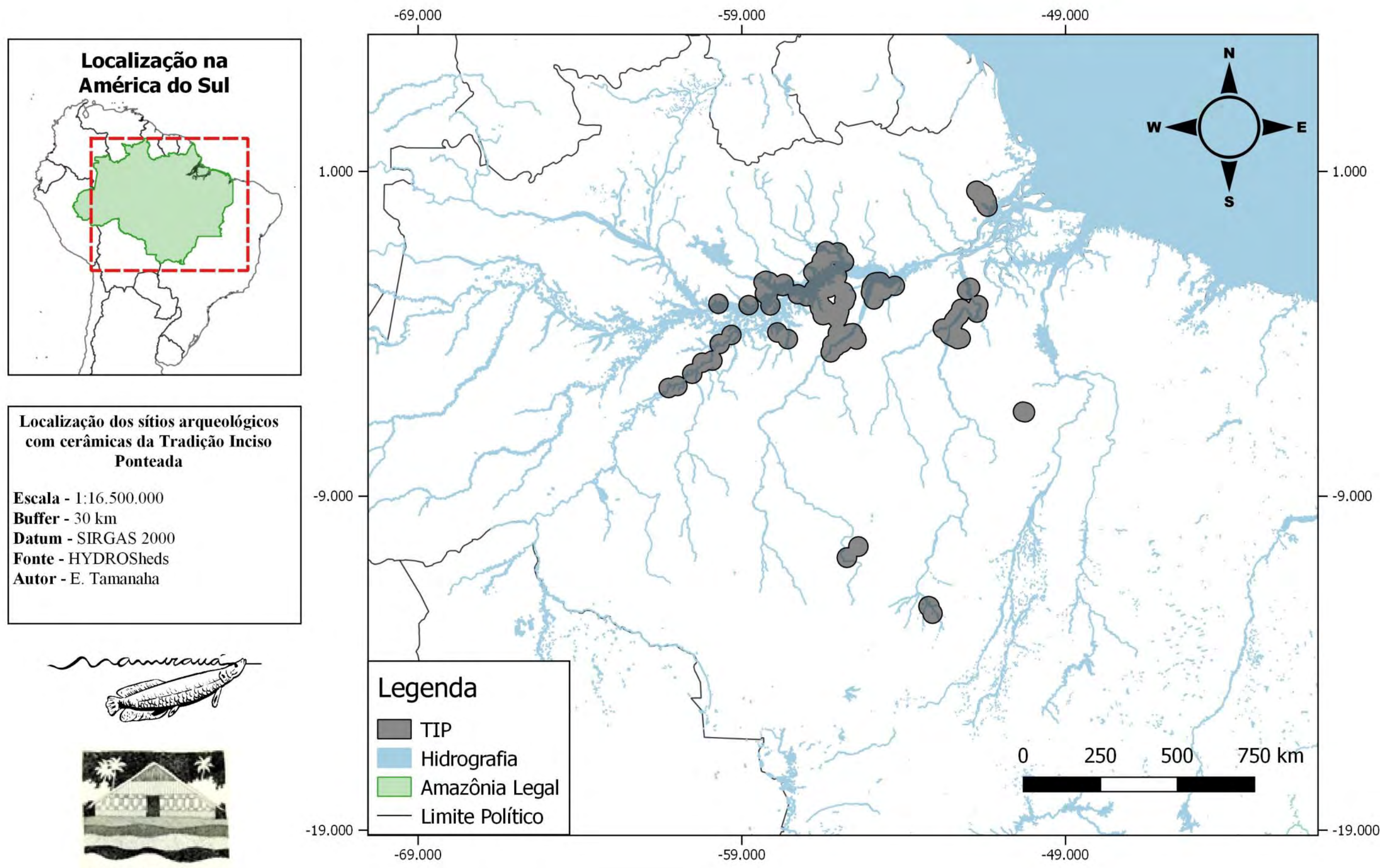

ARQUEOTROP

Mapa 3.4.1-2: Localização dos sítios arqueológicos com vestígios da Tradição Inciso Ponteada (TIP). 

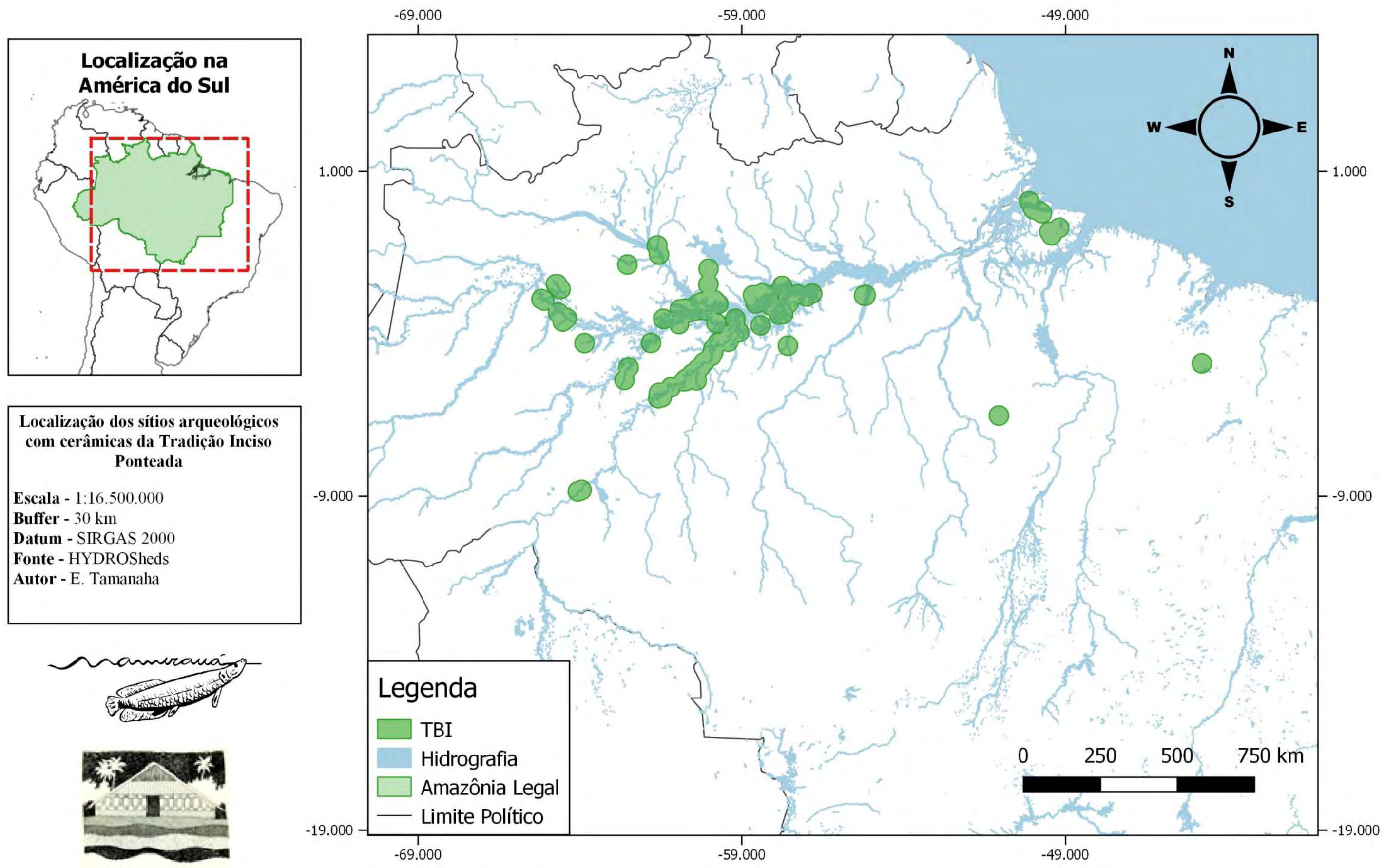

ARQUEOTROP

Mapa 3.4.1-3: Localização dos sítios arqueológicos com vestígios da Tradição Borda Incisa (TBI). 


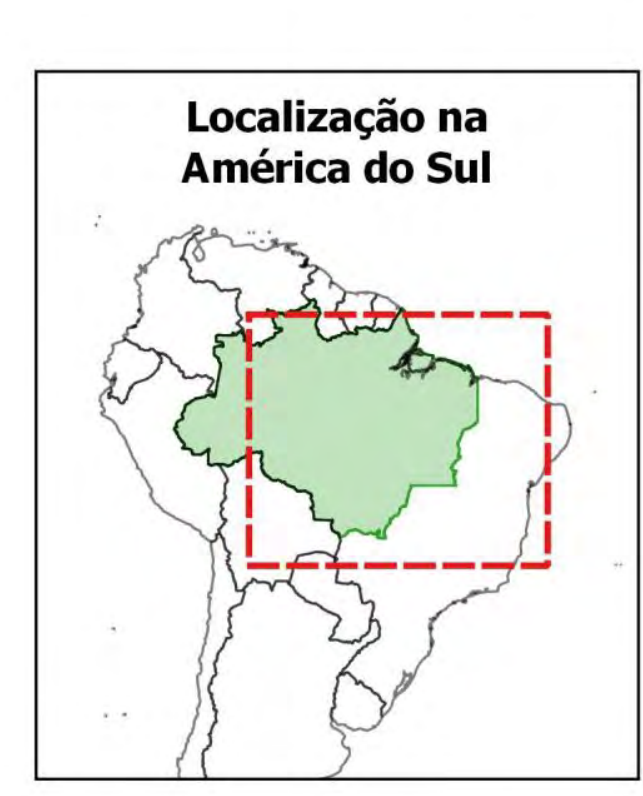

\begin{tabular}{|l|}
\hline $\begin{array}{c}\text { Localização dos sítios arqueológicos } \\
\text { com cerâmicas da Subtradição } \\
\text { Tupinambá da Amazônia }\end{array}$ \\
Escala - 1:16.500.000 \\
Buffer - $30 \mathrm{~km}$ \\
Datum - SIRGAS 2000 \\
Fonte - HYDROSheds \\
Autor - E. Tamanaha \\
\hline
\end{tabular}
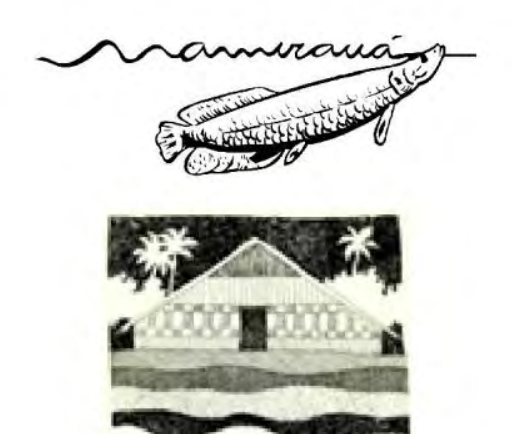

AROUEOTROP

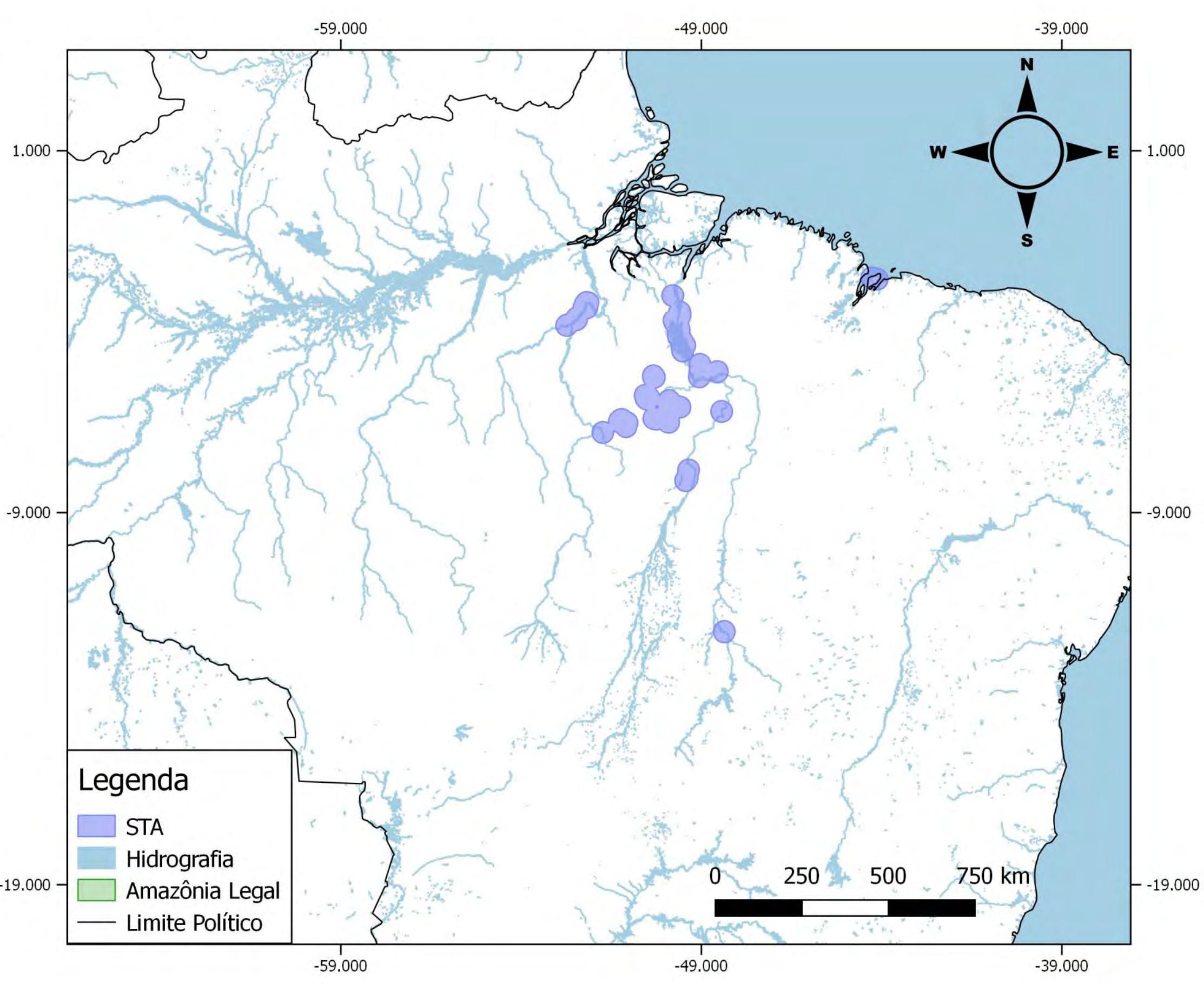

wastrat

Mapa 3.4.1-4: Localização dos sítios arqueológicos com vestígios da Subtradição Tupinambá da Amazônia (STA). 

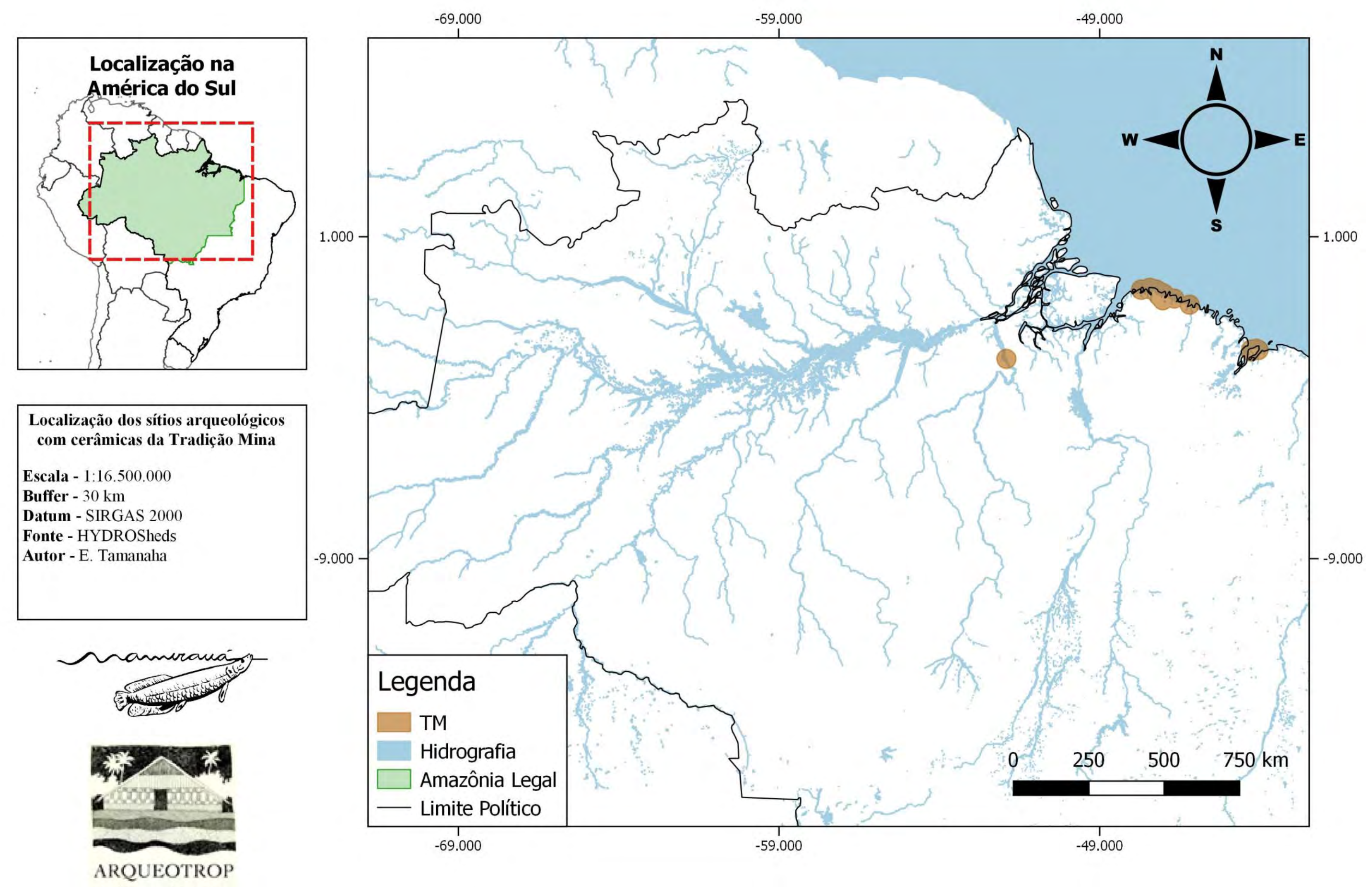

ARQUEOTROP

$-69.000$

$-59.000$ 

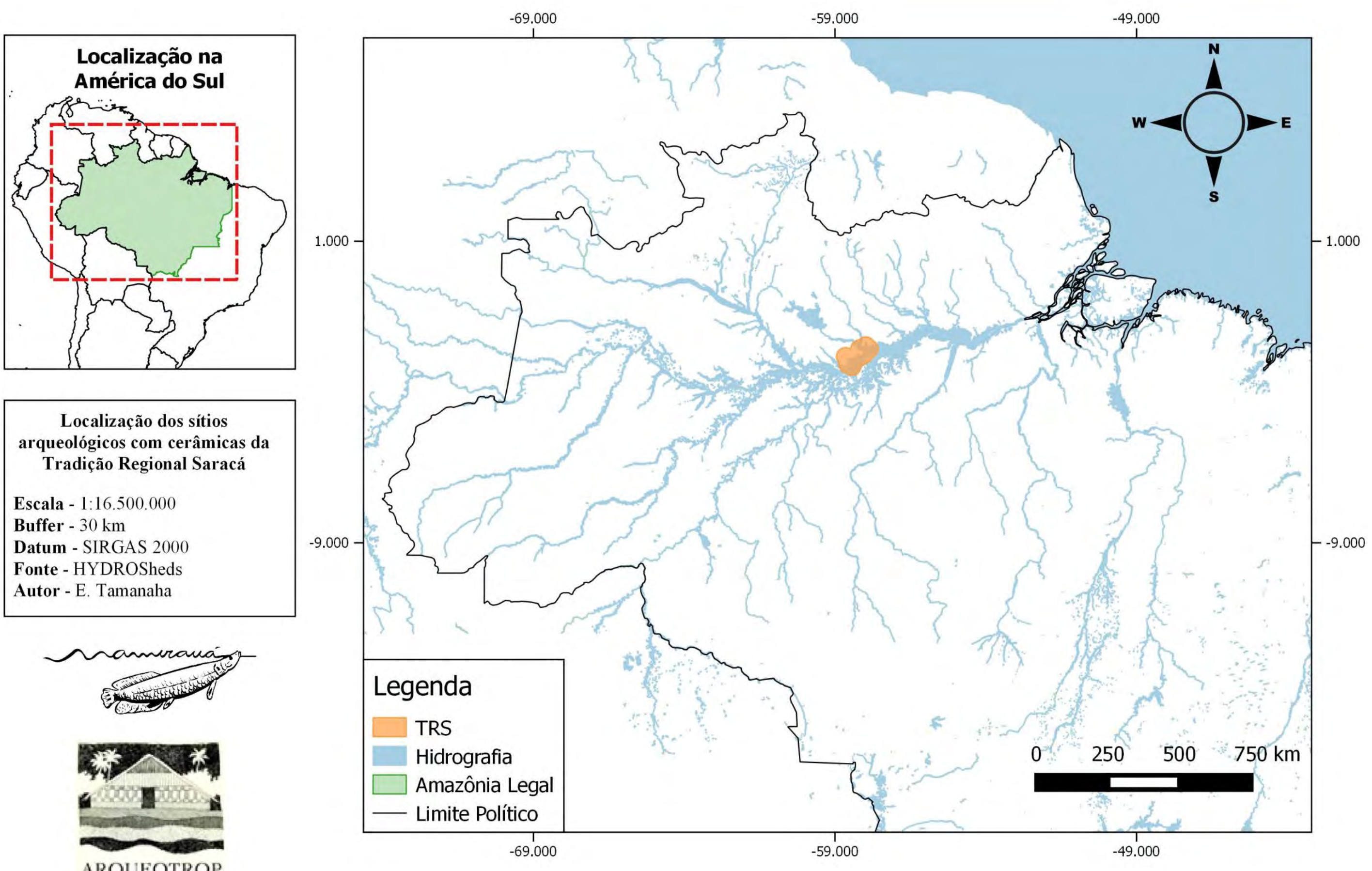

Mapa 3.4.1-6: Localização dos sítios arqueológicos com vestígios da Tradição Regional Saracá (TRS). 

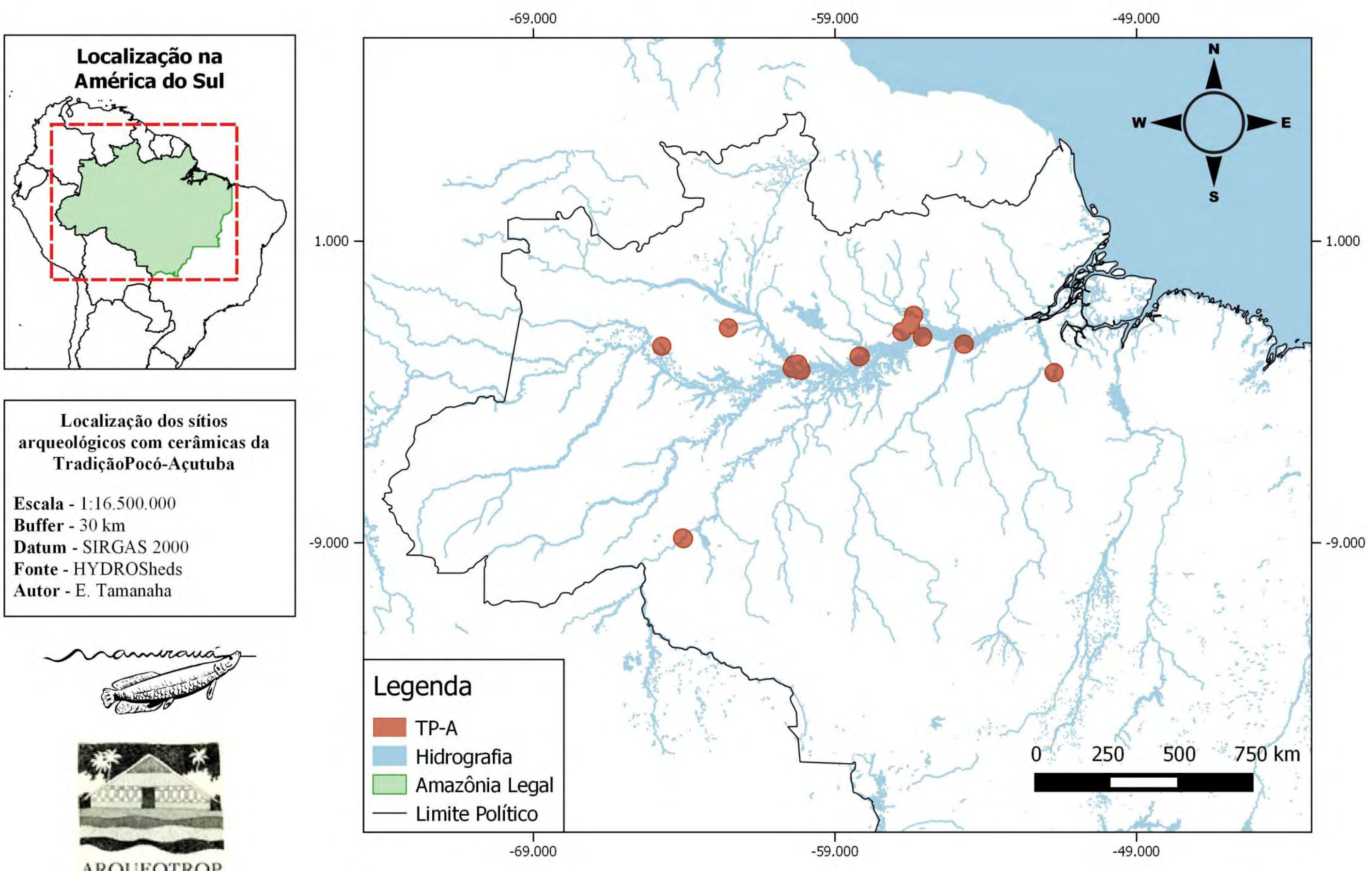

Mapa 3.4.1-7: Localização dos sítios arqueológicos com vestígios da Tradição Pocó-Açutuba (TP-A). 

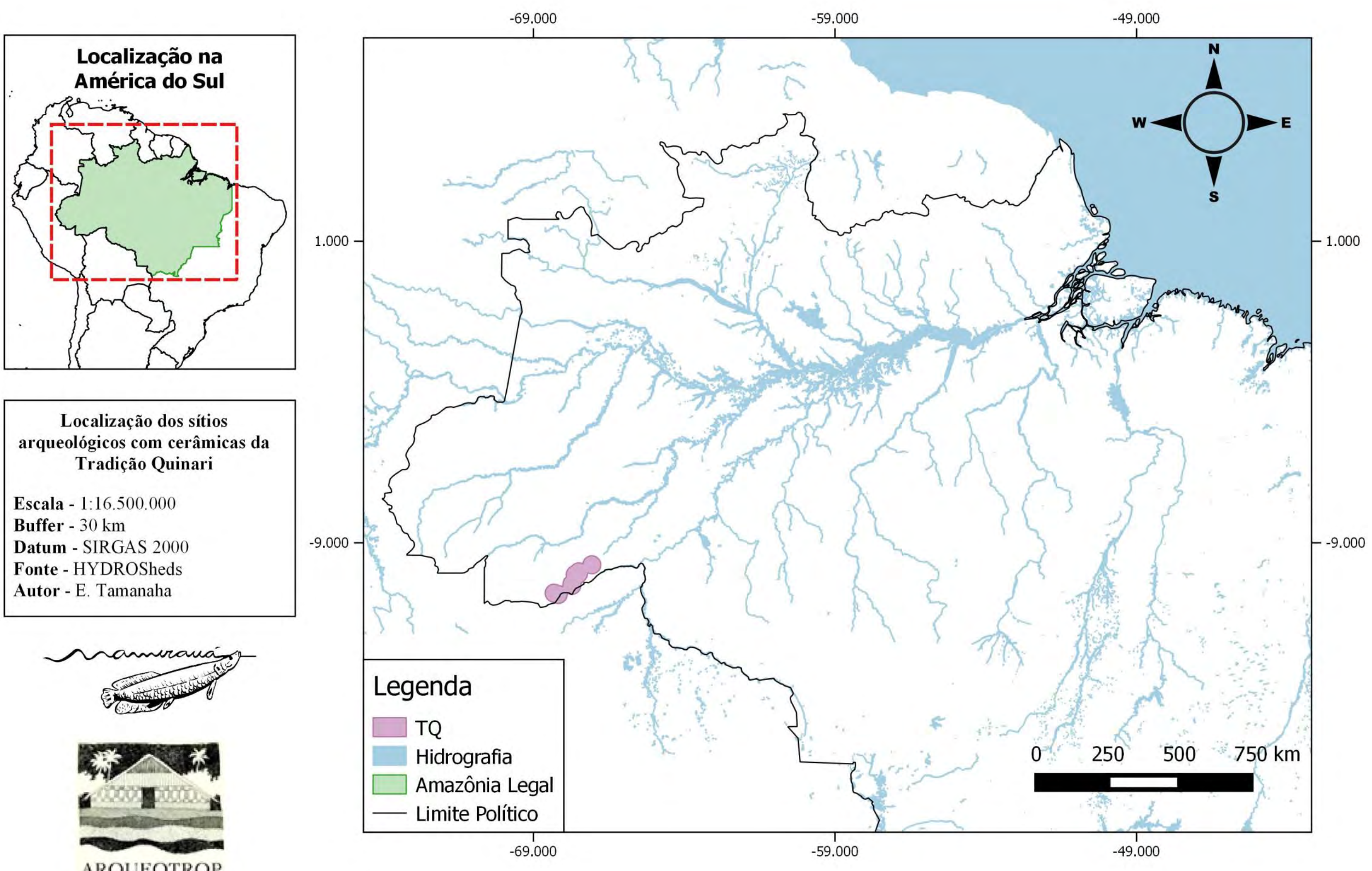

Mapa 3.4.1-8: Localização dos sítios arqueológicos com vestígios da Tradição Quinari (TQ). 


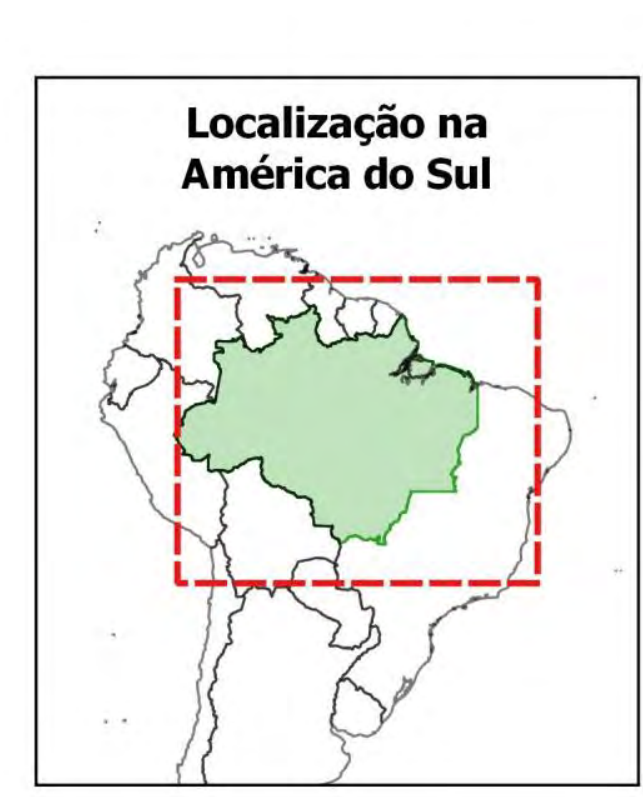

\begin{tabular}{|l|}
\hline $\begin{array}{c}\text { Localização dos sítios arqueológicos } \\
\text { com cerâmicas da Subtradição } \\
\text { Tupinambá da Amazônia }\end{array}$ \\
Escala - 1:20.000.000 \\
Buffer - $30 \mathrm{~km}$ \\
Datum - SIRGAS 2000 \\
Fonte - HYDROSheds \\
Autor - E. Tamanaha \\
\hline
\end{tabular}
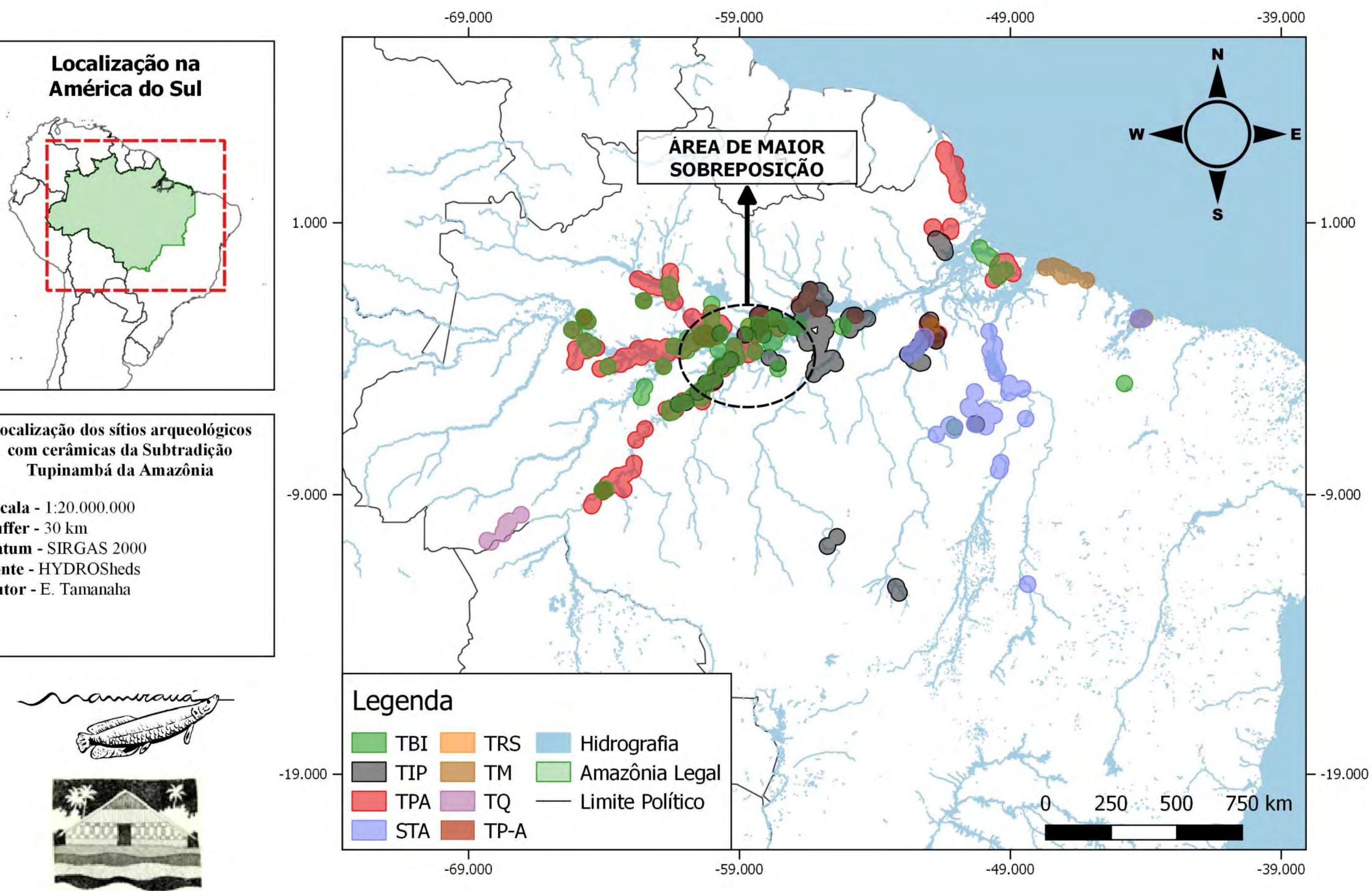

ARQUEOTROP

Mapa 3.4.2-1: Localização de todos os sítios arqueológicos e suas respectivas Tradições associadas. 


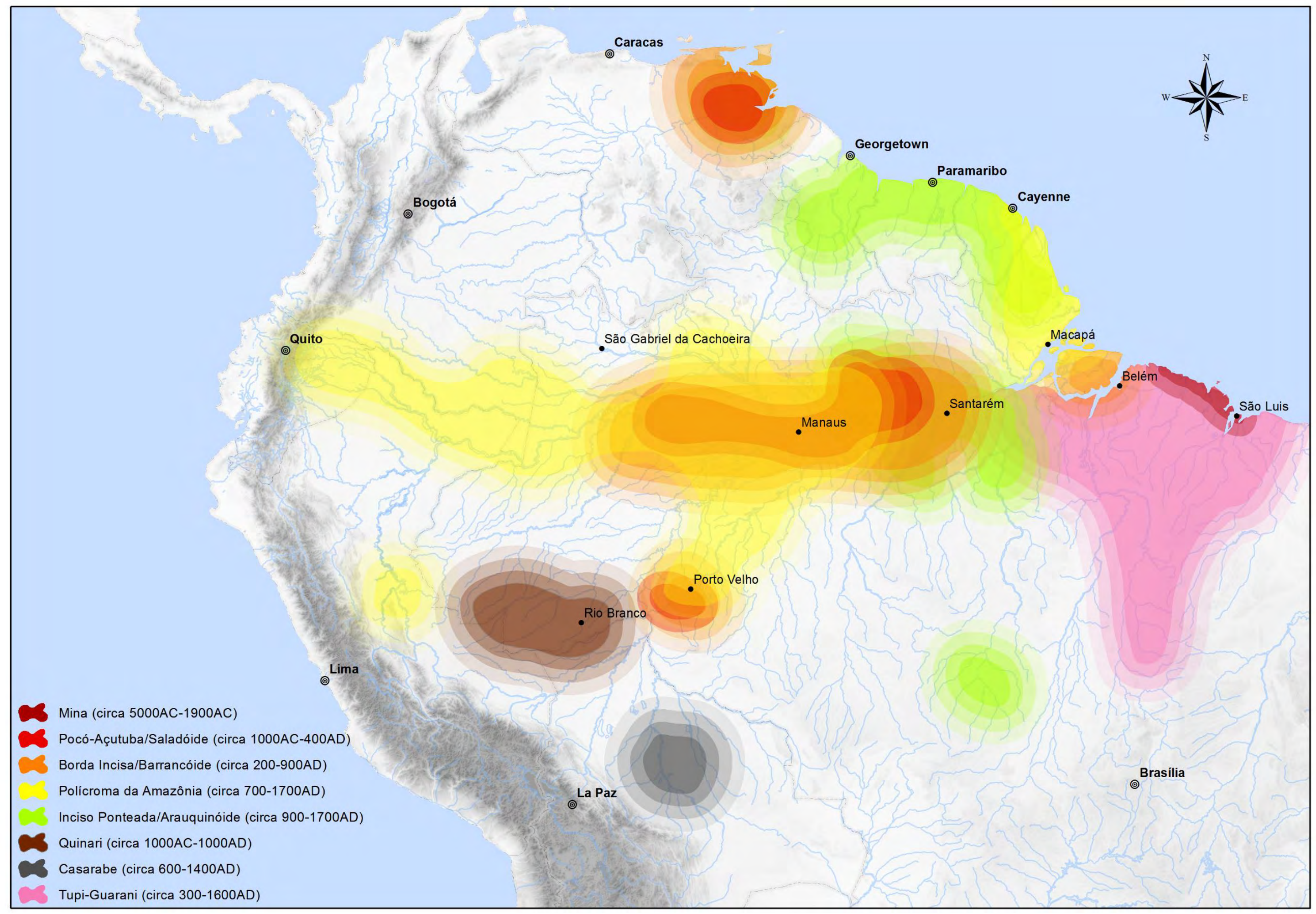

Mapa 3.4.2-1: Dispersão aproximada dos principais complexos cerâmicos mencionados em Barreto, Lima e Betancourt (2016). Extraído de Barreto, Lima e Betancourt (2016). 


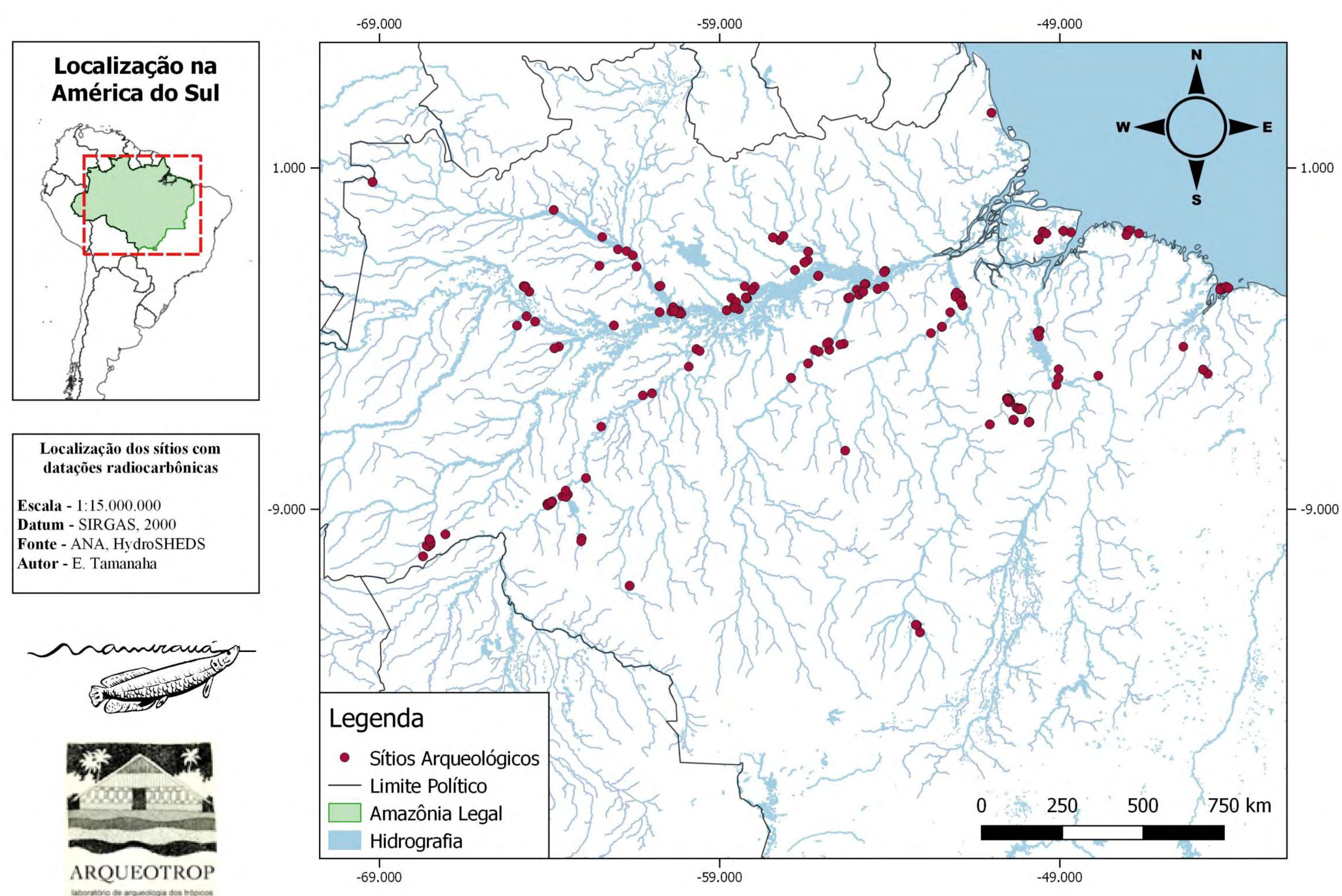

Mapa 3.5.1-1: Localização de todos os sítios arqueológicos com datações radiocarbônicas. 


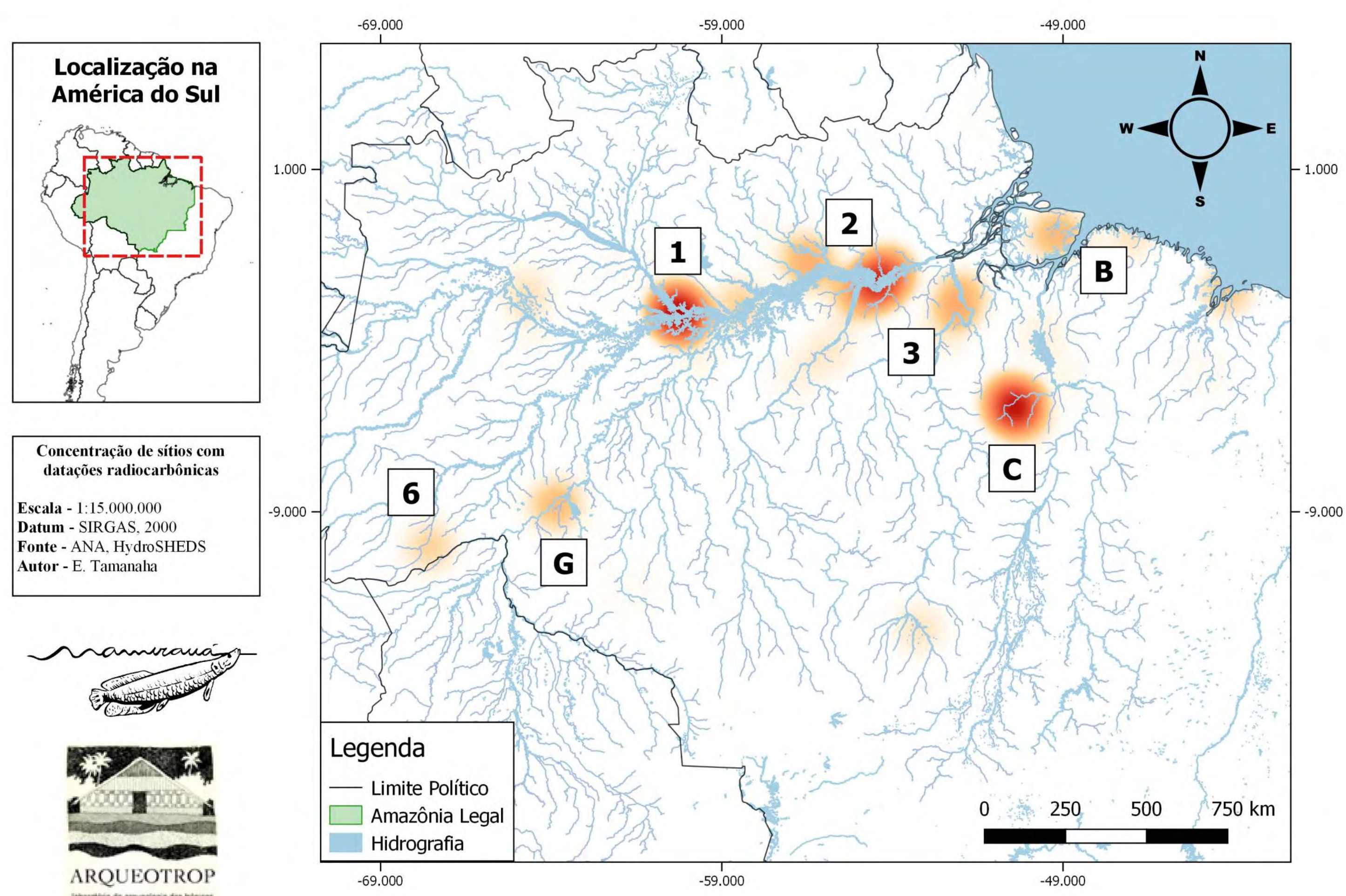

Mapa 3.5.1-2: Concentração das áreas com maior quantidade de sítios datados. 


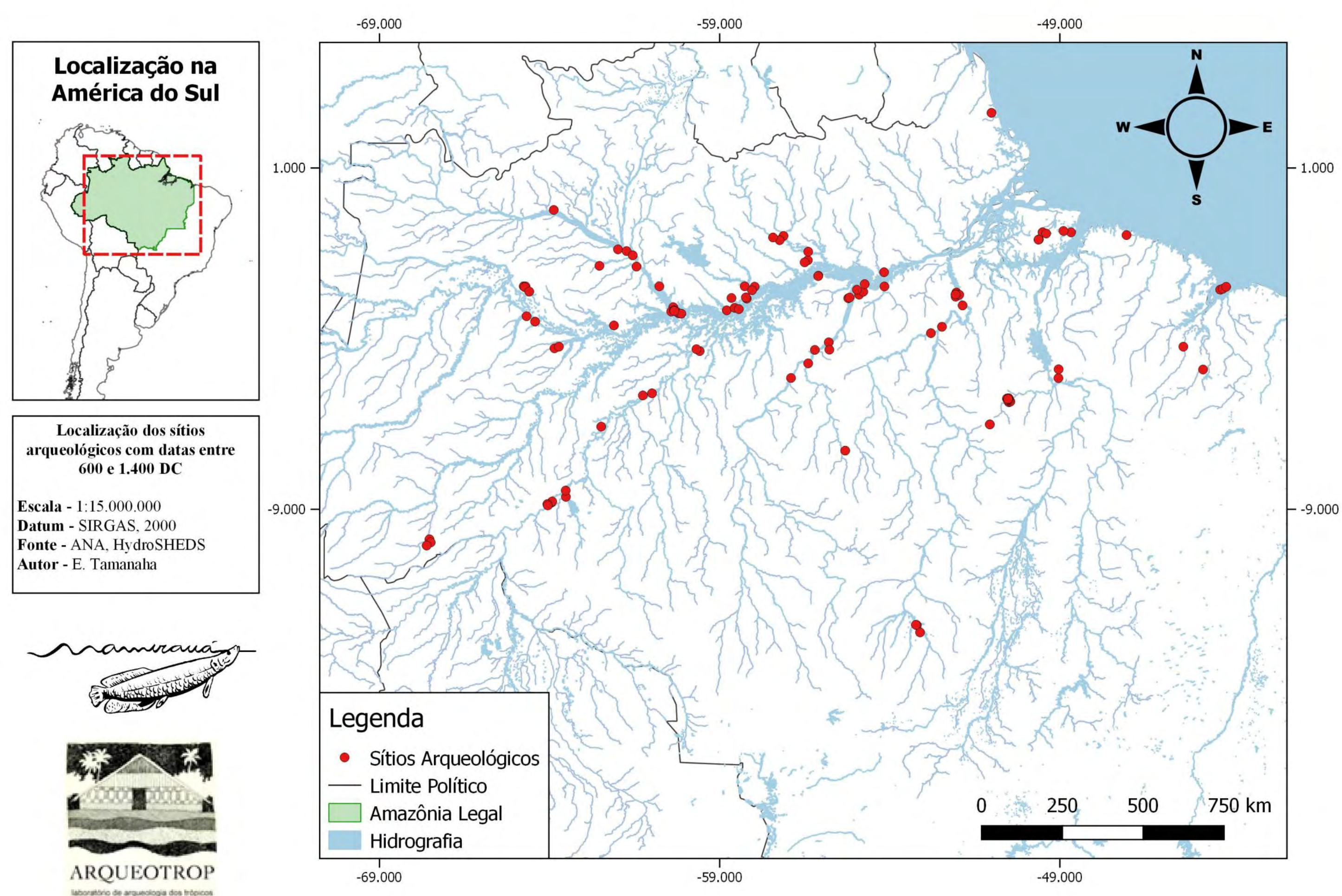

Mapa 3.5.1-3: Localização dos sítios arqueológicos com datas calibradas entre 600 e 1.400 DC 


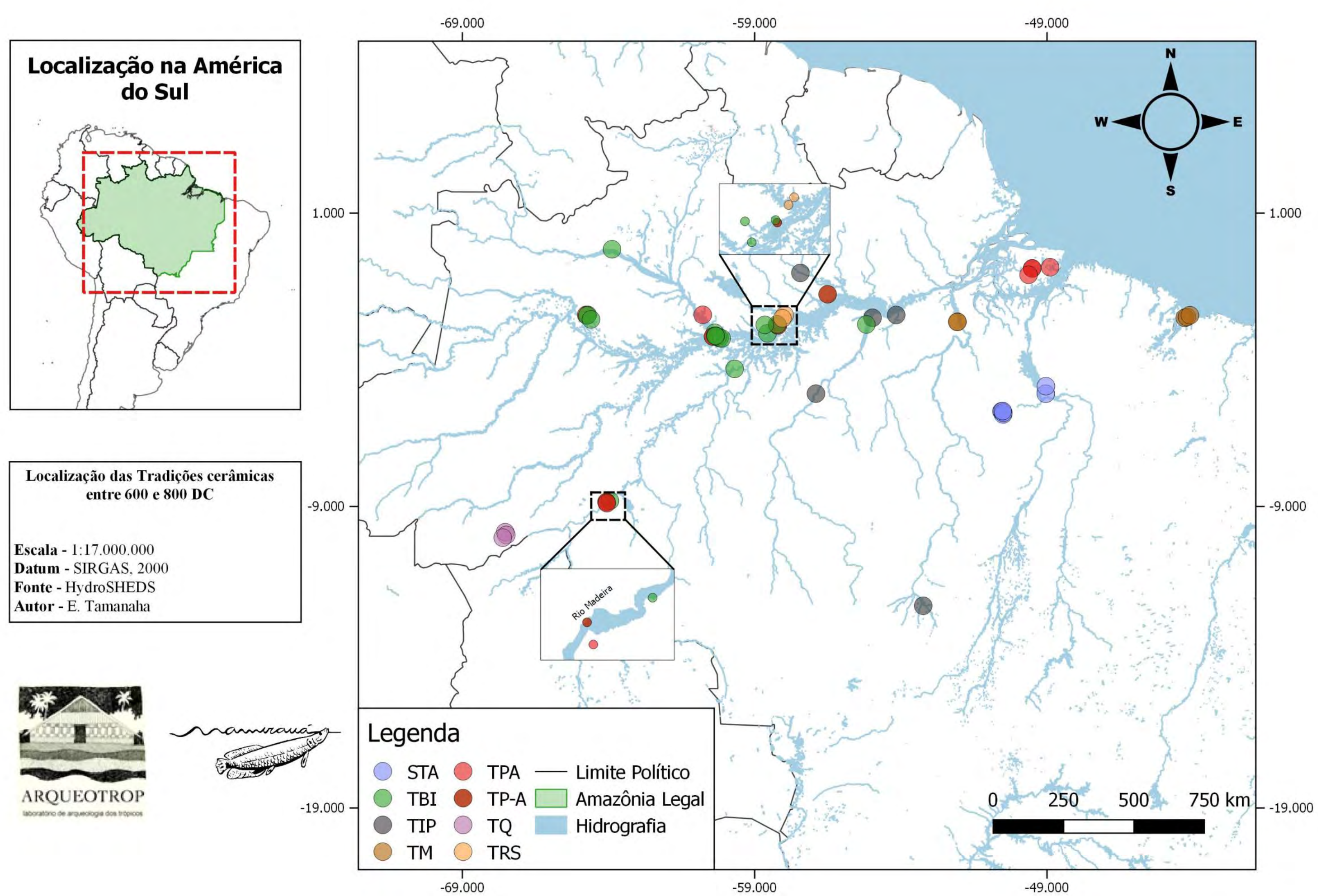

Mapa 3.5.2-1: Localização dos sítios arqueológicos e suas respectivas Tradições cerâmicas entre 600 e 800 DC. 


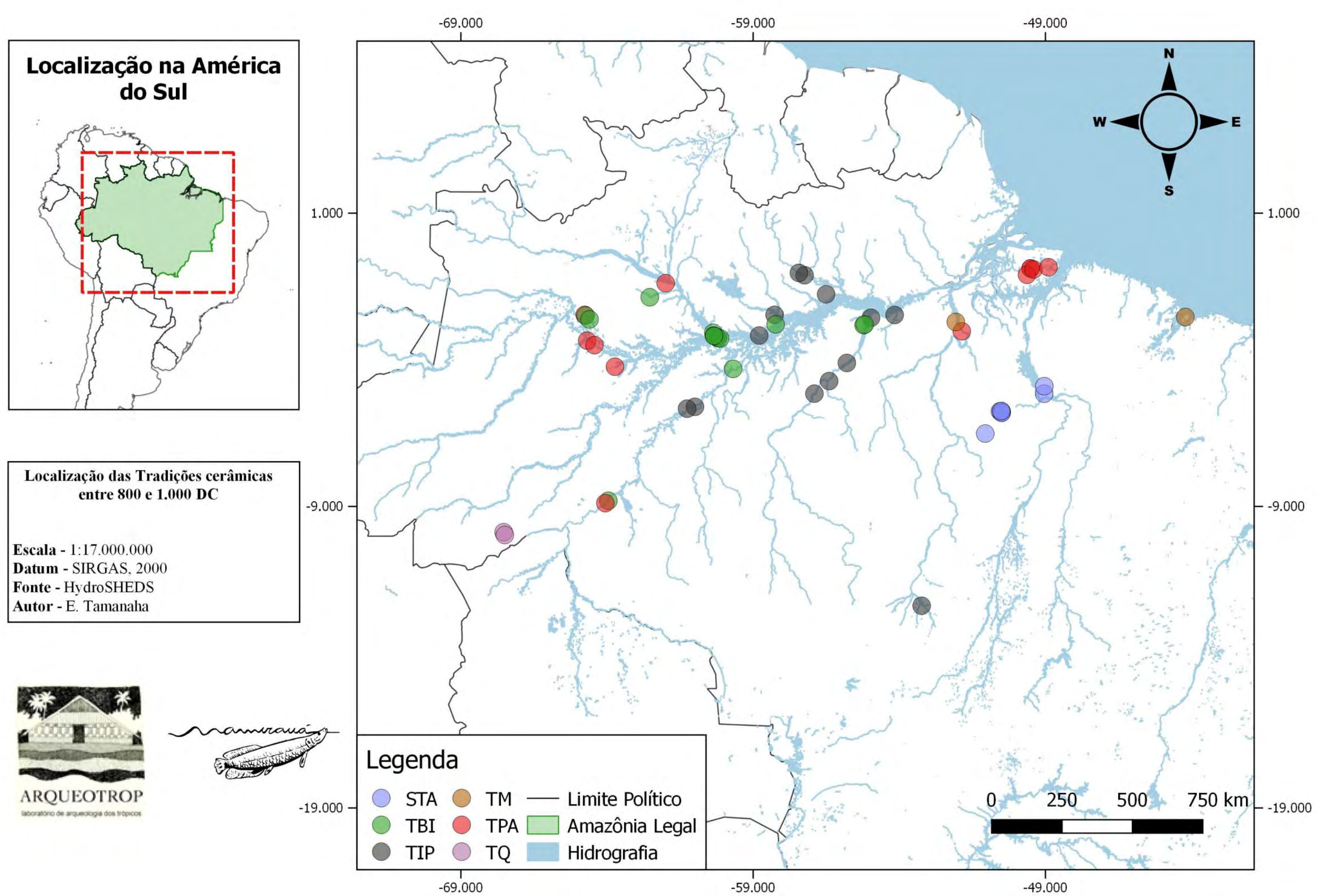

Mapa 3.5.2-2: Localização dos sítios arqueológicos e suas respectivas Tradições cerâmicas entre 800 e 1.000 DC. 


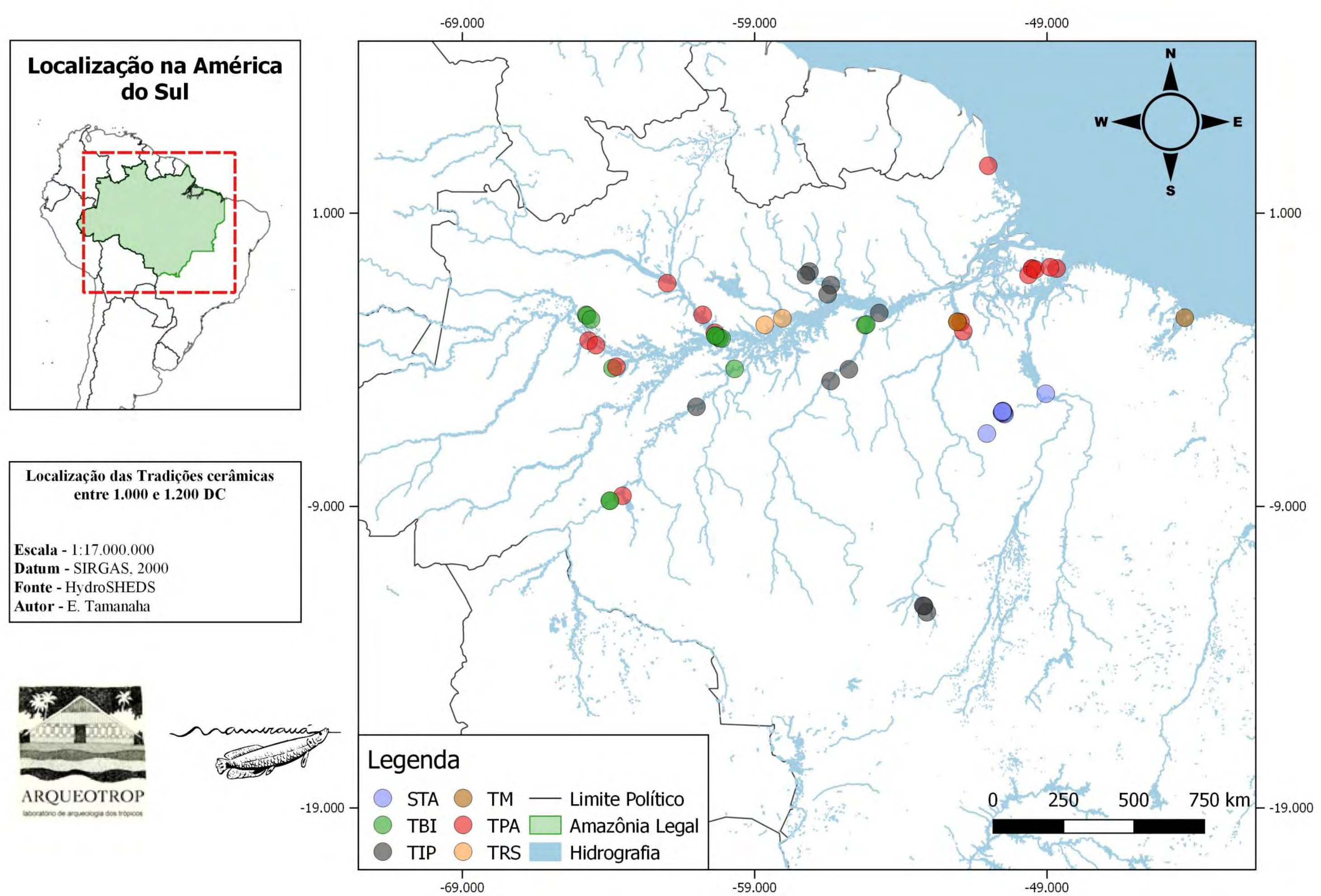

Mapa 3.5.2-3: Localização dos sítios arqueológicos e suas respectivas Tradições cerâmicas entre 1.000 e 1.200 DC. 


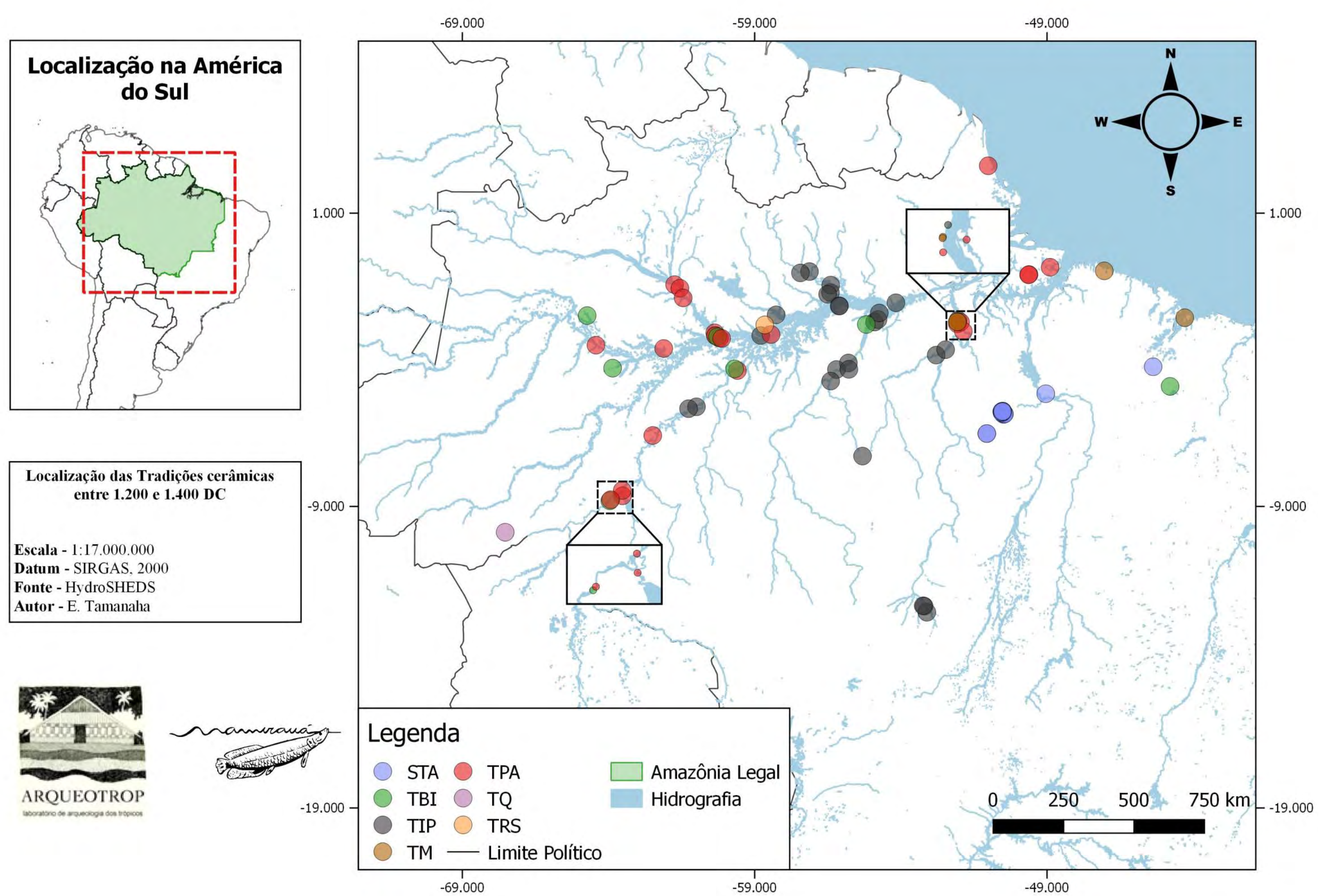

Mapa 3.5.2-4: Localização dos sítios arqueológicos e suas respectivas Tradições cerâmicas entre 1.200 e 1.400 DC 